\title{
MOBILIDADE URBANA SUSTENTÁVEL: UM ESTUDO COMPARATIVO E AS BASES DE UM SISTEMA DE GESTÃO PARA BRASIL E PORTUGAL
}

Dissertação apresentada à Escola de Engenharia de São Carlos da Universidade de São Paulo, como parte dos requisitos para a obtenção do Título de Mestre em Engenharia Civil - Área de Concentração: Transportes.

ORIENTADOR: Prof. Associado Antônio Nélson Rodrigues da Silva

São Carlos 


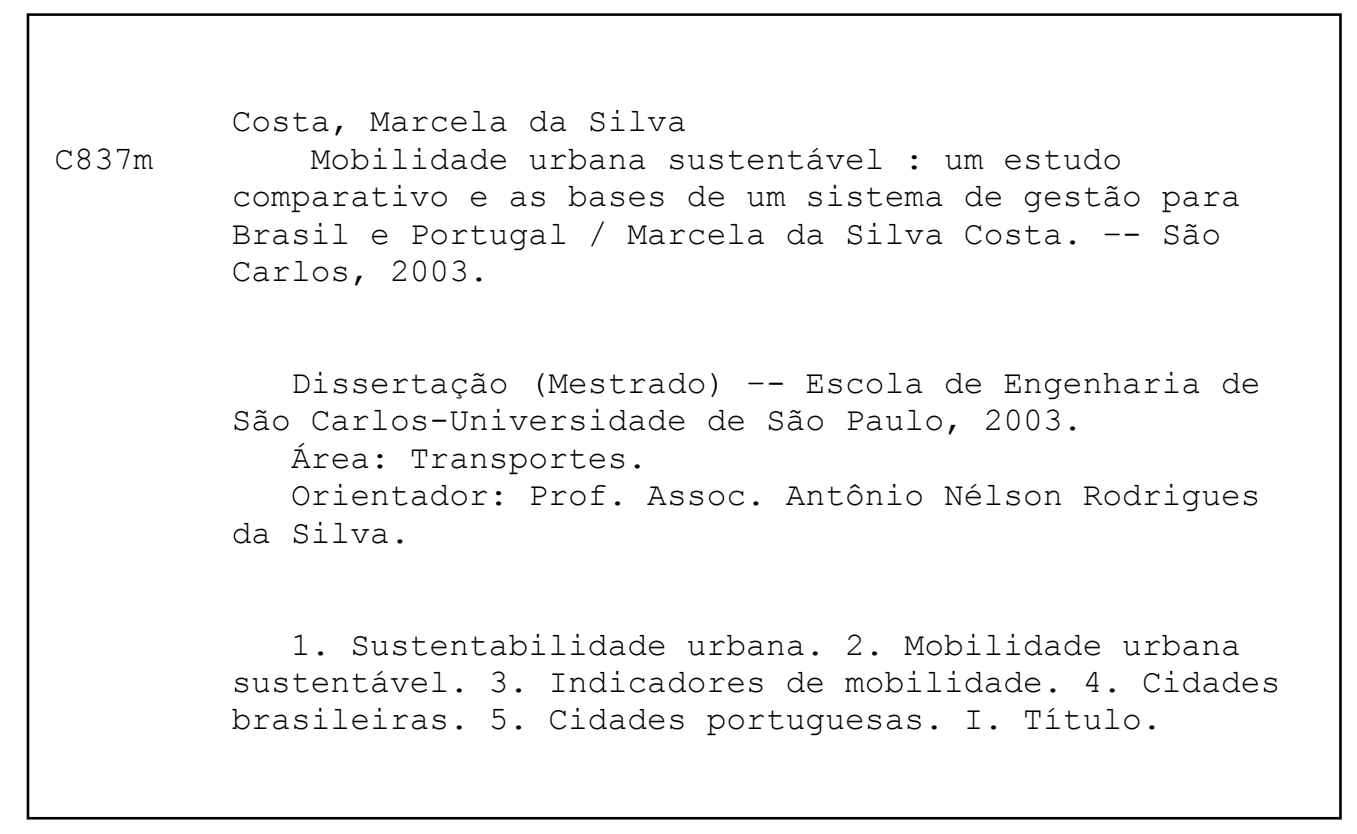


À minha mãe Neusa, pelo carinho, amizade, incentivo e sobretudo pelo empenho em tornar meus sonhos realidade. 


\section{AGRADECIMENTOS}

Ao orientador Prof. Dr. Antônio Nélson Rodrigues da Silva, pelo exemplo de dedicação, competência e integridade em sua profissão e pelo incentivo e apoio fundamentais para a realização deste trabalho;

Ao Prof. Dr. Rui António Rodrigues Ramos, pelos conhecimentos compartilhados, por viabilizar o contato com a equipe da Universidade do Minho e pelo apoio oferecido durante o mestrado;

Ao meu pai Jorge, pelo otimismo, alegria, generosidade e por viabilizar meus estudos em São Carlos;

Às minhas tias Regina e Coca, pelo amor, carinho, amizade e incentivo oferecidos ao longo de toda a minha vida;

Ao meu irmão Fabrício e minha cunhada Vivian, pela amizade e pelos inúmeros conselhos transmitidos;

Ao Cláudio, pelo carinho, otimismo, compreensão e por compartilhar todos os momentos da vida tornando-a ainda melhor;

Aos companheiros de república Ana (Marcão) e Nívea (Rômulo), pela amizade, alegria, companheirismo e sobretudo por compreenderem minha "ausência" nas atividades da casa;

Às maninhas Marcinha, Fabiana, Simone e Renata por tornarem ainda melhor o trabalho no STT e pela amizade dentro e fora do departamento;

Aos professores do Departamento de Transportes, em especial ao Prof. Dr. Antonio Clóvis Pinto Ferraz, Prof. Dr. Edson Martins Aguiar, Prof. Dr. José Leomar Fernandes Jr. e Prof. Dr. Paulo César Lima Segantine pelos conhecimentos compartilhados e pelo apoio oferecido ao longo do programa de mestrado; 
Aos funcionários do Departamento de Transportes, em especial à Magali, Lilian, Sueli, Bete, Heloísa e Toco pela amizade, atenção e pelos inúmeros serviços prestados;

A todos os profissionais e especialistas que participaram do processo de avaliação desenvolvido neste trabalho, em especial aos pesquisadores da Universidade do Minho (Braga, Portugal), UNESP - Bauru e EESC - USP pela paciência, disponibilidade e atenção despendida;

Aos amigos Cheila e Fernando que me receberam com tanto carinho aqui em São Carlos;

Aos amigos do STT, em especial: Josi, Renato, Cira, Karênina, Andréa Hora, Andréa Kobayaschi, Glória, Scarlet, Giselle, Patrícia, Pablo, Marcelo, Giovani, Cíntia, Mauro, Cida, Mário, Vitor, Lucas, Fred, Shirley, Cynthya, Everton, Ricardinho, João Marcello, Babuê, Topó, Flávia, Caio, Lobão, Fábio, Marcos, João Mota, Manuel Lucas e Dinato, pelos muitos momentos de alegria, incentivo e apoio dentro do Departamento de Transportes;

Aos amigos Alf, Marc, Tele, Daniel, Santos, Gordon, Cris, Kinho e Ilka que com sua amizade e companheirismo tornaram a vida em São Carlos ainda mais feliz;

Aos amigos do Rio Grande do Sul, em especial: Leonora, Tiago, Raquel, Kiko, Bianca, Nê, Thaís, Dedé, Aline, Fê, Mário, Ana Cláudia, e Carliza, pela amizade duradoura mesmo diante da distância que nos separa;

À CAPES pelo apoio financeiro concedido nos últimos onze meses de trabalho. 


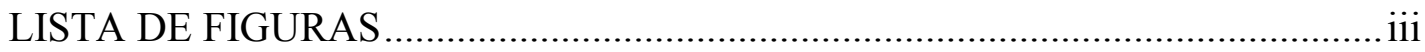

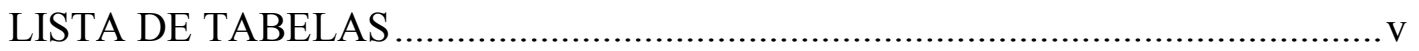

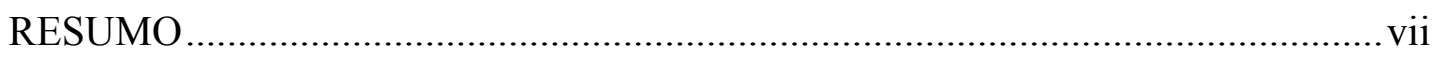

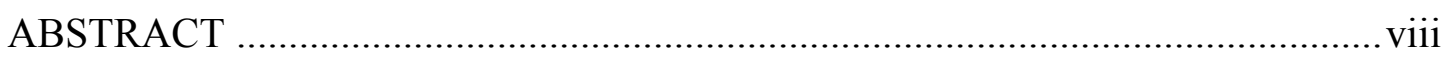

1. INTRODUÇÃ

1.1. Caracterização do problema ................................................................ 1

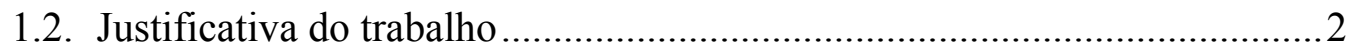

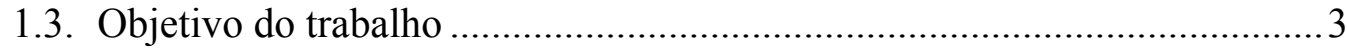

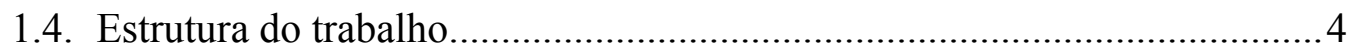

1. AS CIDADES NO CONTEXTO DE BRASIL E PORTUGAL ….....................5

2.1. Características geopolíticas .............................................................. 5

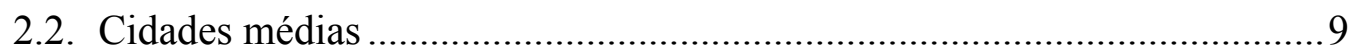

2.2.1 Participação das cidades médias na rede urbana de

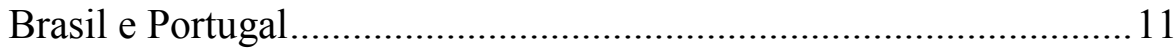

3. DESENVOLVIMENTO SUSTENTÁVEL_.................................................... 15

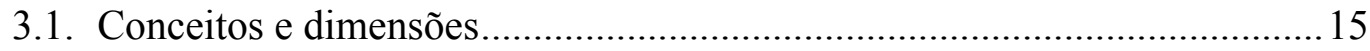

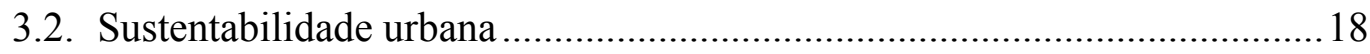

3.3. Considerações sobre o desenvolvimento sustentável no Brasil e em Portugal.............................................................................2 21

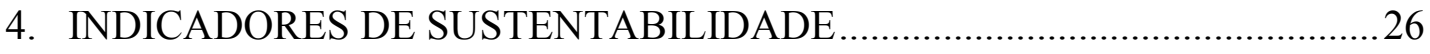

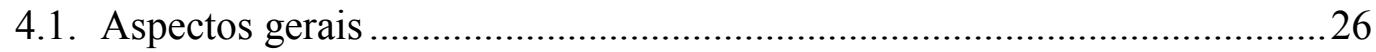

4.2. Tipos de indicadores e estruturas mais utilizadas.....................................28

4.3. Considerações sobre indicadores de sustentabilidade desenvolvidos no Brasil e em Portugal...................................................... 31

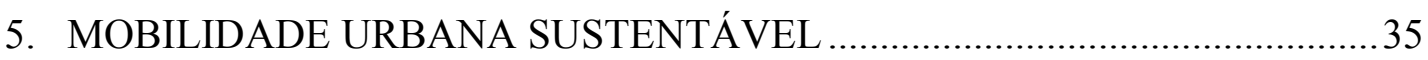

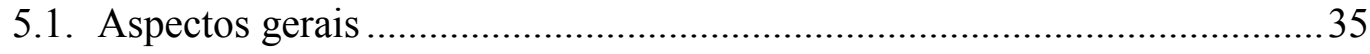

5.2. Considerações sobre mobilidade sustentável

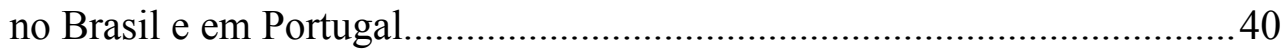

5.3. Indicadores para a gestão da mobilidade ...................................................4 43

6. MÉTODO E CARACTERIZAÇÃO DOS DADOS BÁSICOS …........................45

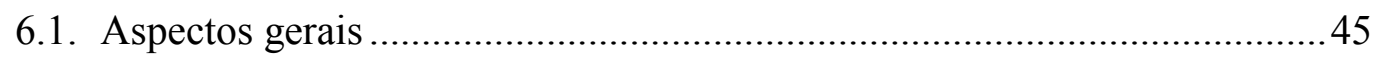

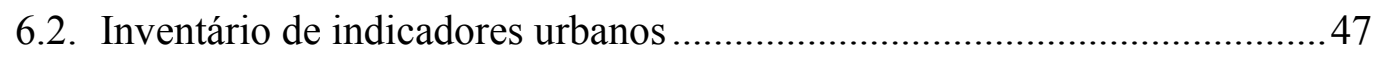


6.3. Classificação das cidades pesquisadas.....................................................51

6.3.1. Avaliação multicritério e o Processo Analítico Hierárquico .............51

6.3.2. Obtenção de pesos para as informações disponíveis via Internet através do Processo Analítico Hierárquico ....................58

6.4. Identificação e análise de indicadores de mobilidade urbana.......................60

6.4.1. Sistemas de indicadores selecionados.............................................61

6.4.2. Identificação preliminar dos indicadores

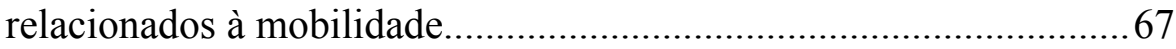

6.4.3. Avaliação das Categorias, Temas e Indicadores de mobilidade .......76

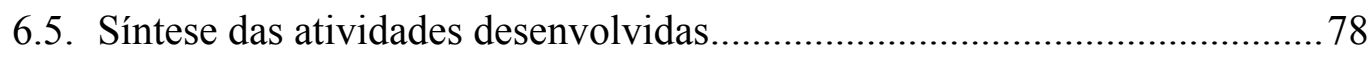

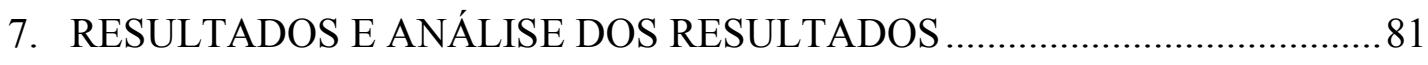

7.1. Inventários de indicadores urbanos (Fase1) ........................................... 81

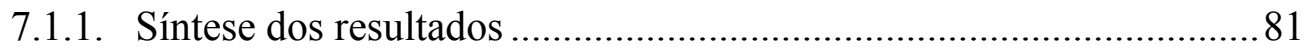

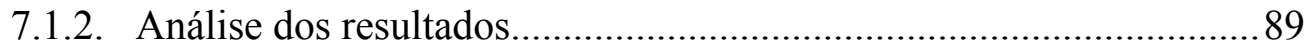

7.2. Avaliação das Categorias, Temas e Indicadores relacionados à monitoração da mobilidade urbana sustentável (Fases 2 e 3).................. 96

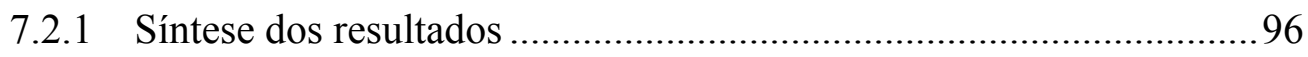

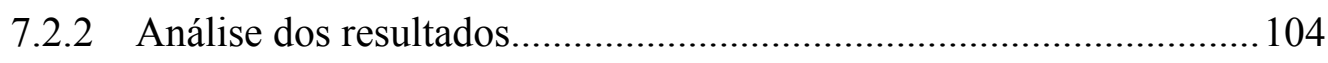

7.3. Confronto dos resultados obtidos a partir do inventário de indicadores urbanos e da análise de indicadores de mobilidade............. 118

8. CONCLUSÕES E SUGESTÕES PARA TRABALHOS FUTUROS .................121

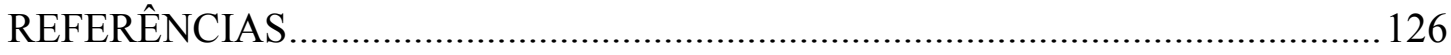

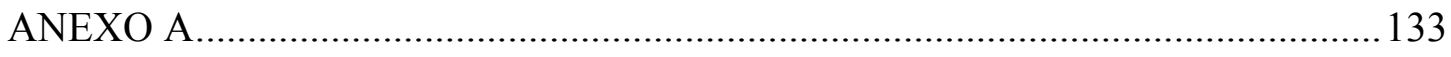

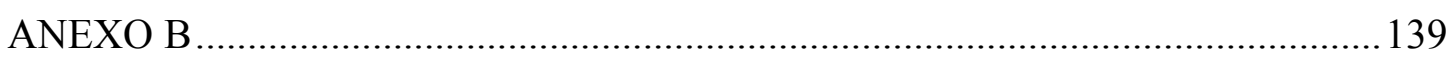

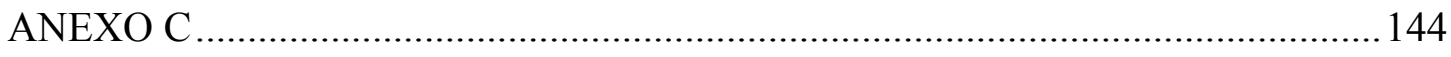

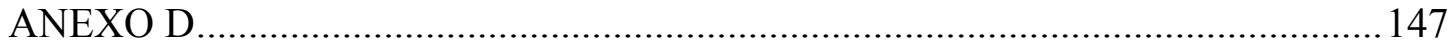

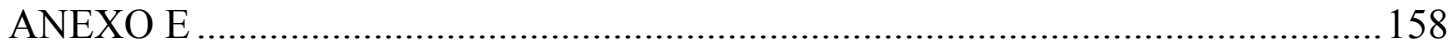

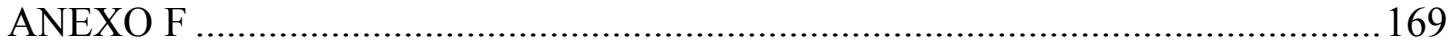

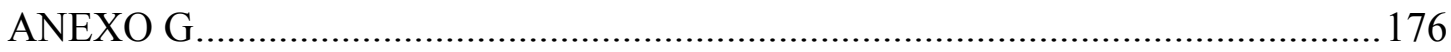


FIGURA 1: Divisão territorial do Brasil e Portugal Continental em Estados e

Distritos, respectivamente 6

FIGURA 2: Divisões dos Estados no Brasil e dos Distritos em Portugal em Municípios e Concelhos, respectivamente (A) e (B) 7

FIGURA 3: Mapa do Concelho de Braga, Portugal, onde se visualizam as diferenças entre os limites das Freguesias e da Cidade de Braga em si 8

FIGURA 4: Participação no total da população urbana do Brasil segundo as classes de tamanho dos Municípios no período 1970/2000 12

FIGURA 5: Participação no total da população urbana de Portugal Continental segundo as classes de tamanho dos Concelhos no período 1970/2001

FIGURA 6: Dimensões freqüentemente consideradas nos diferentes conceitos de sustentabilidade e o "espaço" onde ocorreria o desenvolvimento sustentável .17

FIGURA 7: Propostas de Agendas 21 Locais para as regiões brasileiras .25

FIGURA 8: Classificação das cidades brasileiras .84

FIGURA 9: Classificação das cidades portuguesas .84

FIGURA 10: Proporção de cidades incluídas em cada grupo para Brasil e Portugal. .92

FIGURA 11: Proporção de cidades classificadas em cada grupo para as regiões brasileiras .93

FIGURA 12: Proporção de cidades classificadas em cada grupo para as regiões portuguesas .96 
FIGURA 13: Pesos para as Categorias de informação relacionadas à monitoração da mobilidade urbana para Brasil e Portugal

FIGURA 14: Pesos para os Temas incluídos na Categoria

Transportes e Meio Ambiente (A) para Brasil e Portugal .98

FIGURA 15: Pesos para os Temas incluídos na categoria Gestão da Mobilidade Urbana (G) para Brasil e Portugal 99

FIGURA 16: Pesos para os Temas incluídos na categoria Infra-estrutura e Tecnologias de Transportes (I) para Brasil e Portugal. 99

FIGURA 17: Pesos para os Temas incluídos na categoria Planejamento Espacial e Demanda por Transportes (P) para Brasil e Portugal 100

FIGURA 18: Pesos para os Temas incluídos na categoria Aspectos Socioeconômicos dos Transportes (S) para Brasil e Portugal 101

FIGURA 19: Scores obtidos para os indicadores de mobilidade avaliados pelos especialistas brasileiros 104

FIGURA 20: Scores obtidos para os indicadores de mobilidade avaliados pelos especialistas portugueses

FIGURA 21: Hierarquia de Categorias, Temas e Indicadores de Mobilidade para o Brasil .107

FIGURA 22: Hierarquia de Categorias, Temas e Indicadores de Mobilidade para Portugal 


\section{LISTA DE TABELAS}

TABELA 1: Dimensões e temas que compõem os Indicadores de Desenvolvimento Sustentável para o Brasil 32

TABELA 2: Dimensões e setores que constituem o Sistema de Indicadores de Desenvolvimento Sustentável para Portugal .33

TABELA 3: Matriz de comparação par a par .53

TABELA 4: Escala de comparação dos critérios. .54

TABELA 5: Escala de comparação de critérios segundo Saaty ...... .54

TABELA 6: Índice de Aleatoriedade (RI) para $n=1,2,3, \ldots, 15$ .57

TABELA 7: Categorias, Temas e Palavras-chave relacionadas à mobilidade urbana

TABELA 8: Resumo da seleção de indicadores de mobilidade .76

TABELA 9: Pesos obtidos para as categorias de informação disponíveis via Internet para as cidades de Brasil e Portugal. 82

TABELA 10: Critérios para a classificação das cidades pesquisadas .83

TABELA 11: Grupos de cidades brasileiras .85

TABELA 12: Grupos de cidades portuguesas .87

TABELA 13: Número e proporção de cidades classificadas em cada grupo para Brasil e regiões .93 
TABELA 14: Número e proporção de cidades classificadas em cada grupo para Portugal e regiões .

TABELA 15: Pesos obtidos para os indicadores de mobilidade para Brasil e Portugal. .101

TABELA 16: Estrutura de Categorias, Temas e Indicadores comum à Brasil e Portugal. 
COSTA, M. S. (2003). Mobilidade urbana sustentável: um estudo comparativo e as bases de um sistema de gestão para Brasil e Portugal. Dissertação (Mestrado) - Escola de Engenharia de São Carlos, Universidade de São Paulo, São Carlos, 2003.

A necessidade de implementação de princípios e diretrizes de sustentabilidade, bem como a monitoração dos elementos que caracterizam o ambiente urbano é evidente, à medida que ampliam-se os problemas ambientais, econômicos e sociais responsáveis pelo declínio da qualidade de vida nas cidades. Desta forma, os indicadores tornam-se instrumentos fundamentais para promover o conhecimento e a informação necessários para a compreensão das especificidades e problemas presentes nos centros urbanos. Este trabalho tem por objetivo principal identificar indicadores voltados a monitorar as condições de mobilidade urbana em cidades selecionadas no Brasil e em Portugal, com base na preocupação principal de promover sua sustentabilidade. A primeira etapa compreende um inventário de sistemas de indicadores urbanos, já existentes ou em desenvolvimento, para um grupo de cidades dos dois países, a partir dos dados e informações disponibilizados através de suas páginas na Internet. Com base nos dados obtidos através do inventário e no julgamento de especialistas sobre a importância relativa de cada conjunto de informações analisado, as 106 cidades brasileiras e as 121 cidades portuguesas foram classificadas em diferentes grupos. Os resultados mostram que nos dois países, ao menos no tocante aos meios de acesso público via Internet, existe uma carência de informações e dados que permitam hoje o acompanhamento das condições de mobilidade urbana. A segunda etapa deste trabalho compreende a seleção e análise de indicadores de mobilidade a partir de um conjunto de experiências nacionais e internacionais de indicadores de sustentabilidade. Os indicadores identificados foram organizados em uma estrutura de Categorias e Temas e, posteriormente, submetidos à avaliação por parte de especialistas do Brasil e de Portugal com o objetivo de determinar sua importância relativa para a monitoração da mobilidade urbana no contexto dos dois países. Para o Brasil, os critérios ambientais obtiveram os maiores pesos a partir da avaliação dos especialistas do país. Já para Portugal, aos indicadores relacionados ao planejamento espacial das cidades e à monitoração da demanda por transportes, foram atribuídos os maiores pesos com base na opinião dos especialistas portugueses. Para os dois países os indicadores relacionados à monitoração das características de infra-estrutura e tecnologias de transporte foram considerados menos relevantes dentre todos os avaliados.

Palavras-chave: sustentabilidade urbana, mobilidade urbana sustentável, indicadores de mobilidade, cidades brasileiras, cidades portuguesas. 
COSTA, M. S. (2003). Sustainable urban mobility: a comparative study and the bases for a management system in Brazil and Portugal. M.Sc. Dissertation - Escola de Engenharia de São Carlos, Universidade de São Paulo, São Carlos, 2003.

There is a clear need for the implementation of sustainability principles and guidelines in urban areas, as well as for strategies for controlling the elements that shape the urban environment. The growing environmental, social, and economic problems make this need continuously more evident because they negatively impact the urban quality of life. As a consequence, indicators become essential tools to provide the knowledge and information required for understanding particular aspects and problems of the cities. Therefore, the main objective of this work is to identify indicators that are suitable for monitoring the urban mobility conditions of selected cities in Brazil and Portugal aiming at a sustainable development. An inventory of urban indicators in cities of the two countries has been carried out through Internet and the data collected, which reflected either existing or under development indicator systems, were combined with weights extracted from experts' evaluation of the relative importance of each information group considered. The 106 Brazilian cities and 121 Portuguese cities were thereafter classified into groups of similar characteristics regarding the previous evaluation. The results showed that, at least regarding what is available to the public through Internet, both countries clearly have limitations of data and information for monitoring their urban mobility conditions. The second phase of the research was the selection and analysis of mobility indicators extracted from several national and international experiences of sustainability indicators. Those indicators were organized under a framework of Categories and Themes and also submitted to the evaluation of groups of experts in both countries, in order to determine their relative importance for monitoring urban mobility conditions. Indicators dealing with environmental aspects were among those identified with the higher weights in Brazil, while the evaluation of the Portuguese experts put indicators regarding urban spatial planning and transport demand management at the top of the list. A common point in the evaluation was the fact that indicators related to transport technologies and infrastructure have the smallest weights in both countries.

Keywords: urban sustainability, sustainable urban mobility, mobility indicators, Brazilian cities, Portuguese cities. 


\section{INTRODUÇÃO}

Nesta seção é feita uma breve caracterização do problema estudado, que diz respeito à questão da mobilidade em cidades de médio porte no Brasil e em Portugal, bem como são apresentados a justificativa, o objetivo e a estrutura deste trabalho.

\subsection{Caracterização do problema}

O crescimento do número de pessoas vivendo nas cidades, a contínua sobrecarga nos recursos, infra-estrutura e instalações urbanas, além dos profundos impactos causados no meio ambiente têm por conseqüência principal, a deterioração da qualidade de vida nas cidades. Os problemas relacionados à mobilidade acabam por agravar ainda mais este quadro. Questões como a segregação espacial ainda maior das atividades e serviços urbanos, a adoção crescente de modos de transporte pouco sustentáveis, a ineficiência do transporte coletivo, ruído, poluição e congestionamento, estão cada vez mais presentes no contexto de muitas cidades.

Este quadro de intensa pressão tem incentivado a promoção de conferências e debates sobre o desenvolvimento sustentável. Nestes eventos, promovidos principalmente a partir da última década do século XX, a necessidade de se criar instrumentos para monitorar os esforços em direção ao desenvolvimento sustentável tem sido igualmente abordada. Desta forma, inúmeras experiências de desenvolvimento de indicadores de sustentabilidade começaram a ser amplamente divulgadas em diversos países, inclusive no Brasil. Neste sentido, há inúmeros indicadores voltados a monitorar as condições de sustentabilidade em nível "nacional", mas relativamente poucos orientados à escala "urbana". A mesma dificuldade existe ao se tentar identificar indicadores específicos para as questões relacionadas à mobilidade. Ainda que já existam algumas iniciativas 
em nível internacional (OECD, 1999; EEA, 2002), no Brasil estes sistemas ainda não configuram ferramentas usuais, disponíveis para o processo de gestão.

\subsection{Justificativa do trabalho}

O agravamento dos problemas urbanos tem impulsionado a adoção de ferramentas inovadoras, que superem as limitações dos atuais instrumentos de gestão. No entanto, qualquer que seja a estratégia adotada para o planejamento urbano e de transportes, esta irá exigir a identificação e quantificação detalhada de muitos dos elementos e funções envolvidos nestes processos.

Desta forma, o desenvolvimento de indicadores voltados a monitorar as condições de mobilidade em cidades de médio porte, tanto no Brasil como em Portugal, assume grande importância no processo de planejamento, ao fornecer os subsídios necessários para a elaboração de qualquer plano ou projeto que vise a maior sustentabilidade do ambiente urbano.

Assim, um dos aspectos relevantes deste trabalho está em contribuir para a maior compreensão dos atributos relacionados ao desenvolvimento de um transporte sustentável e na identificação de indicadores fundamentais para a monitoração das condições e tendências em nível urbano.

Esta pesquisa insere-se ainda em um estudo maior que tem por objetivo desenvolver técnicas visando a criação de um Sistema de Apoio à Decisão que contribua para o desenvolvimento sustentável em cidades de pequeno e médio portes no Brasil e em Portugal. Este projeto integra três equipes em particular, pertencentes às seguintes instituições: Universidade de São Paulo, através da Escola de Engenharia de São Carlos; Universidade Estadual Paulista "Júlio Mesquita Filho", através da Faculdade de Arquitetura, Artes e Comunicação, e Universidade do Minho, Portugal, através da sua Escola de Engenharia.

Deste modo, ao se promover um estudo que englobe países inseridos em contextos tão distintos como é o caso de Brasil e Portugal, busca-se compartilhar as experiências de 
ambos no processo de gestão da mobilidade e na promoção do desenvolvimento sustentável. A experiência de Portugal no contexto da União Européia, onde a implementação do conceito de mobilidade sustentável já compartilha de muitos esforços, pode ser de grande valia para a realidade brasileira, onde este ainda é pouco explorado. O Brasil, por sua vez, pode contribuir com sua experiência na gestão de cidades de médio porte, as quais têm experimentado rápido crescimento especialmente nas últimas décadas, além do conhecimento de questões complexas relacionadas à metropolização de centros urbanos, contribuindo assim para o diagnóstico e a antecipação de soluções para problemas ainda não observados nas cidades portuguesas.

\subsection{Objetivo do trabalho}

O objetivo principal deste trabalho é identificar indicadores adequados a monitorar as condições de mobilidade em um grupo de cidades de médio porte no Brasil, aqui entendidas como aquelas selecionadas em um estudo recentemente conduzido pelo Instituto de Pesquisa Econômica Aplicada (IPEA, 1999), e em Portugal, para um grupo de cidades pertencentes à porção continental do país, reunidas no Atlas das Cidades de Portugal, estudo promovido pelo Instituto Nacional de Estatística (INE, 2002). Aliado a este objetivo principal, este trabalho pretende também:

- No contexto da mobilidade, contribuir para a identificação dos principais elementos e atributos relacionados à promoção de um transporte sustentável;

- Promover um estudo comparativo, avaliando o nível de informação sobre as condições urbanas (ou seja, dados estatísticos e informações que caracterizem aspectos geográficos, demográficos, socioeconômicos ou ambientais) disponibilizado em páginas da Internet relacionadas aos centros urbanos que constituem objeto de estudo deste trabalho. 


\subsection{Estrutura do trabalho}

Este documento é composto por oito capítulos, estruturados da seguinte forma: após esta introdução, a próxima seção apresenta algumas das principais características geopolíticas de Brasil e Portugal, dando destaque à questão das cidades médias nos dois países. No Capítulo 3 são discutidos os principais conceitos relativos ao tema sustentabilidade, com ênfase na sua inserção no contexto urbano. No Capítulo 4 são abordadas questões referentes aos instrumentos de gestão do desenvolvimento sustentável, representados pelos indicadores de sustentabilidade. No Capítulo 5 são discutidos aspectos gerais relativos à mobilidade urbana, bem como questões referentes à implementação do conceito de mobilidade urbana sustentável. No Capítulo 6 é apresentado o método proposto para desenvolvimento deste trabalho, constituído de um inventário de indicadores urbanos, além de uma seleção e análise de indicadores de mobilidade urbana sustentável a partir de um grupo de experiências nacionais e internacionais de indicadores de sustentabilidade. No Capítulo 7 são descritos e analisados os resultados obtidos a partir do inventário, além dos indicadores selecionados para avaliação, identificados a partir de um conjunto de experiências nacionais e internacionais. No Capítulo 8 constam as conclusões obtidas, bem como sugestões para o desenvolvimento de trabalhos futuros. Finalmente são apresentadas as referências utilizadas para o desenvolvimento deste trabalho. 


\section{AS CIDADES NO CONTEXTO DE BRASIL E PORTUGAL}

Nesta seção são identificadas algumas das principais características geopolíticas de Brasil e Portugal, dando enfoque especial ao contexto das cidades, objeto de estudo deste trabalho. A questão das cidades médias, nos dois países, é igualmente abordada com destaque neste capítulo.

\subsection{Características geopolíticas}

Conforme SOUZA et al. (2003), as diferenças entre Brasil e Portugal não estão limitadas apenas às condições geográficas manifestadas em termos de localização e clima, entre outras características, sendo evidentes também em termos de escala. Enquanto mais de 171 milhões de habitantes distribuem-se em uma área de 8.514.215 $\mathrm{km}^{2}$ no Brasil, os cerca de 10 milhões de habitantes de Portugal, incluindo aqui os habitantes do continente e dos arquipélagos de Madeira e Açores, ocupam uma área equivalente a $91.982 \mathrm{~km}^{2}$. Como resultado tem-se uma densidade não uniformemente distribuída de cerca de 19 habitantes $/ \mathrm{km}^{2}$ para o Brasil e de 109 habitantes $/ \mathrm{km}^{2}$ para Portugal.

Ainda que situados em contextos geográficos bastante distintos, é possível identificar algumas semelhanças entre Brasil e Portugal no que se refere à divisão do território para fins político-administrativos, embora haja uma clara distinção de nomenclatura nos dois países. Tais semelhanças podem ser naturalmente explicadas pelo fato do Brasil ter sido colônia de Portugal por mais de 300 anos. Assim, Portugal apresenta-se dividido em 18 Distritos (excluindo os arquipélagos) enquanto o Brasil é dividido em 26 Estados (mais o Distrito Federal), como mostra a Figura 1. A principal diferença, no entanto, é que em Portugal continental os Distritos não constituem um nível administrativo, ou seja, não 
possuem governo próprio, ao contrário dos Estados brasileiros, geridos por governadores eleitos pelas suas respectivas populações. Tal diferença justifica-se pelas dimensões dos Distritos portugueses e dos Estados brasileiros, já que os últimos são significativamente maiores que os primeiros.
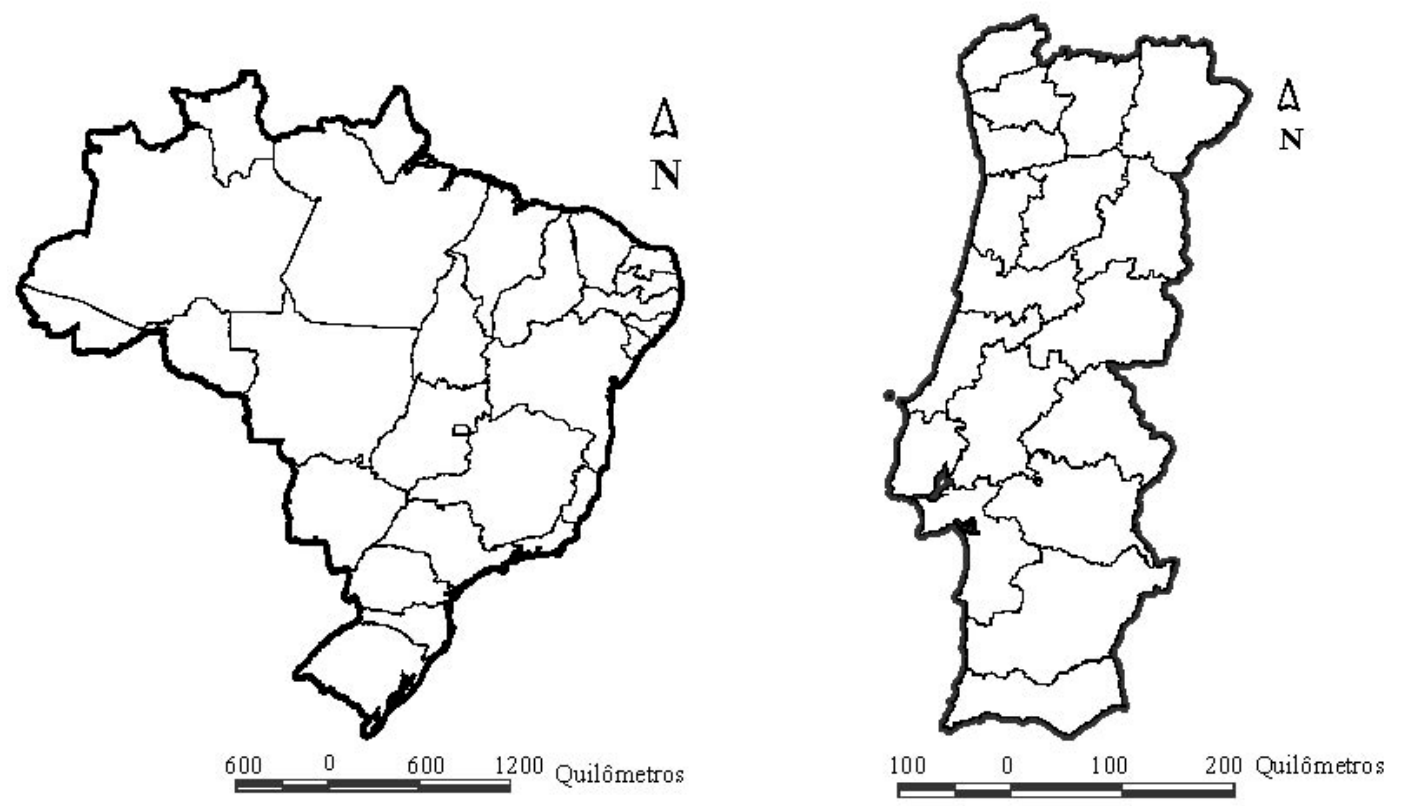

Figura 1: Divisão territorial do Brasil e Portugal Continental em Estados e Distritos, respectivamente

Fonte: SOUZA et al. (2003).

Dando seqüência à divisão do território de Brasil e Portugal, imediatamente abaixo dos Estados e dos Distritos estão, respectivamente, os Municípios e os Concelhos, como mostra a Figura 2. Desta forma, no ano de 2001, o Brasil apresentava 5.561 Municípios enquanto que Portugal continental contava com 275 Concelhos. Como os Concelhos constituem subdivisões dos Distritos, um Concelho é sempre sede de Distrito, podendo dar nome ao mesmo. No caso brasileiro a situação é semelhante, uma vez que um Município é capital de Estado, embora não necessariamente dê nome ao mesmo. Tanto os Concelhos portugueses como os Municípios brasileiros constituem níveis de governo. Em Portugal sua administração cabe aos Presidentes de Câmara Municipal, que representam o Poder Executivo neste nível. Já no Brasil, cabe aos Prefeitos Municipais. 


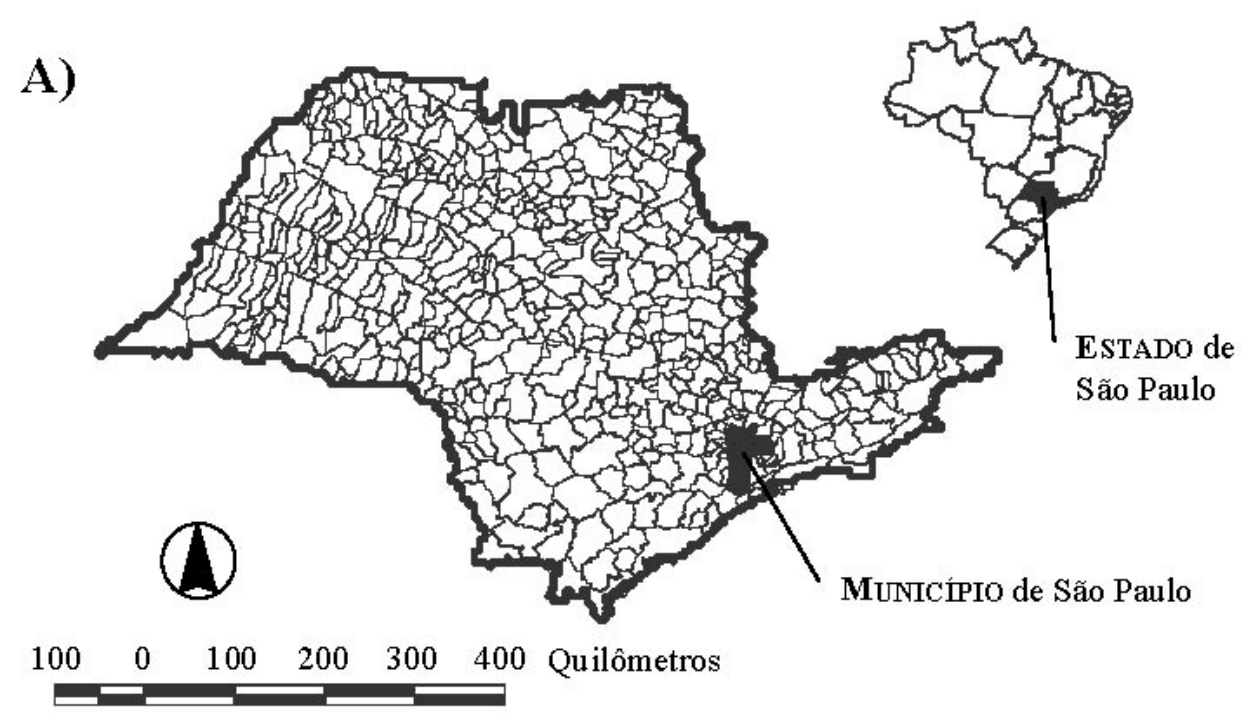

B)

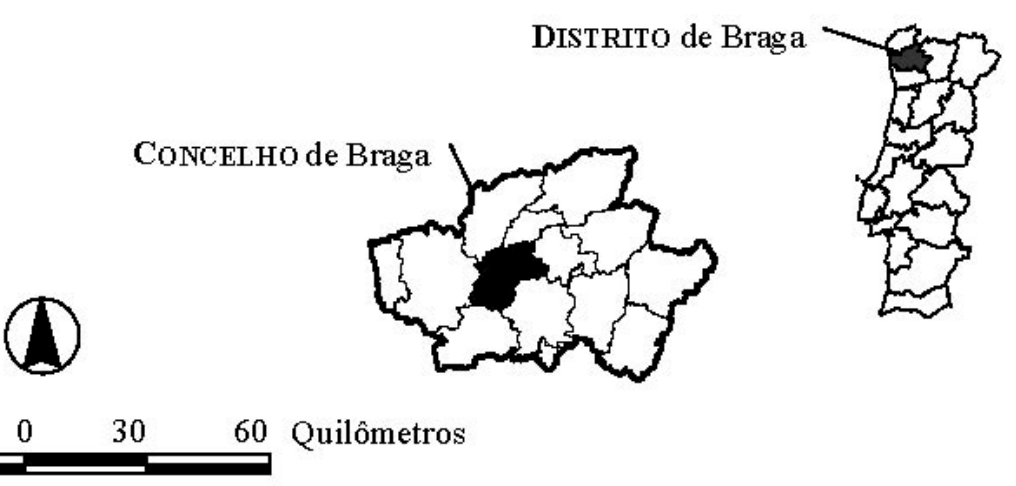

Figura 2: Divisões dos Estados no Brasil e dos Distritos em Portugal em Municípios e Concelhos, respectivamente (A) e (B)

Fonte: SOUZA et al. (2003).

Os Concelhos portugueses apresentam ainda uma outra subdivisão, as Freguesias, que constituem outro nível administrativo, gerido pelos Presidentes das Juntas de Freguesia. Os limites das Freguesias, no entanto, não coincidem necessariamente com os limites da cidade, como mostrado no exemplo da Figura 3. Até recentemente, este fato se constituía em um problema, uma vez que muitas das informações estatísticas em Portugal apresentavam-se desagregadas somente até o nível das Freguesias, ocasionando certa dificuldade na identificação de dados referentes ao espaço urbano ou ao espaço rural. No Brasil, embora não haja uma subdivisão semelhante a das Freguesias, alguns municípios apresentam além de sua sede, Distritos, que constituem Anexos geridos pela mesma administração. 


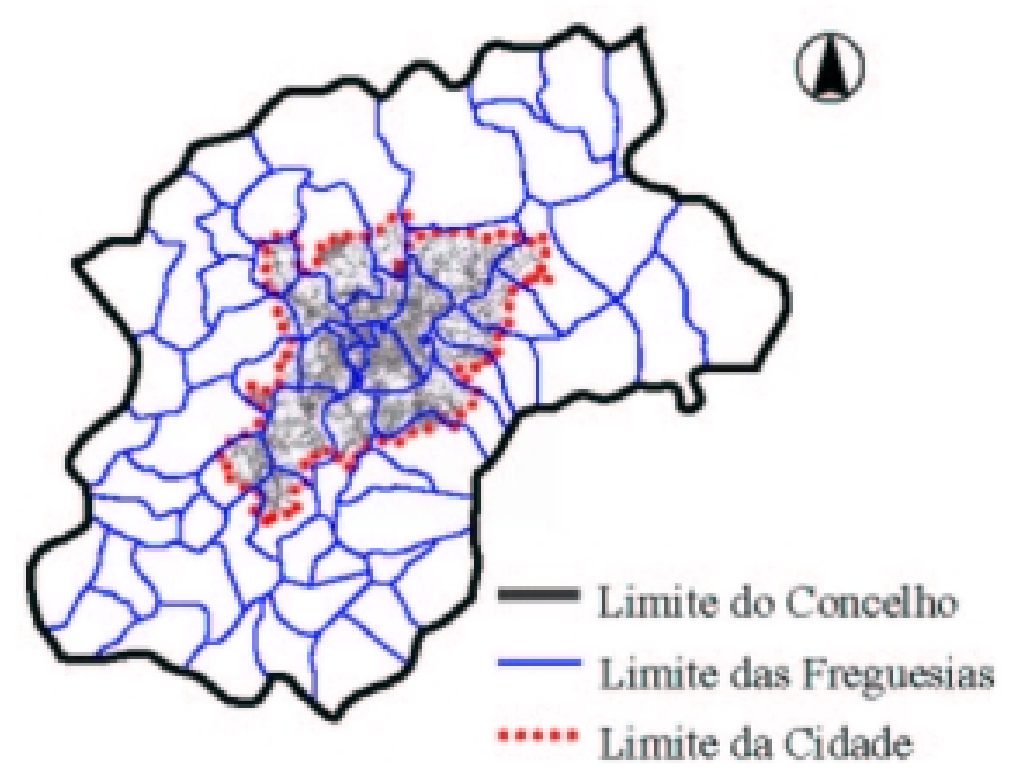

Figura 3: Mapa do Concelho de Braga, Portugal, onde se visualizam as diferenças entre os limites das Freguesias e da Cidade de Braga em si Fonte: SOUZA et al. (2003).

Para o caso de Portugal, cabe destacar ainda que, para uma vila ou aglomeração ser elevada à categoria de cidade, devem ser observados os seguintes aspectos:

- Contar com um número de eleitores, em aglomerado populacional contínuo, superior a oito mil pessoas;

- Possuir pelo menos metade dos seguintes equipamentos coletivos: instalações hospitalares com serviço de permanência; farmácias; corporação de bombeiros; casa de espetáculos e centro cultural; museu e biblioteca; instalações de hotelaria; estabelecimento de ensino preparatório e secundário; estabelecimento de ensino pré-primário e infantário (estabelecimento de educação infantil).

No entanto, muitas vezes os limites definidos pelo Instituto Nacional de Estatística para as cidades não coincidem com os limites que as autarquias consideram para sua administração. Em geral, os órgãos autárquicos identificam esses limites com o perímetro urbano definido nos Planos Diretores Municipais. Em virtude da atualização e revisão periódica destes planos, estes limites podem ser eventualmente alterados (ALBERGARIA, 1999). 
Para efeito deste estudo, considerou-se como definição de cidade (no caso específico de Portugal, onde as dificuldades para a sua delimitação são maiores), o território correspondente ao conjunto de Freguesias pelas quais se espalha, eliminando aquelas em que a percentagem da população da cidade aí residente não atinge os $50 \%$ da população da própria Freguesia. Tal definição tem sido utilizada pelas estatísticas oficiais desenvolvidas para o território português (ALBERGARIA, 1999; INE, 2002).

Apresentadas as principais características geopolíticas dos dois países, este trabalho irá concentrar-se agora na questão das cidades médias brasileiras e portuguesas. Deste modo, são apresentados a seguir alguns conceitos relacionados ao tema, bem como uma avaliação da distribuição da população nas cidades nos últimos anos, procurando retratar o processo de transformação ocorrido na rede urbana tanto no Brasil como em Portugal.

\subsection{Cidades médias}

Com relação às cidades médias, não existe um conceito único ou mesmo uma definição que possa ser usada indistintamente no meio técnico-científico do que constituem os centros urbanos abrangidos por esta categoria. Muitos dos conceitos ou definições associadas ao tema estão subordinadas aos objetivos ou critérios subjetivos ditados por seus pesquisadores. No entanto, as experiências de muitos países que desenvolveram políticas de descentralização territorial possibilitaram a acumulação de um importante conjunto de informações sobre este nível hierárquico de cidades (AMORIM e SERRA, 2001).

Dentre os critérios empregados para identificar um grupo de cidades, o critério demográfico têm sido o mais utilizado, dada a sua ampla disponibilidade e simplicidade de aplicação. Critérios como relações externas, estrutura interna, nível de infra-estrutura e grau de concentração de atividades urbanas também devem ser considerados. No entanto, estes podem variar bastante de uma região para outra, sendo função do estágio de desenvolvimento e das condições geográficas específicas de cada área em questão. 
As questões relacionadas às cidades médias constituíram objeto de grande preocupação para o planejamento urbano em muitos países durante a década de 70. A experiência acumulada através dos estudos e planos promovidos neste período contribuiu para identificação de alguns atributos utilizados para qualificar um centro como cidade média, dentre eles:

- O estabelecimento de interações constantes não só com aglomerações urbanas próximas e de hierarquia inferior (espaço regional subordinado) como com aglomerações urbanas de hierarquia superior;

- Tamanho demográfico e funcional suficiente para o oferecimento de um leque variado de bens e serviços;

- Capacidade de receber e fixar os migrantes de cidades menores ou da zona rural, por meio do oferecimento de oportunidades de trabalho, interrompendo assim o fluxo migratório para os centros já saturados;

- Condições necessárias ao estabelecimento de relações dinâmicas com o espaço rural que o envolve;

- Diferenciação do espaço intra-urbano, com centro funcional bem caracterizado pela presença de atividades de caráter comercial e de serviços, e periferia dinâmica que evolui com a multiplicação de novos núcleos habitacionais periféricos.

No Brasil, a procura de maior equilíbrio interurbano e a necessidade de interromper o fluxo migratório em direção às grandes cidades acabaram por constituir os objetivos principais das políticas urbanas que apoiavam o desenvolvimento das cidades médias. Alguns aspectos geográficos e socioeconômicos estiveram associados a esta preocupação, cabendo citar:

- O aumento dos problemas e desequilíbrios urbanos;

- A deterioração da qualidade de vida nas grandes aglomerações urbanas, bem como o aumento acelerado dos problemas sociais já verificados; 
- A frágil organização hierárquica das cidades, caracterizada pela insuficiência de centros intermediários dinâmicos que pudessem contribuir para a interiorização do desenvolvimento.

Ao contrário da década de 70, a década de 80 foi marcada por um profundo desinteresse pelas políticas regionais e, em conseqüência, por aquelas destinadas a promover o desenvolvimento das cidades médias. Tal desinteresse refletiu a priorização de políticas macroeconômicas, a menor disponibilidade de recursos públicos e a diminuição dos deslocamentos populacionais inter-regionais.

Já na década de 90, a chamada "globalização" e as mudanças paradigmáticas ocorridas nos seus primeiros anos contribuíram para a retomada do interesse governamental, econômico e acadêmico sobre as questões relacionadas às cidades médias. Desde então, estas são valorizadas como elementos de equilíbrio paras as redes urbanas de muitos países, principalmente naqueles onde as disparidades entre as cidades grandes e pequenas são maiores. Dentre os inúmeros aspectos associados à sua valorização estão:

- A possibilidade de minimização da pobreza urbana;

- A melhoria da capacidade gerencial e financeira do Estado em prover equipamentos e serviços urbanos;

- A preservação do meio ambiente.

De um modo geral, as cidades médias são vistas ainda como "diques" de contenção dos fluxos migratórios que se dirigem às grandes cidades ou mesmo uma alternativa espacial capaz de absorver parte do crescimento da população.

\subsubsection{Participação das cidades médias na rede urbana do Brasil e de Portugal}

Ainda com respeito a temática das cidades médias, é interessante proceder a uma avaliação da dinâmica populacional tanto no Brasil como em Portugal, procurando identificar a crescente participação destas cidades no contexto urbano dos dois países. 
Conforme SOUZA et al. (2003), podem ser identificados alguns pontos em comum entre os dois países no período compreendido entre 1970 e 2000/2001, dentre eles a tendência de redução da participação relativa da população urbana total em cidades com menos de 20 mil habitantes, além do deslocamento progressivo da população para algumas faixas de cidades maiores. No caso do Brasil merece destaque o crescimento ocorrido na faixa que vai de 250 a 500 mil habitantes, ao mesmo tempo em que para Portugal observa-se um crescimento na faixa que compreende as cidades entre $100 \mathrm{e}$ 250 mil habitantes. Estes aspectos refletem a tendência de urbanização presente nos dois países, ainda que guardadas suas respectivas particularidades, principalmente no que diz respeito à questão da escala. As Figuras 4 e 5 ilustram o exposto.

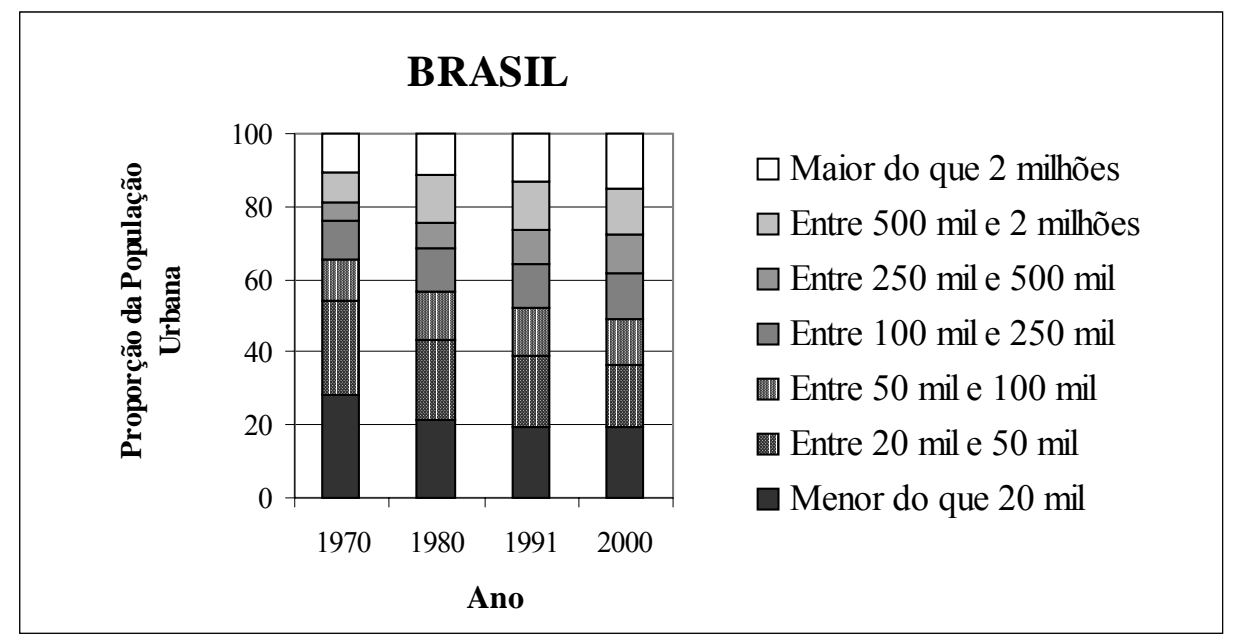

Figura 4: Participação no total da população urbana do Brasil segundo as classes de tamanho dos Municípios no período 1970/2000

Fonte: Adaptado de ANDRADE e SERRA (2001).

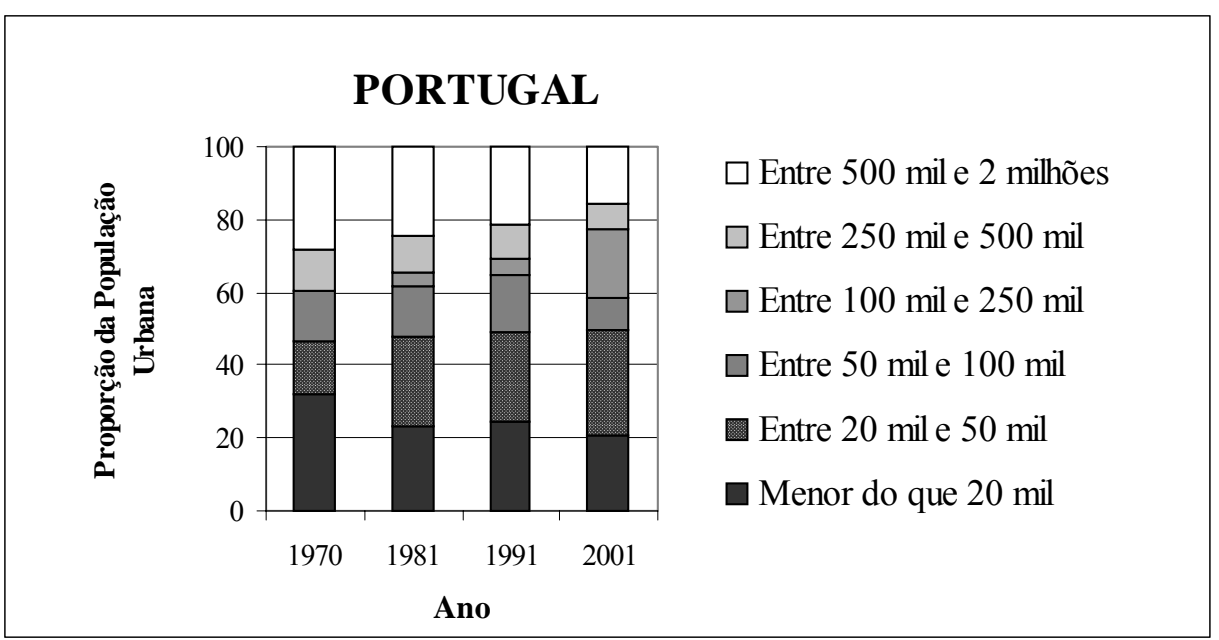

Figura 5: Participação no total da população urbana de Portugal Continental segundo as classes de tamanho dos Concelhos no período 1970/2001

Fonte: ALBERGARIA (1999) e INE (2002). 
Conforme ANDRADE e SERRA (2001), a configuração de um sistema de cidades reflete o estágio de desenvolvimento de um país ou região. Nas economias mais primitivas, a atividade econômica tende a se concentrar em alguns poucos aglomerados urbanos. Em uma situação oposta, sistemas mais desenvolvidos revelam uma configuração espacial mais equilibrada e estável, com fortes vínculos interurbanos.

No caso do Brasil, a extensão territorial do país favorece a convivência de subsistemas regionais em fases distintas de seu ciclo de vida. Desde as configurações mais primitivas, onde praticamente inexistem cidades médias (nas regiões-fronteira, por exemplo), passando por subsistemas em fase de transição (como a Região Nordeste, com cidades médias distribuídas ao longo da Zona da Mata e do Agreste), até configurações mais evoluídas, em que há um equilíbrio entre os vários estratos de tamanhos urbanos, como no caso do Centro-sul do país. Deste modo, pode-se concluir que o sistema brasileiro de cidades pode ser interpretado como uma média ponderada dos vários subsistemas regionais, onde os pesos refletem a importância econômicodemográfica de cada região.

Para Portugal, verifica-se que a dimensão média das cidades situadas no Continente é muito pequena, com $70 \%$ destas possuindo menos de 20 mil habitantes. No entanto, com base em dados referentes ao período entre 1864 e 1991, verifica-se que a população que vive nas áreas hoje consideradas cidades triplicou, ficando muito acima do crescimento populacional do Continente no mesmo período (ALBERGARIA, 1999).

Para o caso de Portugal cabe destacar também a existência de diferenças significativas entre as cinco regiões do Continente, no que diz respeito aos valores médios da população. Os valores mais elevados pertencem às regiões Lisboa e Norte, em virtude do peso das áreas metropolitanas de Lisboa e Porto. Já a maioria das cidades com população inferior a 5 mil habitantes, bem como a maioria das cidades com população entre 5 mil e 10 mil habitantes situam-se na região Norte. No que se refere à região Centro constata-se, para o mesmo período, uma diminuição significativa da população das suas cidades. As regiões do Alentejo e Algarve apresentaram, por sua vez, uma diminuição acentuada da população citadina. 
Apresentadas as principais características geopolíticas que permitem identificar as cidades estudadas nos dos dois países e, ainda, discutidas algumas questões relacionadas às cidades médias, no próximo capítulo são abordados os principais conceitos relacionados à questão da sustentabilidade, bem como sua inserção no contexto urbano. 


\section{DESENVOLVIMENTO SUSTENTÁVEL}

Há talvez uma dezena de definições para as expressões "sustentabilidade" e “desenvolvimento sustentável”, sendo notória a dificuldade em obter-se uma definição precisa e consensual para estes termos. Deste modo, são resumidos neste capítulo alguns dos principais conceitos relacionados a estes temas, dando ênfase para a questão urbana. Posteriormente, são feitas algumas considerações a respeito do desenvolvimento sustentável no Brasil e em Portugal, procurando retratar como a questão tem sido abordada nos dois países.

\subsection{Conceitos e dimensões}

Somando-se à multiplicidade de conferências e debates ocorridos especialmente nos últimos dez anos sobre desenvolvimento sustentável, uma série de documentos e definições sobre o tema foram elaborados e divulgados internacionalmente, constituindo as bases para a implementação do conceito em muitos países (ICLEI, 1994; UNCED, 1992; UNCHS, 1996; WCED, 1987). Ainda que muitas destas definições sejam influenciadas por fatores como localização geográfica, estágio de desenvolvimento econômico e interesses específicos de cada grupo em particular, é possível distinguir alguns aspectos comuns dentre os diversos conceitos encontrados.

Para muitos dos trabalhos já publicados, sustentabilidade implica na capacidade das nações em dar continuidade às formas atuais de produção e desenvolvimento econômico. Outros descrevem sustentabilidade em termos dos impactos gerados no ambiente natural pelos sistemas atuais de tecnologia ou como a questão dos países subdesenvolvidos em busca de patamares de desenvolvimento comparáveis às nações do primeiro mundo (MOORE e JOHNSON, 1994). 
O conceito apresentado pela Comissão Mundial de Meio Ambiente e Desenvolvimento (WCED, 1987), que define desenvolvimento sustentável como "aquele que atende às necessidades da geração atual sem pôr em risco a capacidade das gerações futuras de atender às suas próprias necessidades", constitui uma das referências mais conhecidas sobre o assunto. No entanto, tal conceito não constituiu uma definição absoluta e comumente aceita do termo, tendo gerado interpretações diversas e até mesmo contraditórias, dado o contexto a que se aplica.

Outro documento que define as bases para a compreensão do conceito de desenvolvimento sustentável é a Agenda 21. Este constitui um plano de ação composto por 40 capítulos, discutido e adotado por diversos países durante a Conferência das Nações Unidas sobre Meio Ambiente e Desenvolvimento ocorrida em junho de 1992 no Rio de Janeiro (UNCED, 1992). Na Agenda 21 não são tratadas apenas questões ligadas à preservação e conservação da natureza. São consideradas, dentre outras, questões estratégicas ligadas à geração de emprego e renda, diminuição das disparidades regionais e interpessoais de renda, mudanças nos padrões de produção e consumo, construção de cidades sustentáveis e a adoção de novos modelos e instrumentos de gestão.

A amplitude e complexidade do conceito de desenvolvimento sustentável permite ainda que uma multiplicidade de dimensões ou potenciais dimensões sejam consideradas. Conforme SOUZA et al. (2003), as primeiras preocupações acerca do desenvolvimento sustentável tiveram sua origem a partir da discussão em torno de problemas ambientais e na expectativa de um potencial esgotamento dos recursos naturais essenciais para sobrevivência da espécie humana. No entanto, as questões econômicas e sociais têm assumido peso equivalente nos debates sobre o tema, não sendo mais admitido o enfoque único sobre as questões ambientais. Desta forma, o ponto em comum entre as muitas definições encontradas tem sido a abordagem integrada das dimensões sociais, econômicas e ambientais no âmbito do desenvolvimento sustentável. Assim, este pode ser entendido como um caminho progressivo em direção a um crescimento econômico mais equilibrado, eqüidade social e proteção ao meio ambiente.

De um modo particular, na dimensão social são considerados aspectos referentes ao bem-estar da população e às condições necessárias para promovê-lo. A preocupação 
principal está na promoção do capital social, constituído pelas habilidades, conhecimentos e capacidades dos indivíduos que integram a sociedade. A dimensão econômica, por sua vez, considera não só o capital econômico ou monetário, como enfatiza a preservação do capital em suas diferentes formas (capital econômico, social e natural). Já a dimensão ambiental tende a enfocar os impactos das atividades humanas sobre o meio ambiente, concentrando sua preocupação na preservação do que os economistas denominam de capital natural. A Figura 6 representa de forma esquemática as conexões existentes entre as três dimensões freqüentemente consideradas nos diferentes conceitos de sustentabilidade e o "espaço" onde ocorreria o desenvolvimento sustentável.

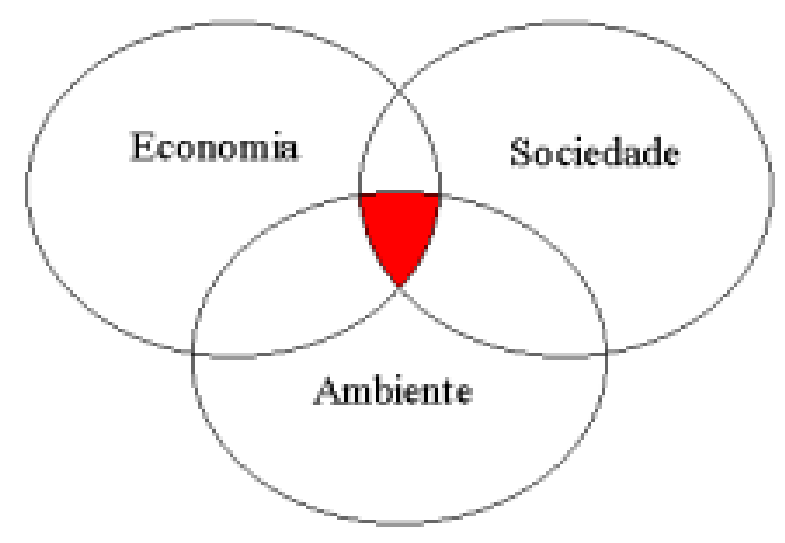

Figura 6: Dimensões freqüentemente consideradas nos diferentes conceitos de sustentabilidade e o "espaço" onde ocorreria o desenvolvimento sustentável Fonte: Adaptado de SOUZA et al. (2003).

Mais recentemente, a dimensão institucional tem sido igualmente identificada como fundamental no contexto do desenvolvimento sustentável. De um modo geral, nesta dimensão são abordados a estrutura e funcionamento das instituições, englobando, além das instituições clássicas, organizações não governamentais e empresas.

Apresentados os principais conceitos relacionados à sustentabilidade, bem como as principais dimensões consideradas para a promoção do desenvolvimento sustentável, na próxima seção é discutida a inserção destes no contexto urbano. 


\subsection{Sustentabilidade urbana}

A problemática que envolve a promoção do desenvolvimento sustentável exige que sejam empreendidas ações em todos os níveis e esferas do desenvolvimento humano, incluindo intervenções no ambiente físico, estratégias político-administrativas e mudanças nos processos sociais. Neste contexto, a Comissão Mundial sobre Ambiente e Desenvolvimento (WCED, 1987), reunida em virtude da elaboração do relatório Nosso Futuro Comum (The Bruntland Report) identificou um grupo de condições necessárias para o desenvolvimento sustentável, incluindo:

- População e desenvolvimento;

- Garantia de alimento;

- Preservação de espécies e ecossistemas;

- Energia;

- Indústria;

- E o desafio urbano.

A questão das cidades, ou mais precisamente a questão urbana é, portanto, uma questão chave para a promoção do desenvolvimento sustentável. No entanto, dúvidas e contradições são freqüentes quando considerado este nível de intervenção. De um modo geral, estas dúvidas residem no conceito de desenvolvimento sustentável e de sustentabilidade urbana propriamente ditos.

Segundo MACLAREN (1996), as expressões "sustentabilidade urbana" e “desenvolvimento urbano sustentável" possuem significados muito próximos e têm sido utilizadas indistintamente nos muitos trabalhos já publicados sobre o assunto. Uma forma de distinguir estas duas expressões, entretanto, é considerar a sustentabilidade como um estado desejável ou um conjunto de condições que se mantêm ao longo do tempo. Já a palavra "desenvolvimento" no termo "desenvolvimento urbano sustentável" implicaria no processo pelo qual a sustentabilidade pode ser alcançada.

Algumas características-chave relacionadas à sustentabilidade urbana são encontradas com freqüência na literatura, incluindo: 
- Eqüidade entre gerações;

- Eqüidade intragerações, incluindo eqüidade social, geográfica (minimização das desigualdades entre diferentes comunidades) e governamental;

- Proteção ao ambiente natural e respeito aos seus limites;

- Minimização do uso de recursos não-renováveis;

- Vitalidade e diversidade econômica;

- Autoconfiança por parte da comunidade;

- Bem-estar individual;

- Satisfação das necessidades básicas (MACLAREN, 1996).

MOORE e JOHNSON (1994), por sua vez, identificam uma série de atributos e características comuns ao planejamento de comunidades sustentáveis, representados por:

- Equilíbrio entre o ambiente construído e o ambiente nãoconstruído, entre o homem e a natureza, entre diferentes comunidades e diferentes modos de transporte;

- Diversidade de padrões, formas, pessoas e atividades;

- Consciência ecológica ou consciência da importância dos sistemas naturais;

- Flexibilidade das políticas para alcance dos objetivos comuns;

- Visão holística: todos os sistemas devem ser vistos de forma integrada ou como pequenos subsistemas de um sistema maior e mais complexo;

- Integração entre as diferentes formas e padrões, em contraste à segregação dos mesmos. Variedade de sistemas, planos e objetivos;

- Simbiose: o desenvolvimento sustentável sugere a complementação e manutenção das formas e sistemas existentes, mais do que a substituição ou destruição dos mesmos; 
- Sistemas: todos os elementos de um ambiente devem ser vistos sob forma de redes interativas e flexíveis, e não como elementos rígidos ou inflexíveis.

Já uma abordagem mais operacional tem, como centrais ao desenvolvimento de comunidades sustentáveis, os seguintes aspectos:

- No nível econômico, os custos associados à construção, operação e manutenção das infra-estruturas e serviços de suporte ao desenvolvimento urbano não devem superar as limitações existentes ou comprometer demandas de investimento em setores prioritários;

- No nível social, as cidades devem ser socialmente diversas, adaptáveis a diferentes estilos de comportamento e, adicionalmente, oferecer aos habitantes oportunidades eqüitativas de acesso às atividades e serviços essenciais;

- Em termos ambientais, cidades sustentáveis devem ser projetadas de forma a minimizar a poluição do ar, do solo, da água, reduzir desperdícios e o consumo de recursos, além de proteger os sistemas naturais de suporte à vida (PBD,1995 apud SILVA et al., 2002).

Ainda que não exista um entendimento a respeito da diversidade de elementos que devem ser considerados para o desenvolvimento urbano sustentável, há um consenso no que no que se refere à introdução das questões ambientais nos debates em torno do futuro de nossas cidades. No entanto, enquanto alguns grupos mantêm estas questões como foco principal de discussão, outros se esforçam para introduzir uma visão holística que permita contrabalancear aspectos econômicos, sociais e ambientais.

Não é possível, igualmente, estabelecer uma definição única ou mesmo uma definição “ótima" para a sustentabilidade urbana, uma vez que cada comunidade irá desenvolver seu conceito próprio, baseado em suas características econômicas, sociais, ambientais e no julgamento de sua população. No entanto, qualquer que seja a definição ou conceituação teórica adotada tanto para desenvolvimento sustentável como para 
sustentabilidade urbana, é fundamental desenvolver estratégias para sua implementação no nível das cidades. Neste contexto, a próxima seção discute como a questão da sustentabilidade urbana tem sido abordada no Brasil e em Portugal, e quais são as principais estratégias em desenvolvimento nos dois países.

\subsection{Considerações sobre o desenvolvimento sustentável no Brasil e em Portugal}

Uma vez inseridos em contextos distintos, é natural que Brasil e Portugal apresentem abordagens um pouco diversas no que diz respeito à questão do desenvolvimento sustentável. No entanto, iniciativas a fim de promover a sustentabilidade dos centros urbanos já podem ser identificadas nos dois países.

Portugal, no contexto da União Européia, apresenta não só inúmeras iniciativas locais, como dispõe de uma série de instrumentos políticos e institucionais de cooperação com as demais nações européias em prol do desenvolvimento sustentável. Algumas das principais estratégias formuladas em nível nacional e continental, bem como o papel desempenhado pelas principais instituições envolvidas neste processo, são resumidos a seguir.

Dentre as iniciativas em nível continental empreendidas na Europa, vale destacar a Campanha das Cidades e Vilas Européias Sustentáveis, originada no final de conferência sobre o tema realizada em maio de 1994, na Dinamarca, onde ocorreu a assinatura da "Carta das Cidades e Vilas Européias para a Sustentabilidade" (Carta de Aalborg). Esta campanha, da qual Portugal é participante, tem por objetivo principal encorajar e apoiar cidades e vilas nas suas ações com vista à sustentabilidade através da construção da Agenda 21 Local. A fim de contribuir para este processo, o International Council for Local Environment Initiatives (ICLEI) disponibiliza o Guia Europeu de Planejamento para a Agenda 21 Local, que esboça passo a passo o processo de desenvolvimento de um Plano de Ação Ambiental, que pode ser utilizado por cada país membro da UE para criar sua própria Agenda 21 Local (ICLEI, 2000).

No que diz respeito às atividades desenvolvidas pela União Européia no campo da sustentabilidade cabe destacar a estratégia formulada em dezembro de 1999 tendo em 
vista um desenvolvimento sustentável em nível econômico, social e ecológico. $\mathrm{Na}$ fase inicial deste trabalho foram identificados seis temas principais que deveriam ser considerados de forma prioritária no contexto da União Européia, resumidos a seguir:

- Alterações climáticas e energia limpa;

- Saúde pública;

- Gestão dos recursos naturais;

- Pobreza e exclusão social;

- Envelhecimento da população;

- Mobilidade, utilização do solo e desenvolvimento territorial (UNIÃO EUROPÉIA, 2001).

A Comissão Européia é responsável ainda pelo Quinto Programa de Ação Ambiental: Rumo à Sustentabilidade (1992-2000). Elaborado paralelamente à Agenda 21, tem o objetivo de integrar políticas, leis e projetos em um programa global orientado para o desenvolvimento sustentável. Segundo avaliação da própria Comissão Européia, 70 \% dos compromissos assumidos no nível da União Européia foram cumpridos, no entanto, ainda é bastante difícil avaliar os progressos realizados em cada um dos países membros.

No nível do continente europeu deve ser destacada também a Estratégia de Lisboa, formulada em 2001, a qual estabelece um compromisso para a renovação econômica, social e ambiental no nível da União Européia. Esta estratégia baseia-se em um conjunto de medidas que visam promover um maior dinamismo econômico e aumento da oferta de empregos, além de políticas sociais e ambientais capazes de garantir o desenvolvimento sustentável e a inclusão social.

No que diz respeito às iniciativas de caráter local desenvolvidas em Portugal, a Estratégia Nacional de Desenvolvimento Sustentável (ENDS) constitui um dos principais instrumentos disponíveis no país. Elaborada no âmbito da Agenda 21, tem como base quatro Domínios Estratégicos: 
- O território como um bem a ser preservado;

- Melhoria da qualidade do ambiente;

- Produção e consumo sustentáveis das atividades econômicas;

- Construção de uma sociedade solidária e do conhecimento (INSTITUTO DO AMBIENTE, 2002a).

A ENDS segue ainda uma estrutura baseada em um conjunto de Painéis Setoriais que incluem os seguintes temas:

- Pescas;

- Agricultura,

- Desenvolvimento Rural e Florestas;

- Transportes;

- Economia;

- Ambiente e Ordenamento do Território;

- Aspectos Sociais e Questões Financeiras e Fiscais.

A comunidade como um todo é encorajada a participar da construção da ENDS, analisando os documentos elaborados no âmbito de cada um dos Painéis Setoriais, disponíveis através da Internet, e enviando comentários e sugestões diretamente ao Instituto do Ambiente, responsável pela coordenação geral do projeto.

Já no Brasil, os esforços no sentido de promover o desenvolvimento sustentável concentram-se na construção da Agenda 21 Brasileira, coordenados pela Comissão de Políticas de Desenvolvimento Sustentável e da Agenda 21 Nacional - CPDS. A Agenda 21 Brasileira, compromisso assumido pelo Brasil durante a Conferência das Nações Unidas sobre Meio Ambiente e Desenvolvimento (Eco 92), consiste em um plano estratégico de desenvolvimento sustentável para o país, que envolve não só o setor público como também a sociedade civil (MINISTÉRIO DO MEIO AMBIENTE, 2003).

No processo de construção da Agenda 21 Brasileira foram identificados seis temas centrais, de modo a integrar toda a diversidade e complexidade do país e suas regiões dentro do conceito da sustentabilidade ampliada, incluindo: 
- Agricultura Sustentável;

- Cidades Sustentáveis;

- Infra-estrutura e Integração Regional;

- Gestão dos Recursos Naturais;

- Redução das Desigualdades Sociais;

- Ciência e Tecnologia para o Desenvolvimento Sustentável.

Para cada tema foi realizado um trabalho de consulta aos diferentes segmentos da sociedade, procurando, por meio de workshops e seminários abertos ao público, envolver todos os setores que se relacionam com os temas em questão. Os resultados do trabalho de consultoria realizado durante o ano de 1999 foram sistematizados e consolidados em seis publicações, conforme os seis eixos temáticos identificados, sendo um deles referente às Cidades Sustentáveis. Neste documento foram identificadas estratégias para auxiliar na formulação e implementação de políticas urbanas fundadas nos princípios do desenvolvimento sustentável definidos pela Agenda 21. A dimensão ambiental, por sua vez, mereceu destaque dentro das políticas a serem adotadas em todos os níveis de governo.

Ainda que distribuídas de modo desigual pelo país, merecem destaque também algumas iniciativas de desenvolvimento de Agendas 21 Locais para municípios brasileiros, tais como as de:

- Porto Alegre, Pelotas e Santa Cruz do Sul, Florianópolis, Blumenau, Joinville, Curitiba e Londrina, na Região Sul;

- São Paulo, Piracicaba, Santos, Sete Lagoas, Juiz de Fora, Angra dos Reis, Barra Mansa, Vitória e Vila Velha, na Região Sudeste;

- Campo Grande, Corumbá, Goiânia e Cuiabá, na Região Centro-Oeste;

- Santarém, Pimenta Bueno e Boa Vista dos Ramos, na Região Norte;

- São Luiz, Teresina, Sobral, Petrolina, Olinda, Arapiraca e Vitória da Conquista, na Região Nordeste. 
A Figura 7 ilustra a distribuição das iniciativas de desenvolvimento de Agendas 21 Locais para as diferentes regiões brasileiras, registradas pela Secretaria de Políticas para o Desenvolvimento Sustentável - SDS e pelo Ministério do Meio Ambiente - MMA até o mês de junho de 2003.

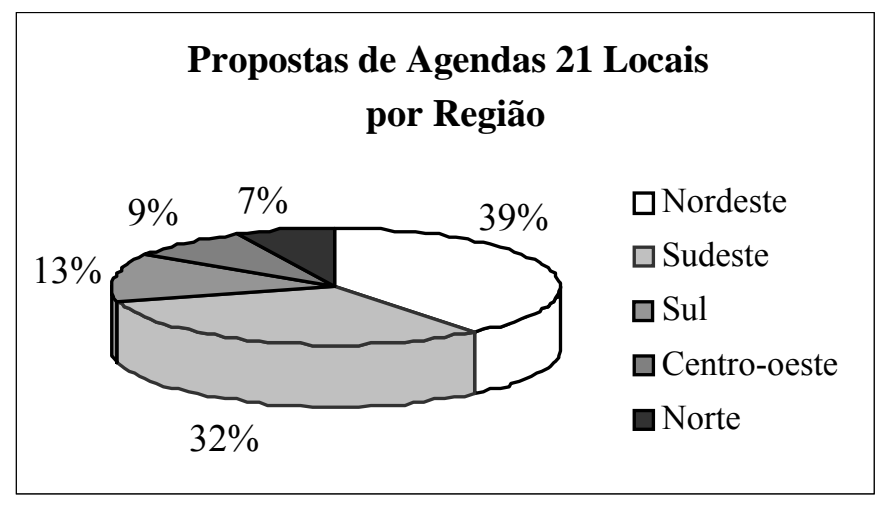

Figura 7: Propostas de Agendas 21 Locais para as regiões brasileiras Fonte: Adaptado de MINISTÉRIO DO MEIO AMBIENTE (2003).

Para o Brasil também deve ser considerado o papel desempenhado pelo recém criado Ministério das Cidades, que, por meio da Secretaria Nacional de Programas Urbanos, busca estimular o desenvolvimento de processos participativos e democráticos que contribuam para a melhor organização do espaço urbano. O ministério é responsável ainda pelo Sistema Nacional de Indicadores Urbanos (SNIU), o qual disponibiliza, via Internet, dados sobre 5507 municípios brasileiros (MINISTÉRIO DAS CIDADES, 2003).

Conclui-se que, independente da definição ou conceituação teórica adotada tanto para sustentabilidade como para sustentabilidade urbana, devem ser criadas estratégias para sua implementação em diferentes níveis. Estas estratégias envolvem a definição cuidadosa dos elementos que a influenciam, além da identificação e análise de indicadores, que deverão refletir o estágio atual de desenvolvimento de uma determinada comunidade ou área geográfica.

Deste modo, após apresentados os principais conceitos relacionados à sustentabilidade urbana e algumas iniciativas empreendidas no sentido de promovê-la no Brasil e em Portugal, no próximo capítulo são discutidas questões relativas aos indicadores e sua aplicação para monitoração das condições de sustentabilidade nos dois países. 


\section{INDICADORES DE SUSTENTABILIDADE}

Neste capítulo são discutidos aspectos relacionados aos indicadores de sustentabilidade urbana. Primeiramente são abordadas questões sobre o desenvolvimento de indicadores e suas principais aplicações, além dos atributos que caracterizam um indicador de sustentabilidade. Posteriormente são apresentados alguns modelos e estruturas que podem ser utilizados para o desenvolvimento de sistemas de indicadores urbanos. $\mathrm{Na}$ última seção são feitas algumas considerações a respeito dos indicadores desenvolvidos no Brasil e em Portugal.

\subsection{Aspectos gerais}

Indicadores são instrumentos que reduzem grande quantidade de informação a um número apropriado de parâmetros para análise e tomada de decisão. Traduzem conceitos abstratos e difíceis de serem mensurados em entidades operacionais e mensuráveis, fornecendo uma informação sintética sobre determinado fenômeno. Sua utilização permite revelar condições e ao mesmo tempo tendências, apontando aspectos deficientes ou aqueles que necessitam de intervenção.

Os indicadores possuem múltiplas finalidades. Agregados através de métodos aritméticos ou regras de decisão, possibilitam a construção de índices, que podem simplificar ainda mais alguns parâmetros complexos. Dentre as inúmeras aplicações de índices e indicadores podem ser citadas:

- Alocação de recursos;

- Comparação de diferentes locais ou áreas geográficas; 
- Cumprimento de normas ou critérios legais;

- Análise de tendências no tempo e no espaço;

- Informação ao público e investigação científica, servindo de alerta para a necessidade de pesquisas mais aprofundadas sobre determinadas questões (DIRECÇÃO GERAL DO AMBIENTE, 2000).

A variedade e complexidade dos problemas urbanos fazem das cidades um campo promissor para a utilização e desenvolvimento de indicadores. De fato, os indicadores podem auxiliar para a maior compreensão das questões econômicas, sociais e ambientais, bem como para o conhecimento das características e especificidades dos centros urbanos. Neste nível, os indicadores provém informação que pode ser utilizada para a proposição de planos e políticas que visam a melhoria da qualidade de vida da população.

No que diz respeito aos indicadores de sustentabilidade, estes possuem algumas características especiais que os diferem dos indicadores tradicionais, incluindo:

- Integração: permitem visualizar as conexões existentes entre as dimensões econômica, social e ambiental da sustentabilidade;

- Visão a longo prazo: os indicadores permitem acompanhar o progresso em direção à sustentabilidade, ao revelar tendências e ao fornecer informações indiretas sobre o futuro da comunidade;

- Preocupação com as futuras gerações: devem medir a equiidade intra e entre gerações. Podem focalizar ainda, diferentes populações ou regiões geográficas;

- Desenvolvido com a contribuição de múltiplos participantes: as experiências têm mostrado que os indicadores de maior influência e confiabilidade têm sido aqueles desenvolvidos a partir da contribuição de diferentes grupos (MACLAREN, 1996). 
Além destas, outras características dos indicadores de sustentabilidade são freqüentemente encontradas na literatura tais como: simplicidade, abrangência ou escopo, sensibilidade a mudanças, capacidade de quantificação, fácil compreensão, confiabilidade e relevância dentro do contexto aplicado (OECD, 1997; BELL e MORSE, 1999; SUSTAINABLE MEASURES, 2002).

O processo de desenvolvimento de indicadores constitui uma etapa importante para a maior compreensão do referencial de sustentabilidade adotado por uma comunidade, permitindo ainda acompanhar os progressos realizados nesta direção. De fato, a construção de um referencial de desenvolvimento sustentável e a identificação de ferramentas que permitam seu acompanhamento constituem processos paralelos e complementares que possibilitam, dentre outros, visualizar de forma mais clara as interações existentes entre os diferentes níveis e dimensões fundamentais para o desenvolvimento sustentável.

Um grande número de indicadores urbanos pode ser desenvolvido. No entanto, o tamanho ideal de um sistema irá depender de fatores como o público ao qual se destina, a disponibilidade de dados e especificamente, das necessidades da comunidade que irá utilizá-lo. Do mesmo modo, diferentes estruturas ou modelos podem ser utilizados para a construção destes sistemas. Uma breve revisão destas estruturas, bem como alguns exemplos de comunidades que as utilizaram, é feita na próxima seção.

\subsection{Tipos de indicadores e estruturas mais utilizadas}

Conforme MACLAREN (1996), uma revisão de trabalhos recentes relacionados à qualidade de vida, sustentabilidade urbana e relatórios sobre o estado do meio ambiente permite identificar seis estruturas gerais que podem ser utilizadas para $o$ desenvolvimento de indicadores de sustentabilidade, as quais são resumidas a seguir.

Uma destas estruturas tem como base as principais dimensões consideradas para o desenvolvimento sustentável, sendo elas as dimensões social, econômica e ambiental. Dimensões adicionais podem ser definidas, onde as mais comuns estão relacionadas à saúde ou às instituições governamentais. Categorias que integram duas ou mais 
dimensões também podem ser incluídas, destacando as relações que as mesmas podem estabelecer.

Um dos exemplos mais conhecidos de sistemas de indicadores que fez uso desta estrutura são os Indicadores de Seattle. Atualmente, os quarenta indicadores que compõem este sistema encontram-se subdivididos em quatro dimensões: Ambiente; População e Recursos; Economia e Juventude e Educação (SUSTAINABLE SEATTLE, 2003).

Outra estrutura utilizada para a construção de um sistema de indicadores de sustentabilidade é desenvolvida com base nos objetivos ou metas relacionados ao desenvolvimento sustentável. Como o próprio nome implica, este tipo de estrutura exige a identificação dos objetivos por parte da comunidade e posteriormente, a identificação de indicadores para cada um individualmente ou para combinações dos mesmos. A Comissão Local de Gestão do Reino Unido (Local Government Management Board), constitui um dos exemplos de agências que utilizam esta estrutura. Neste caso, os indicadores têm sido desenvolvidos com base nos seguintes objetivos: Manutenção da capacidade e Qualidade de vida.

A terceira estrutura identificada por MACLAREN (1996) é caracterizada pelo desenvolvimento de indicadores dentro de diferentes setores, os quais tipicamente encontram-se sob a responsabilidade do governo, tais como: moradia, transportes, gerenciamento de resíduos, uso do solo ou serviços públicos. Esta estrutura é mais apropriada quando o público alvo é constituído por políticos ou decisores e é utilizada de modo a facilitar a identificação de problemas particulares de cada setor.

Já a estrutura baseada em assuntos ou temas é organizada em torno de uma lista de questões-chave relacionadas à sustentabilidade, incluindo aspectos como o gerenciamento de resíduos, poluição do ar, educação, saúde, emprego, entre outros. Esta estrutura constitui um dos modelos mais utilizados para o desenvolvimento de indicadores, uma vez que é de fácil construção e compreensão por parte da comunidade. Entretanto, um dos seus pontos fracos é que cada questão é tipicamente tratada conforme o ponto de vista particular de seus gerenciadores, não contemplando muitas vezes indicadores compatíveis com as três principais dimensões da sustentabilidade. 
A quinta estrutura que pode ser utilizada para a construção de um sistema de indicadores baseia-se no princípio de causa e efeito, conhecida tipicamente como o modelo pressão-estado-resposta. Relatórios sobre as condições do meio ambiente constituem bons exemplos de aplicação desta estrutura. Através desta estrutura podem ser identificadas respostas para as seguintes questões fundamentais:

- O que está acontecendo no ambiente?

- Por que está acontecendo?

- Qual o seu significado?

- O que está sendo feito a respeito destas questões?

Nesta estrutura, as atividades humanas são vistas como causadoras de estresse no meio ambiente, modificando suas condições. Em virtude destas modificações, são empreendidas políticas de resposta que visam minimizar os efeitos causados pelas atividades humanas. Dentre os exemplos de instituições que utilizaram esta estrutura estão a OECD (1985) em seu relatório internacional sobre o Estado do Meio Ambiente; a UNCSD (1996a) para os Indicadores de Desenvolvimento Sustentável e também a administração da Região Metropolitana de Toronto para o relatório local sobre as condições do ambiente (MUNICIPALITY OF METROPOLITAN TORONTO, 1995).

Finalmente, a sexta estrutura identificada por MACLAREN (1996) baseia-se em uma combinação dos modelos descritos anteriormente, uma vez que este procedimento permite minimizar algumas das desvantagens encontradas para os mesmos. Um exemplo de estrutura combinada foi adotada pela Community Oriented Model of the Lived Environment - COMLE (MURDIE et al., 1992), a qual contém três segmentos principais: um para políticas setoriais, outro para "componentes da habitabilidade" que correspondem às principais dimensões da sustentabilidade e o último para "indicadores de habitabilidade" que equivalem a subcategorias das dimensões anteriores.

Apresentadas as principais estruturas utilizadas para a construção de sistemas de indicadores de sustentabilidade, na próxima seção são abordadas algumas iniciativas de desenvolvimento destes indicadores no Brasil e em Portugal, bem como uma breve caracterização destas experiências. 


\subsection{Considerações sobre indicadores de sustentabilidade desenvolvidos no Brasil e em Portugal}

Algumas experiências em matéria de desenvolvimento de indicadores de sustentabilidade já podem ser identificadas tanto para o Brasil como para Portugal. No entanto, estas experiências apresentam um conjunto limitado de indicadores e, principalmente, foram desenvolvidas para serem aplicadas em nível nacional, deixando de contemplar muitas das questões relevantes para o contexto específico das cidades brasileiras e portuguesas.

Nesta seção são resumidas duas experiências em particular:

- O conjunto de Indicadores de Desenvolvimento Sustentável proposto pelo Instituto Brasileiro de Geografia e Estatística (IBGE, 2002);

- E o Sistema de Indicadores de Desenvolvimento Sustentável proposto pela Direcção Geral do Ambiente, Portugal (DIRECÇÃO GERAL DO AMBIENTE, 2000).

Os Indicadores de Desenvolvimento Sustentável do IBGE foram desenvolvidos a fim de possibilitar o acesso à informação já disponível sobre temas relevantes para o desenvolvimento do país. Estes indicadores permitem identificar variações, processos e tendências a curto, médio e longo prazo e podem ser utilizados para realizar comparações com outros países ou mesmo entre as diferentes regiões brasileiras.

Este sistema integra um conjunto de 50 indicadores divididos nas categorias econômica, social, ambiental e institucional, as quais incluem um conjunto de temas ou subcategorias, conforme mostra a Tabela 1: 
Tabela 1: Dimensões e temas que compõem os Indicadores de Desenvolvimento Sustentável para o Brasil

\begin{tabular}{cc}
\hline Dimensão & Tema \\
& População \\
Eqüidade & Saúde \\
Social & Educação \\
& Habitação \\
& Segurança \\
\hline \multirow{2}{*}{ Ambiental } & Atmosfera \\
& Terra \\
& Oceanos, mares e áreas costeiras \\
& Biodiversidade \\
Econômica & Saneamento \\
\hline \multirow{2}{*}{ Institucional } & Estrutura econômica \\
& Padrôes de produção e consumo \\
\hline
\end{tabular}

Fonte: Adaptado de IBGE (2002).

Os indicadores sociais, disponíveis em maior número neste sistema, têm por objetivo promover uma síntese da situação social, da distribuição de renda e das condições de vida da população. Já os indicadores ambientais estão relacionados ao uso dos recursos naturais e à degradação ambiental. Os indicadores econômicos, por sua vez, tratam do desempenho macroeconômico e financeiro, além dos impactos no consumo de recursos materiais e uso de energia primária. Finalmente, os indicadores institucionais dizem respeito à orientação política, capacidade e esforço despendido para as mudanças necessárias para uma efetiva implementação do desenvolvimento sustentável.

Já o Sistema de Indicadores de Desenvolvimento Sustentável elaborado pela Direcção Geral do Ambiente de Portugal, o qual abrange um conjunto de 132 indicadores, foi desenvolvido com o objetivo de fornecer uma proposta sistematizada de indicadores de desenvolvimento sustentável para Portugal, que orientasse a cooperação e coleta de informações no que diz respeito à sustentabilidade do país. Os indicadores deste sistema encontram-se subdivididos nas mesmas categorias que o sistema anterior, no entanto, ao contrário do modelo proposto pelo IBGE, os indicadores ambientais predominam neste sistema. A Tabela 2 apresenta as dimensões consideradas neste sistema, bem como os diferentes setores nos quais estas apresentam-se subdivididas. 
Uma característica que deve ser destacada para este conjunto é que o mesmo apresenta indicadores que podem ser medidos do ponto de vista de sua variação em escala regional, ou seja, possui indicadores capazes de refletir as assimetrias regionais existentes no país.

Tabela 2: Dimensões e setores que constituem o Sistema de Indicadores de Desenvolvimento Sustentável para Portugal

\begin{tabular}{cc}
\hline Dimensão & Setores \\
\hline \multirow{3}{*}{ Social } & População \\
& Saúde \\
& Educação \\
& Segurança social \\
& Emprego \\
& Cultura \\
& Justiça \\
& Outros \\
\hline & Ar \\
Ambiental & Ambientes marinho e costeiro \\
& Água doce \\
& Solos \\
& Conservação da natureza \\
& Floresta \\
& Biotecnologia \\
& Resíduos \\
& Ruído \\
\hline Econômica & Economia \\
& Energia \\
& Transportes \\
& Agricultura \\
Institucional & Turismo \\
& Indústria \\
\hline & Instituições \\
\hline
\end{tabular}

Fonte: Adaptado de DIRECÇÃO GERAL DO AMBIENTE (2000).

No que diz respeito aos indicadores relacionados à questão da mobilidade, estes são contemplados de maneira direta apenas no sistema SIDS, o qual inclui a subcategoria denominada "Transportes" (Dimensão Econômica), além de outros indicadores distribuídos em subcategorias como "Ar", "Ruído" e "Energia" que podem estar relacionados de maneira indireta à questão. Já o sistema proposto pelo IBGE, não inclui indicadores em categorias específicas relacionadas aos transportes ou mobilidade. No entanto, alguns indicadores podem estar ligados a estas questões de forma indireta, como é o caso dos indicadores relacionados ao consumo energético, poluição do ar, entre outros. 
Questões específicas relacionadas ao conceito de mobilidade urbana sustentável e aos indicadores utilizados para a sua monitoração são discutidas mais detalhadamente no Capítulo 5 deste documento. 


\section{MOBILIDADE URBANA SUSTENTÁVEL}

Neste capítulo são abordados aspectos referentes aos transportes e sua importância para o desenvolvimento das atividades urbanas, bem como são apresentados alguns dos principais conceitos relacionados à mobilidade urbana sustentável. Posteriormente são feitas algumas considerações sobre o tratamento que vem sendo dado ao tema no Brasil e em Portugal, além de discutidas algumas questões relacionadas ao desenvolvimento de indicadores para a gestão da mobilidade urbana.

\subsection{Aspectos gerais}

Ao longo da história da humanidade os transportes têm sido promotores de desenvolvimento, tornando possível à realização de atividades comerciais, o acesso aos serviços de saúde, educação e lazer e o crescimento das cidades. Os transportes têm contribuído igualmente para o desenvolvimento de um extenso corpo de teorias que relacionam acessibilidade e mobilidade ao progresso econômico e social. Se por um lado são fundamentais para a manutenção de diversos setores da sociedade, por outro, têm sido responsáveis por uma variedade de "efeitos colaterais", muitos deles prejudiciais ao meio ambiente. Estes incluem poluição sonora, poluição da água e do ar, geração de resíduos sólidos e destruição de habitats naturais por conseqüência da construção e ampliação da infra-estrutura de transportes.

Nas cidades, a importância dos transportes para o desenvolvimento econômico e eqüidade social, além dos muitos impactos que podem causar ao meio ambiente têm exigido o desenvolvimento de uma perspectiva mais sustentável para a mobilidade urbana. Mesmo que esta intenção já tenha sido expressa em diferentes partes do mundo, ainda são poucos os esforços conhecidos no sentido de definir o que é "mobilidade sustentável". 
Para GUDMUNDSSON e HÖJER (1996) quatro princípios básicos que compõem o conceito de desenvolvimento sustentável devem ser aplicados no contexto dos transportes:

- A proteção dos recursos naturais dentro de limites, níveis e modelos pré-estabelecidos;

- A manutenção do capital produtivo para as futuras gerações;

- A melhoria da qualidade de vida dos indivíduos;

- E a garantia de uma distribuição justa da qualidade de vida.

Um primeiro conceito trabalhado pela OECD e posteriormente complementado pelo Grupo de Especialistas em Transportes e Meio Ambiente da Comissão Européia, define como um transporte sustentável aquele que "contribui para o bem-estar econômico e social, sem prejudicar a saúde humana e o meio ambiente. Integrando as dimensões sociais, econômicas e ambientais, pode ser definido como aquele que:

- Permite a satisfação das necessidades básicas de acesso e mobilidade de pessoas, empresas e sociedade, de forma compatível com a saúde humana e o equilíbrio do ecossistema, promovendo igualdade dentro das gerações e entre as mesmas;

- Possui custos aceitáveis, funciona eficientemente, oferece a possibilidade de escolha do modo de transporte e apóia uma economia dinâmica e o desenvolvimento regional;

- Limita as emissões e os resíduos em função da capacidade da Terra para absorvê-los, utiliza recursos renováveis a um ritmo inferior ou igual a sua renovação, utiliza os recursos não renováveis a um ritmo inferior ou igual ao desenvolvimento de substitutos renováveis e reduz ao mínimo o uso do solo e a emissão de ruído" (OECD, 2000 apud MOURELO, 2002).

No contexto da Agenda 21, os transportes são considerados em diversos capítulos, dentre eles os Capítulos 7 e 9, que abordam respectivamente questões relacionadas à "Atmosfera" e aos "Assentamentos Humanos". Neste documento reforça-se a idéia de 
que sistemas de transporte eficientes e adequados são fundamentais dentro das estratégias de combate à pobreza e que medidas que minimizem os impactos das atuais tecnologias de transporte sobre a saúde humana e o meio ambiente necessitam ser desenvolvidas (UNDSD, 2003).

No que se refere às dimensões social, econômica e ambiental freqüentemente consideradas no conceito de desenvolvimento sustentável, o WORLD BANK (1996) destaca algumas questões. A sustentabilidade econômica e financeira exige que os recursos sejam utilizados eficientemente e que o direito à propriedade seja mantido corretamente. Já a sustentabilidade ambiental ou ecológica exige que os efeitos externos dos transportes sejam considerados por completo nas decisões tomadas tanto pelo setor público como privado. Finalmente, a sustentabilidade social exige que os benefícios oriundos dos transportes sejam distribuídos de forma igualitária a todos os segmentos da sociedade.

As bases de uma mobilidade urbana sustentável passam ainda pelo amplo acesso à informação relativa aos custos e formas de financiamento das diversas opções de transporte. Informações mais detalhadas dos benefícios e dos custos sociais (poluição, ruído, congestionamento, uso do solo) causados pelas diferentes modalidades de transportes devem, tanto quanto possível, estar disponíveis ao público, já que a quantificação apropriada destes fatores é fundamental para a proposição de planos e políticas para o setor. Além destes, os seguintes aspectos também são fundamentais na implantação de políticas de mobilidade sustentável:

- Equilíbrio entre os diferentes modos de transporte e incentivo ao uso de modos não motorizados, como caminhada ou bicicleta;

- Transportes e energia. O uso eficiente dos recursos energéticos constitui uma questão-chave para o desenvolvimento sustentável. Esta preocupação deve, portanto, estar presente nos planos e estratégias desenvolvidas para o setor de transportes, uma vez que o mesmo é responsável por consumir uma parcela considerável de recursos energéticos não-renováveis do planeta; 
- Tecnologia para um transporte sustentável. Os impactos causados pelos transportes não são imutáveis, mas são dependentes diretos das tecnologias empregadas para promovê-los. Não há dúvidas que mudanças tecnológicas são fundamentais para se alcançar a sustentabilidade, porém, questões como a viabilidade econômica e a aceitação de novas tecnologias por parte dos usuários devem ser investigadas;

- Questões sobre a demanda por transportes. A demanda por transportes é resultado da separação física das atividades humanas. O desenvolvimento de medidas de gerenciamento da demanda visam, portanto, reduzir a necessidade por transporte em sua origem, promovendo maior adensamento das cidades, incentivando o uso misto do solo, encorajando a substituição da viagem pela telecomunicação e concedendo privilégios especiais para a maior ocupação dos automóveis;

- Questões sobre a oferta de transportes. A provisão de infraestrutura de transporte para satisfazer ou mesmo estimular a demanda, num crescente movimento de pessoas e bens, é vista como pré-requisito para a prosperidade econômica. No entanto, o incentivo à construção de rodovias e vias de trânsito rápido tem aumentado as oportunidades de deslocamento a maiores distâncias, acelerando a trajetória das cidades para os subúrbios e contribuindo para seu maior espalhamento. Somente recentemente o gerenciamento da oferta de transportes para o controle do crescimento da demanda tem sido reconhecido. Desta forma, os impactos gerados por projetos de infra-estruturas de grande escala têm sido discutidos mais detalhadamente, ao mesmo tempo em que são incentivadas medidas para a restrição do uso do automóvel, construção e renovação dos caminhos para pedestres, além da melhoria da qualidade do transporte coletivo; 
- Integração transportes e uso do solo. Não existe consenso no que diz respeito ao estabelecimento de uma estrutura ideal do ponto de vista de um transporte sustentável, nem da forma urbana que colabore para isso. Sabe-se, no entanto, que a configuração urbana influi na necessidade de viagens e nas características dos deslocamentos realizados, determinado aspectos como tempo médio de viagem, modo utilizado, consumo de combustíveis, entre outros (GREENE e WEGENER, 1997; GUDMUNDSSON e HÖJER, 1996; MOORE e JOHNSON, 1994).

Paralelamente aos esforços em identificar uma definição para a mobilidade urbana sustentável, bem como apontar as questões-chave que devem ser abordadas no sentido de promovê-la, algumas iniciativas no sentido de pôr em prática alguns dos conceitos aqui apresentados têm sido desenvolvidas.

Dentre as iniciativas mais recentes, cabe destacar o trabalho desenvolvido pela União Internacional de Transporte Público (Union Internationale de Transport Public - UITP), o qual incluiu, no ano de 2003, a publicação da Carta UITP do Desenvolvimento Sustentável e o guia "Bilhete para o Futuro - 3 Paradas para a Mobilidade Sustentável" (Ticket to the Future - 3 Stops to Sustainable Mobility), de modo a auxiliar os trabalhos das instituições signatárias (incluindo organizações de países como Itália, Holanda, França, Espanha, Estados Unidos, Canadá, África do Sul, Portugal e Brasil) no desenvolvimento de estratégias que visam assegurar a promoção do conceito de mobilidade sustentável em suas áreas de abrangência. $\mathrm{O}$ documento "Bilhete para $\mathrm{O}$ Futuro - 3 Paradas para a Mobilidade Sustentável" reafirma a idéia de que a mobilidade sustentável constitui um aspecto fundamental para a sustentabilidade global e destaca o seu papel para o estabelecimento de relações harmônicas entre ambiente, economia e sociedade (ANTP, 2003a; UITP, 2003).

É interessante ainda proceder a uma avaliação das iniciativas que vêm sendo desenvolvidas, em particular, no Brasil e em Portugal. Neste sentido, na próxima seção são feitas algumas considerações a respeito da abordagem que o tema mobilidade 
urbana sustentável tem recebido nos dois países, bem como são apresentadas algumas iniciativas empreendidas no sentido de implementar o conceito.

\subsection{Considerações sobre mobilidade sustentável no Brasil e em Portugal}

Em Portugal, os trabalhos desenvolvidos no sentido de implementar o conceito de mobilidade sustentável no país são coordenados, de um modo geral, pelo Instituto do Ambiente, responsável pela Estratégia Nacional de Desenvolvimento Sustentável (ENDS), a qual inclui em sua estrutura o Painel Setorial sobre Transportes. No entanto, como país membro da União Européia, Portugal insere-se ainda em inúmeros outros projetos que dizem respeito à promoção do conceito no nível do continente.

No que diz respeito às iniciativas desenvolvidas pela União Européia cabe destacar o "Programa de Ação para a Mobilidade Sustentável: 2000-2004", que tem por objetivo aplicar uma política comum de transportes segura, eficaz e competitiva, que leve em consideração interesses sociais e ambientais nos países membros da União Européia. Dentre as estratégias previstas para o alcance destes objetivos, incluem-se:

- Melhoria do acesso aos mercados;

- Introdução de sistemas de transportes integrados dando prosseguimento as redes integradas transeuropéias e implementação de sistemas de transportes inteligentes;

- Aplicação de tarifas eqüitativas e eficazes que reduzam as distorções entre os modos de transportes e entre os Estadosmembros;

- Valorização dos aspectos sociais (UNIÃO EUROPÉIA, 2002).

Outra iniciativa que merece destaque é a "Semana Européia da Mobilidade", campanha iniciada em 2002 que contempla uma série de eventos e debates relacionados à mobilidade urbana. Nesta ocasião, autoridades, organizações não-governamentais e comunidade dos 21 países participantes podem apresentar as estratégias que vêm sendo desenvolvidas em seus territórios no sentido de construir uma base sólida para a 
implementação do conceito de mobilidade sustentável. Esta campanha inclui ainda o "Dia Europeu Sem Carros" que tem por objetivo encorajar a adoção de modos de transportes sustentáveis e promover a conscientização da comunidade sobre os impactos ambientais oriundos dos transportes.

A Estratégia Nacional de Desenvolvimento Sustentável, através do Painel Setorial sobre Transportes, permitiu definir, por sua vez, um conjunto de objetivos, metas e ações para o setor de transportes em Portugal, no contexto dos Domínios Estratégicos estabelecidos pela ENDS, citados no Capítulo 3 deste documento. Neste trabalho foi realizada ainda uma revisão dos indicadores de transportes incluídos no Sistema de Indicadores de Desenvolvimento Sustentável (SIDS) proposto pelo Instituto do Ambiente, além da proposição de novos indicadores a fim de complementar este sistema. Dentre os indicadores analisados pelo Painel Setorial sobre Transportes em nível nacional, incluem-se:

- Ecoeficiência do setor de transportes;

- Idade média dos veículos;

- Passageiros transportados por modo de transporte;

- Estrutura da rede viária;

- Acidentes rodoviários;

- Carga transportada por unidade do PIB;

- Passageiros transportados por unidade do PIB (INSTITUTO DO AMBIENTE, 2002b).

Já no Brasil, o conceito de mobilidade urbana sustentável ainda é pouco explorado, e somente recentemente alguns esforços têm sido notados no sentido de melhor definí-lo. Dentre eles, cabe destacar a iniciativa do recém criado Ministério das Cidades, através da Secretaria Nacional de Transporte e da Mobilidade Urbana, a qual tem se empenhado em formular uma definição para o tema, de modo a nortear os trabalhos a serem desenvolvidos. Esta definição procurou, de um modo geral, incluir os princípios de sustentabilidade econômica e ambiental, além da questão da inclusão social, que constituem a base do conceito de desenvolvimento sustentável propriamente dito. Conforme o documento divulgado pela secretaria, mobilidade urbana sustentável pode ser assim definida: 


\begin{abstract}
"Mobilidade Urbana Sustentável é o resultado de um conjunto de políticas de transporte e circulação que visam proporcionar o acesso amplo e democrático ao espaço urbano, através da priorização dos modos de transporte coletivo e não motorizados de maneira efetiva, socialmente inclusiva e ecologicamente sustentável” (ANTP, 2003b).
\end{abstract}

A Secretaria Nacional de Transporte e Mobilidade Urbana é, portanto, a principal responsável por conduzir os trabalhos no sentido de implementar o conceito de mobilidade sustentável no país. Esta secretaria encontra-se subdividida em três departamentos com suas respectivas gerências, apresentados a seguir:

- Departamento de Regulação e Gestão, subdividido nas gerências de Regulação, Desenvolvimento da Gestão e Integração Metropolitana;

- Departamento de Cidadania e Inclusão Social, subdividido nas gerências de Inclusão Social e de Estatísticas e Pesquisas;

- Departamento de Mobilidade Urbana, subdividido nas gerências de Integração das Políticas de Mobilidade, Financiamento e Infra-estrutura e Desenvolvimento Tecnológico.

No que se refere ao desenvolvimento de medidas voltadas a monitorar as condições de mobilidade no país, ainda são poucas as iniciativas empreendidas no Brasil. Neste sentido, um trabalho que visa desenvolver um sistema de informações técnicas sobre transporte público e trânsito vem sendo desenvolvido pela Associação Nacional de Transportes Públicos (ANTP) em parceria com o Banco Nacional de Desenvolvimento Econômico e Social (BNDES). Este sistema busca integrar dados gerados por órgãos destes dois segmentos em cidades com população superior a 60 mil habitantes, abrangendo um número aproximado de 300 municípios brasileiros.

Na primeira etapa do processo de construção desta ferramenta, foram definidos os blocos de informação que irão compor o sistema e as interações que os mesmos iriam estabelecer, além dos recursos técnicos necessários para a implementação do projeto. Já 
os principais critérios para a escolha dos indicadores basearam-se na pertinência dos mesmos para as questões relacionadas ao transporte público e trânsito, além da sua viabilidade de operacionalização. Mesmo consciente da relevância de determinados indicadores, a comissão responsável pelo projeto reconhece a dificuldade em desenvolvê-los, uma vez que muitas das informações necessárias para a construção dos mesmos não estão disponíveis para o universo de cidades abrangidas pelo sistema (ANTP, 2003c).

A carência de dados e informações é, portanto, um dos principais problemas associados à construção de indicadores de mobilidade. Neste sentido, outras questões pertinentes relacionadas ao desenvolvimento destes indicadores são tratadas na próxima seção.

\subsection{Indicadores para a gestão da mobilidade}

Conforme MOURELO (2002), para o desenvolvimento de estratégias que visam estabelecer padrões de mobilidade sustentáveis, é fundamental conhecer previamente a situação e evolução do sistema de transportes sobre o qual se quer atuar. No entanto, os indicadores estatísticos tradicionais, amplamente utilizados, tendem a enfocar somente a eficiência econômica dos sistemas de transportes (oferta e demanda), deixando de contemplar outras dimensões fundamentais para a sustentabilidade.

A construção de indicadores de mobilidade requer que sejam observadas as particularidades de cada sistema de transporte em questão, a disponibilidade de dados estatísticos para a área onde se deseja intervir e, sobretudo, a necessidade de integrar as dimensões fundamentais para a promoção do conceito de desenvolvimento sustentável.

A seleção de indicadores de mobilidade está vinculada ainda aos objetivos específicos estabelecidos em um determinado nível. Dentre estes objetivos podem se destacar preocupações ambientais, preocupações com o maior equilíbrio na repartição modal, otimização do aproveitamento da infra-estrutura, introdução de novas tecnologias, entre outros. No entanto, ainda que aspectos específicos mereçam maior destaque por uma determinada comunidade, em virtude de suas características ou mesmo pelas deficiências que possam apresentar, uma visão integrada que relacione também questões 
como uso e ocupação do solo, crescimento da população urbana, aspectos econômicos, sociais e ambientais, deve estar sempre presente no desenvolvimento de indicadores de mobilidade urbana.

Embora os assuntos tratados aqui tenham sido amplamente discutidos nos últimos anos, não há como negar que muitos aspectos ainda carecem de maior investigação, principalmente aqueles relacionados ao desenvolvimento de indicadores voltados à monitorar a mobilidade em escala urbana. Neste sentido, a abordagem proposta neste trabalho e apresentada na próxima seção busca contribuir para o maior conhecimento das questões relativas à implementação de indicadores de sustentabilidade e mobilidade urbanas, voltados para o contexto específico de cidades brasileiras e portuguesas. 


\section{MÉTODO E CARACTERIZAÇÃO DOS DADOS BÁSICOS}

Neste capítulo é apresentado o método proposto para o desenvolvimento deste trabalho, bem como são caracterizados os dados básicos necessários para sua elaboração. Primeiramente são discutidos alguns aspectos gerais referentes ao método e, posteriormente, são descritos de forma detalhada todos os procedimentos realizados de modo a atingir os objetivos desejados. Este capítulo inclui ainda um resumo das atividades desenvolvidas, de modo a auxiliar a elaboração de trabalhos futuros.

\subsection{Aspectos gerais}

O método proposto para desenvolvimento deste trabalho é constituído, primeiramente, de um inventário dos sistemas de indicadores urbanos já existentes ou em desenvolvimento para um grupo de cidades localizadas no Brasil e em Portugal. O inventário tem por objetivo permitir a análise da disponibilidade e natureza da informação obtida por meio das páginas oficiais na Internet, para cada uma das cidades abrangidas nesta pesquisa. Os dados obtidos através deste inventário permitirão também avaliar de forma comparativa como a Internet vem sendo utilizada nos dois países, a fim de verificar se a mesma constitui um instrumento efetivo de comunicação do poder público com a comunidade a qual deve servir.

A utilização da Internet como instrumento de pesquisa neste trabalho justifica-se por constituir um meio de comunicação que possibilita o acesso rápido a um amplo conjunto de informações de origens e fontes diversas, tornando viável a cobertura de um maior número de cidades. Este estudo, se realizado "in loco" ou conduzido por meios "tradicionais" de comunicação, poderia tornar-se inviável por questões óbvias, relacionadas aos custos e ao tempo de aquisição dos dados necessários. 
Ainda na etapa de inventário de indicadores urbanos é realizada também a classificação das cidades pesquisadas de acordo com o número de informações obtidas em suas páginas na Internet e com o peso atribuído às mesmas. Estes pesos, por sua vez, foram obtidos por meio de um painel de especialistas do Brasil e Portugal, cujos julgamentos foram ponderados com o auxílio de técnicas de avaliação multicritério, descritas ao longo deste capítulo.

A segunda etapa do método compreende uma busca por experiências nacionais e internacionais de indicadores de sustentabilidade e de mobilidade. Neste sentido, buscase estabelecer um referencial teórico para a mobilidade urbana sustentável, identificando os principais elementos e atributos que a caracterizam, bem como os instrumentos usuais para sua monitoração. Tanto a revisão bibliográfica como o inventário proposto na primeira etapa deste trabalho devem contribuir, igualmente, para a identificação destes elementos e atributos.

Uma vez estabelecido o referencial teórico para a mobilidade urbana sustentável e definidas as principais categorias de informação e temas relacionados à sua monitoração, a etapa seguinte contempla a identificação dos indicadores relevantes e adequados ao contexto das cidades selecionadas no Brasil e em Portugal, objetivo principal a que se propõe este trabalho. A seleção destes indicadores baseia-se no julgamento de profissionais e especialistas de diferentes áreas de conhecimento sobre a importância relativa dos principais atributos anteriormente identificados, bem como dos indicadores fundamentais à monitoração dos mesmos no contexto específico das cidades abrangidas por este estudo. Nesta etapa, novamente são utilizadas técnicas de avaliação multicritério para a avaliação dos elementos relacionados à monitoração da mobilidade urbana.

As duas análises propostas, tanto a que abrange os grupos de informação disponíveis via Internet como a avaliação dos indicadores de mobilidade selecionados, devem ser confrontadas em uma etapa final deste trabalho. Busca-se, deste modo, identificar se os centros urbanos que apresentam um conjunto relativamente amplo de informações em suas páginas na Internet dispõem, de fato, de instrumentos adequados à monitoração de suas condições de mobilidade urbana. 


\subsection{Inventário de indicadores urbanos}

A primeira etapa do inventário exigiu a identificação das cidades brasileiras e portuguesas que constituiriam o objeto de estudo desta pesquisa. Para o Brasil, foram abrangidas as cidades identificadas no recente estudo intitulado "Caracterização e Tendências da Rede Urbana do Brasil” (IPEA, 1999). Deste, constam os 111 principais centros urbanos que estruturam a rede municipal do país, assim classificados com base nos seguintes critérios:

- Tamanho da população total em 1996 (acima de 100 mil habitantes);

- Densidade demográfica em 1996 (acima de 60 habitantes $/ \mathrm{km}^{2}$ );

- Porcentagem da População Economicamente Ativa - PEA em atividades urbanas em 1991 (acima de $65 \%$ );

- Posição no Regiões de Influência das Cidades - REGIC, pesquisa realizada pelo IBGE em 1993 que qualifica como Muito Forte (4), Forte (3), Médio (2) e Fraco (1) a intensidade dos fluxos entre as cidades brasileiras.

De acordo com sua importância, estes centros estão agrupados, segundo IPEA (1999), nas seguintes categorias: metrópoles (globais, nacionais e regionais), centros regionais, centros sub-regionais de nível um e centros sub-regionais de nível dois. Este estudo, por sua vez, concentra-se somente nas três últimas categorias, englobando 86 dos principais centros urbanos de médio porte do país. Como alguns destes configuram aglomerados e, portanto, são constituídos por mais de um núcleo urbano, estes foram desmembrados e considerados isoladamente. Deste modo, o inventário contempla um total de 106 cidades brasileiras.

Já as cidades portuguesas selecionadas são aquelas pertencentes à porção continental do país, reunidas na publicação denominada "Atlas das Cidades de Portugal", realizada pelo Instituto Nacional de Estatística (INE, 2002), baseada em sua maioria, em informações provenientes do Censo 2001. Ao excluir as cidades localizadas nos 
arquipélagos, além das áreas metropolitanas de Lisboa e Porto, este estudo abrange um total de 121 centros urbanos portugueses.

Uma vez identificadas as cidades a serem contempladas nesta pesquisa, a segunda etapa compreendeu uma busca pelas suas respectivas páginas oficiais na Internet. No Brasil, as páginas oficiais correspondem na maioria dos casos às páginas das Prefeituras Municipais, disponíveis, de um modo geral, através do endereço $<$ http://www.nomedacidade.uf.gov.br>.

Já para Portugal, as páginas oficiais correspondem àquelas desenvolvidas para as Câmaras Municipais, Poder Executivo ao nível dos Concelhos naquele país. Estas, de um modo geral, encontram-se disponíveis através do endereço <http://www.cmnomedoconcelho.pt.>. Uma vez que em Portugal os limites das cidades e das Freguesias podem não ser coincidentes, e mesmo que um Concelho pode conter mais de um núcleo urbano, foram consideradas, para estes casos particulares, as páginas das Freguesias que concentram a maior parte da população destas cidades. Estas encontram-se disponíveis através do endereço $<$ http://www.jf-nomedafreguesia.pt $>$.

Quando as páginas oficiais não existiam ou não puderam ser acessadas, buscou-se outras fontes que pudessem contribuir com informações mais detalhadas sobre a realidade de cada uma das cidades em questão. As listas completas contendo os centros identificados tanto para o Brasil como para Portugal, bem como suas respectivas populações e páginas na Internet são apresentadas, respectivamente, nas Tabelas A-1 e A-2 do Anexo A. No que diz respeito à população de cada centro analisado, cabe esclarecer os seguintes aspectos:

- Para as cidades brasileiras, além da população total do município núcleo no ano de 1996, critério utilizado no estudo realizado pelo IPEA, julgou-se conveniente inserir na Tabela A-1 também o valor da população urbana no ano de 2000 para cada cidade em questão. Esta opção justifica-se pela necessidade de um dado mais atual para os centros urbanos brasileiros, que permitisse o confronto com os dados 
disponíveis para as cidades portuguesas abrangidas neste estudo;

- Para as cidades portuguesas é identificada, além da população total do Concelho, a população do núcleo urbano que o constitui. Em muitos casos, a população urbana é bastante inferior à população total do Concelho, uma vez que os limites dos mesmos não são necessariamente coincidentes.

$\mathrm{Na}$ etapa posterior do inventário foram definidos os elementos e características a serem avaliados na página consultada na Internet (oficial ou não oficial) para cada uma das cidades em questão. Estes grupos ou categorias de informação foram estabelecidos com o intuito de facilitar a análise do conteúdo apresentado em cada página, bem como permitir a identificação de dados e informações disponíveis, os quais eventualmente podem constituir base para o desenvolvimento de indicadores urbanos. Cabe ressaltar que estes elementos foram identificados e agrupados pela própria pesquisadora a partir de uma análise preliminar das páginas consultadas, uma vez que estes constituíam os temas comumente disponíveis através da Internet. Estes atributos são, de um modo geral, constituídos por:

- Existência de um plano ou estratégia de desenvolvimento urbano, uma vez que estes podem vir acompanhados de diagnósticos mais detalhados das condições urbanas e mesmo disponibilizar uma série de indicadores fundamentais para a compreensão da realidade local. Esta informação permite também verificar se as cidades pesquisadas contemplam ou não estratégias para a implementação do conceito de desenvolvimento sustentável em nível urbano (Categoria de Informação 1);

- Disponibilidade de índices ou indicadores urbanos e/ou indicadores de sustentabilidade propriamente ditos, ainda que não sistematizados. Neste caso, os indicadores correspondem aos dados estatísticos agregados através de 
métodos aritméticos ou regras de decisão (Categoria de Informação 2);

- Informações sobre elementos relacionados à mobilidade urbana, tais como: transporte público, frota veicular, vias especiais para pedestres, poluição sonora, impactos ambientais causados pelos transportes, consumo energético, entre outros (Categoria de Informação 3);

- Disponibilidade e natureza dos dados estatísticos e informações gerais desagregadas contidas na página pesquisada, tais como: dados econômicos e sociais, informações relacionadas à saúde, educação, infra-estrutura e meio ambiente (Categoria de Informação 4);

- Dados físicos e demográficos que permitam caracterizar a área urbana e a população residente nas cidades pesquisadas (Categoria de Informação 5).

A fim de sistematizar as informações obtidas através da Internet para cada uma das cidades incluídas neste estudo, e de modo auxiliar nos procedimentos de classificação das mesmas, os quais são descritos de forma detalhada na Seção 6.3 deste capítulo, foram organizadas planilhas eletrônicas onde a ausência ou a disponibilidade de cada um dos grupos de informação listados anteriormente foi representada através dos códigos 0 e 1 , respectivamente.

O resumo das informações obtidas entre os meses de janeiro a maio de 2003, período em que foi realizada a pesquisa na Internet para os 106 centros urbanos brasileiros e 121 centros urbanos portugueses, encontra-se disponível no Anexo B deste documento (Tabelas B-1 e B-2). Neste estão incluídos também: os pesos atribuídos para cada categoria de informação (identificadas pelos números $1,2,3,4$ e 5 respectivamente) e os scores finais obtidos para cada conjunto de cidades em particular, cujos procedimentos para a sua determinação são discutidos nas próximas seções. Nestas tabelas foram acrescentados ainda os dados UF (Unidade da Federação) e Região para o caso do Brasil, e Região para o caso de Portugal, informações que foram utilizadas na análise dos resultados descrita no Capitulo 7 deste documento. No Anexo B as cidades já estão ordenadas de acordo com os resultados obtidos a partir do inventário realizado em suas páginas na Internet. 


\subsection{Classificação das cidades pesquisadas}

Em uma etapa posterior ao que se denominou aqui de inventário de indicadores urbanos foi realizado o agrupamento e a classificação das cidades pesquisadas com base no número de informações disponíveis em sua página na Internet e no peso atribuído a cada uma das categorias de informação identificadas neste estudo.

De forma a evitar uma atribuição arbitrária destes pesos, os mesmos foram obtidos por meio de uma avaliação desenvolvida com base na opinião de um grupo de especialistas de diferentes áreas do conhecimento, os quais exercem no Brasil e em Portugal, atividades ligadas ao planejamento urbano e de transportes. Deste modo, todas as análises realizadas aqui buscaram refletir a opinião de um conjunto maior de profissionais e especialistas, não ficando restritas somente à opinião e julgamento de quem conduziu a pesquisa.

Todo o processo de avaliação que culminou com a obtenção dos pesos para as categorias de informação avaliadas nesta etapa do trabalho e nas demais descritas a seguir, foi desenvolvido com base na técnica da avaliação multicritério conhecida como Processo Analítico Hierárquico (Analytic Hierarchy Process, ou AHP, em sua sigla em inglês). Deste modo, na próxima seção são discutidos alguns aspectos relacionados a estas técnicas e em especial, ao Processo Analítico Hierárquico e, posteriormente, sua aplicação nas avaliações que compõem este estudo.

\subsubsection{Avaliação multicritério e o Processo Analítico Hierárquico}

Conforme RAMOS e RODRIGUES (2002), os processos de decisão buscam satisfazer um ou múltiplos objetivos e são desenvolvidos com base na avaliação de um ou vários critérios. Deste modo, em um processo de decisão é comum que diversos critérios tenham que ser avaliados e combinados, e os procedimentos para fazê-lo constituem o que se denomina de Avaliação Multicritério.

MALCZEWSKI (1999), por sua vez, identifica uma série de elementos que estruturam um processo de decisão, dentre eles: 
- Objetivo ou conjunto de objetivos que devem ser atingidos;

- Decisor ou grupo de decisores envolvidos no processo e suas preferências no que diz respeito aos critérios de avaliação;

- Conjunto de critérios de avaliação (elementos e/ou atributos) com base nos quais os decisores irão avaliar as alternativas de ação;

- Conjunto de alternativas de decisão ou variáveis de ação;

- Conjunto de variáveis externas ou fora do controle dos decisores (estados da natureza);

- Conjunto de conseqüências ou resultados associados a cada uma das alternativas (KEENEY e RAIFFA 1976; PITZ e MCKILLIP, 1984 apud MALCZEWSKI, 1999).

Uma das grandes dificuldades encontradas em um processo de decisão que envolve múltiplos critérios é, no entanto, a forma como se deve quantificar a importância relativa de cada um deles, uma vez que os mesmos podem possuir importâncias variáveis para cada decisor. Neste sentido, comumente são definidos pesos para os critérios, de modo a refletir sua importância relativa. A correta atribuição destes pesos é, portanto, fundamental para que sejam mantidas as preferências dos decisores.

Muitos métodos para a definição de pesos podem ser encontrados na literatura (MALCZEWSKI, 1999; SAATY, 1980). Entre os métodos mais utilizados estão os baseados no ordenamento dos critérios; os baseados em escalas de pontos; os baseados na distribuição de pontos e os baseados em comparações de critérios par a par, cujos procedimentos foram aplicados neste estudo.

A metodologia de comparação par a par constitui uma ferramenta promissora para a obtenção de pesos para vários critérios. A técnica denominada de Processo Analítico Hierárquico (Analytic Hierarchy Process,) foi desenvolvida na Wharton School of Business pelo matemático Thomas Saaty (SAATY 1977, 1980, 1987), com o objetivo de facilitar a solução de problemas complexos relacionados à tomada de decisão. Por meio desta, pesos e prioridades são derivados a partir de um conjunto de julgamentos subjetivos realizados por avaliadores ou participantes envolvidos no processo. $\mathrm{O}$ modelo permite ainda o desenvolvimento de uma estrutura hierárquica na qual são 
visualizadas as relações existentes entre a meta principal ou objetivo a ser atingido, e os demais elementos, critérios, sub-critérios e alternativas, considerados para a tomada de decisão (FORMAN e SELLY, 2001).

Esta técnica baseia-se em uma matriz quadrada $n \times n$ de comparação de $n$ critérios, onde estes são dispostos na mesma ordem ao longo das linhas e das colunas. Deste modo, o valor $a_{i j}$ representa a importância relativa do critério da linha $i$ face ao critério da coluna $j$, conforme a Equação 1.

$$
a_{i j}=\frac{1}{a_{j i}} \quad \text { e } \quad a_{i i}=1
$$

Esta matriz é, portanto, uma matriz recíproca. Por exemplo, se o critério da linha $i=1$ é três vezes mais importante que o critério da coluna $j=5$ então, $a_{1,5}=3$ e $a_{5,1}=1 / 3$. Isto implica que apenas a metade triangular superior direita da matriz necessita ser avaliada, já que a outra metade deriva desta e a diagonal principal assume valores unitários. A Tabela 3 ilustra um exemplo de matriz de comparação par a par de 6 critérios. As células em destaque correspondem às células da metade superior que deve ser avaliada. As células da metade inferior correspondem aos valores que são derivados a partir dos valores inseridos na metade superior. Todas as células da diagonal principal recebem o valor 1, uma vez que nelas se estabelece a igualdade entre os critérios dispostos nas linhas e nas colunas.

Tabela 3: Matriz de comparação par a par

\begin{tabular}{|l|c|c|c|c|c|c|}
\hline & Critério 1 & Critério 2 & Critério 3 & Critério 4 & Critério 5 & Critério 6 \\
\hline Critério 1 & $\mathbf{1}$ & $1 / 2$ & 2 & 2 & 3 & 1 \\
\hline Critério 2 & 2 & $\mathbf{1}$ & 4 & 4 & 6 & 2 \\
\hline Critério 3 & $1 / 2$ & $1 / 4$ & $\mathbf{1}$ & 1 & 2 & $1 / 2$ \\
\hline Critério 4 & $1 / 2$ & $1 / 4$ & 1 & $\mathbf{1}$ & 2 & $1 / 2$ \\
\hline Critério 5 & $1 / 3$ & $1 / 6$ & $1 / 2$ & $1 / 2$ & $\mathbf{1}$ & $1 / 3$ \\
\hline Critério 6 & 1 & $1 / 2$ & 2 & 2 & 3 & $\mathbf{1}$ \\
\hline
\end{tabular}

Fonte: Adaptado de RAMOS (2000). 
Para a realização de uma comparação par a par é necessário ainda definir uma escala, de modo a normalizar todos os julgamentos efetuados. Neste trabalho, adotou-se a escala proposta por SAATY (1980), traduzida em nove níveis numéricos conforme as Tabelas 4 e 5 :

Tabela 4: Escala de comparação dos critérios

\begin{tabular}{l|c|c|c|c|c|c|c|c|}
\hline $\mathbf{1 / 9}$ & $\mathbf{1 / 7}$ & $\mathbf{1 / 5}$ & $\mathbf{1 / 3}$ & $\mathbf{1}$ & $\mathbf{3}$ & $\mathbf{5}$ & $\mathbf{7}$ & $\mathbf{9}$ \\
\hline
\end{tabular}
Extremamente
MENastante

Tabela 5: Escala de comparação de critérios segundo Saaty

\begin{tabular}{|c|c|}
\hline Valor & Definição e explicação \\
\hline 1 & $\begin{array}{l}\text { Igual importância - os dois critérios contribuem de uma forma } \\
\text { idêntica para o objetivo. }\end{array}$ \\
\hline 3 & $\begin{array}{l}\text { Pouco mais importante - um critério é um pouco mais importante } \\
\text { que o outro. }\end{array}$ \\
\hline 5 & $\begin{array}{l}\text { Muito mais importante - um critério é claramente mais importante } \\
\text { que outro. }\end{array}$ \\
\hline 7 & $\begin{array}{l}\text { Bastante mais importante - um dos critérios é predominante para o } \\
\text { objetivo. }\end{array}$ \\
\hline 9 & $\begin{array}{l}\text { Extremamente mais importante - um dos critérios é absolutamente } \\
\text { predominante para o objetivo. }\end{array}$ \\
\hline $2,4,6,8$ & Valores intermediários - também podem ser utilizados. \\
\hline $\begin{array}{l}\text { Valores } \\
\text { recíprocos aos } \\
\text { anteriores } \\
\end{array}$ & $\begin{array}{l}\text { Se um critério } i \text { possui um dos valores anteriores quando comparado } \\
\text { com o critério } j \text {, então o critério } j \text { possui o valor recíproco quando } \\
\text { comparado com o critério } i \text {. }\end{array}$ \\
\hline
\end{tabular}
Fonte: Adaptado de SAATY (1980) e RAMOS (2000).

A determinação de pesos para os critérios através do Processo Analítico Hierárquico é feita em três etapas principais, detalhadas a seguir com base nos trabalhos de MALCZEWSKI (1999) e de RAMOS (2000). A fim de proporcionar um exemplo prático do desenvolvimento destas etapas foi utilizada a matriz de comparação par a par apresentada na Tabela 3 desta seção. A planilha contendo todas as operações necessárias para a determinação de pesos para um conjunto de seis critérios é apresentada no Anexo $\mathrm{C}$ deste documento.

ETAPA 1: Construção da matriz de comparação par a par

Conforme a Tabela 3, os critérios são dispostos na mesma ordem nas linhas e nas colunas da matriz, que deve ser preenchida de acordo com a escala indicada nas Tabelas 
4 e 5, de modo a comparar todos os critérios par a par. Cabe esclarecer que, se atribuída uma importância maior ao critério disposto na linha em relação ao critério disposto na coluna deve ser inserido um valor inteiro na célula correspondente. Caso seja atribuída uma importância maior ao critério disposto na coluna em relação ao critério disposto na linha, deve ser inserido o valor recíproco (inverso) na célula correspondente.

ETAPA 2: Obtenção de pesos para os critérios (cálculo do eigenvector principal ou $w$ ) Para qualquer matriz $A$ pode-se calcular o vetor $w_{i}$ pela resolução do sistema da Equação 2:

$$
\mathrm{A}_{\mathrm{W}}=\lambda_{\text {máx } \mathrm{W}}
$$

onde:

$\mathrm{A}_{\mathrm{w}}$ é a matriz de comparação par a par;

$w$ é o vetor de pesos pretendidos;

$\lambda_{\max }$ é o máximo eigenvalue da matriz $A$.

SAATY (1980) mostrou que o eigenvector resultante do máximo eigenvalue da matriz $A$ traduz a prioridade dos fatores e preserva a preferência ordinal entre as alternativas. Os valores do vetor $w$ podem então ser obtidos pela Equação 3.

$$
\mathrm{w}_{i}=\left(\prod_{j=1}^{n} a_{i j}\right)^{1 / n} / \sum_{k=1}^{n}\left[\left(\prod_{j=1}^{n} a_{k j}\right)^{1 / n}\right]
$$

De um modo simplificado, a resolução desta equação implica nas seguintes operações:

- Soma dos valores de cada coluna da matriz de comparação par a par;

- Divisão de cada elemento da matriz pelo somatório da coluna a que pertence. A matriz resultante é denominada de Matriz de Comparação Par a Par Normalizada;

- Obtenção de $\mathrm{w}_{\mathrm{i}}$ dividindo-se a soma dos scores normalizados de cada linha da matriz pelo número de critérios avaliados (neste caso, seis critérios). Este 
procedimento fornece uma estimativa dos pesos relativos dos critérios que estão sendo comparados.

Utilizando a Tabela 3 para exemplificação obtém-se:

$$
w_{i=}\left[\begin{array}{l}
0,18665 \\
0,37331 \\
0,09823 \\
0,09823 \\
0,05693 \\
0,18665
\end{array}\right]
$$

Já o máximo eigenvalue. $\left(\lambda_{\max }\right)$ é dado pela Equação 4.

$$
\lambda_{\text {max }}=\frac{1}{n}\left(\frac{w_{11}^{\prime}}{w_{1}}+\frac{w_{2}^{\prime}}{w_{2}}+\ldots+\frac{w_{3}}{w_{3}}\right)
$$

sendo o vetor w' obtido da seguinte forma:

$$
w^{\prime}=A x w
$$

onde:

$A$ é a matriz de comparação par a par;

$w$ é o vetor de pesos encontrado na etapa anterior.

Para o exemplo apresentado obtém-se $\lambda_{\max }=6,01703$.

ETAPA 3: Cálculo do Grau de Consistência (CR - Consistency Ratio)

O Grau de Consistência fornece uma medida da precisão ou consistência dos julgamentos efetuados, e é obtido pela Equação 6.

$$
C R=\frac{C I}{R I}
$$

onde:

CI é o Índice de Consistência (Consistency Index);

RI é o Índice de Aleatoriedade (Random Index), valor tabelado. 
O valor do CI é obtido pela Equação 7.

$$
C I=\frac{\lambda_{\max }-n}{n-1}
$$

onde:

$n$ é o número de critérios comparados.

Para o exemplo apresentado obtém-se $C I=0,003405$.

SAATY (1980) propôs valores para $R I$ através do cálculo dos valores médios de $C I$ obtidos para matrizes recíprocas geradas aleatoriamente. Estes valores são apresentados na Tabela 6.

Tabela 6: Índice de Aleatoriedade (RI) para $n=1,2,3, \ldots, 15$

\begin{tabular}{cc|cc|cc}
\hline $\boldsymbol{n}$ & $\mathbf{R I}$ & $\boldsymbol{n}$ & $\mathbf{R I}$ & $\boldsymbol{N}$ & $\mathbf{R I}$ \\
\hline $\mathbf{1}$ & 0,00 & $\mathbf{6}$ & 1,24 & $\mathbf{1 1}$ & 1,51 \\
$\mathbf{2}$ & 0,00 & $\mathbf{7}$ & 1,32 & $\mathbf{1 2}$ & 1,48 \\
$\mathbf{3}$ & 0,58 & $\mathbf{8}$ & 1,41 & $\mathbf{1 3}$ & 1,56 \\
$\mathbf{4}$ & 0,90 & $\mathbf{9}$ & 1,45 & $\mathbf{1 4}$ & 1,57 \\
$\mathbf{5}$ & 1,12 & $\mathbf{1 0}$ & 1,49 & $\mathbf{1 5}$ & 1,59 \\
\hline
\end{tabular}

Fonte: Adaptado de SAATY (1980) e RAMOS (2000).

Para este exemplo obtém-se $R I=1,24$.

Finalmente, para o exemplo apresentado aqui, $C R=0,003405 / 1,24=0,00275$.

Uma eventual reavaliação da matriz de comparação pode ser necessária caso o valor de CR seja superior a 0,1. Este valor é freqüentemente citado na literatura como indicativo de um razoável nível de consistência para a comparação par a par (MALCZEWSKI, 1999 e FORMAN e SELLY, 2001). Já SAATY e VARGAS (1991, apud RAMOS, 2000), afirmam ser razoável aceitar valores obtidos para os pesos sempre que o valor do CR for inferior a 0,1 , sendo necessário reavaliar os julgamentos realizados se este valor é ultrapassado. 
Cabe destacar ainda que a obtenção de pesos para diferentes critérios utilizando o Processo Analítico Hierárquico, por constituir uma tarefa bastante trabalhosa, pode ser desenvolvida inclusive com o auxílio de programas específicos como o software Expert Choice, por exemplo (WYATT, 1999). Através destes são estruturadas matrizes de comparação par a par e utilizadas escalas de avaliação (que podem conter palavras, gráficos ou números) de modo a traduzir os julgamentos dos profissionais $\mathrm{e}$ especialistas com respeito a cada par de critérios analisado. Estes programas permitem também verificar os valores de consistência das avaliações e mesmo proceder a análises de sensibilidade detalhadas, a fim de avaliar os possíveis impactos dos julgamentos efetuados.

$\mathrm{Na}$ próxima seção são descritos os procedimentos para a avaliação das informações obtidas via Internet para as cidades brasileiras e portuguesas, os quais permitiram a obtenção de pesos para as mesmas.

\subsubsection{Obtenção de pesos para as informações disponíveis via Internet através do Processo Analítico Hierárquico}

As avaliações incluídas neste trabalho foram desenvolvidas por meio de planilhas eletrônicas enviadas a todos os profissionais e especialistas brasileiros e portugueses convidados a participar do painel de avaliação. Estas planilhas continham não só as matrizes de comparação, como também todas as instruções e informações necessárias para o preenchimento das mesmas.

Aos profissionais consultados foi solicitado que efetuassem uma comparação par a par de critérios ou categorias de informação analisadas no inventário, com base na importância relativa de cada conjunto para a monitoração da mobilidade urbana. Esta etapa foi denominada de Fase 1 do processo de avaliação, uma vez que esta pesquisa inclui ainda mais duas outras fases, descritas na seção 6.4.3 deste documento.

Para facilitar a construção e sobretudo o manuseio das matrizes de comparação par a par nas planilhas eletrônicas, os nomes dos critérios foram abreviados ou reduzidos. No entanto, para todos eles, ao selecionar a célula correspondente, era apresentada a 
identificação completa do critério, além de uma breve descrição ou comentário a fim de facilitar o seu entendimento por parte dos avaliadores.

Todos os campos em amarelo das matrizes de comparação deveriam ser preenchidos. Ao selecionar estes campos, uma questão relacionada à importância relativa dos dois critérios podia ser visualizada, a qual deveria ser respondida com base na escala numérica apresentada de forma simplificada junto a cada uma das matrizes de comparação. Ao se escolher um dos valores sugeridos, determinava-se a importância relativa dos critérios analisados. Para as avaliações realizadas neste trabalho não foi necessário que os avaliadores preenchessem a metade inferior da matriz de comparação com os valores recíprocos à metade superior, uma vez que nas planilhas eletrônicas enviadas aos mesmos este procedimento era feito automaticamente.

Foi permitido aos avaliadores monitorar o Grau de Consistência dos seus julgamentos, cujo valor era obtido logo abaixo da matriz de comparação para a par assim que a mesma era preenchida. Se o valor do Grau de Consistência fosse superior a 0,1, o avaliador era alertado para revisar seus julgamentos até que o mesmo atingisse um valor inferior ao especificado. Quando este era inferior a 0,1 , a mensagem "Julgamentos Consistentes" indicava o final da avaliação. Os modelos de matrizes de comparação utilizadas neste trabalho são apresentadas no Anexo D deste documento.

Uma vez realizadas todas as comparações par a par com base nos procedimentos descritos anteriormente, foram obtidos assim os pesos para as categorias de informação identificadas nas páginas oficiais na Internet relacionadas às cidades brasileiras e portuguesas incluídas neste estudo. Os pesos finais foram obtidos através da média aritmética dos pesos calculados a partir das avaliações individuais, agrupados para cada país em particular. Deste modo, para o Brasil foi considerada somente a opinião dos profissionais e especialistas brasileiros, sendo o mesmo procedimento aplicado para o caso de Portugal.

O número de avaliadores para cada fase do processo, os pesos obtidos com base na opinião de cada avaliador, os valores finais atribuídos para cada critério, bem como o desvio padrão dos pesos individuais, incluindo informações referentes às Fases 2 e 3 (descritas no item 6.4.3 deste trabalho) são apresentados no Anexo E deste documento. Já as tabelas contendo as cidades brasileiras e portuguesas classificadas a partir dos scores finais obtidos para as mesmas podem ser visualizadas no Anexo B. Cabe destacar 
ainda que a definição dos grupos para Brasil e Portugal baseou-se na média e no desvio padrão obtidos para cada conjunto de cidades em particular, etapa descrita de forma mais detalhada no Capítulo 7 deste documento.

Concluídas as etapas de inventário e classificação das cidades pesquisadas, na próxima seção é abordado o método proposto para a identificação de indicadores de mobilidade, com base na seleção de exemplos e experiências em nível nacional e internacional.

\subsection{Identificação e análise de indicadores de mobilidade urbana}

Com o objetivo de identificar indicadores adequados a monitorar as condições de mobilidade em cidades de médio porte no Brasil e em Portugal foi realizada, a princípio, uma seleção de experiências nacionais e internacionais de indicadores de sustentabilidade, de modo a extrair destes sistemas, indicadores relacionados à questão. Buscou-se através deste procedimento estabelecer um referencial teórico para a mobilidade urbana sustentável, uma vez que indicadores selecionados a partir destas experiências irão representar os principais atributos e características que devem ser monitorados no sentido de promover o conceito.

Esta seleção buscou incluir sistemas com características e escalas de abrangência distintas, de modo a contemplar um amplo número de informações e dados que pudessem contribuir para a identificação e caracterização dos elementos e funções envolvidos pelo complexo conceito de sustentabilidade. Ainda que muitos dos sistemas disponíveis tenham sido desenvolvidos para monitorar a sustentabilidade ou a mobilidade em nível nacional, adaptações podem ser realizadas no sentido de adequar estes indicadores ao contexto urbano. Deste modo, foram selecionadas para análise experiências em diferentes escalas, as quais incluíram diversas dimensões da sustentabilidade. Como não poderia deixar de ser, sistemas específicos voltados a monitorar a questão dos transportes e mobilidade também foram incluídos nesta seleção. Todos os sistemas analisados neste estudo são descritos de forma resumida a seguir. 


\subsubsection{Sistemas de indicadores selecionados}

Indicadores da Agenda 21 (estrutura Pressão-Estado-Resposta)

Buscam integrar, de maneira equilibrada, questões relativas ao meio ambiente e ao desenvolvimento, auxiliando na formulação de políticas em nível institucional com base em uma perspectiva sustentável. Permitem, em um primeiro momento, realizar comparações entre os diversos países signatários da Agenda 21. No entanto, fica a critério de cada instituição governamental, o emprego destes indicadores em diferentes níveis em cada país, e a elaboração de Agendas Locais visando o desenvolvimento sustentável.

Este sistema é composto por 132 indicadores relacionados de forma direta aos 40 capítulos que compõem a Agenda 21, classificados nas categorias social, econômica, ambiental e institucional. Todos os procedimentos para o desenvolvimento destes indicadores encontram-se disponíveis via Internet na página oficial da organização (UNCSD, 1996b).

\section{Indicadores da UNCSD, 2001}

Trata-se de um aprimoramento da lista de indicadores proposta pela UNCSD em 1996, estruturada segundo um conjunto de temas e subtemas em que encontram-se subdivididas as quatros principais dimensões do desenvolvimento sustentável. Estes temas incluem, de um modo geral:

- Eqüidade;

- Saúde;

- Educação;

- Moradia;

- Segurança;

- População;

- Atmosfera;

- Solo;

- Oceanos, mares e litoral;

- Água potável;

- Biodiversidade; 
- Estrutura econômica;

- Modelos de consumo e produção;

- Estrutura Institucional;

- Capacidade Institucional (UNCSD, 2001).

\section{Indicadores Urbanos - UNCHS (HABITAT)}

Sistema elaborado com o objetivo de monitorar as condições e tendências dos assentamentos humanos, com base nas 20 áreas-chave relacionadas pela Agenda Habitat (UNCHS, 1996a).

Este sistema, constituído por 23 indicadores-chave (que incluem índices, percentagens e relações) e 9 informações qualitativas (destinadas a avaliar áreas que não podem ser medidas facilmente através de métodos quantitativos), encontra-se subdividido nas seguintes categorias:

- Abrigo;

- Desenvolvimento social e erradicação da pobreza;

- Gerenciamento ambiental;

- Desenvolvimento econômico;

- Governo;

- Cooperação internacional.

Para o desenvolvimento dos indicadores propostos a $U N C H S$ disponibiliza, via Internet, um guia completo contendo todas as informações necessárias para a coleta de dados e formulação dos mesmos (UNCHS, 1996b).

\section{Indicadores de sustentabilidade baseados na Teoria da Orientação}

Com base na teoria proposta por BOSSEL (1997), indicadores são identificados a partir de sua capacidade em atender as exigências de determinados sistemas ou de seus componentes. Este conjunto inclui as seguintes categorias de indicadores:

- Indicadores éticos e normativos;

- Indicadores psicológicos;

- Indicadores de qualificação; 
- Indicadores organizacionais;

- Indicadores de condições de vida;

- Indicadores sociais e de bem-estar;

- Indicadores de recursos materiais;

- Indicadores econômicos e financeiros;

- Indicadores de dependência;

- Indicadores de sobrecarga (BOSSEL, 1997).

Base de dados de indicadores - Sustainable Measures

A consultoria privada Sustainable Measures, com sede em North Andover, Massachusetts, busca auxiliar governos, comunidades e organizações a promover o desenvolvimento sustentável com base no desenvolvimento e identificação de indicadores apropriados para cada contexto. Em sua página na Internet encontra-se disponível uma extensa base de dados que inclui indicadores desenvolvidos nos Estados Unidos, Canadá e Reino Unido, classificados por categorias ou palavras chaves. Alguns dos temas abordados são: economia, educação, ambiente, governo, saúde, transportes, entre outros.

Categorias e variáveis relacionadas à sustentabilidade urbana

DICKEY (2001) com base no trabalho de HALL e PFEIFFER (2000) identificou um amplo conjunto de categorias e variáveis associadas, as quais explicam a natureza e as causas da sustentabilidade em nível urbano. Do conjunto de 1800 variáveis identificadas pelo autor, 317 foram selecionadas para análise neste estudo, de modo a facilitar o trabalho de identificação dos indicadores de mobilidade, etapa que é descrita de forma detalhada na seção 6.42 .

Dentre as categorias identificadas por DICKEY (2001) incluem-se:

- Futuro das cidades;

- Administração/Gerenciamento;

- Pobreza;

- Concentração/Dispersão;

- Crescimento e desenvolvimento;

- Renda; 
- Estratégias para os transportes;

- Estratégias tecnológicas, entre outras.

\section{Indicadores Comuns Europeus}

Desenvolvido com o objetivo de monitorar as iniciativas em direção à sustentabilidade promovidas na Europa de forma harmônica e integrada, este sistema é composto por 10 indicadores-chave listados a seguir:

- Satisfação do cidadão com a comunidade local;

- Contribuição local para as mudanças climáticas globais;

- Mobilidade local e passageiros transportados;

- Disponibilidade de áreas abertas e de serviços públicos locais;

- Qualidade do ar;

- Deslocamento das crianças para a escola;

- Gerenciamento sustentável por parte das autoridades e empresas locais;

- Poluição sonora;

- Uso sustentável do solo;

- Produtos que contribuem para a sustentabilidade (AMBIENTE ITALIA RESEARCH INSTITUTE, 2003).

Sistema para Planejamento e Pesquisa em Centros e Cidades para a Sustentabilidade Urbana - SPARTACUS

Resultado de um estudo promovido por pesquisadores da Finlândia, Reino Unido, Itália, Espanha e Alemanha, foi desenvolvido com o objetivo de analisar as interações entre uso do solo, transportes, fatores econômicos, sociais e ambientais, de modo a antecipar o impacto das políticas e estratégias aplicadas em nível urbano em países da União Européia. Inclui os seguintes indicadores:

- Indicadores ambientais;

- Indicadores sociais;

- Indicadores econômicos e variáveis de origem; 
- Estatísticas de uso do solo (LAUTSO, 1998; UNIÃO EUROPÉIA, 1998).

Indicadores sobre a integração transportes e meio ambiente na União Européia TERM (Transport and Environment Reporting Mechanism)

Sistema desenvolvido pela Agência Européia de Meio Ambiente (European Environment Agency - EEA), com o objetivo de monitorar as questões relativas aos transportes no contexto da União Européia. Inclui indicadores subdivididos nas seguintes categorias:

- Conseqüências ambientais dos transportes;

- Demanda por transportes;

- Planejamento espacial e acessibilidade;

- Oferta de infra-estrutura de transportes e serviços;

- Custos de transportes e preços;

- Tecnologia e eficiência de utilização;

- Gerenciamento da integração (EEA, 2000 e 2002).

Indicadores para a integração das questões ambientais nas políticas de transportes OECD

Sistema voltado a monitorar as questões relacionadas aos transportes em nível nacional, subdividido em três áreas principais:

- Tendências setoriais e padrões de significado ambiental;

- Interações com o meio ambiente;

- Considerações políticas e econômicas (LINSTER, 1997; OECD, 1999).

Estas áreas incluem ainda temas como: crescimento do tráfego e divisão modal; infraestrutura; uso do solo; poluição da água e do ar; ruído; risco e segurança; taxação e subsídios, entre outros. 


\section{Indicadores do Reino Unido}

No trabalho de FARINHA (1998) é identificado um conjunto de indicadores sobre transportes e planejamento urbano desenvolvidos por diferentes organizações no Reino Unido. Estes indicadores abordam questões como acessibilidade, disponibilidade de transporte público, segurança viária, entre outros.

Sistema de Indicadores de Desenvolvimento Sustentável - SIDS

Este sistema, desenvolvido pela Direcção Geral do Ambiente de Portugal e apresentado de forma detalhada no Capítulo 4 deste documento, contempla um total de 132 indicadores incluídos nas quatro categorias principais consideradas para $\mathrm{o}$ desenvolvimento sustentável (DIRECÇÃO GERAL DO AMBIENTE, 2000).

\section{Indicadores de Seattle}

Os Indicadores de Seattle constituem um dos exemplos mais difundidos de indicadores comunitários que visam auxiliar na promoção do desenvolvimento sustentável em nível urbano. Este sistema, que inclui 40 indicadores, aborda os seguintes temas:

- Meio ambiente;

- População e recursos;

- Economia;

- Juventude e educação;

- Saúde e comunidade (SUSTAINABLE SEATTLE, 1992).

\section{Indicadores de Desenvolvimento Sustentável - IBGE}

Também descrito de forma detalhada no Capítulo 4, este sistema contempla um total de 50 indicadores e constitui um dos exemplos brasileiros selecionados para a análise (IBGE, 2002).

\section{Sistema Nacional de Indicadores Urbanos - SNIU}

Este sistema, disponibilizado pelo Ministério das Cidades através do Programa de Gestão da Política de Desenvolvimento Urbano, fornece, via Internet, dados sobre 5507 municípios brasileiros. Os temas abordados incluem: demografia, perfil socioeconômico da população, atividades econômicas, habitação, saneamento básico, transporte urbano, gestão urbana e eleições. 


\section{Índice de Qualidade de Vida Urbana de Belo Horizonte - IQVUBH}

Desenvolvido pela Secretaria de Planejamento da Prefeitura Municipal de Belo Horizonte com consultoria da Pontifícia Universidade Católica de Minas Gerais (PUC/MG), este índice busca expressar em números a complexidade dos fatores que interferem na qualidade de vida nas diversas regiões da cidade de Belo Horizonte. Para o seu desenvolvimento são necessários dados sobre os seguintes temas:

- Abastecimento;

- Assistência social;

- Cultura;

- Renda média;

- Demografia;

- Educação;

- Esportes;

- Habitação;

- Infra-estrutura urbana;

- Meio ambiente;

- Saúde;

- Serviços urbanos;

- Segurança urbana (PREFEITURA MUNICIPAL DE BELO HORIZONTE, 1996).

Foram selecionadas para esta pesquisa, portanto, 16 experiências em diferentes níveis, totalizando 1350 indicadores. A partir deste conjunto partiu-se para a identificação dos indicadores relacionados à mobilidade, cujos procedimentos são descritos a seguir.

\subsubsection{Identificação preliminar dos indicadores relacionados à mobilidade}

Para facilitar a busca por indicadores de mobilidade nas 16 experiências selecionadas neste trabalho foram identificados, primeiramente, Categorias e Temas relacionados à questão. Nesta estrutura foram incluídos, portanto, os aspectos fundamentais para a monitoração dos transportes e mobilidade, identificados a partir da revisão bibliográfica e do referencial teórico estabelecido através da análise preliminar dos sistemas de indicadores selecionados. Estas Categorias e Temas incluíram também questões 
relacionadas à dinâmica populacional, desenvolvimento urbano, qualidade do ambiente urbano, acessibilidade, uso do solo, além de aspectos econômicos, sociais e ambientais que podem influenciar as condições de mobilidade no nível das cidades.

Todos estes elementos foram agregados em cinco Categorias principais, cada uma contendo quatro subdivisões representadas pelos Temas. Cada Tema, por sua vez, possui um conjunto de Palavras-chave ou expressões (neste caso, partes de palavras) utilizadas para auxiliar a identificação dos indicadores de mobilidade disponíveis em cada sistema. Buscou-se, deste modo, listar os temas mais relevantes e comumente encontrados na literatura que incluem elementos ou funções ligadas à questão dos transportes e mobilidade urbana.

As cindo Categorias, bem como os vinte Temas e suas respectivas Palavras-chave são apresentados na Tabela 7. Estes constituíram, portanto, o referencial para a busca dos indicadores de mobilidade. Para cada item disposto nas linhas da tabela foi atribuído um Identificador (ID) representando a Categoria e o Tema a que pertence. O Identificador foi utilizado em uma etapa posterior para agrupar os indicadores dos diferentes sistemas dentro dos Temas e Categorias identificados neste estudo.

A definição das Categorias e Temas relacionados à monitoração da mobilidade é feita a seguir. Do mesmo modo como as categorias de informação avaliadas na primeira fase deste processo, cujos procedimentos foram descritos na fase 6.3.2 deste documento, os nomes destes elementos foram abreviados ou reduzidos em virtude da construção das matrizes de comparação par a par. Estas estruturas são apresentadas entre parênteses ao lado do nome completo das Categorias e Temas identificados na lista apresentada na sequência. Cabe destacar também que os elementos contidos na coluna Palavras-chave não representam somente palavras, incluindo ainda expressões ou radicais que podem estar contidos em mais de uma palavra relacionada ao Tema em questão - por exemplo: energ (energia, energética); polu (poluentes, poluição) e popul (população, populacional). 
Tabela 7: Categorias, Temas e Palavras-chave relacionadas à mobilidade urbana

\begin{tabular}{|c|c|c|c|}
\hline Categoria & ID & Tema & Palavras-chave \\
\hline \multirow{4}{*}{ 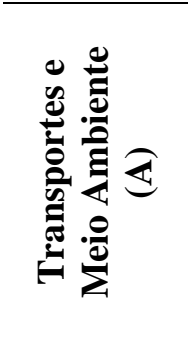 } & A1 & Energia/Combustíveis & $\begin{array}{l}\text { consumo, combustív, ene } \\
\text { efic, fós, gasolina, renov }\end{array}$ \\
\hline & A2 & Impactos ambientais & $\begin{array}{l}\text { ambient, eco, desca } \\
\text { fragment, impactc }\end{array}$ \\
\hline & A3 & Qualidade do ar & $\begin{array}{l}\text { ar, emiss, estufa, ozôni, } \\
\text { partícula, polu, qualidade }\end{array}$ \\
\hline & A4 & Ruído de tı & ruído, sonor \\
\hline \multirow{4}{*}{ 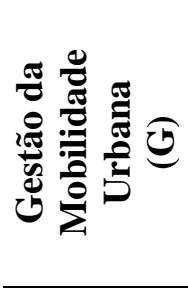 } & G5 & $\begin{array}{l}\text { Despesas/Inv } \\
\text { Estratégias e }\end{array}$ & $\begin{array}{r}\text { despesa, } \\
\text { subsíd }\end{array}$ \\
\hline & 6 & Gerenciamento/Monitoração & aval, gerenc, monitor \\
\hline & G7 & & $\begin{array}{l}\text { estratégia, incentivo, iniciativa, medida, } \\
\text { plano, política, regul }\end{array}$ \\
\hline & G8 & Novas tecn & biocombust, ecológ, limp, intel \\
\hline \multirow{4}{*}{ 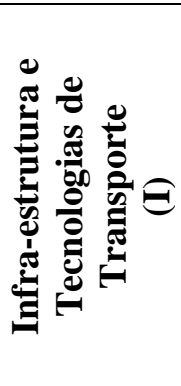 } & I9 & Frota & $\begin{array}{l}\text { autor } \\
\text { taman }\end{array}$ \\
\hline & I10 & Infra-estrutura/Sistema viário & $\begin{array}{l}\text { capacidade, estacionamento, ext, infra, } \\
\text { paviment, ponte, rede, rodovia, via }\end{array}$ \\
\hline & I11 & $\begin{array}{r}\text { Tecnologias e s } \\
\text { transpo }\end{array}$ & $\begin{array}{l}\text { aér, carga, ferrov, mar, rodov, } \\
\text { ônibus, metrô, barc, bicicleta }\end{array}$ \\
\hline & I12 & Tráfego & $\begin{array}{l}\text { congest, inters, ocupação, sinal, } \\
\text { tráfego, trânsito, velocidade }\end{array}$ \\
\hline \multirow{4}{*}{ 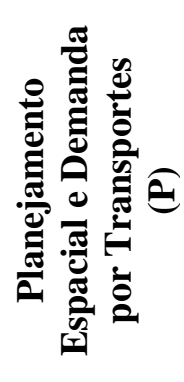 } & P13 & $\begin{array}{l}\text { Acesso aos serviços e } \\
\text { atividades urbanas }\end{array}$ & $\begin{array}{r}\text { acess, } \mathrm{e} \\
\text { serv }\end{array}$ \\
\hline & 914 & $\begin{array}{l}\text { Desenvolvimento urbano/Uso } \\
\text { do solo }\end{array}$ & $\begin{array}{r}\text { área, conc, desent } \\
\text { espalha, }\end{array}$ \\
\hline & P15 & População urbana & $\begin{array}{l}\text { crescimento, demanda, demog, } \\
\text { densidade, habitant, popul, rend, urbana }\end{array}$ \\
\hline & P16 & Viagens/Deslocamentos & $\begin{array}{l}\text { caminha, deslocamento, distância, } \\
\text { mobilidade, } \text { mod, perc, tempo }\end{array}$ \\
\hline \multirow{4}{*}{ 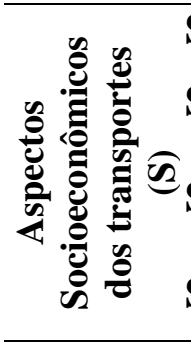 } & S17 & Custos/Preços/Ta & custo, preço, tarifa \\
\hline & S18 & $\begin{array}{c}\text { Impactos socioeconômicos dos } \\
\text { transportes }\end{array}$ & benefício, prejuízo, rendiment, soc \\
\hline & S19 & Segurança & $\begin{array}{c}\text { acidente, ferido, pedestre, } \\
\text { segurança, vítima }\end{array}$ \\
\hline & $\mathbf{S 2 0}$ & Transporte público & $\begin{array}{l}\text { coletivo, corredor, frequência, } \\
\text { passag, públic, transp, usuári }\end{array}$ \\
\hline
\end{tabular}




\section{CATEGORIA A - TRANSPORTES E MEIO AMBIENTE (TranspAmbient)}

Nesta categoria incluem-se os indicadores voltados a monitorar as interações entre transportes e meio ambiente, subdivididos conforme os seguintes Temas:

\section{A1 - Energia/Combustíveis (EnergCombust)}

Palavras-chave: consumo, combustív, energ, efic, fós, gasolina, renováv

Neste tema estão incluídos indicadores para a monitoração do consumo de energia e combustíveis pelos transportes; consumo de energia dos transportes em relação ao total de energia consumida em um determinado nível; consumo por modo; eficiência energética; parcela de utilização de energia renovável e de combustíveis fósseis, entre outros.

\section{A2 - Impactos ambientais (ImpactAmbient)}

Palavras-chave: ambient, eco, descarga, despej, fragment, impacto, resíduo.

Refere-se, de um modo geral, aos indicadores que relacionam de maneira direta os impactos ambientais decorrentes dos transportes, destacando a fragmentação de ecossistemas pela construção e desenvolvimento de infra-estrutura de transportes, a geração de resíduos, descargas e derramamentos de substâncias tóxicas pelos diferentes modos.

\section{A3 - Qualidade do ar (QualiAr)}

Palavras-chave: ar, emiss, estufa, ozôni, partícula, polu, qualidade.

Neste tema estão incluídos indicadores relacionados à monitoração da qualidade do ar no ambiente urbano, uma vez que esta é fortemente determinada pelas tecnologias de transportes empregadas nas cidades. São observados os seguintes aspectos: emissões específicas de diversos poluentes; emissões por modo de transporte; consumo de substâncias de depleção ozônica; índice de qualidade do ar que leva em conta fatores como emissão de gases tóxicos, micropartículas, substâncias voláteis, entre outros.

\section{A4 - Ruído de tráfego (RuidTraf)}

Palavras-chave: ruído, sonor.

Inclui indicadores para a monitoração do impacto sonoro dos transportes em nível urbano: identificação das áreas e população expostas a maiores intensidades de ruído de tráfego e medidas empregadas para a minimização deste impacto. 


\section{CATEGORIA G - GESTÃO DA MOBILIDADE URBANA (GestaoMob)}

Inclui indicadores relacionados ao gerenciamento, monitoração e avaliação dos sistemas de transportes e desenvolvimento de dados e estatísticas para o setor.

\section{G5 - Despesas/Investimentos/Estratégias econômicas (DespInvestEstratEco)}

Palavras-chave: despesa, gasto, invest, subsídio, taxação.

Abrange os indicadores relacionados de maneira direta às estratégias econômicas empregadas para o desenvolvimento da mobilidade urbana: indicadores para a monitoração das despesas, investimentos e gastos com infra-estrutura e tecnologia de transportes; subsídios e taxações sobre os transporte urbanos.

\section{G6 - Gerenciamento/Monitoração (GerencMonitor)}

Palavras-chave: aval, gerenc, monitor.

Indicadores para acompanhar o desenvolvimento de ferramentas para o gerenciamento, monitoração e avaliação dos sistemas de transportes e o desenvolvimento de dados e estatísticas para o setor.

\section{G7 - Medidas para o incremento da mobilidade urbana (MedIncrementMob)}

Palavras-chave: estratégia, incentivo, iniciativa, medida, plano, política, regul.

Indicadores para monitorar o desenvolvimento de políticas, planos ou estratégias para o desenvolvimento dos sistemas de transportes e mobilidade urbana sustentável; medidas integradas para a melhoria das condições de mobilidade urbana.

\section{G8 - Novas tecnologias (NovaTecno)}

Palavra-chave: biocombust, ecolog, limp, intel.

Inclui indicadores para a monitoração das novas tecnologias desenvolvidas com o objetivo de minimizar os impactos ambientais oriundos dos transportes, tais como: biocombustíveis; fontes alternativas de energia; combustíveis "limpos"; entre outras. Desenvolvimento e emprego de tecnologias como sistemas inteligentes, bilhetagem eletrônica e seus impactos sobre a mobilidade urbana. 


\section{CATEGORIA I - INFRA-ESTRUTURA E TECNOLOGIAS DE TRANSPORTE} (InfraServTransp)

Nesta categoria incluem-se os Temas relacionados à monitoração das características de infra-estrutura e tecnologia, fundamentais para a oferta de transportes tanto de carga como de passageiros em nível urbano. Inclui ainda tecnologias que não são empregadas diretamente no transporte urbano mas que podem influenciar de maneira direta o dia-adia das cidades tanto pela infra-estrutura que necessitam como pelos impactos que ocasionam.

\section{I9 - Frota (Frota)}

Palavras-chave: automóv, idade, frota, tamanho, tipo, veículo.

Indicadores para monitorar as características da frota veicular em circulação na área urbana (idade média, tamanho, vida útil) e índice de motorização.

\section{I10 - Infra-estrutura/Sistema viário (InfraSistVia)}

Palavras-chave: capacidade, estacionamento, ext, infra, paviment, ponte, rede, rodovia, via.

Indicadores sobre a provisão e características da infra-estrutura de transportes; capacidade da rede viária; condições do sistema viário; pavimentação; áreas de estacionamento; vias especiais, entre outros.

\section{I11 - Tecnologias e serviços de transporte (TecnoServTransp)}

Palavras-chave: aér, carga, ferrov, mar, rodov, ônibus, metrô, barc, bicicleta.

Indicadores para a monitoração das tecnologias empregadas para o transporte de carga e passageiros em nível urbano e interurbano e sua influência para a economia das cidades; infra-estrutura necessária para o seu desenvolvimento e interações com o espaço e população urbanos.

\section{I12 - Tráfego (Tráfego)}

Palavras-chave: congest, inters, ocupação, sinal, tráfego, trânsito, velocidade.

Indicadores destinados a monitorar as interações entre os diferentes modos de transporte no ambiente urbano: monitoração do fluxo de tráfego (velocidade, densidade, tipo); taxa de ocupação dos veículos; tempo gasto em interseções; sinalização, etc. 


\section{CATEGORIA P - PLANEJAMENTO ESPACIAL E DEMANDA POR TRASPORTES (PlaneEspac)}

Esta categoria inclui Temas que relacionam características como forma urbana, padrões de uso e ocupação do solo, modelos de desenvolvimento urbano e crescimento da população com a demanda por transportes e a necessidade de viagens.

\section{P13 - Acesso aos serviços e atividades urbanas (AcessServAtivUrb)}

Palavras-chave: acess, espaço, facilidade, serviço, atividade.

Neste tema estão incluídos indicadores para a monitoração das condições de acessibilidade urbana, incluindo o acesso às atividades, espaços e serviços essenciais; acesso aos meios de transportes, entre outros.

\section{P14 - Desenvolvimento urbano/Uso do solo (DesenvUrbUsoSolo)}

Palavras-chave: área, conc, desenvolvimento, desc, dispers, espalha, forma, solo, uso. Indicadores para a monitoração do crescimento urbano; forma urbana; concentração ou dispersão das atividades e serviços urbanos; características e modelos de uso do solo.

\section{P15 - População urbana (PopUrb)}

Palavras-chave: crescimento, demanda, demog, densidade, habitant, popul, rend, urbana.

Indicadores para monitorar o crescimento e distribuição da população urbana de modo a auxiliar na provisão de infra-estrutura e oferta de transportes, planejamento e operação de sistemas de transportes. Acompanhamento de características como, densidade, taxa de crescimento, estrutura etária, nível de renda e demais características que possam influenciar a demanda por transportes ou as características dos deslocamentos realizados.

\section{P16 - Viagens/Deslocamentos (ViagDesloca)}

Palavras-chave: caminha, deslocamento, distância, mobilidade, mod, perc, tempo.

Indicadores voltados a monitorar os deslocamentos diários realizados para o trabalho, escola, lazer, entre outros, incluindo informações como tempo de viagem, distância, freqüência dos deslocamentos, conforto, comodidade, entre outros. 


\section{CATEGORIA S - ASPECTOS SOCIOECONÔMICOS DOS TRANSPORTES} (AspSocioEcoTransp)

Nesta categoria estão incluídos Temas relacionados à interação transportes, economia e sociedade. Inclui não só os impactos (prejuízos e benefícios) econômicos e sociais oriundos dos transportes como a provisão e qualidade do transporte público.

\section{S17 - Custos/Preços/Tarifas (CustPreçoTar)}

Palavras-chave: custo, preço, tarifa.

Neste tema estão incluídos indicadores para a monitoração dos custos, preços e tarifas do transporte público ou privado, variações nos preços de insumos e combustíveis.

\section{S18 - Impactos socioeconômicos dos transportes (ImpactSocioEcoTransp)}

Palavras-chave: benefício, prejuízo, rendiment, soc.

Neste tema estão incluídos indicadores para a monitoração dos benefícios sociais e econômicos decorrentes dos transportes: custos e benefícios sociais; custos econômicos; benefícios econômicos para sociedade, governo e operadores; custos do congestionamento e funcionamento ineficiente dos sistemas de transportes; prejuízos e benefícios econômicos e sociais decorrentes da introdução de novas tecnologias de transporte.

\section{S19 - Segurança (Segurança)}

Palavras-chave: acidente, ferido, pedestre, segurança, vítima.

Indicadores para a monitoração das condições de segurança dos deslocamentos ocorridos na área urbana: índices de acidentes; mortos e feridos em acidentes de trânsito; segurança de veículos; pedestres e ciclistas.

\section{S20 - Transporte público (TranspPublic)}

Palavras-chave: coletivo, corredor, frequência, passag, públic, transp, usuári.

Indicadores relacionados à oferta e provisão de transporte público incluindo: cobertura; oferta e qualidade; freqüência e nível de serviço; diversidade; informação ao usuário, entre outros. 
Com base nas Palavras-chave listadas para cada uma das Categorias e Temas relacionados aqui, foi realizada uma busca por indicadores de mobilidade nos 16 sistemas selecionados. Deste modo, ao identificar um indicador que continha determinada palavra-chave ou expressão, este era classificado no Tema correspondente, atribuindo-lhe seu respectivo Número de Identificação (ou ID).

Além da busca por Palavras-chave, uma análise pormenorizada de cada sistema também foi realizada, evitando assim uma possível exclusão de indicadores relacionados à mobilidade que, no entanto, não continham nenhuma das expressões listadas anteriormente. Do mesmo modo foi observado se, mesmo contendo uma Palavra-chave indicativa de um determinado Tema, um indicador não poderia ser melhor classificado em outra categoria. O número de indicadores de mobilidade identificados nestas duas situações foi, no entanto, inexpressivo na busca realizada neste trabalho.

Com base nestes procedimentos foram identificados cerca de 465 indicadores relacionados à questão da mobilidade, do total de 1350 que foram contemplados nos 16 sistemas selecionados. Por meio dos IDs atribuídos na etapa anterior, estes indicadores foram posteriormente agrupados de acordo com os 20 Temas apresentados na Tabela 7.

Uma vez que muitos destes indicadores constituíam medidas semelhantes entre si ou eram totalmente inadequados para serem aplicadas no nível urbano, uma nova seleção foi realizada a fim de estabelecer um conjunto mínimo que pudesse ser submetido à avaliação de especialistas do Brasil e Portugal. Com base nesta nova seleção, desenvolvida pela própria autora, o conjunto a ser avaliado foi reduzido para 115 indicadores. $\mathrm{Na}$ Tabela 8 é apresentado um resumo contendo o número total de indicadores de cada sistema analisado, o número de indicadores de mobilidade identificado e o número final de indicadores selecionados para cada sistema. 
Tabela 8: Resumo da seleção de indicadores de mobilidade

\begin{tabular}{cccc}
\hline $\begin{array}{c}\text { Sistema } \\
\text { Analisado }\end{array}$ & $\begin{array}{c}\text { Número de } \\
\text { Indicadores }\end{array}$ & $\begin{array}{c}\text { Indicadores de } \\
\text { Mobilidade }\end{array}$ & $\begin{array}{c}\text { Seleção } \\
\text { Final }\end{array}$ \\
\hline Agenda 21 & 132 & 16 & 3 \\
UNCSD (2001) & 62 & 8 & 3 \\
UNCHS (Habitat) & 32 & 4 & 1 \\
Bossel & 215 & 15 & 3 \\
Sustainable Measures & 102 & 87 & 17 \\
Dickey & 317 & 156 & 26 \\
Ind. Comuns Europeus & 10 & 7 & 2 \\
SPARTACUS & 28 & 21 & 7 \\
TERM & 37 & 37 & 20 \\
OECD & 32 & 32 & 15 \\
Reino Unido & 48 & 36 & 8 \\
SIDS & 132 & 25 & 7 \\
Seattle & 40 & 6 & 0 \\
IDS (IBGE) & 50 & 5 & 1 \\
SNIU & 73 & 3 & 1 \\
IQVUBH & 40 & 7 & 1 \\
\hline Total & $\mathbf{1 3 5 0}$ & $\mathbf{4 6 5}$ & $\mathbf{1 1 5}$ \\
\hline
\end{tabular}

A estrutura completa contendo as Categorias, Temas e Indicadores submetidos à avaliação pelo painel de especialistas pode ser visualizada no Anexo $F$ deste documento. Já os 115 indicadores selecionados para avaliação, classificados conforme as Categorias e Temas identificados neste estudo, os sistemas de origem, bem como uma breve definição ou comentário sobre os mesmos são apresentados no Anexo G. Em virtude da construção das matrizes de comparação, do mesmo modo que os demais critérios avaliados, os nomes dos indicadores foram reduzidos ou abreviados. Estas estruturas são apresentadas entre parênteses logo abaixo das definições dos indicadores na Tabela G-1 do Anexo G.

\subsubsection{Avaliação das Categorias, Temas e Indicadores de mobilidade}

Definidas as Categorias, Temas e Indicadores de mobilidade com base no referencial teórico adotado e na análise de experiências nacionais e internacionais de indicadores de sustentabilidade, a etapa posterior consistiu na avaliação destes elementos por profissionais e especialistas de Brasil e Portugal com base no Processo Analítico Hierárquico $(A H P)$, detalhado nas seções 6.3.1 e 6.3.2 deste documento. 
A avaliação das Categorias e Temas relacionados à monitoração da mobilidade em nível urbano foi denominada aqui de Fase 2 do processo de avaliação. Do mesmo modo que a Fase 1, onde foram obtidos pesos para as informações identificadas via Internet para o conjunto de cidades brasileiras e portuguesas incluídas neste estudo, a Fase 2 foi desenvolvida por meio de planilhas eletrônicas enviadas a todos os especialistas convidados a participar do painel de avaliação. Nesta ocasião, foi solicitado a estes profissionais que comparassem os critérios par a par (Categorias e Temas), de acordo com sua relevância para a monitoração da mobilidade urbana no contexto dos países abrangidos pelo estudo. Esta avaliação buscou identificar quais os elementos fundamentais, na opinião destes especialistas, para constituir as bases para um sistema de indicadores voltado a monitorar as condições de mobilidade em cidades brasileiras e portuguesas.

Já a Fase 3 do processo de avaliação compreendeu a comparação par a par dos Indicadores de mobilidade incluídos em cada uma das Categorias e Temas avaliados na etapa anterior. Uma vez que a Fase 3 configurou-se bastante extensa, optou-se por desenvolvê-la independentemente da Fase 2, de modo a facilitar a análise dos especialistas consultados.

As matrizes de comparação par a par elaboradas para as Fases 1, 2 e 3 do processo de avaliação são apresentadas no Anexo D deste documento. Já os pesos obtidos para cada um dos critérios avaliados nestas fases podem ser visualizados no Anexo E.

Em uma etapa final deste trabalho, as análises descritas nos itens 6.2 e 6.4 devem ser confrontadas, de modo a permitir a comparação entre os dados e indicadores já disponíveis para as cidades analisadas com os indicadores identificados a partir do referencial teórico adotado. Busca-se desta forma avaliar se, para as cidades nas quais um amplo conjunto de informações encontra-se disponível via Internet, são contemplados os indicadores fundamentais à monitoração de suas condições de mobilidade urbana visando sua sustentabilidade. 


\subsection{Síntese das atividades desenvolvidas}

Nesta seção é apresentada uma síntese das atividades propostas para a elaboração deste estudo, de forma a alcançar o objetivo almejado. Busca-se deste modo, permitir uma maior compreensão dos procedimentos desenvolvidos, bem como auxiliar na elaboração de trabalhos futuros.

a. Revisão bibliográfica para maior compreensão das características geopolíticas de Brasil e Portugal e para a identificação dos principais conceitos relacionados à sustentabilidade urbana, indicadores de sustentabilidade e mobilidade urbana sustentável;

b. Identificação das cidades portuguesas e brasileiras a serem contempladas pelo inventário;

c. Busca pelas páginas (oficiais e não oficiais) a serem pesquisadas na Internet;

d. Identificação dos atributos avaliados em cada página consultada;

e. Elaboração das tabelas resumo contendo as informações obtidas através do inventário para as cidades brasileiras e portuguesas;

f. Construção das matrizes de comparação par a par para os grupos de informação identificados a priori, através do Processo Analítico Hierárquico $(A H P)$;

g. Submissão dos grupos de informação (com base no modelo desenvolvido no item $f$ à avaliação de especialistas e profissionais ligados à área de planejamento urbano e de transportes, buscando identificar a importância relativa dos mesmos. Esta etapa foi desenvolvida por meio de planilhas eletrônicas enviadas aos profissionais e especialistas consultados;

h. Obtenção de pesos para os critérios avaliados; 
i. Classificação das cidades pesquisadas em diferentes grupos com base na disponibilidade e no peso atribuído às informações obtidas via Internet;

j. Seleção de experiências em nível nacional e internacional de sistemas de indicadores de sustentabilidade;

k. Identificação, a partir da revisão bibliográfica e do referencial teórico com base nas experiências selecionadas no item $j$, dos principais atributos e características relacionados à promoção da mobilidade sustentável (Categorias, Temas e Palavras-chave);

1. Com base nas Categorias, Temas e Palavras-chave identificados no item $k$, busca por indicadores de mobilidade nos sistemas de indicadores selecionados;

m. Definição de um conjunto mínimo de indicadores de mobilidade a partir dos resultados obtidos através da busca realizada no item $l$;

n. Construção das matrizes de comparação par a par dos atributos (Categorias e Temas) e Indicadores préselecionados a partir dos sistemas identificados no item $j$;

o. Submissão destes critérios à avaliação de especialistas e profissionais ligados à área de planejamento urbano e de transportes, buscando estabelecer sua relevância para a monitoração da mobilidade e sua adequabilidade ao contexto específico das cidades brasileiras e portuguesas.

p. Análise dos pesos obtidos para cada elemento de modo a identificar os temas e indicadores relevantes para a monitoração da mobilidade em cidades brasileiras e portuguesas;

q. Proposta de um sistema mínimo de indicadores de mobilidade sustentável aplicável para Brasil e Portugal ;

r. Observação das especificidades guardadas tanto para as cidades brasileiras como para as cidades portuguesas, na seleção dos indicadores para cada contexto;

s. Confronto dos resultados obtidos para as duas análises desenvolvidas (itens $h$ e $p$ ). Com base na classificação obtida 
paras as cidades pesquisadas (disponibilidade e natureza da informação) e para os indicadores avaliados (adequados à monitoração da mobilidade em cidades médias brasileiras e portuguesas), identificar se as cidades que dispõem de um amplo conjunto de informações acessível via Internet, contemplam indicadores considerados relevantes a partir da consulta aos profissionais dos dois países. 


\section{RESULTADOS E ANÁLISE DOS RESULTADOS}

Neste capítulo são apresentados e discutidos, primeiramente, os resultados obtidos a partir do inventário de indicadores urbanos realizado para grupos de cidades de Brasil e Portugal. Do mesmo modo, é apresentada a classificação dos centros urbanos pesquisados conforme a disponibilidade e natureza das informações obtidas por meio de suas páginas oficiais na Internet. Com base nesta classificação, são apontados alguns aspectos específicos no contexto de Brasil e Portugal. Posteriormente, são apresentados os resultados referentes à avaliação das Categorias, Temas e Indicadores de mobilidade feita por especialistas brasileiros e portugueses, destacando os grupos de informação considerados relevantes no contexto de cada país em particular. Com base nesta avaliação é proposto um conjunto mínimo de indicadores para a monitoração da mobilidade em cidades de médio porte no Brasil e em Portugal. Finalmente, as etapas de inventário e seleção de indicadores de mobilidade são confrontadas, de modo a identificar se as cidades para as quais estão disponíveis dados e informações via Internet, possuem de fato, indicadores adequados a monitorar suas condições de mobilidade em nível urbano.

\subsection{Inventário de indicadores urbanos (Fase 1)}

Nesta seção são descritos e analisados os resultados obtidos a partir do inventário de indicadores urbanos realizado para um grupo de cidades brasileiras e portuguesas no período de janeiro a março de 2003.

\subsubsection{Síntese dos resultados}

Conforme descrito no Capítulo 6, na etapa de inventário foi avaliada a disponibilidade, via Internet, de um conjunto de informações para as cidades de Brasil e Portugal 
incluídas neste estudo. As tabelas contendo as cidades pesquisadas nos dois países, bem como as informações obtidas a partir da análise de suas páginas na Internet, os pesos finais atribuídos para cada categoria e os scores calculados para cada centro urbano com base nestes dois fatores são apresentadas no Anexo B deste documento. Cabe lembrar que a ausência ou a disponibilidade de cada grupo de informação foi identificada, respectivamente, pelos algarismos 0 e 1 .

Na Tabela 9 são apresentados os pesos obtidos para as categorias de informação disponíveis via Internet para as cidades de Brasil e Portugal, respectivamente. Para o Brasil estes pesos foram obtidos com base na avaliação de dez especialistas da área de planejamento urbano e de transportes da Escola de Engenharia de São Carlos/USP e Universidade Estadual Paulista "Júlio de Mesquita Filho", UNESP/Bauru. Já para Portugal, esta etapa contou com a participação de nove especialistas destas áreas do conhecimento, os quais exercem suas atividades na Universidade do Minho, Braga/Portugal. Os pesos finais para as categorias de informação foram calculados com base na média aritmética dos valores obtidos a partir da análise de cada avaliador em particular. Para cada país foi considerada somente a opinião dos seus especialistas, respectivamente. Todas as informações para esta etapa (identificada como Fase 1 do processo) e para as demais que compõem este estudo podem ser visualizadas também no Anexo E deste documento.

Tabela 9: Pesos obtidos para as categorias de informação disponíveis via Internet para as cidades de Brasil e Portugal

\begin{tabular}{cccc}
\hline \multirow{2}{*}{ Categoria } & Descrição & \multicolumn{2}{c}{ Pesos } \\
& & Brasil & Portugal \\
\hline 1 & Plano ou estratégia de desenvolvimento urbano & 0,352 & 0,282 \\
2 & Índices ou indicadores urbanos e/ou indicadores de sustentabilidade & 0,206 & 0,204 \\
3 & Informações sobre mobilidade urbana & 0,263 & 0,353 \\
4 & Dados estatísticos e informações gerais & 0,109 & 0,066 \\
5 & Dados físicos e/ou demográficos & 0,070 & 0,095 \\
\hline
\end{tabular}

Com base na disponibilidade e no peso obtido para cada categoria de informação, às 106 cidades brasileiras e 121 cidades portuguesas foram atribuídos scores ou valores finais (incluídos no intervalo de 0 à 1 ), a partir dos quais foram calculados a média e o desvio padrão para conjunto em particular. Foram excluídas desta análise, as cidades para as quais não foi possível o acesso à sua página na Internet ou a mesma não foi encontrada. Estas cidades foram imediatamente classificadas em grupos independentes 
tanto para o Brasil como para Portugal. A média e o desvio padrão, por sua vez, foram utilizados para delimitar os demais grupos de cidades por país. No entanto, o uso destes valores para a classificação dos centros urbanos acabou por determinar um número diferente de grupos para Brasil e Portugal (cinco e seis grupos respectivamente). Todos os grupos, bem como suas características ou intervalos de abrangência e o número de cidades que incluem, são mostrados na Tabela 10.

Tabela 10: Critérios para a classificação das cidades pesquisadas

\begin{tabular}{c|cc|c|cccc}
\hline \multicolumn{4}{c|}{ Brasil } & \multicolumn{4}{c}{ Portugal } \\
\hline Média & 0,346 & Desvio & 0,252 & Média & 0,266 & Desvio & 0,244 \\
\hline Grupos & \multicolumn{2}{c}{ Intervalo } & Cidades & Grupos & \multicolumn{2}{c}{ Intervalo } & Cidades \\
\hline $\mathbf{1}$ & 0,850 & $\mathbf{1 , 0 0 0}$ & 2 & $\mathbf{1}$ & 0,998 & $\mathbf{1 , 0 0 0}$ & 4 \\
$\mathbf{2}$ & 0,598 & 0,850 & 18 & $\mathbf{2}$ & 0,754 & 0,998 & 5 \\
$\mathbf{3}$ & 0,346 & 0,598 & 23 & $\mathbf{3}$ & 0,510 & 0,754 & 4 \\
$\mathbf{4}$ & 0,094 & 0,364 & 34 & $\mathbf{4}$ & 0,266 & 0,510 & 33 \\
$\mathbf{5}$ & $\mathbf{0 , 0 0 0}$ & 0,094 & 15 & $\mathbf{5}$ & 0,022 & 0,266 & 57 \\
$\mathbf{6}$ & Páginas não acessadas & 14 & $\mathbf{6}$ & $\mathbf{0 , 0 0 0}$ & 0,022 & 11 \\
& & & $\mathbf{7}$ & Páginas não acessadas & 7 \\
\hline
\end{tabular}

As Figuras 8 e 9 permitem visualizar a proporção de centros urbanos incluídos em cada grupo para Brasil e Portugal, respectivamente. Em ambas, o comprimento das barras corresponde aos valores finais (scores) atribuídos para cada cidade em questão. O eixo central nas duas figuras corresponde à média dos valores obtidos para as cidades de cada país em particular. Acima deste eixo central estão as cidades para as quais valores superiores à média foram atribuídos. Abaixo estão as cidades para as quais valores inferiores à média foram atribuídos. A distância entre as linhas horizontais (limites dos grupos) corresponde ao valor do desvio padrão obtido para as cidades de cada um dos países.

As Tabelas 11 e 12, por sua vez, apresentam as cidades brasileiras e portuguesas classificadas nos diferentes grupos, com seus respectivos scores. Para as cidades brasileiras são acrescentados os dados: Unidade da Federação (UF), Região e População urbana em 2000 (IBGE, 2003). Para as cidades portuguesas são acrescentados os dados: Região e População do núcleo urbano em 2001 (INE, 2002). 


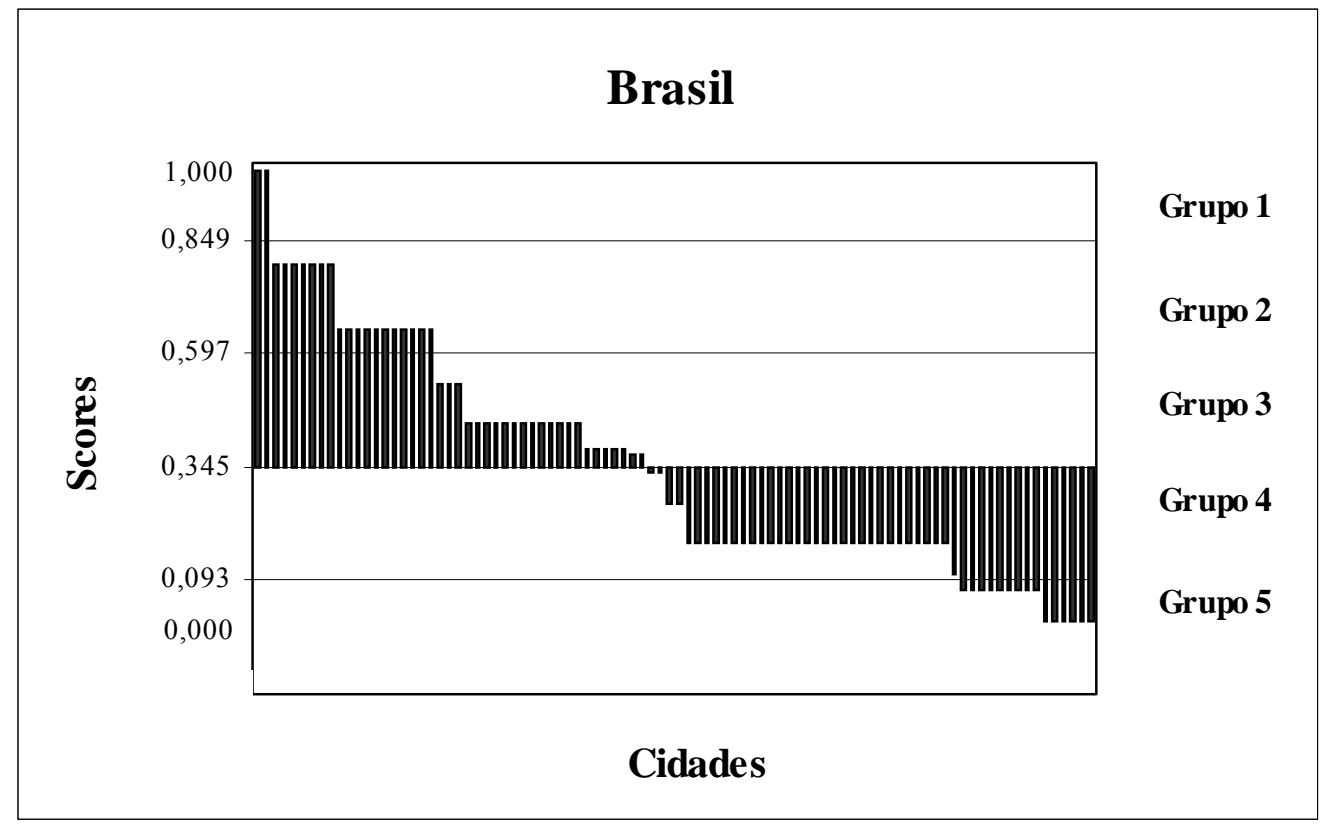

Figura 8: Classificação das cidades brasileiras

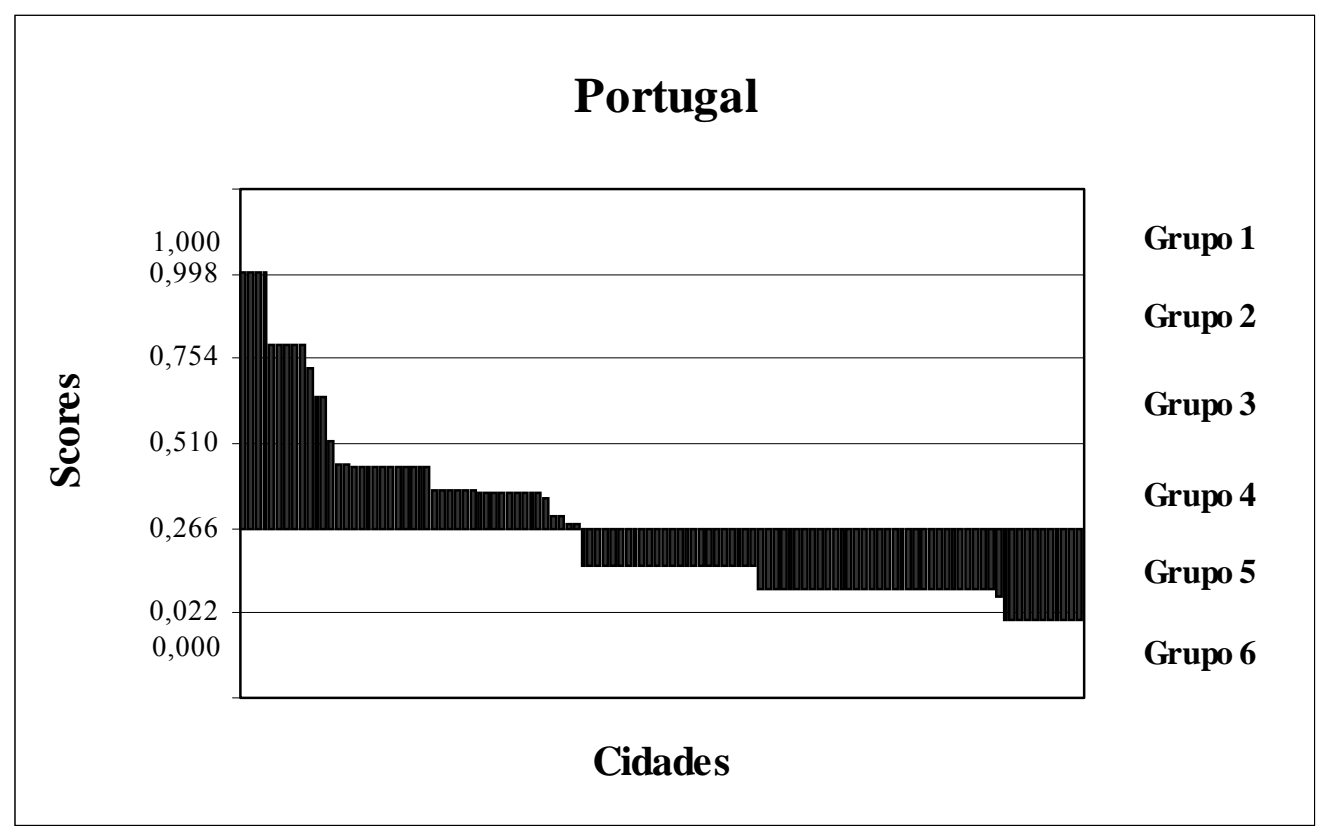

Figura 9: Classificação das cidades portuguesas 
Tabela 11: Grupos de cidades brasileiras

\begin{tabular}{|c|c|c|c|c|c|}
\hline Grupo & Score & Cidade & UF & Região & Pop. 2000 \\
\hline \multirow{2}{*}{1} & 1,000 & Juiz de Fora & MG & Sudeste & 453.002 \\
\hline & 1,000 & Ribeirão Preto & SP & Sudeste & 502.760 \\
\hline \multirow{18}{*}{2} & 0,794 & Barra Mansa & $\mathrm{RJ}$ & Sudeste & 165.134 \\
\hline & 0,794 & Piracicaba & SP & Sudeste & 317.374 \\
\hline & 0,794 & Vitória & $\mathrm{ES}$ & Sudeste & 292.304 \\
\hline & 0,794 & Blumenau & $\mathrm{SC}$ & Sul & 241.943 \\
\hline & 0,794 & Caxias do Sul & $\mathrm{RS}$ & Sul & 333.391 \\
\hline & 0,794 & Chapecó & $\mathrm{SC}$ & Sul & 134.592 \\
\hline & 0,794 & Londrina & PR & Sul & 433.369 \\
\hline & 0,648 & Cuiabá & MT & Centro-Oeste & 476.532 \\
\hline & 0,648 & Dourados & MS & Centro-Oeste & 149.928 \\
\hline & 0,648 & Campina Grande & PB & Nordeste & 337.484 \\
\hline & 0,648 & Natal & $\mathrm{RN}$ & Nordeste & 712.317 \\
\hline & 0,648 & Sobral & $\mathrm{CE}$ & Nordeste & 134.508 \\
\hline & 0,648 & Araraquara & SP & Sudeste & 173.569 \\
\hline & 0,648 & Ipatinga & MG & Sudeste & 210.895 \\
\hline & 0,648 & Jundiaí & $\mathrm{SP}$ & Sudeste & 300.207 \\
\hline & 0,648 & Nova Friburgo & $\mathrm{RJ}$ & Sudeste & 151.851 \\
\hline & 0,648 & Florianópolis & $\mathrm{SC}$ & Sul & 332.185 \\
\hline & 0,648 & Ponta Grossa & PR & Sul & 266.683 \\
\hline \multirow{23}{*}{3} & 0,530 & Campos dos Goitacazes & RJ & Sudeste & 364.177 \\
\hline & 0,530 & Divinópolis & MG & Sudeste & 177.973 \\
\hline & 0,530 & Rio Grande & $\mathrm{RS}$ & Sul & 179.208 \\
\hline & 0,442 & Rondonópolis & MT & Centro-Oeste & 141.838 \\
\hline & 0,442 & Franca & $\mathrm{SP}$ & Sudeste & 282.203 \\
\hline & 0,442 & Poços de Caldas & MG & Sudeste & 130.826 \\
\hline & 0,442 & Santos & $\mathrm{SP}$ & Sudeste & 415.747 \\
\hline & 0,442 & São José dos Campos & SP & Sudeste & 532.717 \\
\hline & 0,442 & Sete Lagoas & MG & Sudeste & 180.785 \\
\hline & 0,442 & Sorocaba & $\mathrm{SP}$ & Sudeste & 486.726 \\
\hline & 0,442 & Uberlândia & MG & Sudeste & 488.982 \\
\hline & 0,442 & Guarapuava & PR & Sul & 141.694 \\
\hline & 0,442 & Itajaí & $\mathrm{SC}$ & Sul & 141.950 \\
\hline & 0,442 & Joinville & $\mathrm{SC}$ & Sul & 414.972 \\
\hline & 0,442 & Passo Fundo & $\mathrm{RS}$ & Sul & 163.764 \\
\hline & 0,442 & Uruguaiana & $\mathrm{RS}$ & Sul & 118.538 \\
\hline & 0,385 & Rio Verde & GO & Centro-Oeste & 106.079 \\
\hline & 0,385 & Guaratinguetá & SP & Sudeste & 99.162 \\
\hline & 0,385 & Uberaba & MG & Sudeste & 244.171 \\
\hline & 0,385 & Cascavel & PR & Sul & 228.673 \\
\hline & 0,385 & Maringá & PR & Sul & 283.978 \\
\hline & 0,372 & Campo Grande & MS & Centro-Oeste & 655.914 \\
\hline & 0,372 & São Luis & MA & Nordeste & 837.584 \\
\hline \multirow{11}{*}{4} & 0,333 & Anápolis & $\mathrm{GO}$ & Centro-Oeste & 280.164 \\
\hline & 0,333 & Bauru & SP & Sudeste & 310.442 \\
\hline & 0,263 & João Pessoa & PB & Nordeste & 597.934 \\
\hline & 0,263 & Teresina & PI & Nordeste & 677.470 \\
\hline & 0,179 & Aracaju & SE & Nordeste & 461.534 \\
\hline & 0,179 & Barreiras & BA & Nordeste & 100.085 \\
\hline & 0,179 & Caruaru & PE & Nordeste & 217.407 \\
\hline & 0,179 & Imperatriz & MA & Nordeste & 218.673 \\
\hline & 0,179 & Jequié & $\mathrm{BA}$ & Nordeste & 130.296 \\
\hline & 0,179 & Juazeiro do Norte & $\mathrm{CE}$ & Nordeste & 202.227 \\
\hline & 0,179 & Mossoró & $\mathrm{RN}$ & Nordeste & 199.081 \\
\hline
\end{tabular}




\begin{tabular}{|c|c|c|c|c|c|}
\hline Grupo & Score & Cidade & $\mathbf{U F}$ & Região & Pop. 2000 \\
\hline \multirow{23}{*}{4} & 0,179 & Parnaíba & PI & Nordeste & 124.988 \\
\hline & 0,179 & Ji-Paraná & RO & Norte & 91.013 \\
\hline & 0,179 & Marabá & PA & Norte & 134.373 \\
\hline & 0,179 & Palmas & TO & Norte & 134.179 \\
\hline & 0,179 & Porto Velho & RO & Norte & 273.709 \\
\hline & 0,179 & Santarém & PA & Norte & 186.297 \\
\hline & 0,179 & Araçatuba & $\mathrm{SP}$ & Sudeste & 164.449 \\
\hline & 0,179 & Botucatu & $\mathrm{SP}$ & Sudeste & 103.993 \\
\hline & 0,179 & Cachoeiro do Itapemirim & ES & Sudeste & 155.401 \\
\hline & 0,179 & Catanduva & SP & Sudeste & 104.268 \\
\hline & 0,179 & Governador Valadares & MG & Sudeste & 236.098 \\
\hline & 0,179 & Itabira & MG & Sudeste & 89.703 \\
\hline & 0,179 & Jaú & SP & Sudeste & 107.198 \\
\hline & 0,179 & Limeira & $\mathrm{SP}$ & Sudeste & 238.349 \\
\hline & 0,179 & Linhares & ES & Sudeste & 92.917 \\
\hline & 0,179 & Presidente Prudente & $\mathrm{SP}$ & Sudeste & 185.229 \\
\hline & 0,179 & São Carlos & SP & Sudeste & 183.433 \\
\hline & 0,179 & Foz do Iguaçu & PR & Sul & 256.524 \\
\hline & 0,179 & Paranaguá & PR & Sul & 122.347 \\
\hline & 0,179 & Pelotas & RS & Sul & 301.081 \\
\hline & 0,179 & Santa Cruz do Sul & RS & Sul & 93.786 \\
\hline & 0,179 & Santa Maria & RS & Sul & 230.696 \\
\hline & 0,109 & Alagoinhas & BA & Nordeste & 112.440 \\
\hline \multirow{15}{*}{5} & 0,070 & Feira de Santana & BA & Nordeste & 413.730 \\
\hline & 0,070 & Arapiraca & $\mathrm{AL}$ & Nordeste & 152.354 \\
\hline & 0,070 & Petrolina & PE & Nordeste & 166.279 \\
\hline & 0,070 & Castanhal & PA & Norte & 121.249 \\
\hline & 0,070 & Rio Branco & $\mathrm{AC}$ & Norte & 226.298 \\
\hline & 0,070 & Bragança Paulista & SP & Sudeste & 111.091 \\
\hline & 0,070 & Cabo Frio & RJ & Sudeste & 106.237 \\
\hline & 0,070 & Teófilo Otoni & MG & Sudeste & 102.812 \\
\hline & 0,070 & Criciúma & $\mathrm{SC}$ & Sul & 153.049 \\
\hline & 0,000 & Ilhéus & BA & Nordeste & 162.125 \\
\hline & 0,000 & Araguaína & TO & Norte & 105.874 \\
\hline & 0,000 & Marília & $\mathrm{SP}$ & Sudeste & 189.719 \\
\hline & 0,000 & Mogi-Guaçu & SP & Sudeste & 116.184 \\
\hline & 0,000 & Mogi-Mirim & SP & Sudeste & 73.099 \\
\hline & 0,000 & Montes Claros & MG & Sudeste & 289.183 \\
\hline \multirow{14}{*}{6} & 0,000 & Crato* & $\mathrm{CE}$ & Nordeste & 83.917 \\
\hline & 0,000 & Itabuna* & BA & Nordeste & 191.184 \\
\hline & 0,000 & Juazeiro* & $\mathrm{BA}$ & Nordeste & 133.278 \\
\hline & 0,000 & Maceió* & $\mathrm{AL}$ & Nordeste & 795.804 \\
\hline & 0,000 & Vitória da Conquista* & BA & Nordeste & 225.545 \\
\hline & 0,000 & Caxias** & MA & Nordeste & 103.485 \\
\hline & 0,000 & Garanhuns* & $\mathrm{PE}$ & Nordeste & 103.435 \\
\hline & 0,000 & Boa Vista* & $\mathrm{RR}$ & Norte & 197.098 \\
\hline & 0,000 & Macapá** & $\mathrm{AP}$ & Norte & 270.628 \\
\hline & 0,000 & São José do Rio Preto* & SP & Sudeste & 337.289 \\
\hline & 0,000 & Volta Redonda* & RJ & Sudeste & 241.996 \\
\hline & 0,000 & Aparecida** & SP & Sudeste & 34.382 \\
\hline & 0,000 & Barbacena** & MG & Sudeste & 103.669 \\
\hline & 0,000 & Lages** & $\mathrm{SC}$ & Sul & 153.582 \\
\hline
\end{tabular}

* Páginas em construção ou em manutenção.

** Páginas não encontradas. 
Tabela 12: Grupos de cidades portuguesas

\begin{tabular}{|c|c|c|c|c|}
\hline Grupo & Score & Cidade & Região & Pop. 2001 \\
\hline \multirow{4}{*}{1} & 1,000 & Sines & Alentejo & 11.788 \\
\hline & 1,000 & Vendas Novas & Alentejo & 9.485 \\
\hline & 1,000 & Aveiro & Centro & 55.305 \\
\hline & 1,000 & Trofa & Norte & 16.196 \\
\hline \multirow{5}{*}{2} & 0,796 & Beja & Alentejo & 21.658 \\
\hline & 0,796 & Portalegre & Alentejo & 15.238 \\
\hline & 0,796 & Castelo Branco & Centro & 30.537 \\
\hline & 0,796 & Póvoa do Varzim & Norte & 38.642 \\
\hline & 0,796 & Vila Nova de Gaia & Norte & 178.255 \\
\hline \multirow{4}{*}{3} & 0,730 & Torres Novas & Lisboa e V. do Tejo & 12.156 \\
\hline & 0,647 & Viana do Castelo & Norte & 36.148 \\
\hline & 0,647 & Vila Nova de Famalicão & Norte & 27.900 \\
\hline & 0,514 & Figueira da Foz & Centro & 27.742 \\
\hline \multirow{33}{*}{4} & 0,448 & Almada & Alentejo & 101.501 \\
\hline & 0,448 & Loulé & Algarve & 12.103 \\
\hline & 0,442 & Montijo & Alentejo & 25.719 \\
\hline & 0,442 & Albufeira & Algarve & 13.646 \\
\hline & 0,442 & Faro & Algarve & 41.934 \\
\hline & 0,442 & Silves & Algarve & 5.869 \\
\hline & 0,442 & Covilhã & Centro & 35.089 \\
\hline & 0,442 & Leiria & Lisboa e V. do Tejo & 42.747 \\
\hline & 0,442 & Marinha Grande & Lisboa e V. do Tejo & 9.130 \\
\hline & 0,442 & Torres Vedras & Lisboa e V. do Tejo & 16.461 \\
\hline & 0,442 & Vila Franca de Xira & Lisboa e V. do Tejo & 16.554 \\
\hline & 0,442 & Chaves & Norte & 17.535 \\
\hline & 0,442 & Santo Tirso & Norte & 24.649 \\
\hline & 0,377 & Seixal & Alentejo & 25.609 \\
\hline & 0,377 & Mangualde & Centro & 6.695 \\
\hline & 0,377 & Ovar & Centro & 16.849 \\
\hline & 0,377 & Entroncamento & Lisboa e V. do Tejo & 18.035 \\
\hline & 0,377 & Bragança & Norte & 20.310 \\
\hline & 0,377 & Matosinhos & Norte & 45.703 \\
\hline & 0,365 & Estremoz & Alentejo & 7.682 \\
\hline & 0,365 & Lagoa & Algarve & 4.806 \\
\hline & 0,365 & Portimão & Algarve & 32.948 \\
\hline & 0,365 & São João da Madeira & Centro & 21.102 \\
\hline & 0,365 & Peniche & Lisboa e V. do Tejo & 15.595 \\
\hline & 0,365 & Pombal & Lisboa e V. do Tejo & 10.031 \\
\hline & 0,365 & Sacavém & Lisboa e V. do Tejo & 17.659 \\
\hline & 0,365 & Tomar & Lisboa e V. do Tejo & 15.764 \\
\hline & 0,365 & Guimarães & Norte & 52.182 \\
\hline & 0,353 & Évora & Alentejo & 41.164 \\
\hline & 0,299 & Pinhel & Centro & 2.578 \\
\hline & 0,299 & Alcobaça & Lisboa e V. do Tejo & 6.232 \\
\hline & 0,282 & Coimbra & Centro & 101.108 \\
\hline & 0,282 & Odivelas & Lisboa e V. do Tejo & 50.845 \\
\hline \multirow{15}{*}{5} & 0,160 & Cantanhede & Centro & 5.004 \\
\hline & 0,160 & Ílhavo & Centro & 12.794 \\
\hline & 0,160 & Abrantes & Lisboa e V. do Tejo & 17.830 \\
\hline & 0,160 & Almeirim & Lisboa e V. do Tejo & 10.520 \\
\hline & 0,160 & Alverca do Ribatejo & Lisboa e V. do Tejo & 28.356 \\
\hline & 0,160 & Amadora & Lisboa e V. do Tejo & 175.872 \\
\hline & 0,160 & Caldas da Rainha & Lisboa e V. do Tejo & 25.314 \\
\hline & 0,160 & Loures & Lisboa e V. do Tejo & 15.967 \\
\hline & 0,160 & Ourém & Lisboa e V. do Tejo & 4.991 \\
\hline & 0,160 & Amarante & Norte & 11.681 \\
\hline & 0,160 & Barcelos & Norte & 20.625 \\
\hline & 0,160 & Braga & Norte & 109.460 \\
\hline & 0,160 & Felgueiras & Norte & 15.525 \\
\hline & 0,160 & Gondomar & Norte & 25.717 \\
\hline & 0,160 & Maia & Norte & 35.625 \\
\hline
\end{tabular}




\begin{tabular}{|c|c|c|c|c|}
\hline Grupo & Score & Cidade & Região & Pop. 2001 \\
\hline \multirow{42}{*}{5} & 0,160 & Santiago do Cacém & Alentejo & 5.240 \\
\hline & 0,160 & Vila Real Santo Antonio & Algarve & 10.489 \\
\hline & 0,160 & Vale de Cambra & Centro & 7.565 \\
\hline & 0,160 & Viseu & Centro & 47.261 \\
\hline & 0,160 & Póvoa de Santa Iria & Lisboa e V. do Tejo & 24.277 \\
\hline & 0,160 & Paços Ferreira & Norte & 8.118 \\
\hline & 0,160 & Paredes & Norte & 12.655 \\
\hline & 0,160 & Penafiel & Norte & 9.343 \\
\hline & 0,160 & Vizela & Norte & 12.698 \\
\hline & 0,095 & Amora & Alentejo & 44.515 \\
\hline & 0,095 & Elvas & Alentejo & 15.115 \\
\hline & 0,095 & Setúbal & Alentejo & 89.306 \\
\hline & 0,095 & Olhão & Algarve & 24.880 \\
\hline & 0,095 & Quarteira & Algarve & 12.290 \\
\hline & 0,095 & Tavira & Algarve & 10.607 \\
\hline & 0,095 & Águeda & Centro & 14.504 \\
\hline & 0,095 & Espinho & Centro & 21.589 \\
\hline & 0,095 & Fiães & Centro & 8.754 \\
\hline & 0,095 & Lourosa & Centro & 9.204 \\
\hline & 0,095 & Santa Comba Dão & Centro & 12.473 \\
\hline & 0,095 & Santa Maria da Feira & Centro & 11.040 \\
\hline & 0,095 & Seia & Centro & 5.702 \\
\hline & 0,095 & Vila Nova de Foz Coa & Centro & 2.823 \\
\hline & 0,095 & Agualva-Cacém & Lisboa e V. do Tejo & 81.843 \\
\hline & 0,095 & Cartaxo & Lisboa e V. do Tejo & 9.507 \\
\hline & 0,095 & Fátima & Lisboa e V. do Tejo & 7.756 \\
\hline & 0,095 & Queluz & Lisboa e V. do Tejo & 78.033 \\
\hline & 0,095 & Rio Maior & Lisboa e V. do Tejo & 7.412 \\
\hline & 0,095 & Ermesinde & Norte & 38.270 \\
\hline & 0,095 & Esposende & Norte & 9.198 \\
\hline & 0,095 & Freamunde & Norte & 7.452 \\
\hline & 0,095 & Lixa & Norte & 4.233 \\
\hline & 0,095 & Macedo de Cavaleiros & Norte & 6.844 \\
\hline & 0,095 & Marco de Canaveses & Norte & 9.042 \\
\hline & 0,095 & Miranda do Douro & Norte & 1.960 \\
\hline & 0,095 & Mirandela & Norte & 10.703 \\
\hline & 0,095 & Peso da Régua & Norte & 9.353 \\
\hline & 0,095 & Rio Tinto & Norte & 47.695 \\
\hline & 0,095 & Valongo & Norte & 17.978 \\
\hline & 0,095 & Valpaços & Norte & 3.751 \\
\hline & 0,095 & Vila Real & Norte & 24.481 \\
\hline & 0,066 & Fafe & Norte & 14.144 \\
\hline \multirow{11}{*}{6} & 0,000 & Alcácer do Sal & Alentejo & 6.602 \\
\hline & 0,000 & Montemor-o-Novo & Alentejo & 8.298 \\
\hline & 0,000 & Esmoriz & Centro & 11.020 \\
\hline & 0,000 & Fundão & Centro & 8.369 \\
\hline & 0,000 & Gafanha da Nazaré & Centro & 12.321 \\
\hline & 0,000 & Gouveia & Centro & 3.759 \\
\hline & 0,000 & Guarda & Centro & 26.062 \\
\hline & 0,000 & Lamego & Centro & 8.848 \\
\hline & 0,000 & Oliveira do Hospital & Centro & 5.222 \\
\hline & 0,000 & Tondela & Centro & 8.772 \\
\hline & 0,000 & São Mamede de Infesta & Norte & 23.542 \\
\hline \multirow{7}{*}{7} & 0,000 & Barreiro* & Alentejo & 40.858 \\
\hline & 0,000 & Moura* & Alentejo & 8.459 \\
\hline & 0,000 & Ponte de Sor* & Alentejo & 7.331 \\
\hline & 0,000 & Lagos* & Algarve & 14.675 \\
\hline & 0,000 & Oliveira de Azeméis* & Centro & 12.047 \\
\hline & 0,000 & Santarém* & Lisboa e V. do Tejo & 28.760 \\
\hline & 0,000 & Vila do Conde* & Norte & 25.731 \\
\hline
\end{tabular}

* Páginas em construção ou em manutenção.

** Páginas não encontradas. 


\subsubsection{Análise dos resultados}

Antes da análise dos resultados obtidos a partir do inventário de indicadores urbanos realizado para 106 cidades brasileiras e 121 cidades portuguesas é interessante avaliar a distribuição dos pesos para as diferentes categorias de informação, obtidos por meio de um painel de especialistas que contou com a participação de profissionais de Brasil e Portugal.

Como pode ser visto na Tabela 9 e no Anexo E deste documento, para cada país foi considerada somente a opinião de seus avaliadores em particular. Assim, para o Brasil, importância maior foi atribuída à categoria de informação representada por Plano ou estratégia de desenvolvimento urbano (peso 0,352), seguida pelas categorias Informações sobre elementos relacionados à mobilidade urbana (peso 0,263) e Índices ou indicadores urbanos (peso 0,206). Já para Portugal, importância maior foi atribuída à categoria Informações sobre elementos relacionados à mobilidade urbana (peso 0,353), seguida pelas categorias Plano ou estratégia de desenvolvimento urbano (peso 0,282) e Índices ou indicadores urbanos (peso $0,204)$.

No que diz respeito às demais categorias avaliadas, representadas por Dados estatísticos gerais e Dados físicos e/ou demográficos, as mesmas também foram classificadas de forma distinta para os dois países. Para o Brasil, à categoria Dados estatísticos gerais foi atribuído um peso maior se comparada à categoria Dados físicos e/ou demográficos $(0,109$ e 0,070 , respectivamente). A mesma situação não ocorreu para o caso de Portugal, onde a categoria Dados físicos e/ou demográficos recebeu um peso maior do que a outra categoria mencionada, ficando em quarto lugar dentre todas as avaliadas.

Diante do crescimento muitas vezes desordenado que vêm sofrendo as cidades brasileiras e da necessidade ainda maior de planejar e gerenciar o espaço urbano em constante transformação, é de certa forma natural que os especialistas brasileiros atribuam uma importância maior às informações relacionadas a existência de planos ou estratégias de desenvolvimento no nível das cidades. Estas informações são, portanto, fundamentais no contexto brasileiro, uma vez que se deseja cada vez mais conhecer o 
espaço onde se vive e, principalmente, propor alternativas no sentido de melhor a qualidade do ambiente urbano. No entanto, se observado o desvio padrão obtido para os pesos atribuídos por todos especialistas que participaram desta etapa de avaliação (Tabela E-1 do Anexo E, igual a 0,201), pode-se identificar uma divergência um pouco maior no que diz respeito a importância atribuída a esta categoria de informação, se comparada às demais categorias avaliadas, as quais apresentaram menores valores de desvio padrão.

Já para os profissionais portugueses, diante das inúmeras iniciativas em promover o conceito de mobilidade sustentável empreendidas no contexto da União Européia, algumas das quais foram abordadas no Capítulo 5 deste documento, parece ser evidente atribuir uma importância maior aos dados relacionados de forma direta à questão da mobilidade urbana. Uma vez que muitas informações ainda necessitam ser produzidas no sentido de acompanhar as tendências da mobilidade ao nível das cidades portuguesas, e que a existência de planos ou estratégias de desenvolvimento urbano em Portugal já são mais comuns do que no Brasil (como mostrado através dos resultados do inventário, onde $25,62 \%$ das cidades pesquisadas apresentam planos ou estratégias de desenvolvimento urbano, contra apenas $11,32 \%$ das cidades brasileiras), é natural que um peso maior seja atribuído a esta categoria de informação. Além disso, o valor do desvio padrão obtido para os pesos atribuídos a esta categoria, no caso português, foi superior aos demais (Tabela E-2 do Anexo E, igual a 0,184), o que também pode revelar certa divergência nos julgamentos efetuados para este grupo de informações.

Quanto ao fato dos especialistas portugueses consultados terem atribuído um peso maior para os dados físicos e demográficos do que os especialistas brasileiros, isto pode ser justificado pela dificuldade de se estabelecer um conceito único de cidade em Portugal e, ainda, pela dificuldade em se delimitar os diferentes núcleos urbanos que podem estar incluídos em um mesmo Concelho (questão abordada de forma mais detalhada no Capítulo 2). Já para o Brasil, onde estas dificuldades são menores e onde os limites dos Municípios já estão consolidados, parece ser mais importante obter informações sobre aspectos como economia, saúde, meio ambiente, entre outros, que caracterizam os dados estatísticos gerais identificados neste estudo. 
No que diz respeito ao inventário de indicadores urbanos propriamente dito, mesmo que a disponibilidade de páginas oficiais na Internet para as cidades pesquisadas já seja uma realidade, uma vez que $86,79 \%$ das cidades brasileiras e $94,21 \%$ das cidades portuguesas já dispunham de algum tipo de página, a pesquisa revelou que o conteúdo das mesmas ainda é bastante limitado. Muitas destas páginas apresentaram um número restrito de informações, não contemplando muitos dos temas relevantes ao diagnóstico das condições dos principais centros urbanos do Brasil e de Portugal. Esta situação pode refletir não só a inexistência ou carência de informações nos dois países, como pode revelar o não interesse por parte das administrações municipais em disponibilizar informações através de veículos de acesso público, como é o caso da Internet.

Para o Brasil, grande parte dos centros pesquisados restringiu suas informações a dados físicos, demográficos e dados estatísticos gerais, incluindo em sua maioria, questões econômicas e sociais, sem um maior detalhamento de temas relacionadas ao ambiente urbano ou mobilidade, entre outros. Muitos destes dados têm como origem o Instituto Brasileiro de Geografia e Estatística - IBGE, sendo poucos aqueles compilados ou desenvolvidos pela própria gestão municipal. Deste modo cria-se uma lacuna, uma vez que é praticamente impossível para um órgão de abrangência nacional cobrir todo o leque de informações relacionadas às áreas urbanas de um país com dimensões continentais, como é o caso do Brasil.

Já no caso das cidades portuguesas o conteúdo de suas páginas na Internet limita-se, na sua maioria, a informações de caráter turístico. Como no Brasil, grande parte dos dados tem origem no órgão oficial de estatísticas (no caso o Instituto Nacional de Estatística INE), estando as informações físicas e demográficas muitas vezes desagregadas ao nível das Freguesias.

De um modo geral, os resultados obtidos para o Brasil mostraram-se um pouco melhores do que aqueles obtidos para Portugal, a começar pela média dos scores atribuídos aos centros pesquisados, que para as cidades brasileiras foi superior à das cidades portuguesas, como mostra a Tabela 10 (0,346 e 0,266, respectivamente). Cabe esclarecer que scores mais elevados podem representar maior disponibilidade de informações ou, ainda, a possibilidade das cidades pesquisadas apresentarem, na 
Internet, as categorias de informação que receberam maiores pesos, a partir da avaliação realizada pelos profissionais e especialistas de cada país em particular.

Ainda que um número inferior de cidades brasileiras $(1,89 \%$ para o Brasil contra 3,31 \% para Portugal) estejam incluídas no Grupo 1, ou seja, tenham atingido scores mais elevados, a proporção de centros brasileiros incluídos nos Grupos 2 e 3 é significativamente maior, se comparado ao número de cidades portuguesas classificadas nestes dois grupos. Para o Brasil, a percentagem de cidades incluídas nos Grupos 2 e 3 é de aproximadamente $39 \%$, enquanto para as cidades portuguesas este valor não chega a $8 \%$. Vale destacar também que $74,38 \%$ dos centros portugueses analisados foram classificadas nos Grupos 4 e 5, com scores variando entre 0,022 e 0,510. Isto significa que a maioria das cidades portuguesas atingiu valores finais inferiores aos das cidades brasileiras, cuja participação das cidades nos Grupos 3 e 4 somados (com scores variando de 0,094 e 0,598 ) atinge $53,78 \%$. A proporção de cidades classificadas nos grupos onde não foi possível o acesso às suas páginas na Internet (Grupo 6 para o Brasil e Grupo 7 para Portugal), no entanto, foi inferior para os centros portugueses $(5,79 \%)$ se comparados aos centros brasileiros pesquisados (13,21\%). A Figura 10 ilustra o exposto.
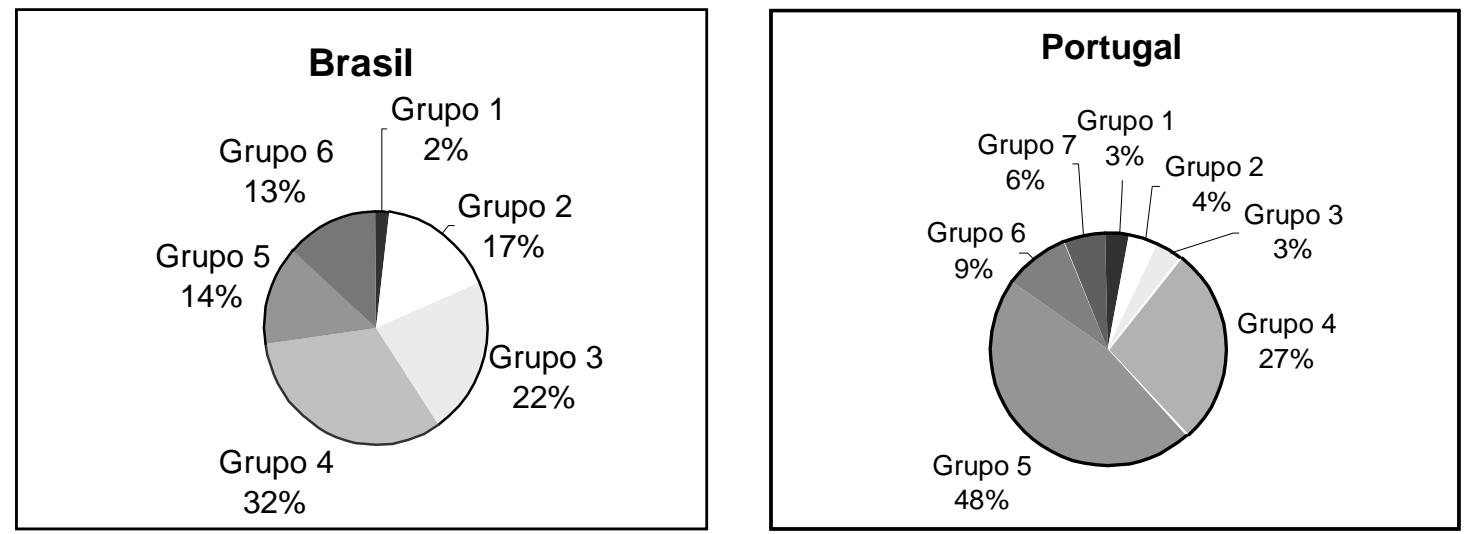

Figura 10: Proporção de cidades incluídas em cada grupo para Brasil e Portugal

Se analisado o caso do Brasil em particular, algumas diferenças podem ser percebidas quanto à participação de cada região do país nos grupos aqui determinados. Pertencem à região Sudeste as duas cidades que atingiram os scores mais elevados dentre todos os centros urbanos avaliados para o Brasil. Para os Grupos 2 e 3, observa-se uma grande participação das cidades localizadas na região Centro-oeste $(33,33 \%$ e 50,00 \%) seguida pelas regiões $\operatorname{Sul}(28,57 \%$ e $38,10 \%)$ e Sudeste $(16,28 \%$ e $25,58 \%)$. Ainda 
quanto aos grupos superiores, foi nula a participação da região Norte nos Grupos 1, 2 e 3. Tanto a região Norte como Nordeste apresentaram uma maior proporção de cidades classificadas nos Grupos 4, 5 e 6, o que revela uma carência maior de dados e informações disponíveis via Internet. Já para o Grupo 6, caracterizado pelas cidades cujas páginas não foram encontradas ou não puderam ser acessadas, participação maior foi a dos centros localizados na região Nordeste. A Tabela 13 e a Figura 11 ilustram os resultados obtidos para o Brasil como um todo e para cada uma de suas regiões.

Tabela 13: Número e proporção de cidades classificadas em cada grupo para Brasil e regiões

\begin{tabular}{ccccccc}
\hline Grupos & Brasil & Centro-oeste & Nordeste & Norte & Sudeste & Sul \\
\hline \multirow{2}{*}{$\mathbf{1}$} & 2 & 0 & 0 & 0 & 2 & 0 \\
& $1,89 \%$ & $0,00 \%$ & $0,00 \%$ & $0,00 \%$ & $4,65 \%$ & $0,00 \%$ \\
\hline \multirow{2}{*}{$\mathbf{2}$} & 18 & 2 & 3 & 0 & 7 & 6 \\
& $16,98 \%$ & $33,33 \%$ & $11,54 \%$ & $0,00 \%$ & $16,28 \%$ & $28,57 \%$ \\
\hline \multirow{2}{*}{$\mathbf{3}$} & 23 & 3 & 1 & 0 & 11 & 8 \\
& $21,70 \%$ & $50,00 \%$ & $3,85 \%$ & $0,00 \%$ & $25,58 \%$ & $38,10 \%$ \\
\hline \multirow{2}{*}{$\mathbf{4}$} & 34 & 1 & 11 & 5 & 12 & 5 \\
& $32,08 \%$ & $16,67 \%$ & $42,31 \%$ & $50,00 \%$ & $27,91 \%$ & $23,81 \%$ \\
\hline \multirow{2}{*}{$\mathbf{5}$} & 15 & 0 & 4 & 3 & 7 & 1 \\
& $14,15 \%$ & $0,00 \%$ & $15,38 \%$ & $30,00 \%$ & $16,28 \%$ & $4,76 \%$ \\
\hline \multirow{2}{*}{ Total } & 14 & 0 & 7 & 2 & 4 & 1 \\
& $13,21 \%$ & $0,00 \%$ & $26,92 \%$ & $20,00 \%$ & $9,30 \%$ & $4,76 \%$ \\
\hline \multirow{2}{*}{ To } & 106 & 6 & 26 & 10 & 43 & 21 \\
& $100,00 \%$ & $100,00 \%$ & $100,00 \%$ & $100,00 \%$ & $100,00 \%$ & $100,00 \%$ \\
\hline
\end{tabular}

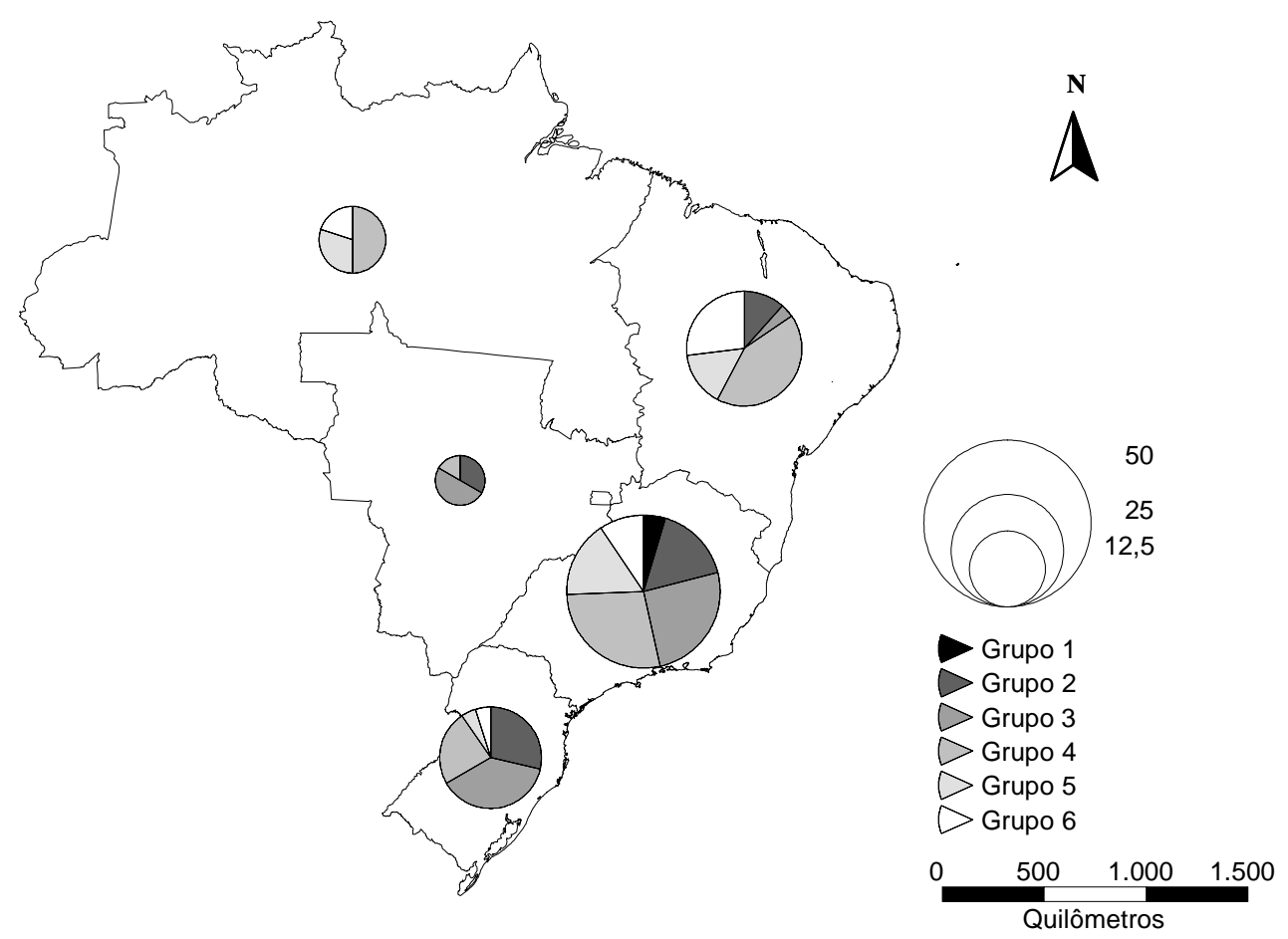

Figura 11: Proporção de cidades classificadas em cada grupo para as regiões brasileiras 
Para Portugal, a análise por regiões foi feita com base na Nomenclatura das Unidades Territoriais Estatísticas (NUTS II), constituídas pelas unidades Alentejo, Algarve, Centro, Lisboa e Vale do Tejo e Norte. Tais unidades foram criadas pelo Serviço de Estatística das Comunidades Européias (EUROSTAT) com o objetivo de padronizar estatísticas comunitárias, diante da indefinição e disparidade dos estatutos administrativos das regiões de cada país membro da União Européia, estabelecendo um esquema único e coerente de repartição territorial (NOGUEIRA, 1995).

Deste modo, para Portugal as regiões que apresentaram maior participação nos Grupos 1 e 2 com melhores resultados foram Alentejo e Norte $(22,22 \%$ e 8,34 \%, respectivamente). Ao mesmo tempo, a região do Alentejo apresentou uma maior proporção de cidades cujas páginas na Internet não foram encontradas ou não puderam ser acessadas (Grupo 7), seguida pelas regiões do Algarve e Lisboa e Vale do Tejo. A maioria das cidades portuguesas, no entanto, foram classificadas nos Grupos 4 e 5, com maior participação das cidades localizadas nas regiões de Norte e Lisboa e Vale do Tejo. A Tabela 14 e a Figura 12 apresentam os resultados obtidos para Portugal como um todo e para cada uma de suas regiões.

Tabela 14: Número e proporção de cidades classificadas em cada grupo para Portugal e regiões

\begin{tabular}{ccccccc}
\hline Grupos & Portugal & Alentejo & Algarve & Centro & $\begin{array}{c}\text { Lisboa e V. } \\
\text { do Tejo }\end{array}$ & Norte \\
\hline \multirow{2}{*}{$\mathbf{1}$} & 4 & 2 & 0 & 1 & 0 & 1 \\
& $3,31 \%$ & $11,11 \%$ & $0,00 \%$ & $3,33 \%$ & $0,00 \%$ & $2,78 \%$ \\
\hline \multirow{2}{*}{$\mathbf{5}$} & 5 & 2 & 0 & 1 & 0 & 2 \\
& $4,13 \%$ & $11,11 \%$ & $0,00 \%$ & $3,33 \%$ & $0,00 \%$ & $5,56 \%$ \\
\hline \multirow{2}{*}{$\mathbf{3}$} & 4 & 0 & 0 & 1 & 1 & 2 \\
& $3,31 \%$ & $0,00 \%$ & $0,00 \%$ & $3,33 \%$ & $3,85 \%$ & $5,56 \%$ \\
\hline \multirow{4}{*}{$\mathbf{5}$} & 33 & 5 & 6 & 6 & 11 & 5 \\
& $27,27 \%$ & $27,78 \%$ & $54,55 \%$ & $20,00 \%$ & $42,31 \%$ & $13,89 \%$ \\
\hline \multirow{2}{*}{$\mathbf{6}$} & 57 & 4 & 4 & 12 & 13 & 24 \\
& $47,11 \%$ & $22,22 \%$ & $36,36 \%$ & $40,00 \%$ & $50,00 \%$ & $66,67 \%$ \\
\hline \multirow{2}{*}{$\mathbf{7}$} & 11 & 2 & 0 & 8 & 0 & 1 \\
\multirow{2}{*}{ Total } & $9,09 \%$ & $11,11 \%$ & $0,00 \%$ & $26,67 \%$ & $0,00 \%$ & $2,78 \%$ \\
\hline & 7 & 3 & 1 & 1 & 1 & 1 \\
& $100,79 \%$ & $16,67 \%$ & $9,09 \%$ & $3,33 \%$ & $3,85 \%$ & $2,78 \%$ \\
\hline
\end{tabular}




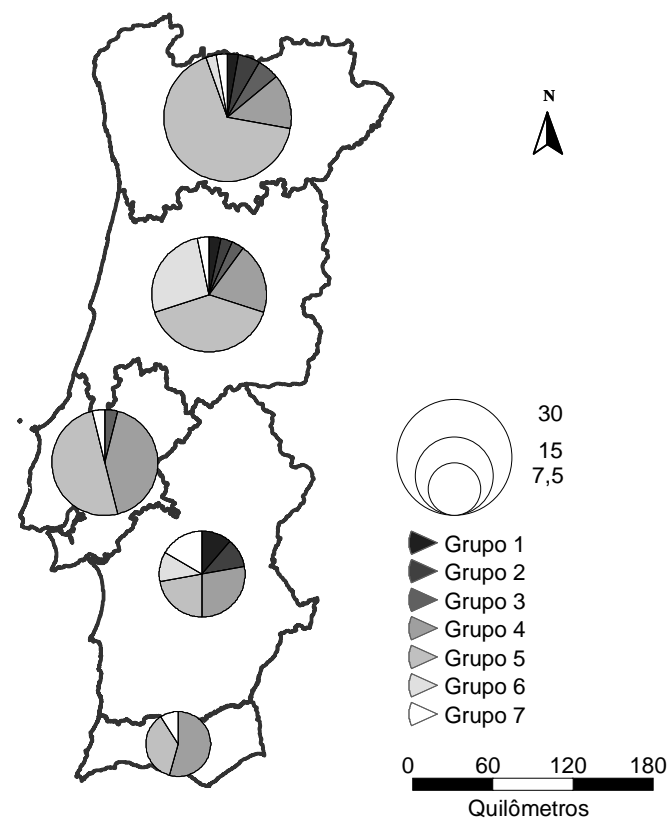

Figura 12: Proporção de cidades classificadas em cada grupo para as regiões portuguesas

No tocante à mobilidade, a percentagem de cidades para as quais já se encontravam disponíveis dados específicos (Categoria 3 das Tabelas B-1 e B-2 do Anexo B) desagregados em nível urbano para Brasil ou Portugal foram, respectivamente, 36,79 \% e $11,57 \%$. De um modo geral, os dados ou indicadores encontrados com maior freqüência nas cidades dos dois países foram:

- Frota veicular do município, em alguns casos diferenciada por categoria;

- Idade média da frota veicular;

- Média de passageiros transportados mensalmente e anualmente por transporte coletivo;

- Índice de motorização;

- Consumo de combustível mensal e anual;

- Tarifas de transporte público e, em alguns casos, resumo de planilhas tarifárias;

- Acidentes de trânsito;

- Área do município servida por transporte coletivo;

- Frota de ônibus urbanos, número e tipo de linhas de transporte público;

- Tempo médio de viagem. 
Já alguns dados apresentados pelas cidades portuguesas, em particular, dizem respeito às vias especiais para circulação de pedestres e ciclistas e, ainda, distribuição e capacidade dos parques de estacionamento urbanos. Vale destacar também, para estas cidades, informações referentes a campanhas que visam sensibilizar a população a optar por meios alternativos de transporte em detrimento ao automóvel para a realização dos percursos urbanos, como é o caso do "Dia Europeu sem Carros", do qual algumas cidades portuguesas já participam.

\subsection{Avaliação das Categorias, Temas e Indicadores relacionados à monitoração da mobilidade urbana sustentável (Fases 2 e 3)}

Nesta seção são apresentados e discutidos os resultados obtidos a partir da avaliação das Categorias, Temas e Indicadores de mobilidade urbana sustentável com base na opinião de especialistas e profissionais de Brasil e Portugal.

\subsubsection{Síntese dos resultados}

Em uma primeira etapa de avaliação dos critérios e indicadores relacionados à monitoração da mobilidade em nível urbano, foram avaliadas Categorias e Temas principais, relacionados de forma direta à questão. Cabe lembrar que estes foram identificados pela própria pesquisadora, a partir da revisão da literatura realizada neste trabalho, bem como através do referencial teórico obtido a partir da análise das experiências nacionais e internacionais de sistemas de indicadores de sustentabilidade. Os resultados obtidos para esta etapa, denominada aqui de Fase 2 do processo de avaliação, incluindo os avaliadores que retornaram as planilhas eletrônicas devidamente preenchidas, os pesos obtidos para cada critério, bem como o desvio padrão para o conjunto de julgamentos, estão disponíveis nas Tabelas E-1 e E-3 (para Brasil e Portugal, respectivamente) do Anexo E deste documento.

No que diz respeito às Categorias de informação avaliadas, algumas considerações podem ser feitas. Para o Brasil as Categorias Transportes e Meio Ambiente e Aspectos Socioeconômicos dos Transportes receberam os maiores pesos a partir da avaliação realizada pelos especialistas do país (0,297 e 0,217, respectivamente), seguidas pelas Categorias Planejamento Espacial e Demanda por Transportes (peso 
0,210), Gestão da Mobilidade Urbana (peso 0,173) e Infra-estrutura e Tecnologias de Transporte (peso 0,102).

Já para Portugal os resultados divergem dos obtidos para o Brasil. Com base nos julgamentos efetuados pelos especialistas portugueses, maior peso foi atribuído à categoria Planejamento Espacial e Demanda por Transportes (peso 0,363) seguida pelas categorias Transportes e Meio Ambiente (peso 0,221) e Gestão da Mobilidade Urbana (peso 0,173). As categorias para as quais foram atribuídos os menores pesos foram Infra-estrutura e Tecnologias de Transporte e Aspectos Socioeconômicos dos Transportes $(0,129$ e 0,114 , respectivamente). A Figura 13 , na qual as categorias são identificadas pelas letras listadas a seguir, ilustra o exposto:

(A) Transportes e meio Ambiente;

(G) Gestão da Mobilidade Urbana;

(I) Infra-estrutura e Tecnologias de Transporte;

(P) Planejamento Espacial e Demanda por Transportes;

(S) Aspectos Socioeconômicos dos transportes.

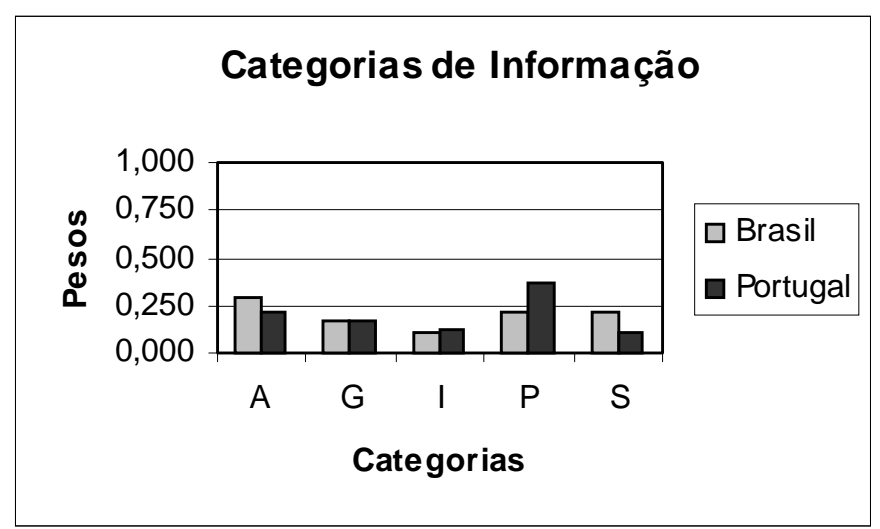

Figura 13: Pesos para as Categorias de informação relacionadas à monitoração da mobilidade urbana para Brasil e Portugal

Para a categoria Transportes e Meio Ambiente, o tema Qualidade do ar recebeu o maior peso dentre todos os temas avaliados nos dois países $(0,311$ e 0,415, respectivamente). No entanto, para o Brasil, o segundo maior peso foi atribuído ao tema Impactos ambientais (peso 0,257), enquanto que para Portugal este foi atribuído ao tema Ruído de tráfego $(0,258)$. Cabe destacar também, para os dois países, que ao tema Energia/Combustíveis foi atribuída a menor importância relativa dentre os quatro critérios avaliados. Os pesos obtidos para todos os temas incluídos nesta categoria para 
Brasil e Portugal, respectivamente, são mostrados na Figura 14. Nela os Temas são identificados pelo seu respectivo código (conforme a Tabela 7) deste documento e apresentados a seguir:

(A1) Energia/Combustíveis;

(A2) Impactos ambientais;

(A3) Qualidade do ar;

(A4) Ruído de tráfego.

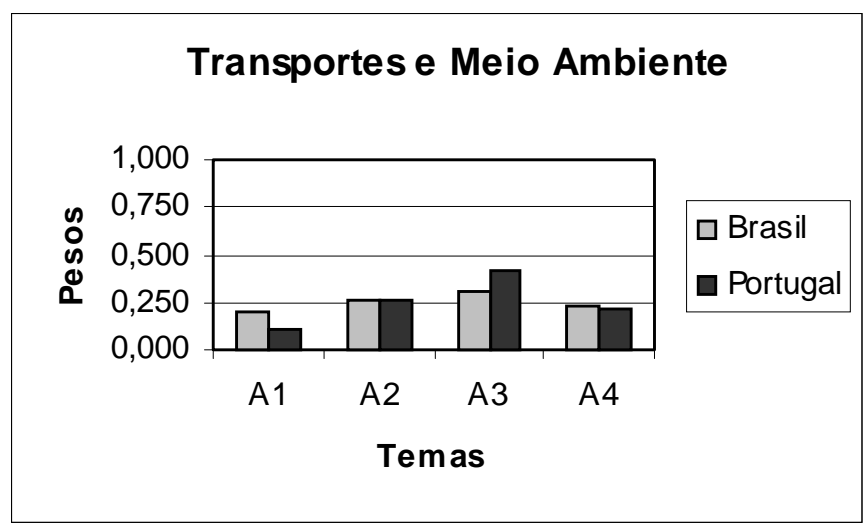

Figura 14: Pesos para os Temas incluídos na Categoria Transportes e Meio Ambiente (A) para Brasil e Portugal

No que diz respeito aos resultados obtidos para os Temas incluídos na categoria Gestão da Mobilidade Urbana, estes foram bastante distintos para os dois países. Para o Brasil, peso maior foi atribuído ao tema Despesas/Investimentos/Estratégias econômicas (peso 0,286), seguido por Medidas para o incremento da mobilidade urbana (peso 0,271), Gerenciamento/Monitoração (peso 0,236) e Novas Tecnologias (peso 0,207). Já para Portugal, importância maior foi atribuída ao critério Medidas para o incremento da mobilidade urbana (peso 0,335), seguido por Novas tecnologias (peso 0,243), Despesas/Investimentos/Estratégias econômicas (peso 0,240) e Gerenciamento/Monitoração (peso 0,183). A Figura 15 ilustra o exposto. Nela os temas incluídos na categoria Gestão da Mobilidade Urbana são identificados igualmente por seus códigos, descritos a seguir:

(G5) Despesas/Investimentos/Estratégias econômicas;

(G6) Gerenciamento/Monitoração

(G7) Medidas para o incremento da mobilidade de urbana

(G8) Novas tecnologias. 


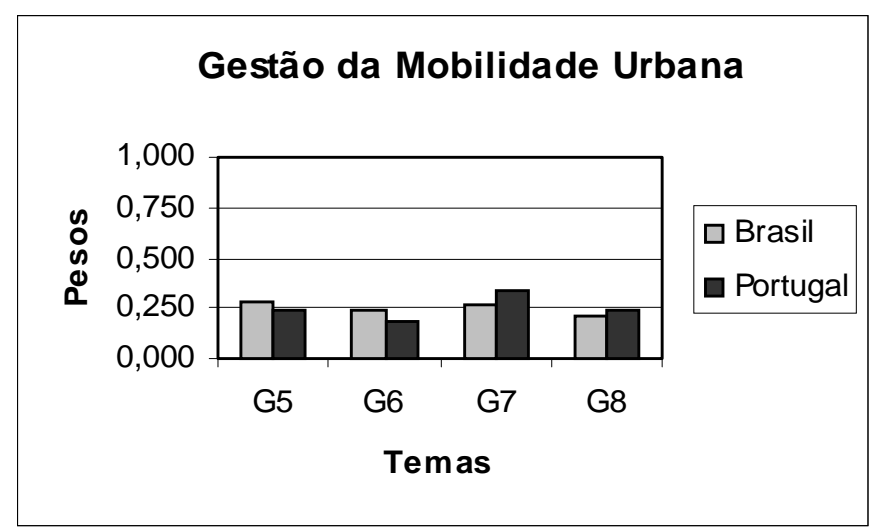

Figura 15: Pesos para os Temas incluídos na categoria Gestão da Mobilidade Urbana (G) para Brasil e Portugal

Já para a categoria Infra-estrutura e Tecnologias de Transporte os resultados foram os seguintes: para o Brasil, maior peso foi atribuído ao tema Tráfego (peso 0,316, seguido por Infra-estrutura/Sistema viário (peso 0,264), Tecnologias e serviços de transportes (peso 0,252) e Frota (peso 0,167). Já para Portugal maior peso foi atribuído ao tema Infra-estrutura/Sistema viário (peso 0,430), seguido por Tráfego (peso 0,264), Tecnologias e serviços de transportes (peso 0,181) e Frota (peso 0,126). Para os dois países, ao tema Frota foi atribuída a menor importância relativa. Os resultados para os temas incluídos na categoria Infra-estrutura e Tecnologias de Transporte são apresentados na Figura 16. Do mesmo os critérios são identificados pelos seus códigos, descritos a seguir:

(I9) Frota;

(I10) Infra-estrutura/Sistema viário;

(I11) Tecnologias e serviços de transportes;

(I12) Tráfego.

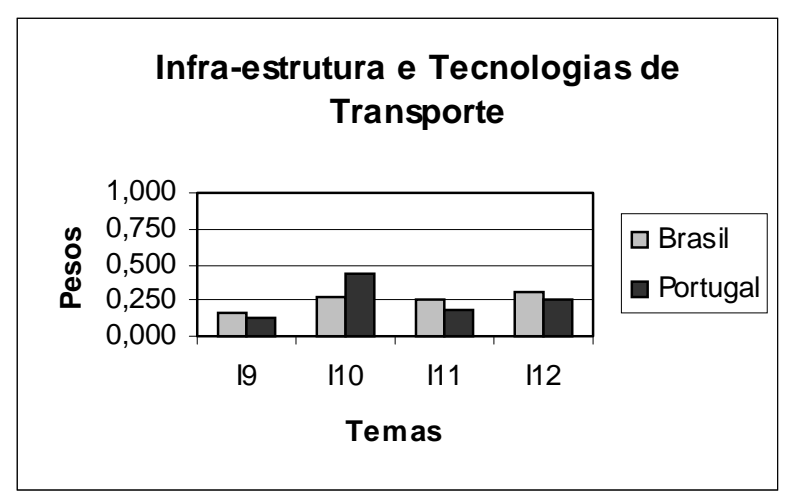

Figura 16: Pesos para os Temas incluídos na categoria Infra-estrutura e Tecnologias de Transportes (I) para Brasil e Portugal. 
Para a categoria Planejamento Espacial e Demanda por Transportes, o tema Acesso aos serviços e atividades urbanas recebeu o maior peso segundo a avaliação dos especialistas brasileiros e portugueses (pesos 0,313 e 0,397, respectivamente). Para o Brasil, o segundo maior peso foi atribuído ao tema População urbana (peso 0,267) seguido por Desenvolvimento urbano/Uso do Solo (peso 0,222). Para Portugal, o segundo maior peso foi atribuído ao tema Viagens/Deslocamentos (peso 0,313), que no entanto foi o critério colocado em último lugar dentre os quatro avaliados, segundo a opinião dos avaliadores brasileiros. A Figura 17 ilustra os resultados obtidos para esta categoria, cujos códigos para os seus respectivos Temas são apresentados a seguir:

(P13) Acesso aos serviços e atividades urbanas;

(P14) Desenvolvimento urbano/Uso do solo;

(P15) População urbana;

(P16) Viagens/Deslocamentos.

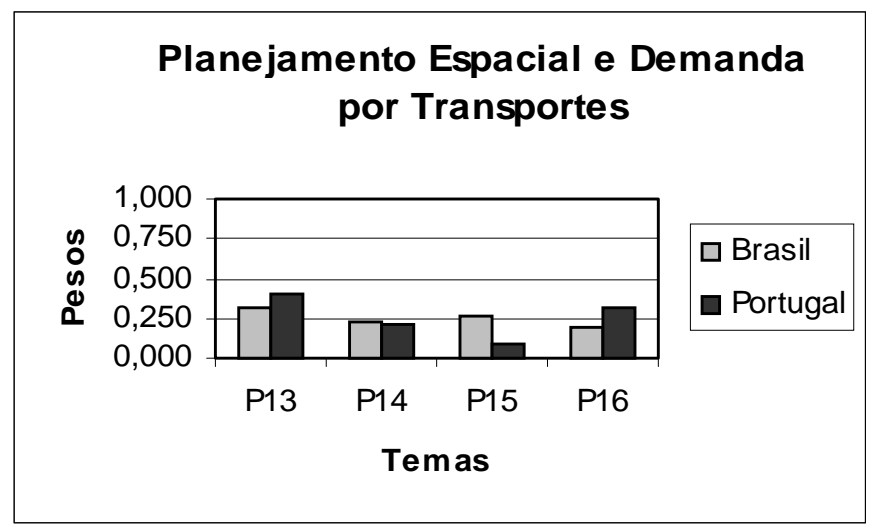

Figura 17: Pesos para os Temas incluídos na categoria Planejamento Espacial e Demanda por Transportes (P) para Brasil e Portugal

Finalmente, para a categoria Aspectos Socioeconômicos dos Transportes os resultados para os dois países foram bastante diferenciados, onde para o Brasil maior peso foi atribuído ao tema Custos/Preços/Tarifas (peso 0,264) enquanto que para Portugal foi atribuído para o tema Segurança (peso 0,377). Os resultados para esta categoria são mostrados na Figura 18. Nela os Temas são identificados conforme os códigos descritos a seguir:

(S17) Custos/Preços/Tarifas;

(S18) Impactos socioeconômicos dos transportes;

(S19) Segurança;

(S20) Transporte público. 


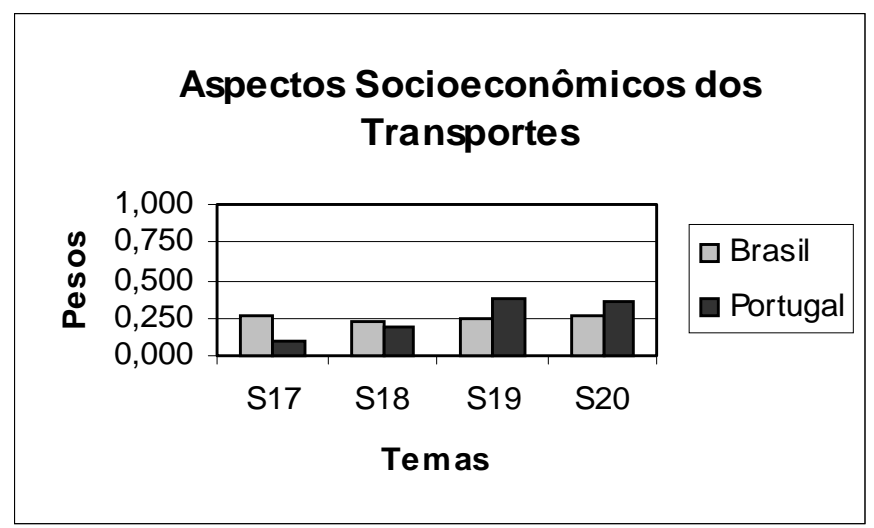

Figura 18: Pesos para os Temas incluídos na categoria Aspectos Socioeconômicos dos Transportes (S) para Brasil e Portugal

Apresentados os resultados obtidos para a Fase 2 do processo de avaliação que compreendeu a obtenção de pesos para as Categorias e Temas relacionadas à monitoração da mobilidade urbana, a seguir são apresentados os resultados obtidos para avaliação dos indicadores identificados a partir das experiências nacionais e internacionais, que constituiu a Fase 3 do processo de avaliação desenvolvido neste trabalho. A Tabela 15 apresenta os pesos obtidos para cada indicador de mobilidade para Brasil e Portugal, respectivamente.

Tabela 15: Pesos obtidos para os indicadores de mobilidade para Brasil e Portugal

\begin{tabular}{|c|c|c|c|c|}
\hline \multirow{2}{*}{$\underbrace{\stackrel{0}{\sigma}}$} & \multirow{2}{*}{ 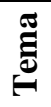 } & \multirow[b]{2}{*}{ Indicador } & \multicolumn{2}{|c|}{ Peso } \\
\hline & & & Brasil & Portugal \\
\hline \multirow{20}{*}{ 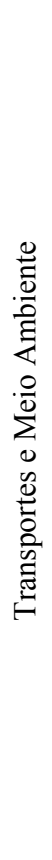 } & \multirow{5}{*}{ 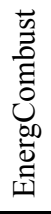 } & Consumo per capita de combustível fóssil por transporte em veículo motorizado & 0,163 & 0,199 \\
\hline & & Eficiência energética do transporte de passageiros e carga & 0,149 & 0,138 \\
\hline & & Energia final consumida pelo setor de transportes & 0,290 & 0,053 \\
\hline & & Intensidade no uso de energia: transportes & 0,213 & 0,347 \\
\hline & & Proporção de energia originada de fontes de combustível fósseis e não-fósseis & 0,185 & 0,263 \\
\hline & \multirow{5}{*}{ 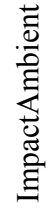 } & Descargas acidentais de óleo no mar por navios & 0,150 & 0,056 \\
\hline & & Fragmentação de terras e florestas & 0,160 & 0,234 \\
\hline & & Impactos do uso de automóveis & 0,292 & 0,263 \\
\hline & & Proximidade de infra-estrutura de transportes a áreas protegidas & 0,121 & 0,142 \\
\hline & & Resíduos gerados por veículos rodoviários & 0,278 & 0,305 \\
\hline & \multirow{6}{*}{$\frac{\text { 离 }}{\stackrel{\Xi}{\Xi}}$} & Dias por ano em que os padrões de qualidade do ar não são atendidos & 0,109 & 0,180 \\
\hline & & Emissão de gases acidificantes pelos transportes & 0,110 & 0,118 \\
\hline & & Emissão de gases que geram o efeito estufa pelos transportes & 0,093 & 0,109 \\
\hline & & Emissões causadas pelos transportes e intensidade das emissões & 0,188 & 0,254 \\
\hline & & População exposta à poluição do ar causada pelos transportes & 0,292 & 0,247 \\
\hline & & Qualidade do ar & 0,208 & 0,092 \\
\hline & \multirow{4}{*}{ 莺 } & Medidas de minimização de ruído & 0,206 & 0,070 \\
\hline & & Poluição sonora & 0,340 & 0,197 \\
\hline & & População exposta ao ruído acima de $65 \mathrm{~dB}(\mathrm{~A})$ causado pelos transportes & 0,267 & 0,478 \\
\hline & & Ruído de tráfego: exposição e incômodo & 0,187 & 0,255 \\
\hline
\end{tabular}




\begin{tabular}{|c|c|c|c|c|}
\hline \multirow{2}{*}{ שֶ } & \multirow{2}{*}{ Е } & \multirow{2}{*}{ Indicador } & \multicolumn{2}{|c|}{ Peso } \\
\hline & & & Brasil & Portugal \\
\hline \multirow{22}{*}{ 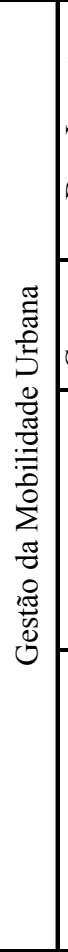 } & \multirow{6}{*}{ 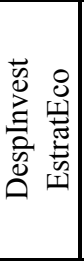 } & Capital investido por modo & 0,195 & 0,173 \\
\hline & & Despesas públicas com transporte privado & 0,055 & 0,051 \\
\hline & & Despesas públicas com transporte público & 0,187 & 0,195 \\
\hline & & Investimentos em infra-estrutura de transportes & 0,308 & 0,239 \\
\hline & & Subsídios diretos aos transportes & 0,162 & 0,152 \\
\hline & & Taxação relativa de veículos e utilização de veículos & 0,094 & 0,190 \\
\hline & \multirow{3}{*}{ 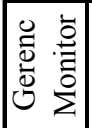 } & Avaliação de impacto ambiental & 0,297 & 0,207 \\
\hline & & Gerenciamento efetivo do tráfego/fiscalização & 0,226 & 0,357 \\
\hline & & Sistemas nacionais para a monitoração dos transportes e meio ambiente & 0,477 & 0,436 \\
\hline & \multirow{6}{*}{ 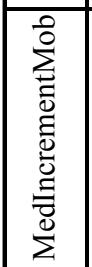 } & Desenvolvimento de planos municipais para a redução das viagens & 0,191 & 0,247 \\
\hline & & Estabelecimento de regulamentação para densidades mínimas na cidade & 0,183 & 0,069 \\
\hline & & Implementação de estratégias ambientais para o setor de transportes & 0,167 & 0,155 \\
\hline & & Medidas: operação eficiente da frota de veículos & 0,155 & 0,117 \\
\hline & & Melhoria dos transportes & 0,171 & 0,289 \\
\hline & & Priorizar viagens eficientes (a pé ou por bicicleta) & 0,132 & 0,123 \\
\hline & \multirow{7}{*}{$\begin{array}{l}\stackrel{8}{0} \\
\stackrel{0}{0} \\
\stackrel{\pi}{0} \\
0 \\
z\end{array}$} & Desenvolv. de combust. limpos e n. de veículos que utilizam combust. alternativos & 0,159 & 0,264 \\
\hline & & Gastos com Pesquisa e Desenvolvimento de "combustíveis limpos" & 0,141 & 0,157 \\
\hline & & Gastos com Pesquisa e Desenvolvimento de "veículos ecológicos & 0,123 & 0,156 \\
\hline & & Novas formas de transporte & 0,270 & 0,177 \\
\hline & & Possível custo inicial de veículos ecológicos & 0,081 & 0,056 \\
\hline & & Uso de tecnologia de cartões inteligentes & 0,160 & 0,126 \\
\hline & & Vida útil dos veículos ecológicos & 0,066 & 0,065 \\
\hline \multirow{25}{*}{ 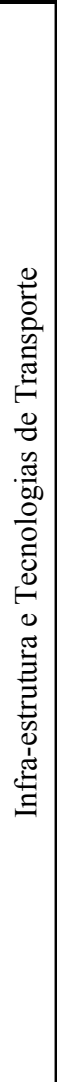 } & \multirow{14}{*}{ 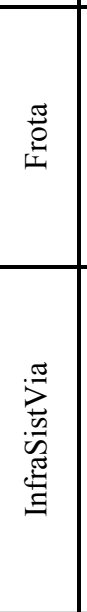 } & Estrutura da frota de veículos rodoviários & 0,157 & 0,072 \\
\hline & & Idade média dos veículos & 0,163 & 0,180 \\
\hline & & Percentagem da frota municipal convertida para reduzir a emissão de poluentes & 0,139 & 0,247 \\
\hline & & Propriedade de automóveis privados & 0,135 & 0,131 \\
\hline & & Relação veículos consumo eficiente de combustível/veículos consumo ineficiente & 0,222 & 0,193 \\
\hline & & Veículos em circulação & 0,183 & 0,177 \\
\hline & & Capacidade das redes de infra-estrutura de transportes & 0,205 & 0,067 \\
\hline & & Comprimento total das vias para ciclistas & 0,112 & 0,075 \\
\hline & & Desenvolvimento de vias para otimizar o fluxo de tráfego & 0,079 & 0,139 \\
\hline & & Estrutura da rede viária & 0,117 & 0,078 \\
\hline & & Extensão total das vias designadas para pedestres & 0,146 & 0,097 \\
\hline & & Número de estacionamentos para carros na cidade & 0,042 & 0,070 \\
\hline & & Possibilidade de acesso de transporte coletivo (pavimentação) & 0,119 & 0,212 \\
\hline & & Provisão de infra-estrutura para traffic calming e vias para bicicletas e pedestres & 0,180 & 0,261 \\
\hline & \multirow{5}{*}{ 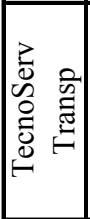 } & Aquisição de bicicletas em cidades menos desenvolvidas & 0,108 & 0,104 \\
\hline & & Mudanças nos modos de transporte & 0,226 & 0,281 \\
\hline & & Tendências do tráfego rodoviário e densidades & 0,280 & 0,274 \\
\hline & & Transporte de carga por modo & 0,124 & 0,102 \\
\hline & & Transporte de passageiros por modo de transporte & 0,262 & 0,240 \\
\hline & \multirow{6}{*}{ 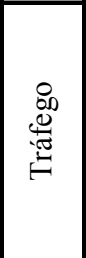 } & Congestionamento de tráfego & 0,262 & 0,216 \\
\hline & & Densidade de tráfego & 0,093 & 0,100 \\
\hline & & Geração de volume de tráfego e tipo & 0,119 & 0,144 \\
\hline & & Taxa de ocupação dos veículos de passageiros & 0,149 & 0,178 \\
\hline & & Tempo total gasto no tráfego & 0,240 & 0,240 \\
\hline & & Velocidade de tráfego & 0,137 & 0,121 \\
\hline
\end{tabular}




\begin{tabular}{|c|c|c|c|c|}
\hline \multirow{2}{*}{ 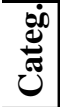 } & \multirow{2}{*}{ 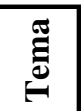 } & \multirow{2}{*}{ Indicador } & \multicolumn{2}{|c|}{ Peso } \\
\hline & & & Brasil & Portugal \\
\hline \multirow{27}{*}{ 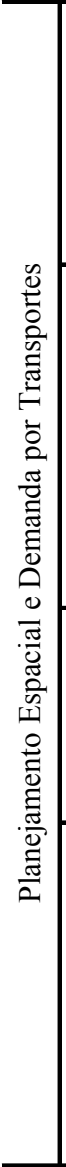 } & \multirow{6}{*}{ 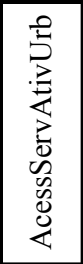 } & Acessibilidade ao bairro & 0,117 & 0,098 \\
\hline & & Acessibilidade ao centro & 0,139 & 0,128 \\
\hline & & Acesso aos serviços básicos & 0,325 & 0,339 \\
\hline & & Acesso aos serviços de transportes & 0,249 & 0,190 \\
\hline & & Percentagem de empregos situados a até $3 \mathrm{~km}$ de distância das residências & 0,115 & 0,179 \\
\hline & & Percentagem de pessoas que vivem a até $3 \mathrm{~km}$ de distância das facilidades de lazer & 0,054 & 0,066 \\
\hline & \multirow{8}{*}{ 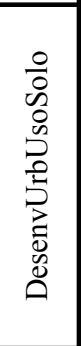 } & Área total em categorias significativas de uso do solo & 0,107 & 0,073 \\
\hline & & Áreas verdes versus áreas destinadas ao automóvel privado & 0,038 & 0,130 \\
\hline & & Desconcentração das atividades & 0,085 & 0,070 \\
\hline & & Forma urbana & 0,184 & 0,092 \\
\hline & & Incentivo ao uso misto/alta densidade & 0,122 & 0,035 \\
\hline & & Mudanças no uso do solo devido a infra-estrutura de transportes & 0,150 & 0,190 \\
\hline & & Planejamento do uso do solo urbano & 0,184 & 0,193 \\
\hline & & Políticas de uso do solo para pedestres, ciclistas e transporte público & 0,131 & 0,217 \\
\hline & \multirow{5}{*}{\begin{tabular}{l}
0 \\
\multirow{2}{0}{} \\
0 \\
0 \\
0
\end{tabular}} & Crescimento do $\mathrm{n}$. de unidades unifamiliares comparado ao crescimento da pop. & 0,051 & 0,094 \\
\hline & & Densidade populacional & 0,352 & 0,362 \\
\hline & & Estrutura etária da população & 0,182 & 0,114 \\
\hline & & Rendimento familiar per capita & 0,186 & 0,113 \\
\hline & & Taxa de crescimento da população & 0,228 & 0,317 \\
\hline & \multirow{8}{*}{ 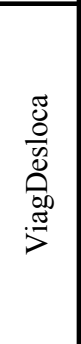 } & Deslocamento de crianças para a escola & 0,045 & 0,098 \\
\hline & & Distância aos serviços básicos & 0,191 & 0,303 \\
\hline & & Distância média entre os moradores e os demais membros de sua família & 0,031 & 0,033 \\
\hline & & Distância percorrida a pé ou por bicicleta per capita por dia & 0,067 & 0,066 \\
\hline & & Mobilidade local e passageiros transportados & 0,269 & 0,170 \\
\hline & & Número de pessoas vivendo e trabalhando no local & 0,113 & 0,062 \\
\hline & & Percent. de pessoas que utilizam o autom. para viagens com dist. inferior a $3 \mathrm{~km}$ & 0,084 & 0,091 \\
\hline & & Tempo de viagem & 0,201 & 0,177 \\
\hline \multirow{21}{*}{ 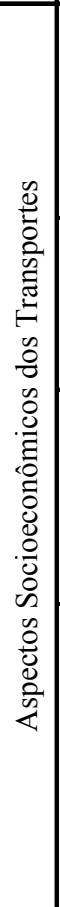 } & \multirow{5}{*}{ 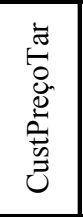 } & Custo por passageiro transportado, corrigido pela inflação & 0,257 & 0,193 \\
\hline & & Evolução dos preços dos diferentes tipos de combustíveis e eletricidade & 0,057 & 0,195 \\
\hline & & Mudanças reais nos preços de transporte por modo & 0,296 & 0,249 \\
\hline & & Preço dos combustíveis e taxas & 0,091 & 0,078 \\
\hline & & Tendências dos preços do transporte público & 0,299 & 0,286 \\
\hline & \multirow{4}{*}{ 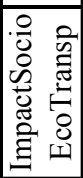 } & Benefícios dos usuários de transportes & 0,394 & 0,230 \\
\hline & & Custos do congestionamento & 0,273 & 0,320 \\
\hline & & Custos sociais dos transportes & 0,262 & 0,378 \\
\hline & & Rendimento dos operadores de transportes & 0,071 & 0,072 \\
\hline & \multirow{5}{*}{ 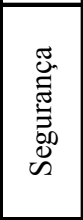 } & Acidentes fatais de transportes & 0,225 & 0,235 \\
\hline & & Feridos por acidentes de tráfego & 0,202 & 0,124 \\
\hline & & Número de crimes violentos ocorridos no trânsito & 0,114 & 0,178 \\
\hline & & Pedestres e ciclistas feridos em acidentes de trânsito & 0,274 & 0,142 \\
\hline & & Segurança e proteção para as vias residenciais & 0,185 & 0,321 \\
\hline & \multirow{7}{*}{ 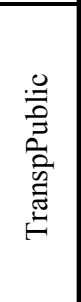 } & Demanda por transporte de passageiros & 0,209 & 0,093 \\
\hline & & Disponibilidade de transporte público & 0,170 & 0,193 \\
\hline & & Fator de diversidade para serviços de transporte & 0,098 & 0,133 \\
\hline & & Necessidade de sistemas de transporte & 0,216 & 0,200 \\
\hline & & Nível de serviço do transporte público e modalidades lentas & 0,150 & 0,103 \\
\hline & & Percentagem de pessoas que consideram o transporte público inseguro & 0,077 & 0,103 \\
\hline & & Percentagem de pessoas que escolhem o transporte público em detrimento ao carro & 0,082 & 0,175 \\
\hline
\end{tabular}




\subsubsection{Análise dos resultados}

A análise realizada nesta seção tem por objetivo extrair, do que foi observado, um conjunto mínimo de indicadores de mobilidade sustentável, de modo a fornecer as bases para o desenvolvimento de sistemas de gestão para as cidades brasileiras e portuguesas incluídas neste estudo. A partir dos pesos obtidos para todos os critérios avaliados nas Fases 2 e 3 e apresentados na seção 7.2.1 deste documento (Categorias, Temas e Indicadores), foram obtidos scores ou valores finais (cuja soma também vale 1) para os 115 indicadores de mobilidade submetidos a análise através do painel de especialistas brasileiros e portugueses. Ou seja, os pesos resultantes para cada critério ou nível de informação foram combinados de modo a gerar um valor final que traduz prioridades para o conjunto de indicadores, considerando de forma particular os resultados obtidos para Brasil e Portugal e, ainda, para os dois países simultaneamente.

Para cada conjunto de scores foram extraídos a média e o desvio padrão, utilizados para delimitar as diferentes classes de indicadores para cada país. As Figuras 19 e 20 ilustram os resultados obtidos para Brasil e Portugal, respectivamente. Nas mesmas, o eixo das abcissas corresponde à média dos scores. Já a distância entre as linhas horizontais (limites das classes de indicadores) corresponde ao desvio padrão obtido para cada conjunto.

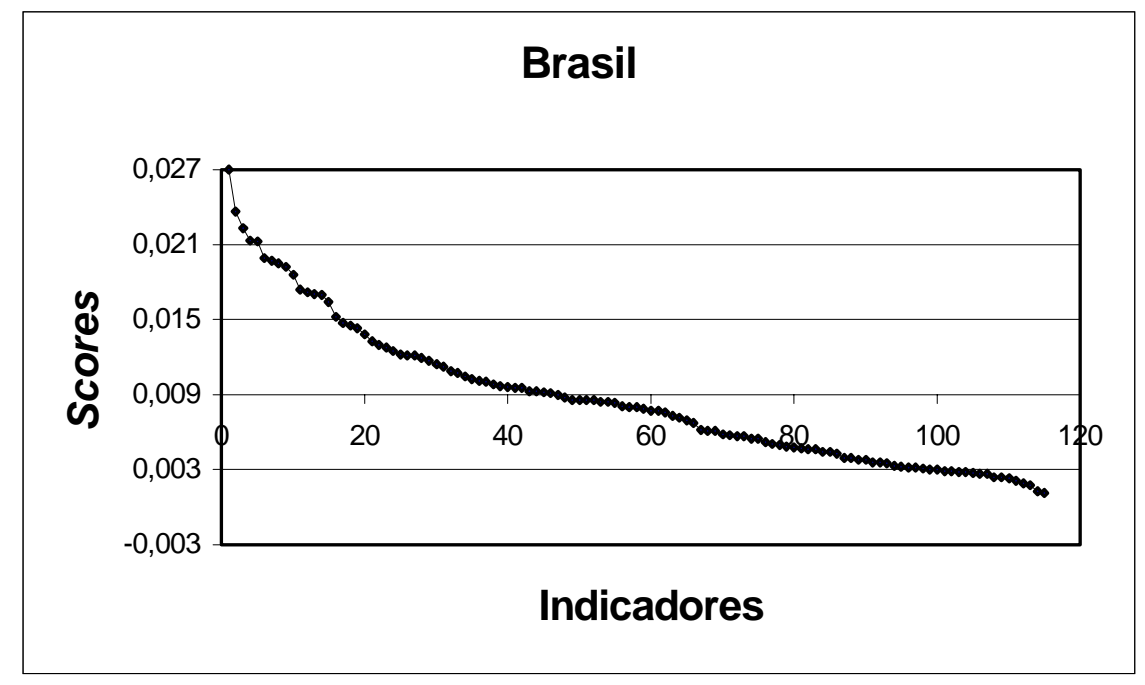

Figura 19: Scores obtidos para os indicadores de mobilidade avaliados pelos especialistas brasileiros 


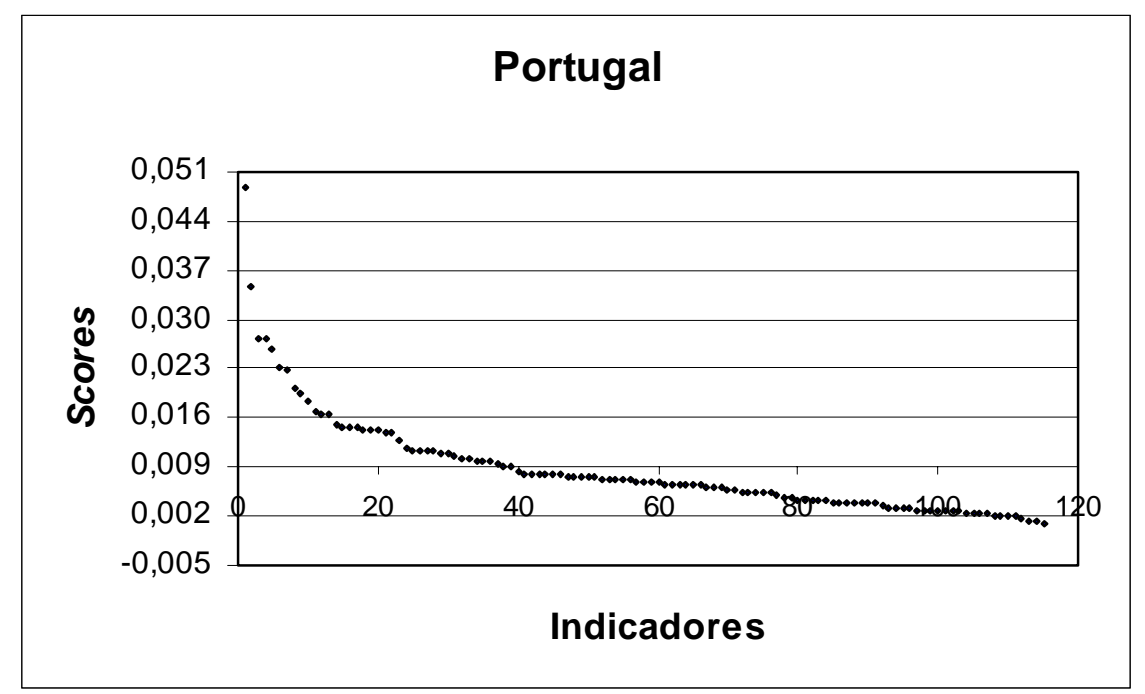

Figura 20: Scores obtidos para os indicadores de mobilidade avaliados pelos especialistas portugueses

Com base nos dados utilizados para a elaboração das Figuras 19 e 20 foram identificados:

- Os grupos de indicadores com melhores scores para Brasil e Portugal, respectivamente. Estes foram considerados como pontos importantes no sentido de desenvolver sistemas de indicadores de mobilidade sustentável para cada país em particular. Para o Brasil, foram identificados 52 Indicadores incluídos nas três primeiras classes (dos maiores para os menores scores, conforme a Figura 19), determinadas a partir do desvio padrão obtido para o conjunto. Estes possuem scores iguais ou superiores à média, incluídos no intervalo de 0,009 a 0,027. Já para Portugal foram identificados um total de 39 Indicadores incluídos nas seis primeiras classes (dos maiores para os menores scores, conforme a Figura 20), determinadas com base no desvio padrão obtido para o conjunto. Estes indicadores possuem scores iguais ou superiores à média, incluídos no intervalo de 0,009 a 0,051 ;

- Os grupos de indicadores com menores scores para Brasil e Portugal, respectivamente. Para o Brasil foram identificados 8 Indicadores com scores inferiores a 0,003 , pertencentes à quinta ou última categoria determinada com base no desvio padrão, conforme mostrado na Figura 19. Já para Portugal 
foram identificados 3 Indicadores com scores inferiores a 0,002, incluídos na oitava ou última categoria determinada com base no desvio padrão, conforme mostrado na Figura 20. Uma vez que não foram determinados aqui critérios de exclusão para os indicadores avaliados, é sugerido apenas que os indicadores que obtiveram os menores scores sejam desconsiderados em uma proposta final para cada país em particular;

- Os grupos de indicadores com maiores scores, comuns para Brasil e Portugal. Estes constituíram, portanto, as bases para o desenvolvimento de um sistema de indicadores de mobilidade sustentável aplicável no contexto dos dois países.

Para facilitar a avaliação, as Figuras 21 e 22 representam a hierarquia de Categorias, Temas e Indicadores criada para Brasil e Portugal. Nestas figuras estão incluídos os pesos obtidos para cada critério, bem como são mostrados os scores finais atribuídos para cada Indicador, com base na combinação dos valores associados a cada nível de informação. As células hachuradas e com margem mais espessa correspondem aos indicadores que obtiveram os maiores scores a partir da combinação dos pesos para os diferentes critérios para cada país em particular. Já as células assinaladas com um " $\mathrm{X}$ " correspondem aos Indicadores que obtiveram os menores scores, os quais seriam candidatos à exclusão em uma proposta final de sistema de indicadores de mobilidade sustentável.

Para o Brasil, em virtude dos Temas Frota e Infra-estrutura/Sistema viário incluírem Indicadores com os piores resultados e não contemplarem nenhum critério pertencente às categorias superiores, estes poderiam eventualmente ser excluídos do sistema proposto. Já para Portugal poderia ser considerada a possível exclusão dos Temas Energia/Combustíveis, Frota e Custos/Preços/Tarifas, uma vez que estes incluíram indicadores com scores inferiores e não contemplaram nenhum critério das categorias superiores. Os demais indicadores incluídos no intervalo de 0,008 a 0,003 para o Brasil e 0,009 a 0,002 para Portugal foram considerados menos relevantes, no entanto, não foi sugerida sua exclusão, dado que estes valores se encontram em uma classe intermediária. 


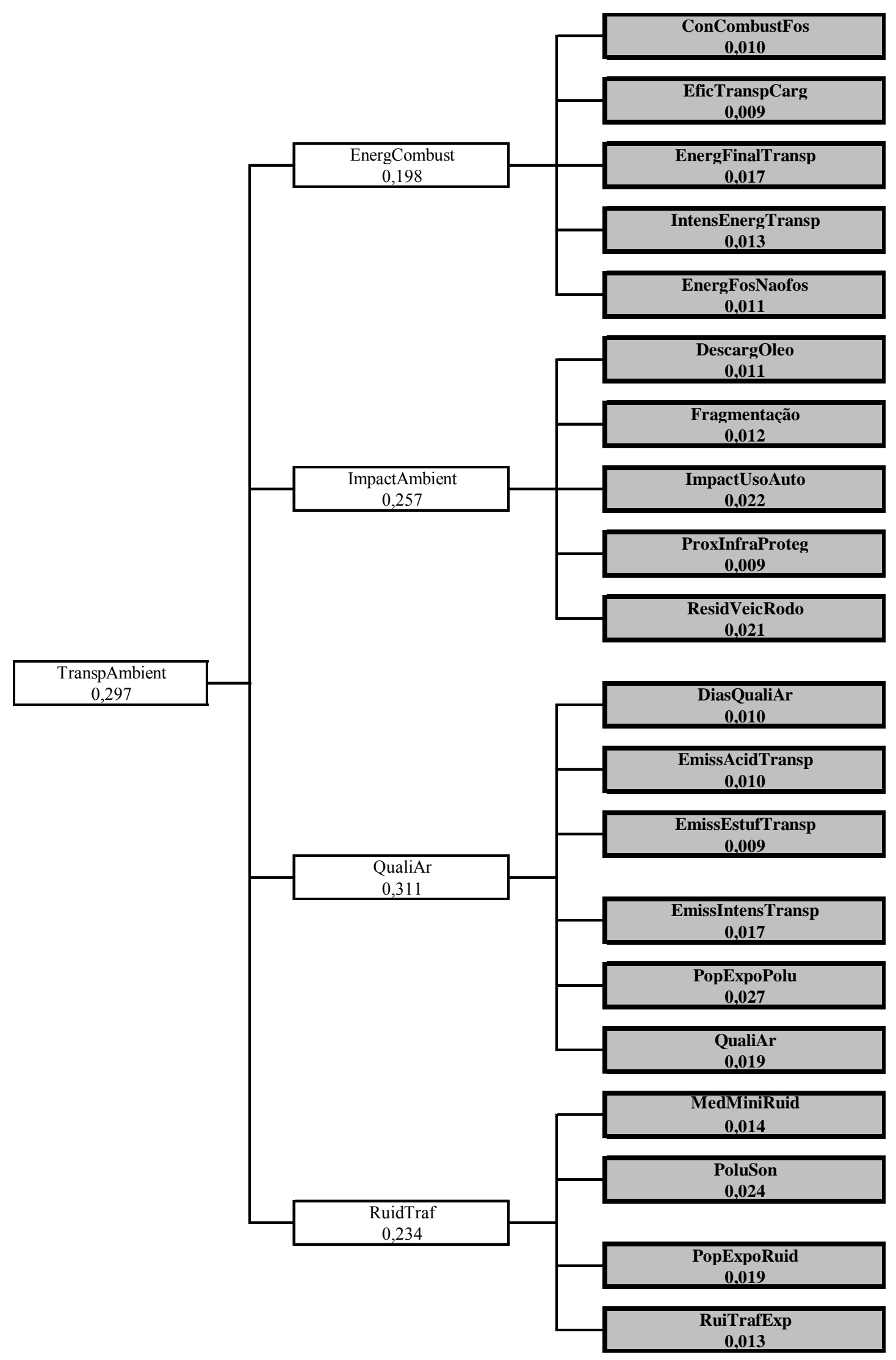

Figura 21: Hierarquia de Categorias, Temas e Indicadores de Mobilidade para o Brasil 


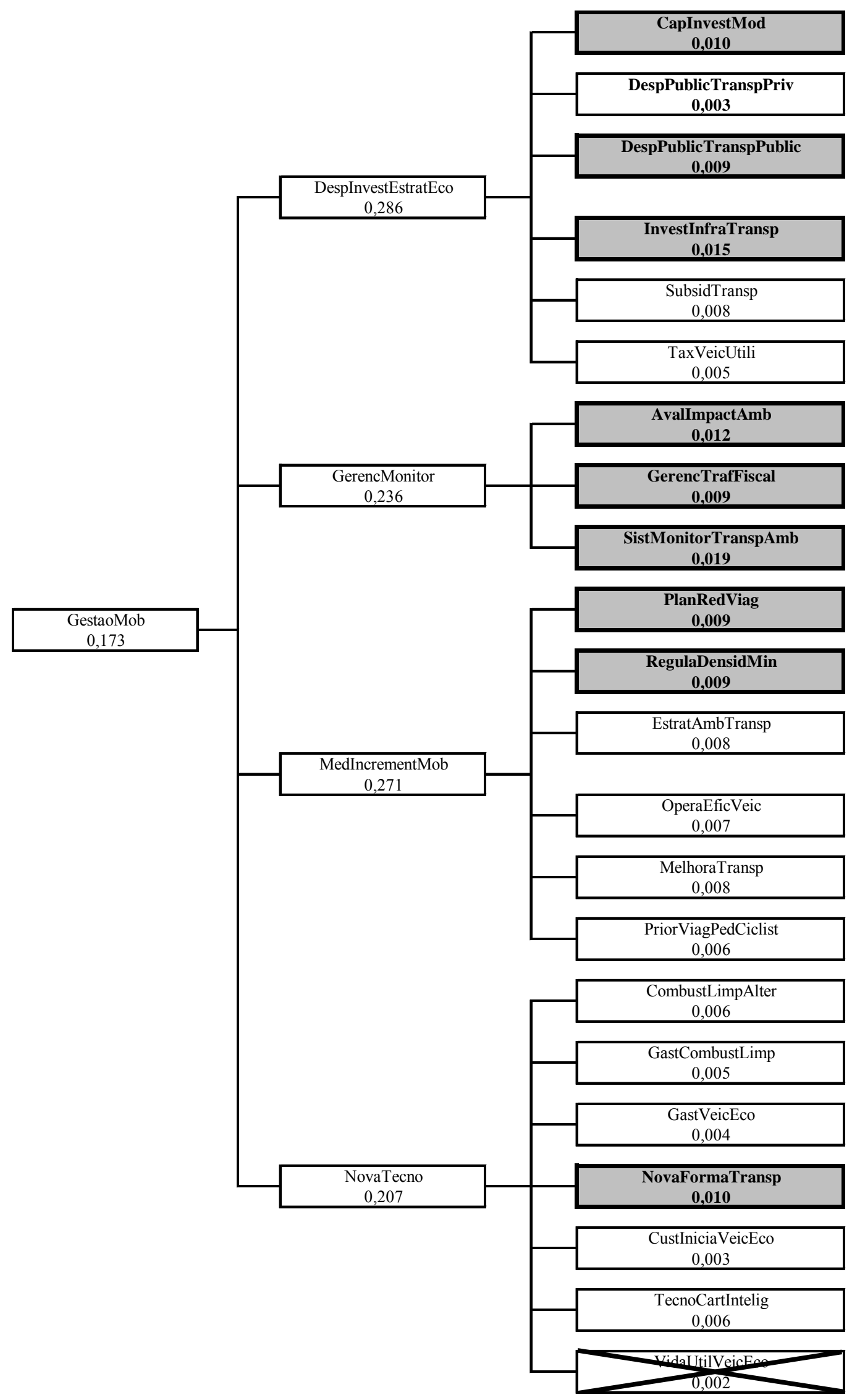

Figura 21: Hierarquia de Categorias, Temas e Indicadores de Mobilidade para o Brasil (continuação) 


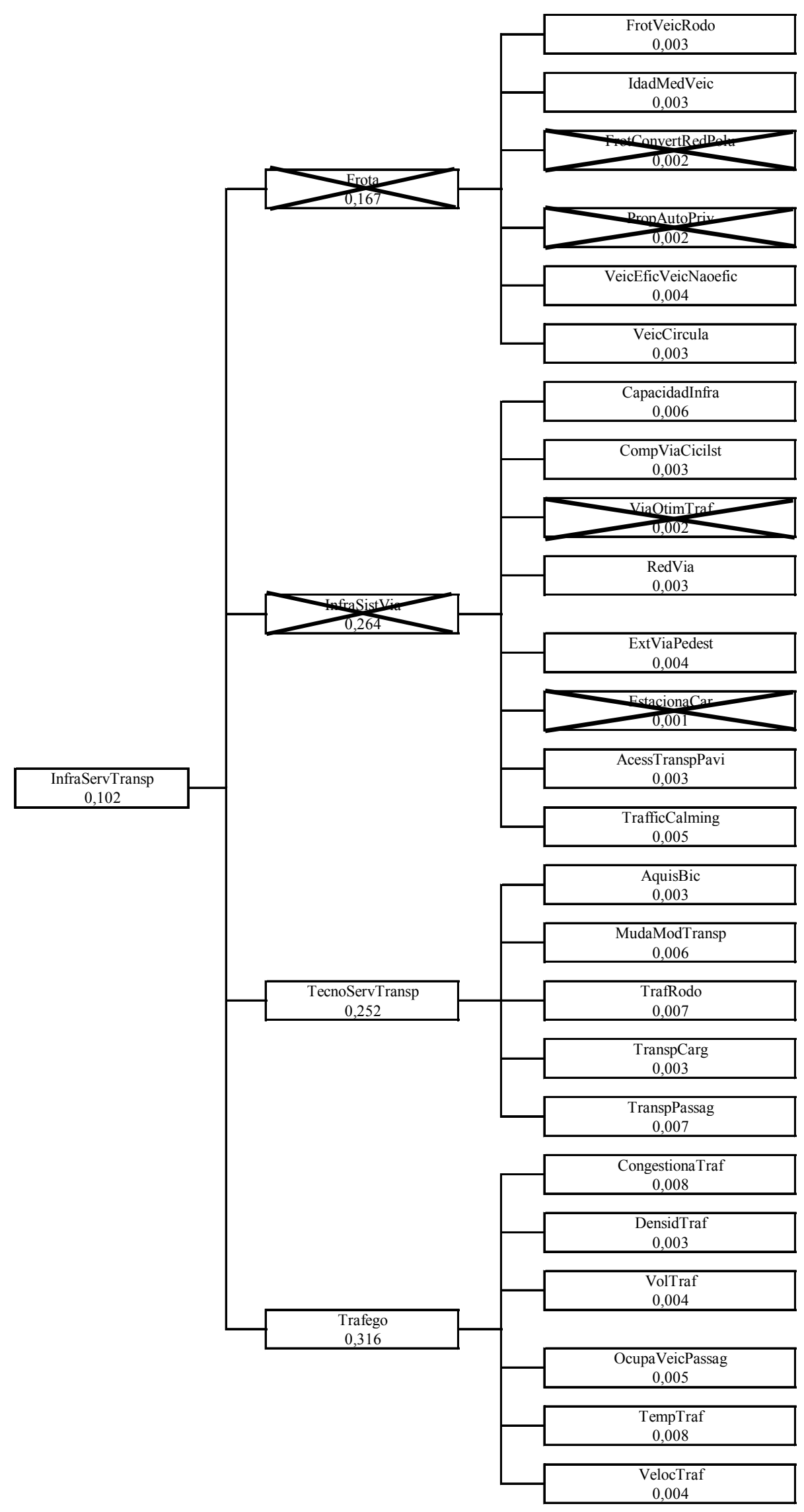

Figura 21: Hierarquia de Categorias, Temas e Indicadores de Mobilidade para o Brasil (continuação) 


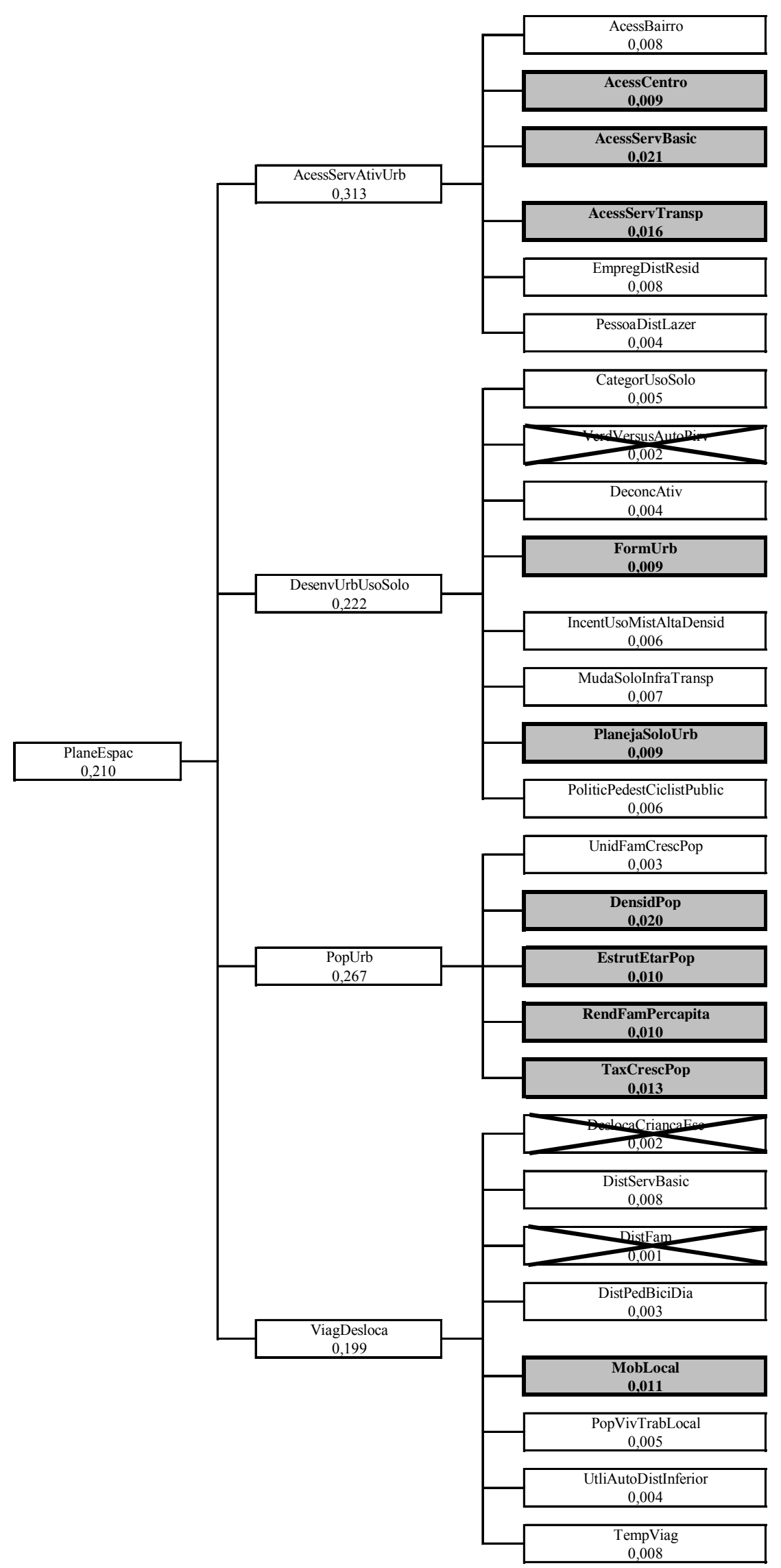

Figura 21: Hierarquia de Categorias, Temas e Indicadores de Mobilidade para o Brasil (continuação) 


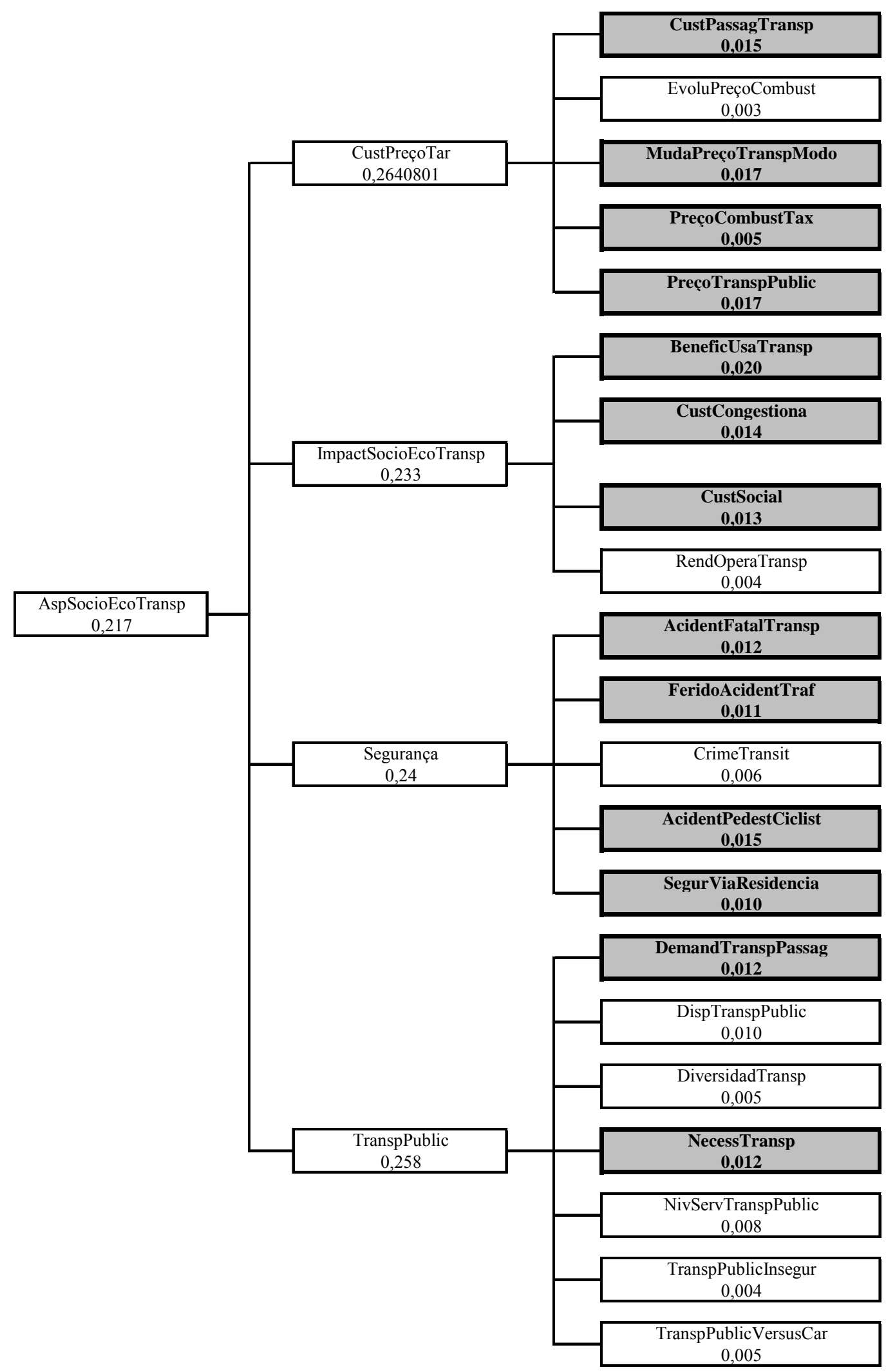

Figura 21: Hierarquia de Categorias, Temas e Indicadores de Mobilidade para o Brasil (continuação) 


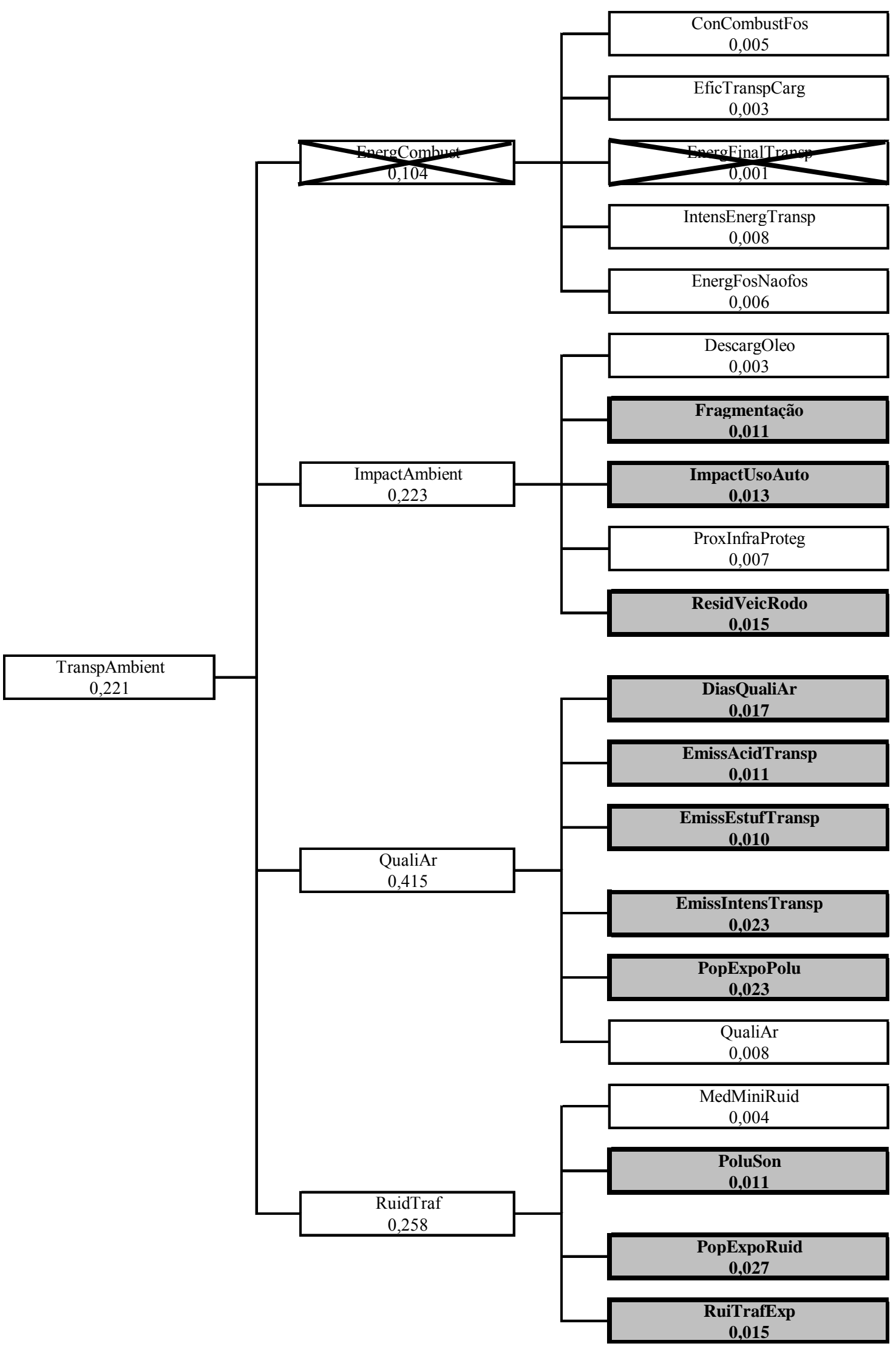

Figura 22: Hierarquia de Categorias, Temas e Indicadores de Mobilidade para Portugal 


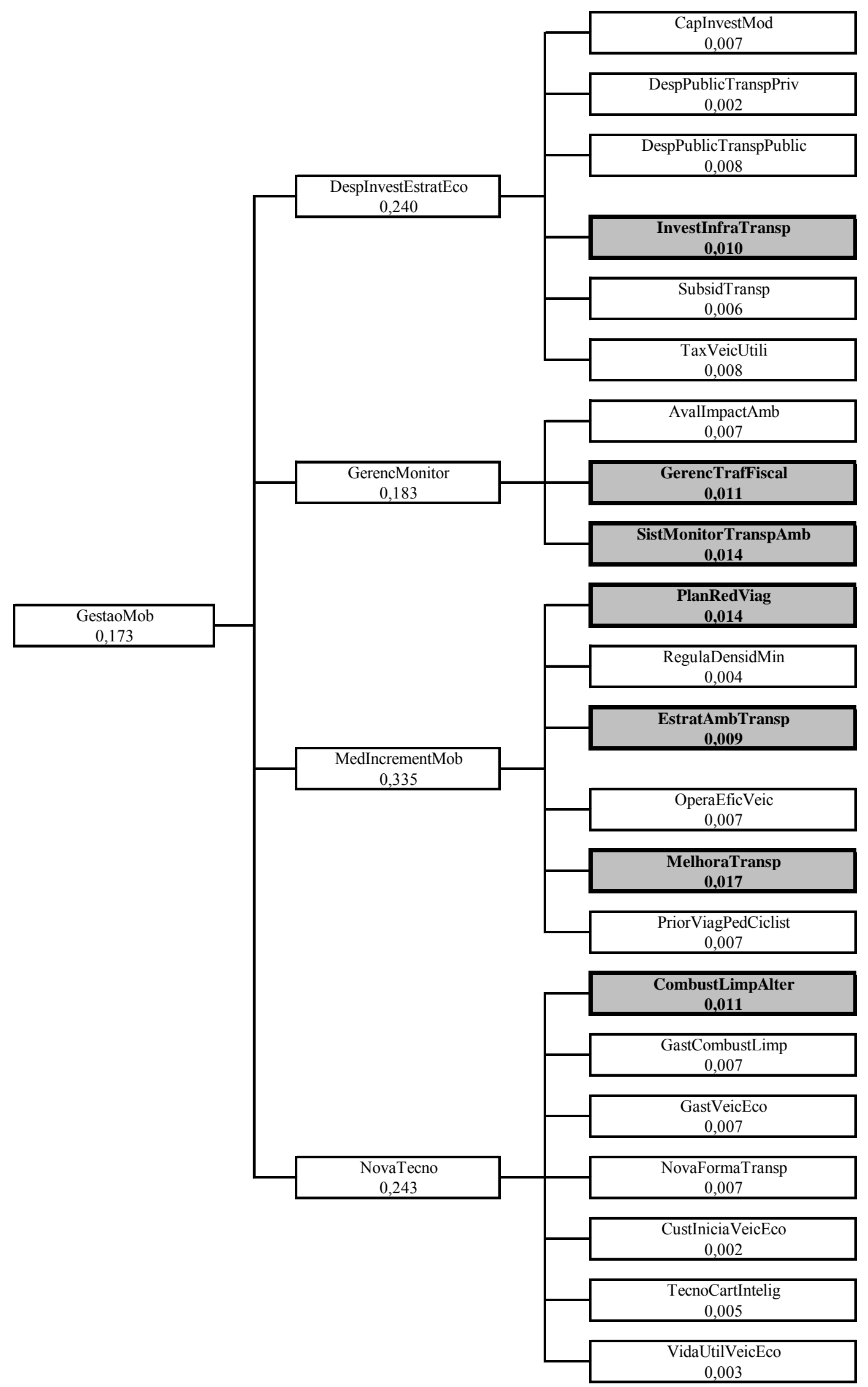

Figura 22: Hierarquia de Categorias, Temas e Indicadores de Mobilidade para Portugal. (continuação) 


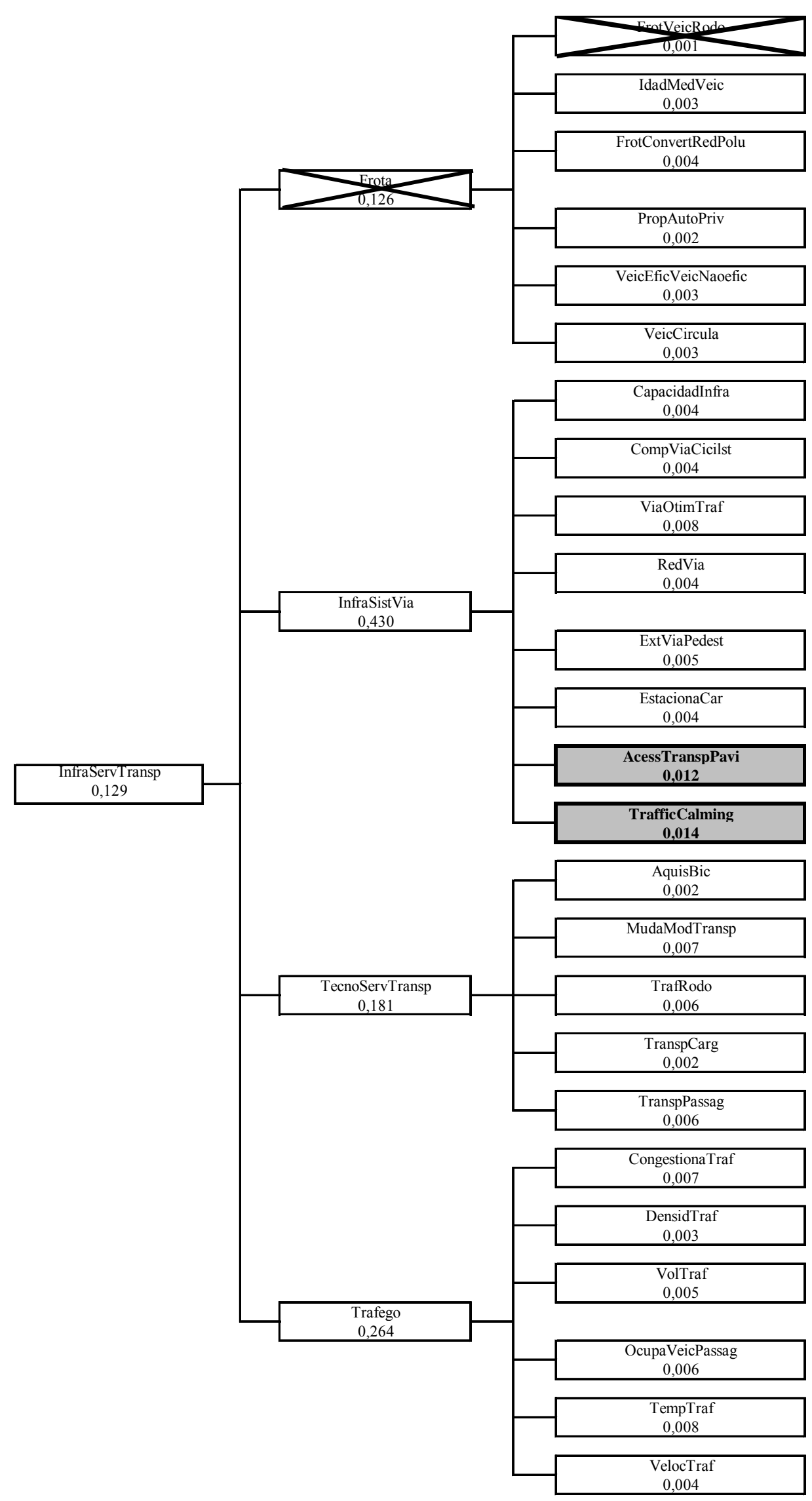

Figura 22: Hierarquia de Categorias, Temas e Indicadores de Mobilidade para Portugal. (continuação) 


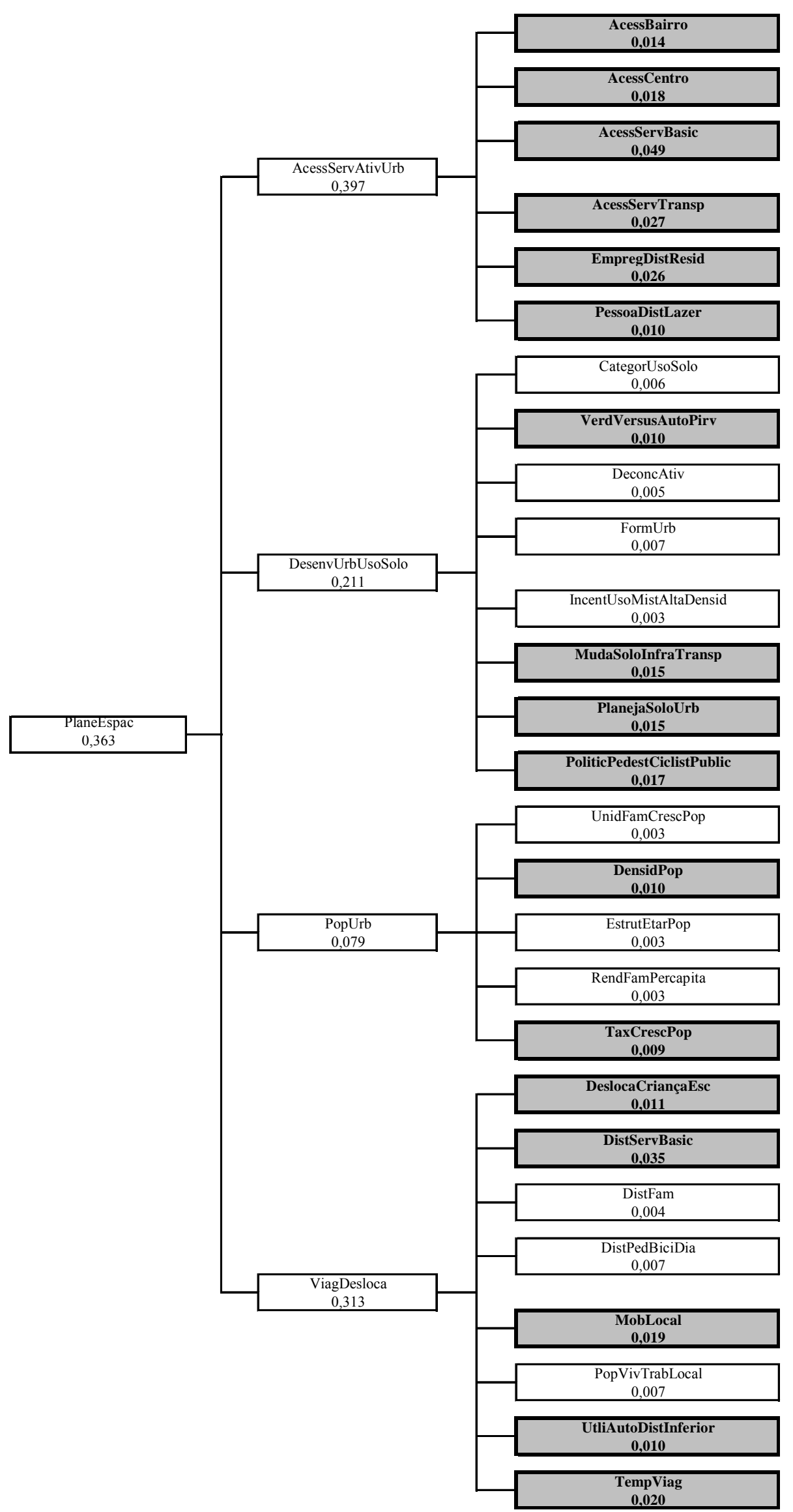

Figura 22: Hierarquia de Categorias, Temas e Indicadores de Mobilidade para Portugal. (continuação) 


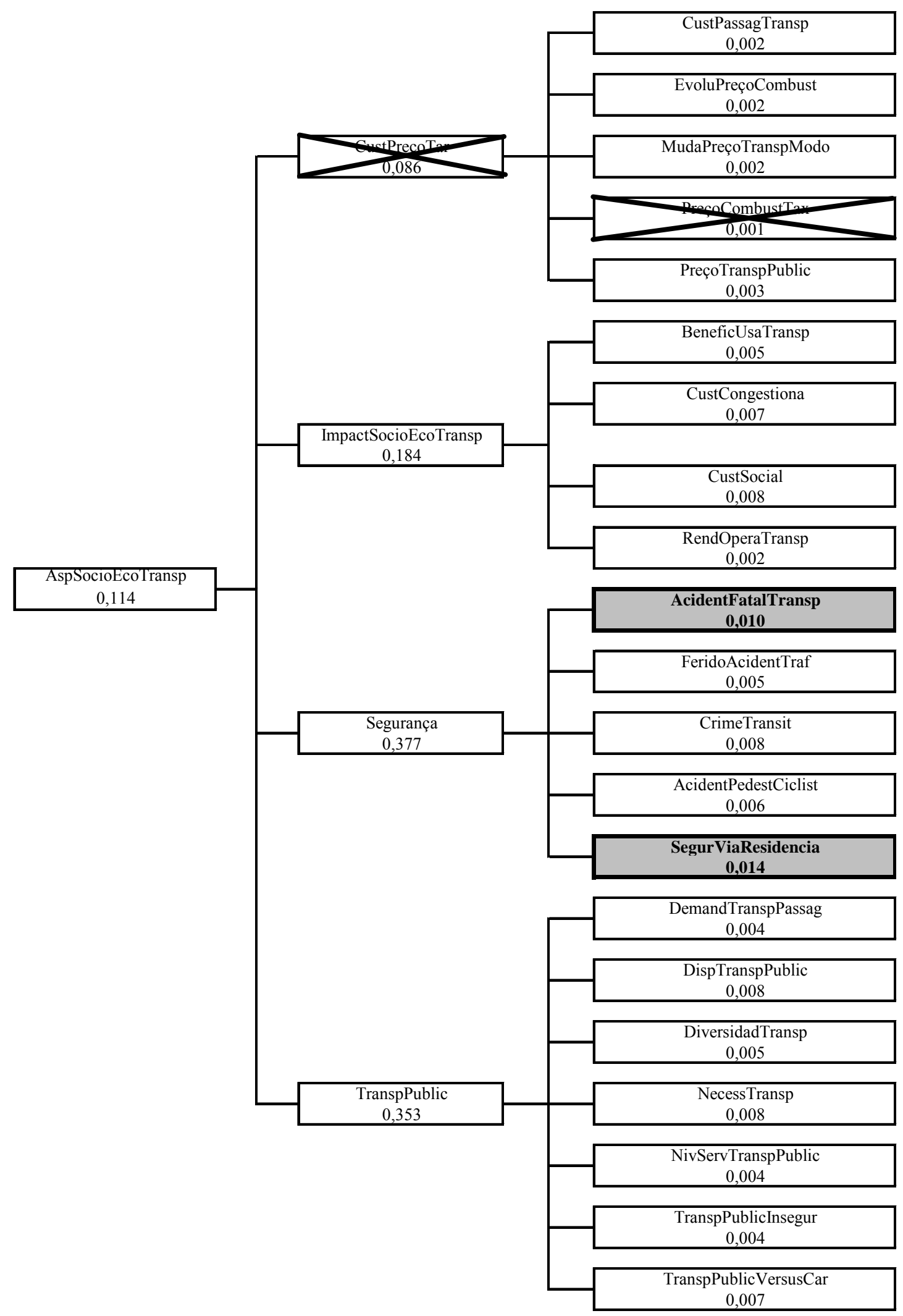

Figura 22: Hierarquia de Categorias, Temas e Indicadores de Mobilidade para Portugal. (continuação) 
No que diz respeito ao desenvolvimento de um sistema comum de indicadores de mobilidade sustentável para Brasil e Portugal poder-se-ia sugerir os indicadores que obtiveram os melhores resultados para os dois países em simultâneo (ou seja, aqueles destacados através da margem mais espessa e hachura nas Figuras 20 e 21), a partir da análise realizada pelos profissionais e especialistas. Estes indicadores, em sua maioria, relacionam-se à questão dos Transportes e Meio Ambiente e ao Planejamento Espacial e Demanda por Transportes, contemplando ainda onze dos vinte Temas avaliados neste trabalho. Para os dois países foi desconsiderada a Categoria Infraestrutura e Tecnologias de Transporte por incluir os indicadores que obtiveram os menores scores. A estrutura contendo os 24 indicadores que poderiam constituir as bases de um sistema de gestão da mobilidade comum aos dois países é mostrada na Tabela 16.

Tabela 16: Estrutura de Categorias, Temas e Indicadores comum à Brasil e Portugal

\begin{tabular}{|c|c|c|c|}
\hline Categoria & Tema & ID & Indicador \\
\hline \multirow{11}{*}{ TranspAmbient } & \multirow{3}{*}{ ImpactAmbient } & $\mathrm{A} 2$ & Fragmentação \\
\hline & & $\mathrm{A} 2$ & ImpactUsoAuto \\
\hline & & A2 & ResidVeicRodo \\
\hline & \multirow{5}{*}{ QualiAr } & A3 & DiasQualiAr \\
\hline & & A3 & EmissAcidTransp \\
\hline & & A3 & EmissEstufTransp \\
\hline & & A3 & EmissIntensTransp \\
\hline & & A3 & PopExpoPolu \\
\hline & \multirow{3}{*}{ RuidTraf } & A4 & PoluSon \\
\hline & & A4 & PopExpoRuid \\
\hline & & A4 & RuiTrafExp \\
\hline \multirow{4}{*}{ GestaoMob } & DespInvestEstratEco & G5 & InvestInfraTransp \\
\hline & \multirow{2}{*}{ GerencMonitor } & G6 & GerencTrafFiscal \\
\hline & & G6 & SistMonitorTranspAmb \\
\hline & MedIncrementMob & G7 & PlanRedViag \\
\hline \multirow{7}{*}{ PlaneEspac } & \multirow{3}{*}{ AcessServAtivUrb } & $\mathrm{P} 13$ & AcessCentro \\
\hline & & $\mathrm{P} 13$ & AcessServBasic \\
\hline & & $\mathrm{P} 13$ & AcessServTransp \\
\hline & DesenvolvUrbUsoSolo & P14 & PlanejaSoloUrb \\
\hline & \multirow{2}{*}{ PopUrb } & P15 & DensidPop \\
\hline & & $\mathrm{P} 15$ & TaxCrescPop \\
\hline & ViagDesloca & P16 & MobLocal \\
\hline \multirow{2}{*}{ AspSocioEcoTransp } & \multirow{2}{*}{ Segurança } & S19 & AcidentFatalTransp \\
\hline & & $\mathrm{S} 19$ & SegurViaResidencia \\
\hline
\end{tabular}




\subsection{Confronto dos resultados obtidos a partir do inventário de indicadores urbanos e da análise de indicadores de mobilidade}

Nesta seção os resultados obtidos a partir do inventário de indicadores urbanos apresentados no item 7.1 deste documento são confrontados com os resultados apresentados para os indicadores de mobilidade avaliados, de modo a identificar se as cidades melhor classificadas para Brasil e Portugal dispõem de fato de instrumentos efetivos para a monitoração da mobilidade urbana.

Para o Brasil as cidades que atingiram os mais altos scores foram Ribeirão Preto (SP) e Juiz de Fora (MG), ambas apresentando, em suas páginas na Internet, dados específicos sobre mobilidade urbana. Para Ribeirão Preto estes dados eram constituídos, de um modo geral, por informações sobre transporte público, incluindo mapas com os itinerários das linhas urbanas e os horários de atendimento. Tais informações permitem estimar, entre outros, o tempo médio de viagem, assim como a distância média viajada, a cobertura do transporte coletivo, o tempo médio de espera, sendo extremamente úteis para a população que utiliza esta modalidade de transporte.

Já para a cidade de Juiz de Fora os dados sobre mobilidade urbana compreendiam informações sobre infra-estrutura de transportes, número de usuários do transporte coletivo, frota de veículos de transporte público e privado. Para esta cidade encontravam-se disponíveis também mapas retratando a evolução da mancha urbana, informações sobre sua evolução demográfica e planos para o sistema viário.

No que diz respeito aos critérios considerados fundamentais para a monitoração da mobilidade urbana a parir da avaliação feita pelos especialistas brasileiros, merecem destaque os indicadores relacionados às questões ambientais e aos impactos produzidos pelos transportes, os quais obtiveram os melhores resultados para todo o conjunto avaliado, seguidos pelos indicadores dirigidos às questões socioeconômicas ligadas principalmente aos custos do transporte urbano.

Com base nos dados obtidos para as cidades melhor classificadas e nos indicadores apontados como de maior importância segundo a opinião dos profissionais brasileiros, constata-se que as cidades brasileiras encontram-se desprovidas de uma série de 
informações relevantes para o diagnóstico das condições de mobilidade em nível urbano ou que, talvez, não exista interesse por parte das administrações municipais em disponibilizar estes dados para a população. Embora os impactos ambientais e sobretudo os impactos sobre a saúde humana oriundos dos transportes tenham se revelado uma preocupação principal, estes estiveram ausentes na análise desenvolvida para as cidades brasileiras. Neste sentido é fundamental que os centros urbanos estejam melhor preparados no sentido de oferecer à sua comunidade informações sobre estas questões. Já no que diz respeito aos dados relacionados às questões socioeconômicas dos transportes, estes foram contemplados em maior número para as cidades brasileiras.

Para Portugal as cidades melhor classificadas segundo análise de suas páginas na Internet foram Sines e Vendas Novas, localizadas na região do Alentejo; Aveiro, pertencente à região Centro; e Trofa, localizada na região Norte do país. Para Sines, os dados disponíveis são relacionados aos acidentes de trânsito e planos urbanísticos, incluindo informações sobre o sistema viário da cidade. Os dados obtidos para o Concelho de Vendas Novas dizem respeito ao tráfego na zona urbana e aos deslocamentos pendulares realizados para o trabalho. Já para Aveiro encontram-se disponíveis informações sobre trânsito, incluindo alterações nos sentidos das vias, obras de infra-estrutura, entre outras. Finalmente para a cidade de Trofa são apresentados mapas de poluição do ar para a área urbana, incluindo a concentração de poluentes como $\mathrm{SO}_{2}, \mathrm{NO}_{2}$ e $\mathrm{O}_{3}$, além de informações sobre campanhas como o "Dia Europeu Sem Carros", iniciativa da qual a cidade é signatária.

No que diz respeito aos indicadores de mobilidade considerados relevantes com base na opinião dos especialistas portugueses consultados, estes são relacionados, de um modo geral, à acessibilidade em nível urbano, principalmente no que se refere ao acesso aos serviços essenciais e aos serviços de transportes. Na prática, no entanto, do mesmo modo que as cidades brasileiras, as cidades portuguesas têm disponibilizado um número restrito de dados sobre mobilidade urbana, pelo menos através da Internet, o que impede um diagnóstico mais detalhado se suas condições em nível urbano.

Ainda que iniciativas em promover o conceito de mobilidade sustentável nas cidades portuguesas já sejam uma realidade, para o engajamento ainda maior da comunidade e 
para o amplo conhecimento dos resultados obtidos através das campanhas promovidas é necessário que um maior número de informações estejam acessíveis ao público.

Realizadas as considerações a respeito dos indicadores de mobilidade disponíveis para as cidades brasileiras e portuguesas e os que de fato são considerados relevantes para o contexto de cada país, com base na opinião do grupo de especialistas que participou do painel de avaliação aqui proposto, no próximo capítulo são apresentadas as principais conclusões deste trabalho e as sugestões para trabalhos futuros. 


\section{CONCLUSÕES E SUGESTÕES PARA TRABALHOS FUTUROS}

A necessidade de implementação de princípios e diretrizes de sustentabilidade, bem como a monitoração dos elementos que caracterizam o ambiente urbano, torna-se cada vez mais evidente à medida que ampliam-se os problemas ambientais, econômicos e sociais responsáveis pelo declínio da qualidade de vida em nossas cidades. Desta forma, os indicadores tornam-se instrumentos fundamentais para promover o conhecimento e a informação necessários para a compreensão das especificidades e problemas presentes nos centros urbanos. Neste sentido, este trabalho buscou contribuir para a identificação de indicadores voltados a monitorar as condições de mobilidade urbana em cidades de Brasil e em Portugal, com base na preocupação principal de promover sua sustentabilidade.

Em um primeiro momento, foram identificadas as principais características geopolíticas de Brasil e Portugal, destacando as semelhanças e diferenças entre os mesmos. Com base nestas questões assumiu-se que seria possível desenvolver um estudo comparativo entre os dois paises, uma vez que os mesmos apresentam algumas semelhanças no que diz respeito à divisão do território e de certa maneira têm apresentado comportamentos parecidos no que se refere ao crescimento e distribuição da população em seus centros urbanos. Para todas estas questões foram observadas, evidentemente, as diferenças de escala existentes entre os dois países.

A revisão bibliográfica contemplada neste trabalho buscou incluir também os principais conceitos relacionados à questão da sustentabilidade e sua inserção no contexto urbano, o uso de indicadores para sua monitoração, além de aspectos relacionados à mobilidade urbana sustentável. Para Brasil e Portugal, buscou-se identificar as principais iniciativas em promover o conceito em nível nacional, apresentando os principais planos e estratégias que vêm sendo implementados nos dois países. Ainda que estas iniciativas já 
sejam uma realidade, muitas questões ainda merecem maior investigação, principalmente às relacionadas ao desenvolvimento de indicadores de sustentabilidade para o contexto das cidades brasileiras e portuguesas.

De modo a promover um diagnóstico inicial sobre a disponibilidade de indicadores urbanos e de mobilidade para estas cidades, foi realizado um inventário com base nas informações obtidas em suas páginas oficiais na Internet. Além de identificar os dados já disponíveis para os centros urbanos dos dois países, buscou-se avaliar se a Internet constitui um instrumento efetivo de comunicação do poder público com a comunidade a qual deve servir.

Em virtude do tempo e dos custos relacionados à aquisição dos dados necessários, a utilização da Internet para a etapa de inventário justificou-se por tornar rápido e fácil o acesso ao conjunto de informações disponíveis para as cidades, permitindo assim incluir um número maior de centros urbanos para análise. No entanto a utilização desta ferramenta pode apresentar algumas desvantagens. Dentre elas, estão a falta de referências para muitas das informações disponíveis e mesmo a constante mudança no conteúdo de cada página.

Os resultados obtidos por meio do inventário mostraram que tanto no Brasil como em Portugal, ao menos no tocante dos meios de acesso público via Internet, o que deve refletir com razoável fidelidade o conjunto de informações de fato disponíveis para os municípios analisados, existe uma carência de informações e dados que permitam hoje a monitoração das condições urbanas, principalmente no que se refere às questões relacionadas à mobilidade.

Mesmo que a disponibilidade de páginas oficiais para as cidades pesquisadas já seja uma realidade, a pesquisa revelou que o conteúdo das mesmas ainda é bastante limitado, abrangendo um número restrito de informações e não contemplando muitos dos temas relevantes ao diagnóstico das condições dos principais centros urbanos brasileiros e portugueses. Esta situação pode refletir não só a inexistência de informações nos dois países, como pode revelar o não interesse por parte das administrações municipais em disponibilizá-las à população. No entanto, o desenvolvimento de instrumentos efetivos de comunicação com a comunidade irá permitir que a mesma acompanhe as 
transformações ocorridas em sua cidade, além de tornar mais efetiva sua participação no sentido de implementar o conceito de desenvolvimento sustentável em nível urbano.

No que diz respeito à classificação das cidades pesquisadas conforme a disponibilidade de informação em suas páginas na Internet os resultados mostraram que, para o Brasil, as duas cidades com mais altos scores, ou seja, para as quais já encontravam-se disponíveis um maior número de informações e ainda dados sobre mobilidade urbana, possuíam população superior a 400 mil habitantes e estavam localizadas na região mais desenvolvida do país, a região Sudeste. Cabe destacar que para o Brasil foram analisadas cidades com população entre 34 mil e 800 mil habitantes, o que significa que as cidades melhor classificadas possuíam população elevada, se consideradas as demais cidades avaliadas para o país. Já para Portugal estes resultados não pareceram estar ligados ao tamanho da população urbana, uma vez que as cidades que atingiram os maiores scores não estavam incluídas na faixa de população mais elevada dentre todas as analisadas. Para Portugal, foram avaliadas cidades com população entre 2 mil e 180 mil habitantes.

O inventário contribuiu igualmente, para o conhecimento da importância relativa de cada um dos grupos de informação avaliados, com base no julgamento de especialistas e profissionais que exercem atividades ligadas ao planejamento urbano e de transportes no Brasil e em Portugal. Enquanto que para o Brasil a categoria que recebeu o maior peso está relacionada a existência de planos ou estratégias de desenvolvimento em nível urbano, para Portugal a categoria considerada como mais importante está relacionada de forma direta à mobilidade urbana.

Em uma etapa posterior deste trabalho, buscou-se estabelecer um referencial teórico para a questão da mobilidade urbana sustentável, a partir da seleção de experiências em nível nacional e internacional de sistemas de indicadores e da identificação dos principais elementos e atributos que devem ser monitorados no sentido de promover o conceito. Esta seleção buscou incluir um conjunto amplo de indicadores, de modo a cobrir um grande leque de informações relacionadas à sustentabilidade e mobilidade urbanas. Ainda que muitos deste indicadores não tenham sido desenvolvidos para o nível urbano ou mesmo não relacionem de forma direta questões presentes nas cidades, 
foi considerada uma possível adaptação dos mesmos para serem aplicados neste contexto.

Com base neste referencial e na revisão bibliográfica realizada na primeira etapa deste estudo, foi identificada uma estrutura ou hierarquia de Categorias, Temas e Indicadores relacionados à monitoração da mobilidade urbana. O desenvolvimento de uma estrutura como essa permitiu visualizar as relações existentes entre diversos temas e sua contribuição para a questão da mobilidade urbana sustentável, uma vez que para todos os critérios avaliados foram atribuídos pesos, baseados na avaliação de especialistas de Brasil e Portugal. No entanto, cabe destacar que a identificação de uma estrutura como essa por um único pesquisador pode deixar de incluir alguns critérios relevantes para o tema em questão, refletindo um só ponto de vista. Daí a necessidade de desenvolver um trabalho conjunto com outros pesquisadores, de modo a cobrir um amplo leque de informações a respeito dos temas tratados aqui.

A partir dos julgamentos realizados pelos especialistas brasileiros e portugueses foi revelada a importância relativa de cada elemento dentro do sistema como um todo. Optou-se por considerar as avaliações para cada país em particular, de modo a revelar as prioridades para cada contexto distinto e, ainda, o estabelecimento de uma estrutura comum através da comparação dos critérios melhor classificados para Brasil e Portugal simultaneamente.

Enquanto que para o Brasil, as Categorias e Temas considerados mais importantes estavam relacionados, de um modo geral, às questões ambientais, principalmente no que diz respeito à poluição provocada pelos sistemas de transportes, para Portugal estes temas tratavam de questões relacionadas ao planejamento espacial e demanda por transportes. Tais diferenças já eram esperadas, uma vez que os países analisados inserem-se em contextos distintos e enfrentam problemas diferenciados no que diz respeito ao meio ambiente e à gestão e organização do seu território. Para o Brasil merece destaque, igualmente, a importância atribuída aos indicadores incluídos na Categoria Aspectos Socioeconômicos dos Transportes, principalmente aqueles relacionados aos custos e tarifas de transporte. 
Para os dois países, os critérios relacionados à monitoração da Infra-estrutura e Tecnologias de Transporte foram considerados menos relevantes dentre todos avaliados. Assim, para um sistema de indicadores comum aos mesmos poder-se-ia, eventualmente, desconsiderar os critérios relacionados a esta Categoria de informação diante dos baixos scores obtidos.

Cabe destacar ainda para o contexto de Brasil e Portugal, a importância atribuída aos critérios relacionados à acessibilidade em nível urbano, principalmente o acesso aos serviços essenciais e aos serviços de transporte. Questões sobre segurança viária e monitoração do crescimento e concentração da população nas áreas urbanas de modo a auxiliar na previsão da demanda por transportes também foram consideradas como extremamente relevantes no contexto dos dois países.

Com relação a trabalhos futuros, para um diagnóstico mais completo sobre as informações disponíveis para as cidades de Brasil e Portugal, recomenda-se o desenvolvimento de uma metodologia que contemple uma avaliação direta ou "in loco", de modo a verificar se os dados apresentados via Internet, de fato representam os dados disponíveis para as cidades pesquisadas (ou pelo menos para parte delas). No que diz respeito à identificação de indicadores de mobilidade sugere-se a participação de múltiplos avaliadores, inclusive na etapa de pré-seleção dos critérios a serem avaliados, a fim de incluir um número maior questões relacionadas ao tema. Do mesmo modo, recomenda-se a inclusão não só de especialistas das áreas de planejamento urbano e de transportes como outros segmentos da sociedade no processo de avaliação dos indicadores selecionados, de forma a garantir a ampla participação da comunidade no processo de identificação de instrumentos voltados a implementar o conceito de sustentabilidade no seu contexto.

Os indicadores identificados aqui podem servir ainda como base para a proposição de um índice global de sustentabilidade para as cidades brasileiras e portuguesas. Neste sentido será necessário também o estabelecimento de parâmetros de comparação que possam indicar o quanto um determinado centro urbano se aproxima ou se distancia da sustentabilidade. É fundamental ainda avaliar o quanto as questões relacionadas à mobilidade urbana têm contribuído para o desenvolvimento sustentável das cidades brasileiras e portuguesas. 


\section{REFERÊNCIAS}

ALBERGARIA, H. (1999). A dinâmica populacional das cidades portuguesas do continente. Revista de Estatística, Lisboa, Portugal, v. 2, n. 11, p.46-47.

AMBIENTE ITALIA RESEARCH INSTITUTE (2003). Development, refinement, management and evaluation of European Common Indicators Project (ECI). Final Report. Milão, Itália. Disponível em: <http://www.sustainable-cities.org/indicators/>. Acesso em: 3 jul. 2003.

AMORIM F ${ }^{\mathrm{O}}$, O.; SERRA, R. V. (2001). Evolução e perspectivas do papel das cidades médias no planejamento urbano e regional. In: THOMPSON ALMEIDA ANDRADE E RODRIGO VALENTE SERRA (org). Cidades Médias Brasileiras. Rio de Janeiro: Instituto de Economia Aplicada. Cap. 1, p.1-34.

ANDRADE, T. A.; SERRA, R. V. (2001). O desempenho das cidades médias no crescimento populacional brasileiro no período (1970/2000). In: THOMPSON ALMEIDA ANDRADE E RODRIGO VALENTE SERRA (org). Cidades Médias Brasileiras. Rio de Janeiro: Instituto de Economia Aplicada. Cap. 4, p.129-169.

ANTP - ASSOCIAÇÃO NACIONAL DE TRANSPORTES PÚBLICOS (2003a). ANTP participa de formulação de política de mobilidade sustentável da UITP. Informativo ANTP, São Paulo, n. 104, jun/jul.

(2003b). Secretaria diz como trabalhará pela mobilidade sustentável. Informativo ANTP, São Paulo, n 101, maio.

(2003c). ANTP e BNDES começam a definir formato do sistema de informações sobre transporte público e trânsito. Informativo ANTP, São Paulo, n. 102, abril.

BRASIL (2002). Sistema Nacional de Indicadores Urbanos (SNIU). Disponível em: <http://www.planalto.gov.br/sedu>. Acesso em: 10 mar. 2003.

BELL, S; MORSE, S. (1999). Sustainability indicators: measuring the immeasurable? London: Earthscan.

BOSSEL, H. (1997). Finding a comprehensive set of indicators of sustainable development by application of the orientation theory. In: MOLDAN, B. et al (ed.). Sustainability indicators: a report on the project on indicators of sustainable development. New York: Wiley. Cap.1, p. 101-109.

COMISSÃO EUROPÉIA (2001). Documento de consulta para a elaboração de uma estratégia da União Européia em matéria de desenvolvimento sustentável. Disponível em: 〈http://europa.eu.int/comm/environment/eussd/consultation_paper_pt.pdf>. Acesso em: 26 set. 2003. 
DICKEY, J. (2001). New conceptual modeling using QCQ: Hall's "Future Cities". In: INTERNATIONAL CONFERENCE ON COMPUTERS IN URBAN PLANNING AND URBAN MANAGEMENT ON THE EDGE OF THE MILLENIUM, 7, 2001, Honolulu, Hawai. Proceedings...(em CD-ROM).

DIRECÇÃO GERAL DO AMBIENTE (2000). Sistema de indicadores de desenvolvimento sustentável. Lisboa, Portugal: Direcção de Serviços de Informação e Creditação. Disponível em:<http://www.iambiente.pt/sids/sids.pdf> Acesso em: 31 out. 2002.

EEA - EUROPEAN ENVIRONMENT AGENCY (2000). Are we moving in the right direction? Indicators on transport and environment integration in the EU. Environment Issues Series, Copenhagen, n.12.

(2002). Indicators of transport and environment integration (TERM). Disponível em: <http://themes.eea.eu.int/ Sectors_and_activities/transport/indicators>. Acesso em: 22 ago. 2003.

FARINHA, J. (1998) Town planning and transport indicators. In: DONALD BOYD \& TJEERD DEELSTRA (eds.). Indicators for sustainable development. Proceedings of the advanced study course. Patrocinado por Directorate-General XII/D Environment and Climate RTD Programme, European Comission. Delft, The Netherlands: The International Institute for the Urban Environment.

FORMAN, E.; SELLY, M. A. (2001) Decision by objectives: how to convince others that you are right. Disponível em: 〈http://www.expertchoice.com/dbo>. Acesso em: 17 abr. 2003.

GREENE, D.; WEGENER, M. (1997). Sustainable Transport. Journal Transport Geography, v. 5, n. 3, p. 177-190.

GUDMUNDSSON, H.; HÖJER, M. (1996). Sustainable development principles and their implications for transport. Ecological Economics, v. 19, p. 269-282.

HALL, P.; PFEIFFER, U. (2000). Urban Future 21: a Global Agenda for Twenty-First Century Cities. London: Spon.

IBGE - INSTITUTO BRASILEIRO DE GEOGRAFIA E ESTATÍSTICA (2002). Indicadores de desenvolvimento sustentável. Disponível em: <http:// www.ibge.gov. br/ home/geografia/ambientais/ids/ids.pdf>. Acesso em: 09 dez. 2002.

(2003). Censo demográfico 2000: resultados do universo. Disponível em: <http://www.ibge.gov.br>. Acesso em: 10 jan. 2003.

ICLEI - INTERNATIONAL COUNCIL FOR LOCAL ENVIRONMENTAL INITIATIVES (1994). Carta da sustentabilidade das cidades européias (Carta de Aalborg). Aalborg, Dinamarca. Disponível em: <http://www.iclei.org/europe/ ECHARTER.HTM>. Acesso em: 22 nov. 2002. 
(2000). Guia Europeu de planeamento para a Agenda 21 Local: como implementar o Planeamento Ambiental a longo prazo com vista à sustentabilidade. In: DIRECÇÃO-GERAL DO ORDENAMENTO DO TERRITÓRIO E DESENVOLVIMENTO URBANO et al. (eds.). Lisboa: ICLEI.

INE - INSTITUTO NACIONAL DE ESTATÍSTICA (2002). Atlas das cidades de Portugal. Lisboa, Portugal.

INSTITUTO DO AMBIENTE (2002a). Estratégia nacional de desenvolvimento sustentável - ENDS 2002. Disponível em: <http://www.iambiente.pt/docs/5421/ ENDS_dp.pdf>. Acesso em: 26 set. 2003.

(2002b). Painel sectorial institucional - Transportes. Disponível em: <http://www.iambiente.pt/docs/5026/PIENDS2transportes.pdf>. Acesso em: 10 out. 2003.

IPEA - INSTITUTO DE PESQUISA ECONÔMICA APLICADA (1999). Caracterização e tendências da rede urbana do Brasil. Campinas. 2v.

LAUTSO, K. (1998). The SPARTACUS approach to assessing urban sustainability. In: DONALD BOYD \& TJEERD DEELSTRA (eds.). Indicators for sustainable development. Proceedings of the advanced study course. Patrocinado por DirectorateGeneral XII/D Environment and Climate RTD Programme, European Comission. Delft, The Netherlands: The International Institute for the Urban Environment.

LINSTER, M (1997). OECD Indicators for the integration of environmental concerns into transport policies. In: BEDRICH MOLDAN, SUZANNE BILLHARZ \& ROBYN MATRAVERS (org). Sustainability indicators: a report on the project on indicators of sustainable development. New York: Willey.

MACLAREN, V. W. (1996). Urban sustainability reporting. Journal of the American Planning Association, Chicago, v.62, n.2, p.184-202.

MALCZEWSKI, J. (1999). Gis and multicriteria decisioan analysis. New York: John Willey \& Sons.

MINISTÉRIO DO MEIO AMBIENTE (2002). Agenda 21 Brasileira. Disponível em: <http://www.mma.gov.br/port/se/agen21/index.cfm>. Acesso em: 29 set. 2003.

MINISTÉRIO DAS CIDADES (2003). Sistema nacional de indicadores urbanos. Disponível em: < http://www.cidades.gov.br/>. Acesso em: 29 set. 2003.

MOORE, J. A.; JOHNSON, J. M. (1994). Transportation, land use and sustainability. Florida Center for Community Design and Research Disponível em:<http://www. fccdr.usf.edu/projects/tlushtml>. Acesso em: 06 ago. 2003.

MOURELO, A. C. A. (2002). Un sistema de indicadores para avanzar en la movilidad sostenible. In: CONGRESO DE INGENIERÍA DEL TRANSPORTE, 5., 2002 Santander, Espanha. Memorias ... Santander: p.171-180. 
MUNICIPALITY OF METROPOLITAN TORONTO (1995). The state of the environment report: Metropolitan Toronto. Toronto: Metropolitan Toronto Planning Department.

MURDIE, R. A.; RHYME, D.; BATES, J. (1992) Modelling quality of life indicators in Canada: a feasibility analysis. Ottawa: Canada Mortgage and Housing Corporation.

OECD - ORGANISATION FOR ECONOMIC COOPERATION AND DEVELOPMENT (1985). The state of environment. Paris: Organisation for Economic Cooperation and Development.

(1997). Better understanding our cities: the role of urban indicators. Paris: Organisation for Economic Cooperation and Development.

(1999). Indicators for the integration of environmental concerns into transport policies. Disponível em: <http://www.olis.oecd.org/olis/1998doc.nsf/LinkTo/ENVEPOC-SE(98)1-FINAL>. Acesso em: 3 jul. 2003.

NOGUEIRA, C. (1995). Going NUTS. A Folha, Boletim Informativo, União Européia, março/abril, p.11. Disponível em: <http://europa.eu.int/comm/translation/bulletins/ folha/folh11/folh11g.htm>. Acesso em: 30 jun 2003.

PREFEITURA MUNICIPAL DE BELO HORIZONTE (1996). Índice de Qualidade de Vida Urbana (IQVU). Disponível em: <http://www.pbh.gov.br/smpl/iqvu/ >. Acesso em: 3 jul. 2003.

RAMOS, R. A. (2000). Localização industrial: um modelo especial para o noroeste de Portugal. 299p. Dissertação (Doutorado) - Escola de Engenharia, Universidade do Minho, Braga, Portugal. 2000.

RAMOS, R. A.; RODRIGUES, D. S. (2002). Uma introdução às técnicas de avaliação multicritério para planejamento urbano, territorial e de transportes. In: SILVA, A. N. R. (ed). Notas de aula do curso de Modelos de Avaliação Multicritério. São Carlos: Universidade de São Paulo, Escola de Engenharia de São Carlos.

SAATY, T.L. (1977). A scaling method for priorities in hierarchical structures. Journal of Mathematical Psycology, v. 13, n. 3, p.234-281.

. (1980). The Analytic Hierarchy Process. New York McGraw Hill.

(1987). Concepts, theory, and techniques: rank generation, preservation, and reversal in the analytic decision process. Decision Sciences, v. 18, n. 2, p. 157-177.

SILVA, A. N.R.; SOUZA, L.C.L.; MENDES, J.F.G (2002). Planejamento integrado: em busca de desenvolvimento sustentável para cidades de pequeno e médio portes. Projeto de Pesquisa CAPES/GRICES. Universidade de São Paulo, Escola de Engenharia de São Carlos, São Carlos, SP. 
SOUZA, L. C. L.; RAMOS, R. A. R; SILVA, A. N. R.; MENDES, J. F. G. (2003). Cidades sustentáveis: um desafio comum para Brasil e Portugal. In: ENCONTRO NACIONAL SOBRE EDIFICAÇÕES E COMUNIDADES SUSTENTÁVEIS, 3., 2003, São Carlos. Anais... São Carlos. 1 CD-ROM.

SUSTAINABLE MEASURES (2002). Indicators of sustainability. Disponível em: <http://www.sustainablemeasures.com>. Acesso em: 12 nov. 2002.

SUSTAINABLE SEATTLE (1992). Summary of indicators. Disponível em: <http://www.sustainableseattle.org/Publications/listindicators.shtml>.Acesso em: 01 out. 2003.

UITP - UNION INTERNATIONALE DE TRANSPORT PUBLIC (2003). UITP Charter of sustainable development. Disponível em: <http://www.uitp.com/Project/ pics/susdev/Charter/Charter-E.pdf>. Acesso em: 08 out. 2003.

(2003). Ticket to the future - 3 stops to sustainable mobility. Disponível em: <http://www.uitp.com/ Project/pics/susdev/BrochureUK.pdf>. Acesso em: 08 out. 2003.

UNCED - UNITED NATIONS CONFERENCE ON ENVIRONMENT AND DEVELOPMENT (1992). Agenda 21. Disponível em: <http://www.um.org/esa/ sustdev/agenda21.htm>. Acesso em 11 nov. 2002.

UNCHS - UNITED NATIONS CONFERENCE ON HUMAN SETTLEMENTS (1996a). The Habitat Agenda. Istambul, Turquia. Disponível em: <http://www.unchs.org/unchs/english/hagenda/ist-dec.htm>. Acesso em 28 out. 2002.

(1996b). Urban Indicators. Disponível em: <http://www.unhabitat.org/ programmes/guo/guo_indicators.asp>. Acesso em: 25 out. 2002.

UNCSD - UNITED NATIONS COMMISSION ON SUSTAINABLE DEVELOPMENT (1996a). CSD Working list of indicators. Disponível em: <http://www.un.org/esa/sustdev/natlinfo/indicators/worklist.htm>. Acesso em: 27 nov. 2002.

(1996b) Indicators of sustainable development. Methodology Sheets. Disponível em: <http://www.un.org/esa/sustdev/natlinfo/indicators/indisd/indsearch/indchapter. html>. Acesso em: 30 out. 2002.

(2001) Indicators of sustainable development: Guidelines and Methodologies. Disponível em: <http://www.un.org/esa/sustdev/natlinfo/indicators/isdms2001/table_4. htm>. Acesso em: 30 out. de 2002.

UNDSD - UNITED NATIONS DIVISION FOR SUSTAINABLE DEVELOPMENT (2003). Sustainable development issues: energy, transport and atmosphere. Disponível em: <http://www.un.org/esa/sustdev/sdissues/transport/transp.htm>. Acesso em: 09 out. 2003. 
UNIÃO EUROPÉIA (1998). System for Planning and Research in Towns and Cities for Urban Sustainability (SPARTACUS). Disponível em: < http://www.ltcon.fi/spartacus/ default.htm>. Acesso em: 3 jul. 2003.

(2001). Documento de consulta para a elaboração de uma estratégia da União Européia em matéria de desenvolvimento sustentável. Disponível em: <http://europa.eu.int/comm/environment/eussd/consultation_paper_pt.pdf>. Acesso em: 25 set. 2003.

(2002). Mobilidade sustentável: programa de acção 2000-2004. Disponível em: <http://europa.eu.int/scadplus/leg/pt/lvb/124208.htm>. Acesso em: 09 out. 2003.

WCED - WORLD COMISSION ON ENVIRONMENT AND DEVELOPMENT (1987). Our common future (The Brundtland Report). Oxford: Oxford University Press.

WORLD BANK (1996). Sustainable transport: priorities for policy reform. Washington: World Bank.

WYATT, R. (1999). Computer-aided poicymaking: lessons form strategic planning software. London: E \& FN Spon. 
ANEXO A - Cidades pesquisadas no Brasil e em Portugal 
Tabela A-1: Centros urbanos identificados pelo IPEA (1999), ordenados de forma decrescente de acordo com a população urbana do município núcleo em 1996, população urbana em 2000 e respectivas páginas na Internet.

\begin{tabular}{|c|c|c|c|c|c|}
\hline \multicolumn{6}{|c|}{ CENTROS URBANOS BRASILEIROS } \\
\hline \multicolumn{6}{|c|}{$\begin{array}{l}\text { CENTROS REGIONAIS } \\
\end{array}$} \\
\hline \multirow{2}{*}{$\mathbf{N}^{\mathbf{o}}$} & \multirow{2}{*}{ Cidade } & \multirow{2}{*}{$\mathbf{U F}$} & \multicolumn{2}{|c|}{ População } & \multirow{2}{*}{ Página na Internet } \\
\hline & & & 1996 & 2000 & \\
\hline 1 & São Luís & MA & 780.833 & 837.584 & http://www.saoluis.ma.gov.br \\
\hline 2 & Maceió & $\mathrm{AL}$ & 723.230 & 795.804 & http://www.maceio.al.gov.br \\
\hline 3 & Natal & $\mathrm{RN}$ & 656.037 & 712.317 & http://www.natal.rn.gov.br \\
\hline 4 & Teresina & PI & 655.473 & 677.470 & http://www.teresina.pi.gov.br \\
\hline 5 & Campo Grande & MS & 600.069 & 655.914 & http://www.campogrande.ms.gov.br \\
\hline 6 & João Pessoa & PB & 549.363 & 597.934 & http://www.joaopessoa.pb.gov.br \\
\hline 7 & São J. dos Campos & SP & 486.467 & 532.717 & http://www.sjc.sp.gov.br \\
\hline 8 & Ribeirão Preto & SP & 462.351 & 502.760 & http://ribeiraopreto.sp.gov.br \\
\hline 9 & Cuiabá & MT & 433.355 & 476.532 & http://www.cuiaba.mt.gov.br \\
\hline 10 & Santos & SP & 429.245 & 415.747 & http://www.santos.sp.gov.br \\
\hline 11 & Aracaju & SE & 428.194 & 461.534 & http://www.aracaju.se.gov.br \\
\hline 12 & Londrina & PR & 421.343 & 433.369 & http://www.londrina.pr.gov.br \\
\hline 13 & Porto velho & RO & 294.227 & 273.709 & http://www.pmpv.net \\
\hline 14 & Florianópolis & $\mathrm{SC}$ & 271.281 & 332.185 & http://www.pmf.sc.gov.br \\
\hline 15 & Vitória & ES & 265.874 & 292.304 & http://www.vitoria.es.gov.br \\
\hline 16 & Rio Branco & $\mathrm{AC}$ & 228.857 & 226.298 & http://www.pmrb.ac.gov.br \\
\hline \multicolumn{6}{|c|}{ CENTROS SUB-REGIONAIS 1} \\
\hline 17 & Feira de Santana & $\mathrm{BA}$ & 450.487 & 413.730 & http://www.feiradesantana.ba.gov.br \\
\hline 18 & Uberlândia & MG & 438.986 & 488.982 & http://www.uberlandia.mg.gov.br \\
\hline 19 & Sorocaba & $\mathrm{SP}$ & 431.561 & 486.726 & http://www.sorocaba.sp.gov.br \\
\hline 20 & Juiz de Fora & MG & 424.479 & 453.002 & http://www.juizdefora.mg.gov.br \\
\hline 21 & Joinville & $\mathrm{SC}$ & 397.951 & 414.972 & http://www.joinville.sc.gov.br \\
\hline 22 & Campos dos Goitacazes & RJ & 389.547 & 364.177 & http://www.campos.rj.gov.br \\
\hline 23 & Campina Grande & PB & 344.730 & 337.484 & http://www.pmcg.pb.gov.br/ \\
\hline 24 & São J. do Rio Preto & SP & 326.315 & 337.289 & http://www.sjriopreto.gov.br \\
\hline 25 & Caxias do Sul & RS & 326.086 & 333.391 & http://www.caxias.rs.gov.br \\
\hline 26 & Pelotas & RS & 307.667 & 301.081 & http://www.pelotas.rs.gov.br \\
\hline 27 & Jundiaí & SP & 293.373 & 300.207 & http://www.jundiai.sp.gov.br \\
\hline 28 & Bauru & SP & 292.566 & 310.442 & http://www.bauru.sp.gov.br \\
\hline 29 & Imperatriz & MA & 274.104 & 218.673 & http://www.imperatriz.ma.gov.br \\
\hline 30 & Maringá & PR & 267.942 & 283.978 & http://www.maringa.pr.gov.br \\
\hline 31 & Anápolis & GO & 264.975 & 280.164 & http://www.anapolis.go.gov.br \\
\hline 32 & Ilhéus & BA & 242.445 & 162.125 & http://www.ilheus.ba.gov.br \\
\hline 33 & Vitória da Conquista & BA & 242.155 & 225.545 & http://www.pmvc.com.br \\
\hline 34 & Uberaba & MG & 237.433 & 244.171 & http://www.uberaba.mg.gov.br \\
\hline 35 & Volta Redonda & RJ & 232.287 & 241.996 & http://www.voltaredonda.rj.gov.br \\
\hline 36 & Caruaru & PE & 231.989 & 217.407 & http://www.caruaru.com.br* \\
\hline 37 & Blumenau & $\mathrm{SC}$ & 231.401 & 241.943 & http://www.blumenau.sc.gov.br \\
\hline 38 & Limeira & SP & 230.348 & 238.349 & http://www.limeira.sp.gov.br \\
\hline 39 & Macapá & AP & 220.962 & 270.628 & Não foi encontrada \\
\hline 40 & Cascavel & PR & 219.652 & 228.673 & http://www.cascavel.pr.gov.br \\
\hline 41 & Petrolina & $\mathrm{PE}$ & 191.238 & 166.279 & http://www.petrolina.pe.gov.br \\
\hline 42 & Juazeiro do Norte & $\mathrm{CE}$ & 189.161 & 202.227 & http://www.juazeiro.ce.gov.br \\
\hline 43 & Itabuna & $\mathrm{BA}$ & 183.403 & 191.184 & http://www.itabuna.gov.br \\
\hline 44 & Rio Grande & $\mathrm{RS}$ & 178.256 & 179.208 & http://www.riogrande.rs.gov.br \\
\hline 45 & Presidente Prudente & SP & 177.367 & 185.229 & http://www.presidenteprudente.sp. gov.br \\
\hline 46 & São Carlos & SP & 175.517 & 183.433 & http://www.saocarlos.sp.gov.br \\
\hline 47 & Araraquara & SP & 172.746 & 173.569 & http://www.araraquara.sp.gov.br \\
\hline 48 & Juazeiro & BA & 172.065 & 133.278 & http://www.juazeiro.ba.gov.br \\
\hline 49 & Barra Mansa & $\mathrm{RJ}$ & 166.745 & 165.134 & http://www.barramansa.rj.gov.br \\
\hline 50 & Boa Vista & RR & 165.518 & 197.098 & http://www.boavista.rr.gov.br \\
\hline 51 & Dourados & MS & 153.191 & 149.928 & http://www.dourados.ms.gov.br \\
\hline 52 & Crato & $\mathrm{CE}$ & 95.521 & 83.917 & http://www.crato.ce.gov.br \\
\hline 53 & Palmas & TO & 86.116 & 134.179 & http://www.palmas.to.gov.br \\
\hline
\end{tabular}




\begin{tabular}{|c|c|c|c|c|c|}
\hline \multicolumn{6}{|c|}{ CENTROS SUB-REGIONAIS 2} \\
\hline \multirow{2}{*}{$\mathbf{N}^{\mathbf{0}}$} & \multirow{2}{*}{ Cidade } & \multirow{2}{*}{ UF } & \multicolumn{2}{|c|}{ População } & \multirow{2}{*}{ Página na Internet } \\
\hline & & & 1996 & 2000 & \\
\hline 54 & Piracicaba & SP & 302.886 & 317.374 & http://www.piracicaba.sp.gov.br \\
\hline 55 & Montes Claros & MG & 271.608 & 289.183 & http://www.montesclaros.mg.gov.br \\
\hline 56 & Franca & SP & 267.235 & 282.203 & http://www.franca.sp.gov.br \\
\hline 57 & Santarém & PA & 263.468 & 186.297 & http://etfpa.br/santarem* \\
\hline 58 & Ponta Grossa & PR & 256.302 & 266.683 & http://www.pontagrossa.pr.gov.br \\
\hline 59 & Santa Maria & $\mathrm{RS}$ & 233.351 & 230.696 & http://www.santamaria.rs.gov.br \\
\hline 60 & Foz do Iguaçu & $\mathrm{PR}$ & 231.627 & 256.524 & http://fozdoiguacu.pr.gov.br \\
\hline 61 & Governador Valadares & MG & 231.242 & 236.098 & http://www.valadares.mg.gov.br \\
\hline 62 & Mossoró & $\mathrm{RN}$ & 205.822 & 199.081 & http://www.mossoro.rn.gov.br \\
\hline 63 & Ipatinga & MG & 195.793 & 210.895 & http://ipatinga.mg.gov.br \\
\hline 64 & Marília & SP & 177.632 & 189.719 & http://www.pmmarilia.com.br \\
\hline 65 & Arapiraca & $\mathrm{AL}$ & 173.339 & 152.354 & http://www.arapiraca.al.gov.br \\
\hline 66 & Divinópolis & MG & 171.565 & 177.973 & http://www.divinopolis.mg.gov.br \\
\hline 67 & Araçatuba & SP & 169.309 & 164.449 & http://www.aracatuba.sp.gov.br \\
\hline 68 & Nova Friburgo & RJ & 169.246 & 151.851 & http://www.pmnf.rj.gov.br \\
\hline 69 & Sete Lagoas & MG & 167.340 & 180.785 & http://www.setelagoas.mg.gov.br \\
\hline 70 & Jequié & $\mathrm{BA}$ & 165.345 & 130.296 & http://www.jequie.ba.gov.br \\
\hline 71 & Criciúma & $\mathrm{SC}$ & 159.101 & 153.049 & http://www.pmc.com.br* \\
\hline 72 & Passo Fundo & RS & 156.333 & 163.764 & http://www.pmpf.rs.gov.br \\
\hline 73 & Guarapuava & PR & 155.835 & 141.694 & $\mathrm{http} / / / 200.201 .133 .25 / \mathrm{pmgcombr} / \mathrm{home} \cdot \mathrm{html}$ \\
\hline 74 & Cachoeiro do Itapemirim & ES & 150.359 & 155.401 & http://www.cachoeiro.es.gov.br \\
\hline 75 & Marabá & PA & 150.095 & 134.373 & http://www.maraba.pa.gov.br \\
\hline 76 & Lages & $\mathrm{SC}$ & 148.860 & 153.582 & Não foi encontrada \\
\hline 77 & Caxias & MA & 146.045 & 103.485 & Não foi encontrada \\
\hline 78 & Rondonópolis & MT & 142.524 & 141.838 & http://www.rondonopolis.mt.gov.br \\
\hline 79 & Sobral & $\mathrm{CE}$ & 138.565 & 134.508 & http://www.sobral.ce.gov.br \\
\hline 80 & Teófilo Otoni & MG & 136.044 & 102.812 & http://www.pmto.mg.gov.br \\
\hline 81 & Itajaí & $\mathrm{SC}$ & 134.942 & 141.950 & http://www.itajai.com.br \\
\hline 82 & Parnaíba & PI & 131.885 & 124.988 & http://www.parnaiba.pi.gov.br \\
\hline 83 & Chapecó & $\mathrm{SC}$ & 131.014 & 134.592 & http://www.chapeco.sc.gov.br \\
\hline 84 & Linhares & ES & 125.297 & 92.917 & http://www.linhares.es.gov.br \\
\hline 85 & Paranaguá & PR & 124.920 & 122.347 & http://paranagua.pr.gov.br \\
\hline 86 & Uruguaiana & RS & 124.881 & 118.538 & http://www.uruguaiana.rs.gov.br \\
\hline 87 & Alagoinhas & BA & 122.838 & 112.440 & http://www.alagoinhas.ba.gov.br \\
\hline 88 & Poços de Caldas & MG & 121.831 & 130.826 & http://www.pocosdecaldas.mg.gov.br \\
\hline 89 & Castanhal & PA & 117.380 & 121.249 & Não foi encontrada \\
\hline 90 & Cabo Frio & RJ & 115.759 & 106.237 & http://www.cabofrio.rj.gov.br \\
\hline 91 & Mogi-Guaçu & SP & 114.546 & 116.184 & http://www.mogiguacu.sp.gov.br \\
\hline 92 & Barreiras & BA & 113.695 & 100.085 & http://www.barreiras.ba.gov.br \\
\hline 93 & Garanhuns & $\mathrm{PE}$ & 110.084 & 103.435 & http://www.garanhuns.pe.gov.br \\
\hline 94 & Bragança Paulista & SP & 110.083 & 111.091 & http://www.braganca.sp.gov.br \\
\hline 95 & Barbacena & MG & 107.810 & 103.669 & Não foi encontrada \\
\hline 96 & Araguaína & TO & 105.019 & 105.874 & http://www.araguaina.to.gov.br \\
\hline 97 & Jaú & SP & 103.601 & 107.198 & http://www.jau.sp.gov.br/prefeitura.asp \\
\hline 98 & Catanduva & SP & 100.942 & 104.268 & http://www.catanduva.sp.gov.br \\
\hline 99 & Botucatu & SP & 100.876 & 103.993 & http://www.botucatu.sp.gov.br \\
\hline 100 & Rio Verde & GO & 100.586 & 106.079 & http://www.rioverdegoias.com.br \\
\hline 101 & Santa Cruz do Sul & RS & 100.433 & 93.786 & http://www.pmscs.rs.gov.br \\
\hline 102 & Guaratinguetá & SP & 98.265 & 99.162 & http://www.guaratingueta.sp.gov.br \\
\hline 103 & Ji-Paraná & RO & 95.356 & 91.013 & http://www.ji-parana.ro.gov.br \\
\hline 104 & Itabira & MG & 95.205 & 89.703 & http://www.itabira.mg.gov.br \\
\hline 105 & Mogi-Mirim & SP & 75.337 & 73.099 & http://www.mogimirim.sp.gov.br \\
\hline 106 & Aparecida & SP & 34.318 & 34.382 & Não foi encontrada \\
\hline
\end{tabular}


Tabela A-2: Centros urbanos da porção continental, identificados no Atlas das Cidades de Portugal (2002), ordenados de forma decrescente de acordo com a população do Concelho a que pertencem em 2001, população do núcleo urbano em 2001 e respectivas páginas na Internet.

\begin{tabular}{|c|c|c|c|c|}
\hline \multirow{2}{*}{$\mathbf{N}^{\mathbf{0}}$} & \multirow{2}{*}{ Cidade } & \multicolumn{2}{|c|}{ População 2001} & \multirow{2}{*}{ Página na Internet } \\
\hline & & Cidade & Concelho & \\
\hline 1 & Vila Nova de Gaia & 178.255 & 288.749 & http://www.cm-gaia.pt \\
\hline 2 & Amadora & 175.872 & 175.872 & http://www.cm-amadora.pt \\
\hline 3 & Braga & 109.460 & 164.193 & http://www.cm-braga.pt \\
\hline 4 & Almada & 101.501 & 160.825 & http://www.m-almada.pt/website \\
\hline 5 & Coimbra & 101.108 & 148.474 & http://www.cm-coimbra.pt \\
\hline 6 & Setúbal & 89.306 & 113.937 & http://www.isfa.com/server/web/setubal/setubal \\
\hline 7 & Agualva-Cacém & 81.843 & 363.704 & $\begin{array}{l}\text { http://www.cm-sintra.pt/default.jsp?file }= \\
\text { ver_artigo\& nivel }=2 \& \text { id }=14 \& \text { idRec }=189\end{array}$ \\
\hline 8 & Queluz & 78.033 & 363.704 & $\begin{array}{l}\text { http://www.cm-sintra.pt/default.jsp?file }= \\
\text { ver artigo\& nivel=2\&id=14\&idRec }=199\end{array}$ \\
\hline 9 & Aveiro & 55.305 & 110.544 & $\mathrm{http}: / /$ www.cm-aveiro.pt \\
\hline 10 & Guimarães & 52.182 & 159.577 & http://www.cm-guimaraes.pt \\
\hline 11 & Odivelas & 50.845 & 133.847 & http://www.cm-odivelas.pt \\
\hline 12 & Rio Tinto & 47.695 & 164.096 & http://www.riotinto.j-f.org \\
\hline 13 & Viseu & 47.261 & 93.502 & http://www.cm-viseu.pt \\
\hline 14 & Matosinhos & 45.703 & 167.026 & $\mathrm{http} / / / \mathrm{www} . \mathrm{cm}-\mathrm{matosinhos} . \mathrm{pt} / \mathrm{index} \cdot \mathrm{asp}$ \\
\hline 15 & Amora & 44.515 & 150.271 & http://www.jf-amora.pt \\
\hline 16 & Leiria & 42.747 & 119.870 & http://www.cm-leiria.pt \\
\hline 17 & Faro & 41.934 & 58.051 & http://www.cm-faro.pt/pt/index.php \\
\hline 18 & Évora & 41.164 & 56.525 & http://www.cm-evora.pt \\
\hline 19 & Barreiro & 40.858 & 79.012 & http://www.cm-barreiro.pt \\
\hline 20 & Póvoa do Varzim & 38.642 & 63.470 & http://www.cm-pvarzim.pt \\
\hline 21 & Ermesinde & 38.270 & 86.005 & http://home.caleida.pt/ masf/ermesinde/index 1.htm \\
\hline 22 & Viana do Castelo & 36.148 & 88.628 & http://www.cm-viana-castelo.pt \\
\hline 23 & Maia & 35.625 & 120.111 & http://www.cm-maia.pt \\
\hline 24 & Covilhã & 35.089 & 54.506 & http://www.cm-covilha.pt/detect.html \\
\hline 25 & Portimão & 32.948 & 44.818 & http://www.cm-portimao.pt \\
\hline 26 & Castelo Branco & 30.537 & 55.709 & http://www.cm-castelobranco.pt \\
\hline 27 & Santarém & 28.760 & 63.563 & http://www.cm-santarem.pt/index.php \\
\hline 28 & Alverca do Ribatejo & 28.356 & 122.908 & $\mathrm{http} / / /$ www.cm-vfxira.pt/autarquia/freguesias.asp \\
\hline 29 & Vila Nova Famalicão & 27.900 & 127.567 & http://www.cm-vnfamalicao.pt \\
\hline 30 & Figueira da Foz & 27.742 & 62.601 & http://www.cm-figfoz.pt \\
\hline 31 & Guarda & 26.062 & 44.084 & http://www.mun-guarda.pt \\
\hline 32 & Vila do Conde & 25.731 & 137.860 & $\mathrm{http} / / / \mathrm{www} . \mathrm{cm}$-viladoconde.pt \\
\hline 33 & Montijo & 25.719 & 39.168 & http://www.mun-montijo.pt \\
\hline 34 & Gondomar & 25.717 & 164.096 & http://www.cm-gondomar.pt \\
\hline 35 & Seixal & 25.609 & 150.271 & http://www.cm-seixal.pt \\
\hline 36 & Caldas da Rainha & 25.314 & 48.844 & http://www.cm-caldas-rainha.pt \\
\hline 37 & Olhão & 24.880 & 40.808 & http://www.cm-olhao.pt/site-bin \\
\hline 38 & Santo Tirso & 24.649 & 72.396 & http://www.cm-stirso.pt \\
\hline 39 & Vila Real & 24.481 & 49.957 & http://www.cm-vilareal.pt \\
\hline 40 & Póvoa de Santa Íria & 24.277 & 122.908 & $\mathrm{http} / / / w w w . c m-v f x i r a . p t / a u t a r q u i a / f r e g u e s i a s . a s p$ \\
\hline 41 & São Mamede de Infesta & 23.542 & 167.026 & http://www.terravista.pt/Meco/3874/ \\
\hline 42 & Beja & 21.658 & 35.762 & http://www.cm-beja.pt \\
\hline 43 & Espinho & 21.589 & 33.701 & http://www.cm-espinho.pt \\
\hline 44 & São João da Madeira & 21.102 & 21.102 & $\mathrm{http} / / / \mathrm{www} . \mathrm{cm}-\mathrm{sjm} . \mathrm{pt}$ \\
\hline 45 & Barcelos & 20.625 & 122.096 & $\mathrm{http} / / /$ www.camaramunicipal.bcl.pt \\
\hline 46 & Bragança & 20.310 & 34.752 & http://www.cm-braganca.pt \\
\hline 47 & Entroncamento & 18.035 & 18.173 & $\mathrm{http}: / /$ www.cm-entroncamento.pt \\
\hline 48 & Valongo & 17.978 & 86.005 & http://www.cmvalongo.net \\
\hline 49 & Abrantes & 17.830 & 42.235 & http://www.cm-abrantes.pt \\
\hline 50 & Sacavém & 17.659 & 199.059 & $\begin{array}{l}\text { http://www.cm-loures.pt/d_concelho.asp? tema }= \\
17 \& \text { freguesia }=0\end{array}$ \\
\hline 51 & Chaves & 17.535 & 43.668 & http://www.cm-chaves.pt \\
\hline 52 & Ovar & 16.849 & 55.198 & $\begin{array}{l}\text { http://www.anmp.pt/munp/mun/mun101w3.php?co } \\
\text { d=M3880 }\end{array}$ \\
\hline 53 & Vila Franca de Xira & 16.554 & 122.908 & http://www.cm-vfxira.pt/home \\
\hline 54 & Torres Vedras & 16.461 & 72.250 & http://www.cm-tvedras.pt \\
\hline 55 & Trofa & 16.196 & 37.581 & http://www.mun-trofa.pt \\
\hline
\end{tabular}




\begin{tabular}{|c|c|c|c|c|}
\hline \multirow{2}{*}{$\mathbf{N}^{\mathbf{0}}$} & \multirow{2}{*}{ Cidade } & \multicolumn{2}{|c|}{ População 2001} & \multirow{2}{*}{ Página na Internet } \\
\hline & & Cidade & Concelho & \\
\hline 56 & Loures & 15.967 & 199.059 & http://www.cm-loures.pt \\
\hline 57 & Tomar & 15.764 & 43.007 & http://www.ribatejo.com/ecos/tomar \\
\hline 58 & Peniche & 15.595 & 27.316 & http://www.cm-peniche.pt \\
\hline 59 & Felgueiras & 15.525 & 57.595 & http://www.valsousa.pt/felgueiras \\
\hline 60 & Portalegre & 15.238 & 25.980 & http://www.cm-portalegre.pt \\
\hline 61 & Elvas & 15.115 & 23.361 & http://www.cm-elvas.pt \\
\hline 62 & Lagos & 14.675 & 25.397 & http://www.cm-lagos.pt \\
\hline 63 & Águeda & 14.504 & 49.041 & http://www.cm-agueda.pt \\
\hline 64 & Fafe & 14.144 & 52.757 & http://www.cm-fafe.pt \\
\hline 65 & Albufeira & 13.646 & 31.543 & http://www.cm-albufeira.pt/pt/index.php \\
\hline 66 & Ílhavo & 12.794 & 37.209 & http://www.cm-ilhavo.pt \\
\hline 67 & Vizela & 12.698 & 22.595 & http://www.cm-vizela.pt \\
\hline 68 & Paredes & 12.655 & 83.376 & http://www.valsousa.pt/paredes \\
\hline 69 & Santa Comba Dão & 12.473 & 12.473 & http://www.cm-santacombadao.pt \\
\hline 70 & Gafanha da Nazaré & 12.321 & 37.209 & $\begin{array}{l}\text { http://www.geocities.com/TheTropics/Harbor/2852/ } \\
\text { gafanha.html }\end{array}$ \\
\hline 71 & Quarteira & 12.290 & 59.160 & $\begin{array}{l}\text { http://www.cm-loule.pt/Concelho/Freguesias/ } \\
\text { quarteira.html }\end{array}$ \\
\hline 72 & Torres Novas & 12.156 & 36.908 & http://www.cm-torresnovas.pt \\
\hline 73 & Loulé & 12.103 & 59.160 & http://www.cm-loule.pt \\
\hline 74 & Oliveira de Azeméis & 12.047 & 70.722 & http://www.cm-oaz.pt \\
\hline 75 & Sines & 11.788 & 13.577 & http://www.mun-sines.pt \\
\hline 76 & Amarante & 11.681 & 59.627 & http://www.cm-amarante.pt \\
\hline 77 & Santa Maria da Feira & 11.040 & 135.964 & http://www.cm-feira.pt \\
\hline 78 & Esmoriz & 11.020 & 55.198 & http://www.esmoriz.com/modules/news \\
\hline 79 & Mirandela & 10.703 & 25.742 & http://www.cm-mirandela.pt \\
\hline 80 & Tavira & 10.607 & 24.995 & http://www.cm-tavira.pt \\
\hline 81 & Almeirim & 10.520 & 21.957 & http://www.cm-almeirim.pt \\
\hline 82 & Vila Real S. Antonio & 10.489 & 17.956 & http://www.cm-vrsa.pt \\
\hline 83 & Pombal & 10.031 & 56.300 & http://www.cm-pombal.pt \\
\hline 84 & Cartaxo & 9.507 & 23.389 & http://www.cm-cartaxo.pt \\
\hline 85 & Vendas Novas & 9.485 & 11.619 & http://www.cm-vn.pt \\
\hline 86 & Peso da Régua & 9.353 & 18.832 & http://www.cm-pregua.espigueiro.pt/index.asp \\
\hline 87 & Penafiel & 9.343 & 155.178 & http://www.valsousa.pt/penafiel/index.html \\
\hline 88 & Lourosa & 9.204 & 135.964 & http://www.cm-feira.pt \\
\hline 89 & Esposende & 9.198 & 33.325 & $\begin{array}{l}\text { http://www.amvc.pt/Site/concelhos/esposende/inde } \\
\text { x.html }\end{array}$ \\
\hline 90 & Marinha Grande & 9.130 & 34.153 & http://www.cm-mgrande.pt \\
\hline 91 & Marco de Canaveses & 9.042 & 52.419 & http://www.cm-marco-canaveses.pt \\
\hline 92 & Lamego & 8.848 & 28.081 & http://www.cm-lamego.pt \\
\hline 93 & Tondela & 8.772 & 31.152 & http://www.cmtondela.com \\
\hline 94 & Fiães & 8.754 & 135.964 & http://www.cm-feira.pt \\
\hline 95 & Moura & 8.459 & 16.590 & http://www.cm-moura.pt \\
\hline 96 & Fundão & 8.369 & 31.482 & http://www.cm-fundao.pt \\
\hline 97 & Montemor-o-Novo & 8.298 & 18.578 & http://www.cm-montemornovo.pt \\
\hline 98 & Paços Ferreira & 8.118 & 52.985 & http://www.valsousa.pt/pferreira \\
\hline 99 & Fátima & 7.756 & 46.216 & http://www.cm-ourem.pt \\
\hline 100 & Estremoz & 7.682 & 15.613 & http://www.cm-estremoz.pt \\
\hline 101 & Vale de Cambra & 7.565 & 24.798 & http://www.cm-vale-cambra.pt \\
\hline 102 & Freamunde & 7.452 & 52.985 & $\begin{array}{l}\text { http://www.valsousa.pt/pferreira/infmunicipal/dine. } \\
\text { html }\end{array}$ \\
\hline 103 & Rio Maior & 7.412 & 21.110 & http://www.cm-riomaior.pt \\
\hline 104 & Ponte de Sor & 7.331 & 17.010 & http://www.cm-pontedesor.pt \\
\hline 105 & Macedo de Cavaleiros & 6.844 & 17.449 & $\begin{array}{l}\text { http://aquinta.espigueiro.pt/camaras/Distritos/ } \\
\text { Braganca/MacedoCavaleiros/index.asp }\end{array}$ \\
\hline 106 & Mangualde & 6.695 & 20.990 & $\begin{array}{l}\text { http://www.anmp.pt/munp/mun/mun101w3.php? } \\
\text { cod=M3530 }\end{array}$ \\
\hline 107 & Alcácer do Sal & 6.602 & 14.287 & http://www.m-alcacerdosal.pt \\
\hline 108 & Alcobaça & 6.232 & 56.794 & $\begin{array}{l}\text { http://www.anmp.pt/munp/mun/mun101w3.php? } \\
\text { cod=M2460 }\end{array}$ \\
\hline 109 & Silves & 5.869 & 33.830 & http://www.cm-silves.pt \\
\hline 110 & Seia & 5.702 & 28.145 & http://www.cm-seia.pt \\
\hline 111 & Santiago do Cacém & 5.240 & 31.105 & http://www.cm-santiago-do-cacem.pt \\
\hline 112 & Oliveira do Hospital & 5.222 & 22.112 & http://www.cm-oliveiradohospital.pt \\
\hline 113 & Cantanhede & 5.004 & 37.370 & http://www.cm-cantanhede.pt/portal/index.asp \\
\hline
\end{tabular}




\begin{tabular}{|c|c|c|c|c|}
\hline \multirow{2}{*}{$\mathbf{N}^{\mathbf{0}}$} & \multirow{2}{*}{ Cidade } & \multicolumn{2}{|c|}{ População 2001} & \multirow{2}{*}{ Página na Internet } \\
\hline & & Cidade & Concelho & \\
\hline 114 & Ourém & 4.991 & 46.216 & http://www.cm-ourem.pt \\
\hline 115 & Lagoa & 4.806 & 20.656 & http://www.amal.pt/cm/cmlga.html \\
\hline 116 & Lixa & 4.233 & 57.595 & http://www.lixa.net \\
\hline 117 & Gouveia & 3.759 & 16.122 & http://cm-gouveia.pt \\
\hline 118 & Valpaços & 3.751 & 19.512 & http://www.cm-valpacos.pt/index.asp \\
\hline 119 & Vila Nova de Foz Coa & 2.823 & 8.494 & http://www.cm-fozcoa.pt \\
\hline 120 & Pinhel & 2.578 & 10.954 & $\begin{array}{l}\text { http://www.anmp.pt/munp/mun/mun101w3.php?co } \\
\text { d=M6400 }\end{array}$ \\
\hline 121 & Miranda do Douro & 1.960 & 8.048 & http://www.cm-mdouro.espigueiro.pt/index.asp \\
\hline
\end{tabular}


ANEXO B - Resultados da pesquisa na Internet realizada para os centros urbanos brasileiros e portugueses 
Tabela B-1: Resumo das informações obtidas para os centros urbanos brasileiros

\begin{tabular}{|c|c|c|c|c|c|c|c|c|c|c|}
\hline \multirow[b]{2}{*}{$\mathbf{N}$} & \multirow[b]{2}{*}{$\begin{array}{l}\text { Centros urbanos } \\
\text { brasileiros }\end{array}$} & \multirow[b]{2}{*}{$\mathbf{U F}$} & \multicolumn{8}{|c|}{ Grupos de Informação } \\
\hline & & & Região & $\begin{array}{c}\mathbf{1} \\
0,352\end{array}$ & $\begin{array}{c}\mathbf{2} \\
0,206\end{array}$ & $\begin{array}{c}\mathbf{3} \\
0,263\end{array}$ & $\begin{array}{c}\mathbf{4}^{3} \\
0,109\end{array}$ & $\begin{array}{c}\mathbf{5} \\
0,070\end{array}$ & Total & Score \\
\hline 1 & Juiz de Fora & MG & Sudeste & 1 & 1 & 1 & 1 & 1 & 5 & 1,000 \\
\hline 2 & Ribeirão Preto & $\mathrm{SP}$ & Sudeste & 1 & 1 & 1 & 1 & 1 & 5 & 1,000 \\
\hline 3 & Barra Mansa & RJ & Sudeste & 1 & 0 & 1 & 1 & 1 & 4 & 0,794 \\
\hline 4 & Piracicaba & SP & Sudeste & 1 & 0 & 1 & 1 & 1 & 4 & 0,794 \\
\hline 5 & Vitória & ES & Sudeste & 1 & 0 & 1 & 1 & 1 & 4 & 0,794 \\
\hline 6 & Blumenau & $\mathrm{SC}$ & Sul & 1 & 0 & 1 & 1 & 1 & 4 & 0,794 \\
\hline 7 & Caxias do Sul & $\mathrm{RS}$ & Sul & 1 & 0 & 1 & 1 & 1 & 4 & 0,794 \\
\hline 8 & Chapecó & $\mathrm{SC}$ & Sul & 1 & 0 & 1 & 1 & 1 & 4 & 0,794 \\
\hline 9 & Londrina & PR & Sul & 1 & 0 & 1 & 1 & 1 & 4 & 0,794 \\
\hline 10 & Cuiabá & MT & Centro-Oeste & 0 & 1 & 1 & 1 & 1 & 4 & 0,648 \\
\hline 11 & Dourados & MS & Centro-Oeste & 0 & 1 & 1 & 1 & 1 & 4 & 0,648 \\
\hline 12 & Campina Grande & $\mathrm{PB}$ & Nordeste & 0 & 1 & 1 & 1 & 1 & 4 & 0,648 \\
\hline 13 & Natal & $\mathrm{RN}$ & Nordeste & 0 & 1 & 1 & 1 & 1 & 4 & 0,648 \\
\hline 14 & Sobral & $\mathrm{CE}$ & Nordeste & 0 & 1 & 1 & 1 & 1 & 4 & 0,648 \\
\hline 15 & Araraquara & SP & Sudeste & 0 & 1 & 1 & 1 & 1 & 4 & 0,648 \\
\hline 16 & Ipatinga & MG & Sudeste & 0 & 1 & 1 & 1 & 1 & 4 & 0,648 \\
\hline 17 & Jundiaí & SP & Sudeste & 0 & 1 & 1 & 1 & 1 & 4 & 0,648 \\
\hline 18 & Nova Friburgo & RJ & Sudeste & 0 & 1 & 1 & 1 & 1 & 4 & 0,648 \\
\hline 19 & Florianópolis & $\mathrm{SC}$ & Sul & 0 & 1 & 1 & 1 & 1 & 4 & 0,648 \\
\hline 20 & Ponta Grossa & PR & Sul & 0 & 1 & 1 & 1 & 1 & 4 & 0,648 \\
\hline 21 & Campos dos Goitacazes & $\mathrm{RJ}$ & Sudeste & 1 & 0 & 0 & 1 & 1 & 3 & 0,530 \\
\hline 22 & Divinópolis & MG & Sudeste & 1 & 0 & 0 & 1 & 1 & 3 & 0,530 \\
\hline 23 & Rio Grande & $\mathrm{RS}$ & Sul & 1 & 0 & 0 & 1 & 1 & 3 & 0,530 \\
\hline 24 & Rondonópolis & MT & Centro-Oeste & 0 & 0 & 1 & 1 & 1 & 3 & 0,442 \\
\hline 25 & Franca & $\mathrm{SP}$ & Sudeste & 0 & 0 & 1 & 1 & 1 & 3 & 0,442 \\
\hline 26 & Poços de Caldas & MG & Sudeste & 0 & 0 & 1 & 1 & 1 & 3 & 0,442 \\
\hline 27 & Santos & $\mathrm{SP}$ & Sudeste & 0 & 0 & 1 & 1 & 1 & 3 & 0,442 \\
\hline 28 & São José dos Campos & SP & Sudeste & 0 & 0 & 1 & 1 & 1 & 3 & 0,442 \\
\hline 29 & Sete Lagoas & MG & Sudeste & 0 & 0 & 1 & 1 & 1 & 3 & 0,442 \\
\hline 30 & Sorocaba & $\mathrm{SP}$ & Sudeste & 0 & 0 & 1 & 1 & 1 & 3 & 0,442 \\
\hline 31 & Uberlândia & MG & Sudeste & 0 & 0 & 1 & 1 & 1 & 3 & 0,442 \\
\hline 32 & Guarapuava & PR & Sul & 0 & 0 & 1 & 1 & 1 & 3 & 0,442 \\
\hline 33 & Itajaí & $\mathrm{SC}$ & Sul & 0 & 0 & 1 & 1 & 1 & 3 & 0,442 \\
\hline 34 & Joinville & $\mathrm{SC}$ & Sul & 0 & 0 & 1 & 1 & 1 & 3 & 0,442 \\
\hline 35 & Passo Fundo & $\mathrm{RS}$ & Sul & 0 & 0 & 1 & 1 & 1 & 3 & 0,442 \\
\hline 36 & Uruguaiana & $\mathrm{RS}$ & Sul & 0 & 0 & 1 & 1 & 1 & 3 & 0,442 \\
\hline 37 & Rio Verde & GO & Centro-Oeste & 0 & 1 & 0 & 1 & 1 & 3 & 0,385 \\
\hline 38 & Guaratinguetá & SP & Sudeste & 0 & 1 & 0 & 1 & 1 & 3 & 0,385 \\
\hline 39 & Uberaba & MG & Sudeste & 0 & 1 & 0 & 1 & 1 & 3 & 0,385 \\
\hline 40 & Cascavel & PR & Sul & 0 & 1 & 0 & 1 & 1 & 3 & 0,385 \\
\hline 41 & Maringá & PR & Sul & 0 & 1 & 0 & 1 & 1 & 3 & 0,385 \\
\hline 42 & Campo Grande & MS & Centro-Oeste & 0 & 0 & 1 & 1 & 0 & 2 & 0,372 \\
\hline 43 & São Luis & MA & Nordeste & 0 & 0 & 1 & 1 & 0 & 2 & 0,372 \\
\hline 44 & Anápolis & GO & Centro-Oeste & 0 & 0 & 1 & 0 & 1 & 2 & 0,333 \\
\hline 45 & Bauru & SP & Sudeste & 0 & 0 & 1 & 0 & 1 & 2 & 0,333 \\
\hline 46 & João Pessoa & PB & Nordeste & 0 & 0 & 1 & 0 & 0 & 1 & 0,263 \\
\hline 47 & Teresina & PI & Nordeste & 0 & 0 & 1 & 0 & 0 & 1 & 0,263 \\
\hline 48 & Aracaju & SE & Nordeste & 0 & 0 & 0 & 1 & 1 & 2 & 0,179 \\
\hline 49 & Barreiras & BA & Nordeste & 0 & 0 & 0 & 1 & 1 & 2 & 0,179 \\
\hline 50 & Caruaru & $\mathrm{PE}$ & Nordeste & 0 & 0 & 0 & 1 & 1 & 2 & 0,179 \\
\hline 51 & Imperatriz & MA & Nordeste & 0 & 0 & 0 & 1 & 1 & 2 & 0,179 \\
\hline 52 & Jequié & BA & Nordeste & 0 & 0 & 0 & 1 & 1 & 2 & 0,179 \\
\hline 53 & Juazeiro do Norte & $\mathrm{CE}$ & Nordeste & 0 & 0 & 0 & 1 & 1 & 2 & 0,179 \\
\hline 54 & Mossoró & $\mathrm{RN}$ & Nordeste & 0 & 0 & 0 & 1 & 1 & 2 & 0,179 \\
\hline 55 & Parnaíba & PI & Nordeste & 0 & 0 & 0 & 1 & 1 & 2 & 0,179 \\
\hline
\end{tabular}




\begin{tabular}{|c|c|c|c|c|c|c|c|c|c|c|}
\hline \multirow{3}{*}{$\mathbf{N}$} & \multirow{3}{*}{$\begin{array}{l}\text { Centros urbanos } \\
\text { brasileiros }\end{array}$} & \multirow{3}{*}{ UF } & \multicolumn{8}{|c|}{ Grupos de Informação } \\
\hline & & & Região & 1 & 2 & 3 & 4 & 5 & Total & Score \\
\hline & & & & 0,352 & 0,206 & 0,263 & 0,109 & 0,07 & & \\
\hline 56 & Ji-Paraná & $\mathrm{RO}$ & Norte & 0 & 0 & 0 & 1 & 1 & 2 & 0,179 \\
\hline 57 & Marabá & PA & Norte & 0 & 0 & 0 & 1 & 1 & 2 & 0,179 \\
\hline 58 & Palmas & TO & Norte & 0 & 0 & 0 & 1 & 1 & 2 & 0,179 \\
\hline 59 & Porto Velho & RO & Norte & 0 & 0 & 0 & 1 & 1 & 2 & 0,179 \\
\hline 60 & Santarém & PA & Norte & 0 & 0 & 0 & 1 & 1 & 2 & 0,179 \\
\hline 61 & Araçatuba & SP & Sudeste & 0 & 0 & 0 & 1 & 1 & 2 & 0,179 \\
\hline 62 & Botucatu & SP & Sudeste & 0 & 0 & 0 & 1 & 1 & 2 & 0,179 \\
\hline 63 & Cachoeiro do Itapemirim & ES & Sudeste & 0 & 0 & 0 & 1 & 1 & 2 & 0,179 \\
\hline 64 & Catanduva & SP & Sudeste & 0 & 0 & 0 & 1 & 1 & 2 & 0,179 \\
\hline 65 & Governador Valadares & MG & Sudeste & 0 & 0 & 0 & 1 & 1 & 2 & 0,179 \\
\hline 66 & Itabira & MG & Sudeste & 0 & 0 & 0 & 1 & 1 & 2 & 0,179 \\
\hline 67 & Jaú & SP & Sudeste & 0 & 0 & 0 & 1 & 1 & 2 & 0,179 \\
\hline 68 & Limeira & SP & Sudeste & 0 & 0 & 0 & 1 & 1 & 2 & 0,179 \\
\hline 69 & Linhares & ES & Sudeste & 0 & 0 & 0 & 1 & 1 & 2 & 0,179 \\
\hline 70 & Presidente Prudente & SP & Sudeste & 0 & 0 & 0 & 1 & 1 & 2 & 0,179 \\
\hline 71 & São Carlos & SP & Sudeste & 0 & 0 & 0 & 1 & 1 & 2 & 0,179 \\
\hline 72 & Foz do Iguaçu & PR & Sul & 0 & 0 & 0 & 1 & 1 & 2 & 0,179 \\
\hline 73 & Paranaguá & PR & Sul & 0 & 0 & 0 & 1 & 1 & 2 & 0,179 \\
\hline 74 & Pelotas & RS & Sul & 0 & 0 & 0 & 1 & 1 & 2 & 0,179 \\
\hline 75 & Santa Cruz do Sul & $\mathrm{RS}$ & Sul & 0 & 0 & 0 & 1 & 1 & 2 & 0,179 \\
\hline 76 & Santa Maria & $\mathrm{RS}$ & Sul & 0 & 0 & 0 & 1 & 1 & 2 & 0,179 \\
\hline 77 & Alagoinhas & BA & Nordeste & 0 & 0 & 0 & 1 & 0 & 1 & 0,109 \\
\hline 78 & Feira de Santana & BA & Nordeste & 0 & 0 & 0 & 0 & 1 & 1 & 0,070 \\
\hline 79 & Arapiraca & $\mathrm{AL}$ & Nordeste & 0 & 0 & 0 & 0 & 1 & 1 & 0,070 \\
\hline 80 & Petrolina & $\mathrm{PE}$ & Nordeste & 0 & 0 & 0 & 0 & 1 & 1 & 0,070 \\
\hline 81 & Castanhal & PA & Norte & 0 & 0 & 0 & 0 & 1 & 1 & 0,070 \\
\hline 82 & Rio Branco & $\mathrm{AC}$ & Norte & 0 & 0 & 0 & 0 & 1 & 1 & 0,070 \\
\hline 83 & Bragança Paulista & SP & Sudeste & 0 & 0 & 0 & 0 & 1 & 1 & 0,070 \\
\hline 84 & Cabo Frio & $\mathrm{RJ}$ & Sudeste & 0 & 0 & 0 & 0 & 1 & 1 & 0,070 \\
\hline 85 & Teófilo Otoni & MG & Sudeste & 0 & 0 & 0 & 0 & 1 & 1 & 0,070 \\
\hline 86 & Criciúma & $\mathrm{SC}$ & Sul & 0 & 0 & 0 & 0 & 1 & 1 & 0,070 \\
\hline 87 & Ilhéus & BA & Nordeste & 0 & 0 & 0 & 0 & 0 & 0 & 0,000 \\
\hline 88 & Araguaína & TO & Norte & 0 & 0 & 0 & 0 & 0 & 0 & 0,000 \\
\hline 89 & Marília & SP & Sudeste & 0 & 0 & 0 & 0 & 0 & 0 & 0,000 \\
\hline 90 & Mogi-Guaçu & SP & Sudeste & 0 & 0 & 0 & 0 & 0 & 0 & 0,000 \\
\hline 91 & Mogi-Mirim & SP & Sudeste & 0 & 0 & 0 & 0 & 0 & 0 & 0,000 \\
\hline 92 & Montes Claros & MG & Sudeste & 0 & 0 & 0 & 0 & 0 & 0 & 0,000 \\
\hline 93 & Crato* & $\mathrm{CE}$ & Nordeste & 0 & 0 & 0 & 0 & 0 & 0 & 0,000 \\
\hline 94 & Itabuna* & BA & Nordeste & 0 & 0 & 0 & 0 & 0 & 0 & 0,000 \\
\hline 95 & Juazeiro* & BA & Nordeste & 0 & 0 & 0 & 0 & 0 & 0 & 0,000 \\
\hline 96 & Maceió* & $\mathrm{AL}$ & Nordeste & 0 & 0 & 0 & 0 & 0 & 0 & 0,000 \\
\hline 97 & Vitória da Conquista* & BA & Nordeste & 0 & 0 & 0 & 0 & 0 & 0 & 0,000 \\
\hline 98 & Caxias** & MA & Nordeste & 0 & 0 & 0 & 0 & 0 & 0 & 0,000 \\
\hline 99 & Garanhuns* & $\mathrm{PE}$ & Nordeste & 0 & 0 & 0 & 0 & 0 & 0 & 0,000 \\
\hline 100 & Boa Vista* & RR & Norte & 0 & 0 & 0 & 0 & 0 & 0 & 0,000 \\
\hline 101 & Macapá** & AP & Norte & 0 & 0 & 0 & 0 & 0 & 0 & 0,000 \\
\hline 102 & São José do Rio Preto* & SP & Sudeste & 0 & 0 & 0 & 0 & 0 & 0 & 0,000 \\
\hline 103 & Volta Redonda* & $\mathrm{RJ}$ & Sudeste & 0 & 0 & 0 & 0 & 0 & 0 & 0,000 \\
\hline 104 & Aparecida** & SP & Sudeste & 0 & 0 & 0 & 0 & 0 & 0 & 0,000 \\
\hline 105 & Barbacena** & MG & Sudeste & 0 & 0 & 0 & 0 & 0 & 0 & 0,000 \\
\hline 106 & Lages** & $\mathrm{SC}$ & Sul & 0 & 0 & 0 & 0 & 0 & 0 & 0,000 \\
\hline
\end{tabular}

* Páginas em construção ou em manutenção.

** Páginas não encontradas. 
Tabela B-2: Resumo das informações obtidas para os centros urbanos portugueses

\begin{tabular}{|c|c|c|c|c|c|c|c|c|c|}
\hline \multirow[b]{2}{*}{$\mathbf{N}$} & \multirow{2}{*}{$\begin{array}{c}\text { Centros urbanos } \\
\text { portugueses }\end{array}$} & \multirow[b]{2}{*}{ Região } & \multicolumn{5}{|c|}{ Grupos de Informação } & \multirow[b]{2}{*}{ Total } & \multirow[b]{2}{*}{ Score } \\
\hline & & & $\frac{1}{028}$ & 2 & 3 & 4 & 5 & & \\
\hline 1 & Sines & Alentejo & $\frac{0,202}{1}$ & $\frac{204}{1}$ & $\frac{1}{1}$ & $\frac{0,000}{1}$ & $\frac{0,073}{1}$ & 5 & 1,000 \\
\hline 2 & Vendas Novas & Alentejo & 1 & 1 & 1 & 1 & 1 & 5 & 1.000 \\
\hline 3 & Aveiro & Centro & 1 & 1 & 1 & 1 & 1 & 5 & 1,000 \\
\hline 4 & Trofa & Norte & 1 & 1 & 1 & 1 & 1 & 5 & 1,000 \\
\hline 5 & Beja & Alentejo & 1 & 0 & 1 & 1 & 1 & 4 & 0,796 \\
\hline 6 & Portalegre & Alentejo & 1 & 0 & 1 & 1 & 1 & 4 & 0,796 \\
\hline 7 & Castelo Branco & Centro & 1 & 0 & 1 & 1 & 1 & 4 & 0,796 \\
\hline 8 & Póvoa do Varzim & Norte & 1 & 0 & 1 & 1 & 1 & 4 & 0,796 \\
\hline 9 & Vila Nova de Gaia & Norte & 1 & 0 & 1 & 1 & 1 & 4 & 0,796 \\
\hline 10 & Torres Novas & Lisboa e V. do Tejo & 1 & 0 & 1 & 0 & 1 & 3 & 0,730 \\
\hline 11 & Viana do Castelo & Norte & 1 & 1 & 0 & 1 & 1 & 4 & 0,647 \\
\hline 12 & Vila Nova de Famalicão & Norte & 1 & 1 & 0 & 1 & 1 & 4 & 0,647 \\
\hline 13 & Figueira da Foz & Centro & 0 & 0 & 1 & 1 & 1 & 3 & 0,514 \\
\hline 14 & Almada & Alentejo & 0 & 0 & 1 & 0 & 1 & 2 & 0,448 \\
\hline 15 & Loulé & Algarve & 0 & 0 & 1 & 0 & 1 & 2 & 0,448 \\
\hline 16 & Montijo & Alentejo & 1 & 0 & 0 & 1 & 1 & 3 & 0,442 \\
\hline 17 & Albufeira & Algarve & 1 & 0 & 0 & 1 & 1 & 3 & 0,442 \\
\hline 18 & Faro & Algarve & 1 & 0 & 0 & 1 & 1 & 3 & 0,442 \\
\hline 19 & Silves & Algarve & 1 & 0 & 0 & 1 & 1 & 3 & 0,442 \\
\hline 20 & Covilhã & Centro & 1 & 0 & 0 & 1 & 1 & 3 & 0,442 \\
\hline 21 & Leiria & Lisboa e V. do Tejo & 1 & 0 & 0 & 1 & 1 & 3 & 0,442 \\
\hline 22 & Marinha Grande & Lisboa e V. do Tejo & 1 & 0 & 0 & 1 & 1 & 3 & 0,442 \\
\hline 23 & Torres Vedras & Lisboa e V. do Tejo & 1 & 0 & 0 & 1 & 1 & 3 & 0,442 \\
\hline 24 & Vila Franca de Xira & Lisboa e V. do Tejo & 1 & 0 & 0 & 1 & 1 & 3 & 0,442 \\
\hline 25 & Chaves & Norte & 1 & 0 & 0 & 1 & 1 & 3 & 0,442 \\
\hline 26 & Santo Tirso & Norte & 1 & 0 & 0 & 1 & 1 & 3 & 0,442 \\
\hline 27 & Seixal & Alentejo & 1 & 0 & 0 & 0 & 1 & 2 & 0,377 \\
\hline 28 & Mangualde & Centro & 1 & 0 & 0 & 0 & 1 & 2 & 0,377 \\
\hline 29 & Ovar & Centro & 1 & 0 & 0 & 0 & 1 & 2 & 0,377 \\
\hline 30 & Entroncamento & Lisboa e V. do Tejo & 1 & 0 & 0 & 0 & 1 & 2 & 0,377 \\
\hline 31 & Bragança & Norte & 1 & 0 & 0 & 0 & 1 & 2 & 0,377 \\
\hline 32 & Matosinhos & Norte & 1 & 0 & 0 & 0 & 1 & 2 & 0,377 \\
\hline 33 & Estremoz & Alentejo & 0 & 1 & 0 & 1 & 1 & 3 & 0,365 \\
\hline 34 & Lagoa & Algarve & 0 & 1 & 0 & 1 & 1 & 3 & 0,365 \\
\hline 35 & Portimão & Algarve & 0 & 1 & 0 & 1 & 1 & 3 & 0,365 \\
\hline 36 & São João da Madeira & Centro & 0 & 1 & 0 & 1 & 1 & 3 & 0,365 \\
\hline 37 & Peniche & Lisboa e V. do Tejo & 0 & 1 & 0 & 1 & 1 & 3 & 0,365 \\
\hline 38 & Pombal & Lisboa e V. do Tejo & 0 & 1 & 0 & 1 & 1 & 3 & 0,365 \\
\hline 39 & Sacavém & Lisboa e V. do Tejo & 0 & 1 & 0 & 1 & 1 & 3 & 0,365 \\
\hline 40 & Tomar & Lisboa e V. do Tejo & 0 & 1 & 0 & 1 & 1 & 3 & 0,365 \\
\hline 41 & Guimarães & Norte & 0 & 1 & 0 & 1 & 1 & 3 & 0,365 \\
\hline 42 & Evora & Alentejo & 0 & 0 & 1 & 0 & 0 & 1 & 0,353 \\
\hline 43 & Pinhel & Centro & 0 & 1 & 0 & 0 & 1 & 2 & 0,299 \\
\hline 44 & Alcobaça & Lisboa e V. do Tejo & 0 & 1 & 0 & 0 & 1 & 2 & 0,299 \\
\hline 45 & Coimbra & Centro & 1 & 0 & 0 & 0 & 0 & 1 & 0,282 \\
\hline 46 & Odivelas & Lisboa e V. do Tejo & 1 & 0 & 0 & 0 & 0 & 1 & 0,282 \\
\hline 47 & Cantanhede & Centro & 0 & 0 & 0 & 1 & 1 & 2 & 0,160 \\
\hline 48 & Ilhavo & Centro & 0 & 0 & 0 & 1 & 1 & 2 & 0,160 \\
\hline 49 & Abrantes & Lisboa e V. do Tejo & 0 & 0 & 0 & 1 & 1 & 2 & 0,160 \\
\hline 50 & Almeirim & Lisboa e V. do Tejo & 0 & 0 & 0 & 1 & 1 & 2 & 0,160 \\
\hline 51 & Alverca do Ribatejo & Lisboa e V. do Tejo & 0 & 0 & 0 & 1 & 1 & 2 & 0,160 \\
\hline 52 & Amadora & Lisboa e V. do Tejo & 0 & 0 & 0 & 1 & 1 & 2 & 0,160 \\
\hline 53 & Caldas da Rainha & Lisboa e V. do Tejo & 0 & 0 & 0 & 1 & 1 & 2 & 0,160 \\
\hline 54 & Loures & Lisboa e V. do Tejo & 0 & 0 & 0 & 1 & 1 & 2 & 0,160 \\
\hline 55 & Ourém & Lisboa e V. do Tejo & 0 & 0 & 0 & 1 & 1 & 2 & 0,160 \\
\hline 56 & Amarante & Norte & 0 & 0 & 0 & 1 & 1 & 2 & 0,160 \\
\hline 57 & Barcelos & Norte & 0 & 0 & 0 & 1 & 1 & 2 & 0,160 \\
\hline 58 & Braga & Norte & 0 & 0 & 0 & 1 & 1 & 2 & 0,160 \\
\hline 59 & Felgueiras & Norte & 0 & 0 & 0 & 1 & 1 & 2 & 0,160 \\
\hline 60 & Gondomar & Norte & 0 & 0 & 0 & 1 & 1 & 2 & 0,160 \\
\hline 61 & Maia & Norte & 0 & 0 & 0 & 1 & 1 & 2 & 0,160 \\
\hline
\end{tabular}




\begin{tabular}{|c|c|c|c|c|c|c|c|c|c|}
\hline \multirow[b]{2}{*}{$\mathbf{N}$} & \multirow{2}{*}{$\begin{array}{c}\text { Centros urbanos } \\
\text { portugueses }\end{array}$} & \multicolumn{8}{|c|}{ Grupos de Informação } \\
\hline & & Região & $\frac{\mathbf{1}}{0,282}$ & $\frac{\mathbf{2}}{0,204}$ & $\frac{\mathbf{3}}{0,353}$ & $\frac{\mathbf{4}}{0,066}$ & $\begin{array}{c}\mathbf{5} \\
0,095\end{array}$ & Total & Score \\
\hline 62 & Santiago do Cacém & Alentejo & 0 & 0 & 0 & 1 & 1 & 2 & 0,160 \\
\hline 63 & Vila Real Santo Antonio & Algarve & 0 & 0 & 0 & 1 & 1 & 2 & 0,160 \\
\hline 64 & Vale de Cambra & Centro & 0 & 0 & 0 & 1 & 1 & 2 & 0,160 \\
\hline 65 & Viseu & Centro & 0 & 0 & 0 & 1 & 1 & 2 & 0,160 \\
\hline 66 & Póvoa de Santa Iria & Lisboa e V. do Tejo & 0 & 0 & 0 & 1 & 1 & 2 & 0,160 \\
\hline 67 & Paços Ferreira & Norte & 0 & 0 & 0 & 1 & 1 & 2 & 0,160 \\
\hline 68 & Paredes & Norte & 0 & 0 & 0 & 1 & 1 & 2 & 0,160 \\
\hline 69 & Penafiel & Norte & 0 & 0 & 0 & 1 & 1 & 2 & 0,160 \\
\hline 70 & Vizela & Norte & 0 & 0 & 0 & 1 & 1 & 2 & 0,160 \\
\hline 71 & Amora & Alentejo & 0 & 0 & 0 & 0 & 1 & 1 & 0,095 \\
\hline 72 & Elvas & Alentejo & 0 & 0 & 0 & 0 & 1 & 1 & 0,095 \\
\hline 73 & Setúbal & Alentejo & 0 & 0 & 0 & 0 & 1 & 1 & 0,095 \\
\hline 74 & Olhão & Algarve & 0 & 0 & 0 & 0 & 1 & 1 & 0,095 \\
\hline 75 & Quarteira & Algarve & 0 & 0 & 0 & 0 & 1 & 1 & 0,095 \\
\hline 76 & Tavira & Algarve & 0 & 0 & 0 & 0 & 1 & 1 & 0,095 \\
\hline 77 & Agueda & Centro & 0 & 0 & 0 & 0 & 1 & 1 & 0,095 \\
\hline 78 & Espinho & Centro & 0 & 0 & 0 & 0 & 1 & 1 & 0,095 \\
\hline 79 & Fiães & Centro & 0 & 0 & 0 & 0 & 1 & 1 & 0,095 \\
\hline 80 & Lourosa & Centro & 0 & 0 & 0 & 0 & 1 & 1 & 0,095 \\
\hline 81 & Santa Comba Dão & Centro & 0 & 0 & 0 & 0 & 1 & 1 & 0,095 \\
\hline 82 & Santa Maria da Feira & Centro & 0 & 0 & 0 & 0 & 1 & 1 & 0,095 \\
\hline 83 & Seia & Centro & 0 & 0 & 0 & 0 & 1 & 1 & 0,095 \\
\hline 84 & Vila Nova de Foz Coa & Centro & 0 & 0 & 0 & 0 & 1 & 1 & 0,095 \\
\hline 85 & Agualva-Cacém & Lisboa e V. do Tejo & 0 & 0 & 0 & 0 & 1 & 1 & 0,095 \\
\hline 86 & Cartaxo & Lisboa e V. do Tejo & 0 & 0 & 0 & 0 & 1 & 1 & 0,095 \\
\hline 87 & Fátima & Lisboa e V. do Tejo & 0 & 0 & 0 & 0 & 1 & 1 & 0,095 \\
\hline 88 & Queluz & Lisboa e V. do Tejo & 0 & 0 & 0 & 0 & 1 & 1 & 0,095 \\
\hline 89 & Rio Maior & Lisboa e V. do Tejo & 0 & 0 & 0 & 0 & 1 & 1 & 0,095 \\
\hline 90 & Ermesinde & Norte & 0 & 0 & 0 & 0 & 1 & 1 & 0,095 \\
\hline 91 & Esposende & Norte & 0 & 0 & 0 & 0 & 1 & 1 & 0,095 \\
\hline 92 & Freamunde & Norte & 0 & 0 & 0 & 0 & 1 & 1 & 0,095 \\
\hline 93 & Lixa & Norte & 0 & 0 & 0 & 0 & 1 & 1 & 0,095 \\
\hline 94 & Macedo de Cavaleiros & Norte & 0 & 0 & 0 & 0 & 1 & 1 & 0,095 \\
\hline 95 & Marco de Canaveses & Norte & 0 & 0 & 0 & 0 & 1 & 1 & 0,095 \\
\hline 96 & Miranda do Douro & Norte & 0 & 0 & 0 & 0 & 1 & 1 & 0,095 \\
\hline 97 & Mirandela & Norte & 0 & 0 & 0 & 0 & 1 & 1 & 0,095 \\
\hline 98 & Peso da Régua & Norte & 0 & 0 & 0 & 0 & 1 & 1 & 0,095 \\
\hline 99 & Rio Tinto & Norte & 0 & 0 & 0 & 0 & 1 & 1 & 0,095 \\
\hline 100 & Valongo & Norte & 0 & 0 & 0 & 0 & 1 & 1 & 0,095 \\
\hline 101 & Valpaços & Norte & 0 & 0 & 0 & 0 & 1 & 1 & 0,095 \\
\hline 102 & Vila Real & Norte & 0 & 0 & 0 & 0 & 1 & 1 & 0,095 \\
\hline 103 & Fafe & Norte & 0 & 0 & 0 & 1 & 0 & 1 & 0,066 \\
\hline 104 & Alcácer do Sal & Alentejo & 0 & 0 & 0 & 0 & 0 & 0 & 0,000 \\
\hline 105 & Montemor-o-Novo & Alentejo & 0 & 0 & 0 & 0 & 0 & 0 & 0,000 \\
\hline 106 & Esmoriz & Centro & 0 & 0 & 0 & 0 & 0 & 0 & 0,000 \\
\hline 107 & Fundão & Centro & 0 & 0 & 0 & 0 & 0 & 0 & 0,000 \\
\hline 108 & Gafanha da Nazaré & Centro & 0 & 0 & 0 & 0 & 0 & 0 & 0,000 \\
\hline 109 & Gouveia & Centro & 0 & 0 & 0 & 0 & 0 & 0 & 0,000 \\
\hline 110 & Guarda & Centro & 0 & 0 & 0 & 0 & 0 & 0 & 0,000 \\
\hline 111 & Lamego & Centro & 0 & 0 & 0 & 0 & 0 & 0 & 0,000 \\
\hline 112 & Oliveira do Hospital & Centro & 0 & 0 & 0 & 0 & 0 & 0 & 0,000 \\
\hline 113 & Tondela & Centro & 0 & 0 & 0 & 0 & 0 & 0 & 0,000 \\
\hline 114 & São Mamede de Infesta & Norte & 0 & 0 & 0 & 0 & 0 & 0 & 0,000 \\
\hline 115 & Barreiro* & Alentejo & 0 & 0 & 0 & 0 & 0 & 0 & 0,000 \\
\hline 116 & Moura* & Alentejo & 0 & 0 & 0 & 0 & 0 & 0 & 0,000 \\
\hline 117 & Ponte de Sor* & Alentejo & 0 & 0 & 0 & 0 & 0 & 0 & 0,000 \\
\hline 118 & Lagos* & Algarve & 0 & 0 & 0 & 0 & 0 & 0 & 0,000 \\
\hline 119 & Oliveira de Azeméis* & Centro & 0 & 0 & 0 & 0 & 0 & 0 & 0,000 \\
\hline 120 & Santarém* & Lisboa e V. do Tejo & 0 & 0 & 0 & 0 & 0 & 0 & 0,000 \\
\hline 121 & Vila do Conde* & Norte & 0 & 0 & 0 & 0 & 0 & 0 & 0,000 \\
\hline
\end{tabular}


ANEXO C - Procedimentos para a obtenção de pesos para seis critérios 
Etapa 1: Matriz de comparação par a par

\begin{tabular}{|c|c|c|c|c|c|c|}
\hline & Critério 1 & Critério 2 & Critério 3 & Critério 4 & Critério 5 & Critério 6 \\
\hline Critério 1 & 1 & $1 / 2$ & 2 & 2 & 3 & 1 \\
\hline Critério 2 & 2 & 1 & 4 & 4 & 6 & 2 \\
\hline Critério 3 & $1 / 2$ & $1 / 4$ & 1 & 1 & 2 & $1 / 2$ \\
\hline Critério 4 & $1 / 2$ & $1 / 4$ & 1 & 1 & 2 & $1 / 2$ \\
\hline Critério 5 & $1 / 3$ & $1 / 6$ & $1 / 2$ & $1 / 2$ & 1 & $1 / 3$ \\
\hline Critério 6 & 1 & $1 / 2$ & 2 & 2 & 3 & 1 \\
\hline
\end{tabular}

Etapa 2: Obtenção dos pesos

\begin{tabular}{|l|l|l|l|l|l|l|}
\hline 1,00000 & 0,50000 & 2,00000 & 2,00000 & 3,00000 & 1,00000 \\
\hline 2,00000 & 1,00000 & 4,00000 & 4,00000 & 6,00000 & 2,00000 \\
\hline 0,50000 & 0,25000 & 1,00000 & 1,00000 & 2,00000 & 0,50000 \\
\hline 0,50000 & 0,25000 & 1,00000 & 1,00000 & 2,00000 & 0,50000 \\
\hline 0,33333 & 0,16667 & 0,50000 & 0,50000 & 1,00000 & 0,33333 \\
\hline 1,00000 & 0,50000 & 2,00000 & 2,00000 & 3,00000 & 1,00000 \\
\hline & $\mathbf{5 , 3 3 3 3 3}$ & $\mathbf{2 , 6 6 6 6 7}$ & $\mathbf{1 0 , 5 0 0 0 0}$ & $\mathbf{1 0 , 5 0 0 0 0}$ & $\mathbf{1 7 , 0 0 0 0 0}$ & $\mathbf{5 , 3 3 3 3 3}$ \\
\hline
\end{tabular}

Matriz de Comparação Par a Par Normalizada

\begin{tabular}{|l|l|l|l|l|l|}
\hline 0,18750 & 0,18750 & 0,19048 & 0,19048 & 0,17647 & 0,18750 \\
\hline 0,37500 & 0,37500 & 0,38095 & 0,38095 & 0,35294 & 0,37500 \\
\hline 0,09375 & 0,09375 & 0,09524 & 0,09524 & 0,11765 & 0,09375 \\
\hline 0,09375 & 0,09375 & 0,09524 & 0,09524 & 0,11765 & 0,09375 \\
\hline 0,06250 & 0,06250 & 0,04762 & 0,04762 & 0,05882 & 0,06250 \\
\hline 0,18750 & 0,18750 & 0,19048 & 0,19048 & 0,17647 & 0,18750 \\
\hline 1,00000 & 1,00000 & 1,00000 & 1,00000 & 1,00000 & 1,00000 \\
\hline
\end{tabular}

wi

$$
2,23985
$$

$\div$

6

0,37331

0,09823

0,09823

0,05693

$$
0,34156
$$

0,18665

Cálculo do máximo eigenvalue ( $\lambda$ max $)$

\begin{tabular}{l|c|c|c|c|c|c|} 
Linha 1 & $\mathbf{1 , 0 0 0 0 0}$ & 0,50000 & 2,00000 & 2,00000 & 3,00000 & 1,00000 \\
\cline { 2 - 7 } Linha 2 & 2,00000 & $\mathbf{1 , 0 0 0 0 0}$ & 4,00000 & 4,00000 & 6,00000 & 2,00000 \\
\cline { 2 - 7 } Linha 3 & 0,50000 & 0,25000 & $\mathbf{1 , 0 0 0 0 0}$ & 1,00000 & 2,00000 & 0,50000 \\
\cline { 2 - 7 } Linha 4 & 0,50000 & 0,25000 & 1,00000 & $\mathbf{1 , 0 0 0 0 0}$ & 2,00000 & 0,50000 \\
\hline Linha 5 & 0,33333 & 0,16667 & 0,50000 & 0,50000 & $\mathbf{1 , 0 0 0 0 0}$ & 0,33333 \\
\cline { 2 - 7 } Linha 6 & 1,00000 & 0,50000 & 2,00000 & 2,00000 & 3,00000 & $\mathbf{1 , 0 0 0 0 0}$ \\
\cline { 2 - 7 }
\end{tabular}

wi

$\mathbf{w}^{\prime}$

\section{Exemplo para linha 1:}

$(1,00000 * 0,18665)+(0,50000 * 0,37331)+(2,00000 * 0,09823)+$

$(2,00000 * 0,09823)+(3,00000 * 0,05693)+(1,00000 * 0,18665)=\mathbf{1 , 1 2 3 6 5 8}$ 


$\begin{array}{ccc} & \mathbf{w}^{\prime} & \text { Pesos }\left(\mathbf{w}^{\prime} / \lambda \mathbf{~ m a x}\right) \\ \text { Linha 1 } & \mathbf{1 , 1 2 3 6 5 7 7 9 6} & 0,18675 \\ \text { Linha 2 } & 2,247315593 & 0,37349 \\ \text { Linha 3 } & 0,590292367 & 0,09810 \\ \text { Linha 4 } & 0,590292367 & 0,09810 \\ \text { Linha 5 } & 0,341809641 & 0,05681 \\ \text { Linha 6 } & 1,123657796 & 0,18675 \\ \lambda \text { max } & \mathbf{6 , 0 1 7 0 2 5 5 6} & \end{array}$

Etapa 3 : Cálculo do Grau de Consistência (CR - Consistency Ratio)

$$
\begin{array}{ll}
\mathbf{C R}=\frac{\mathrm{CI}}{\mathrm{RI}} & \mathbf{C I}=0,0034051 \\
\mathbf{C I}=\frac{1 \mathrm{max}-\mathrm{n}}{\mathrm{n}-1} & 1,24 \\
\mathbf{R I}= & 0,00275
\end{array}
$$


ANEXO D - Matrizes de comparação par a par do processo de avaliação $\boldsymbol{A H P}$ 


\section{Fase 1}

Qual a importância relativa dos critérios abaixo para monitoração da mobilidade urbana? Somente os campos em amarelo devem ser preenchidos.

Instruções detalhadas podem ser encontradas na planilha "Instruções".

Matriz 1 - Comparação das categorias de informação disponiveis via Internet

\begin{tabular}{|c|c|c|c|c|c|}
\hline & PlanDesenvUrb & IndUrb & IndMob & DadoEstaGera & DadoFisicDemo \\
\hline PlanDesenvUrb & 1 & & & & \\
\hline IndUrb & \#DIV/0! & 1 & & & \\
\hline IndMob & \#DIV/0! & \#DIV/0! & 1 & & \\
\hline DadoEsta Geral & \#DIV/0! & \#DIV/0! & \#DIV/0! & 1 & \\
\hline DadoFisicDemo & \#DIV/0! & \#DIV/0! & \#DIV/0! & \#DIV/0! & 1 \\
\hline
\end{tabular}

Grau de

$\mathrm{Se}>0.1$

Revise seus julgamentos!

Consistência

$\mathrm{Se}=0.1$

\section{Julgamentos consistentes!}

\section{Escala numérica}

1 - Igual importância

3 - Linha pouco mais importante que Coluna

5 - Linha muito mais importante que Coluna

1/3 - Coluna pouco mais importante que Linha

$1 / 5$ - Coluna muito mais importante que Linha

7 - Linha bastante mais importante que Coluna

1/7 - Coluna bastante mais importante que Linha

9 - Linha extremamente mais importante que Coluna 1/9 - Coluna extremamente mais importante que Linhs 


\section{Fase 2}

Qual a importância relativa dos critérios abaixo para monitoração da mobilidade urbana? Somente os campos em amarelo devem ser preenchidos.

Instruções detalhadas podem ser encontradas na planilha "Instruções".

Uma vez preenchida esta Matriz Inicial, clique nos links abaixo para acessar as matrizes de comparação relacionadas a cada uma das cinco categorias de informação.

$\begin{array}{llllll}\text { Instruçoes } & \text { Matriz 1 } & \text { Matriz 2 } & \text { Matriz 3 } & \text { Matriz 4 } & \text { Matriz 5 }\end{array}$

Matriz Inicial - Comparação das Categorias de informação relacionadas à mobilidade urbana sustentável

\begin{tabular}{|c|c|c|c|c|c|}
\hline & TranspAmbient & GestaoMob & InfraServTransp & PlaneEspac & AspSocioEcoTransp \\
\hline TranspAmbient & 1 & & & & \\
\hline GestaoMob & \#DIV/0! & 1 & & & \\
\hline InfraServTransp & \#DIV/0! & \#DIV/0! & 1 & & \\
\hline PlaneEspac & \#DIV/0! & \#DIV/0! & \#DIV/0! & 1 & \\
\hline AspSocioEcoTransp & \#DIV/0! & \#DIV/0! & \#DIV/0! & \#DIV/0! & 1 \\
\hline
\end{tabular}

Grau de

$\mathrm{Se}>0.1$

Revise seus julgamentos!

Consistência

$\mathrm{Se}=0.1$

Julgamentos consistentes!

Matriz 1 - Comparação dos Temas relacionados à Categoria TranspAmbient

\begin{tabular}{|c|c|c|c|c|}
\hline & EnergCombust & ImpactAmbient & QualiAr & RuidTraf \\
\hline EnergCombust & 1 & & & \\
\hline ImpactAmbient & \#DIV/0! & 1 & & \\
\hline QualiAr & \#DIV/0! & \#DIV/0! & 1 & \\
\hline RuidTraf & \#DIV/0! & \#DIV/0! & \#DIV/0! & 1 \\
\hline
\end{tabular}

Grau de

Se $>0.1$

Consistênci

$\mathrm{Se}=0.1$

Revise seus julgamentos!

Julgamentos consistentes! 
Matriz 2 - Comparação dos Temas relacionados à Categoria GestaoMob

\begin{tabular}{|c|c|c|c|c|}
\hline & DespInvestEstratEco & GerencMonitor & MedIncrementMob & NovaTecno \\
\hline DespInvestEstratEco & 1 & & & \\
\hline GerencMonitor & \#DIV/0! & 1 & & \\
\hline MedIncrementMob & $\# \mathrm{DIV} / 0 !$ & \#DIV/0! & 1 & 1 \\
\hline NovaTecno & \#DIV/0! & \#DIV/0! & \#DIV/0! & 1 \\
\hline
\end{tabular}

Graude $\quad$ Se $>0.1 \quad$ Revise seus julgamentos!

Consistência

$\mathrm{Se}=0$.

Julgamentos consistentes!

Matriz 3 - Comparação dos Temas relacionados à Categoria InfraServTransp

\begin{tabular}{|c|c|c|c|c|}
\hline & Frota & InfraSistVia & TecnoServTransp & Trafego \\
\hline Frota & 1 & & & \\
\hline InfraSistVia & \#DIV/0! & 1 & & \\
\hline TecnoServTransp & \#DIV/0! & \#DIV/0! & 1 & \\
\hline Trafego & \#DIV/0! & \#DIV/0! & \#DIV/0! & 1 \\
\hline
\end{tabular}

Grau de

Consistência

Se $>0.1$

$\mathrm{Se}=0.1$
Revise seus julgamentos!

Julgamentos consistentes!

Matriz 4 - Comparação dos Temas relacionados à Categoria PlaneEspac

\begin{tabular}{|c|c|c|c|c|}
\hline & AcessServAtivUrb & DesenvUrbUsoSolo & PopUrb & ViagDesloca \\
\hline AcessServAtivUrb & 1 & & & \\
\hline DesenvUrbUsoSolo & \#DIV/0! & 1 & & \\
\hline PopUrb & \#DIV/0! & \#DIV/0! & 1 & \\
\hline ViagDesloca & \#DIV/0! & \#DIV/0! & \#DIV/0! & 1 \\
\hline
\end{tabular}

Grau de

Consistência
$\mathrm{Se}>0.1$

$\mathrm{Se}=0.1$
Revise seus julgamentos!

Julgamentos consistentes! 
Fase 3

Qual a importância relativa dos critérios abaixo para monitoração da mobilidade urbana? Somente os campos em amarelo devem ser preenchidos.

Instruções detalhadas podem ser encontradas na planilha "Instruções".

Clique no link abaixo para voltar ao Menu Principal e acessar as demais matrizes de comparação. Menu Principal

\begin{tabular}{|c|c|c|c|c|c|} 
Matriz 1 - Comparação dos indicadores relacionados ao Tema EnergCombust \\
\begin{tabular}{|c|c|c|c|c|c|}
\hline & ConCombustFos & EficTranspCarg & EnergFinalTransp & IntensEnergTransp & EnergFosNaoFos \\
\hline ConCombustFos & 1 & & & & \\
\hline EficTranspCarg & \#DIV/0! & 1 & & & \\
\hline EnergFinalTransp & \#DIV/0! & \#DIV/0! & 1 & & \\
\hline IntensEnergTransp & \#DIV/0! & \#DIV/0! & \#DIV/0! & 1 & \\
\hline EnergFosNaoFos & \#DIV/0! & \#DIV/0! & \#DIV/0! & \#DIV/0! & 1 \\
\hline
\end{tabular}
\end{tabular}

\begin{tabular}{cc|c} 
Grau de & $\mathrm{Se}>0.1$ \\
Consistência & $\mathrm{Se}=0.1$
\end{tabular}$\quad \begin{gathered}\text { Revise seus julgamentos! } \\
\text { Julgamentos consistentes! }\end{gathered}$

\begin{tabular}{|c|c|c|c|c|c|}
\multicolumn{7}{|c|}{ Matriz 2 - Comparação dos indicadores relacionados ao Tema ImpactAmbient } \\
\hline & DescargOleo & Fragmentação & ImpactUsoAuto & ProxInfraProteg & ResidVeicRodo \\
\hline DescargOleo & 1 & & & & \\
\hline Fragmentação & \#DIV/0! & 1 & & & \\
\hline ImpactUsoAuto & \#DIV/0! & \#DIV/0! & 1 & & \\
\hline ProxInfraProteg & \#DIV/0! & \#DIV/0! & \#DIV/0! & 1 & \\
\hline ResidVeicRodo & \#DIV/0! & \#DIV/0! & \#DIV/0! & \#DIV/0! & 1 \\
\hline
\end{tabular}

\begin{tabular}{cc|} 
Grau de & $\mathrm{Se}>0.1$ \\
Consistência & $\mathrm{Se}=0.1$
\end{tabular}$\quad \begin{gathered}\text { Revise seus julgamentos! } \\
\text { Julgamentos consistentes! }\end{gathered}$


Matriz 3 - Comparaçãoes dos indicadores relacionados ao Tema QualiAr

\begin{tabular}{|c|c|c|c|c|c|c|}
\hline & MasQualiAr & EmissAcidTransp & EmissEstufTransp & EmissIntensTransp & PopExpoPolu & QualiAr \\
\hline DiasQualiAr & 1 & & & & & \\
\hline EmissAcidTransp & \#DIV/0! & 1 & & & & \\
\hline EmissEstufTransp & \#DIV/0! & \#DIV/0! & 1 & & \\
\hline EmissIntensTransp & \#DIV/0! & \#DIV/0! & \#DIV/0! & 1 & & \\
\hline PopExpoPolu & \#DIV/0! & \#DIV/0! & \#DIV/0! & \#DIV/0! & 1 & \\
\hline QualiAr & \#DIV/0! & \#DIV/0! & \#DIV/0! & \#DIV/0! & \#DIV/0! & 1 \\
\hline
\end{tabular}

\begin{tabular}{cl|l}
$\begin{array}{c}\text { Grau de } \\
\text { Consistência }\end{array}$ & $\mathrm{Se}>0.1$ & $\begin{array}{c}\text { Revise seus julgamentos! } \\
\text { Julgamentos consistentes! }\end{array}$ \\
\hline
\end{tabular}

Matriz 4 - Comparação dos indicadores relacionados ao Tema RuidTraf

\begin{tabular}{|c|c|c|c|c|}
\hline & MedMiniRuid & PoluSon & PopExpoRuid & RuiTrafExp \\
\hline MedMiniRuid & 1 & & & \\
\hline PoluSon & \#DIV/0! & 1 & & \\
\hline PopExpoRuid & \#DIV/0! & \#DIV/0! & 1 & \\
\hline RuiTrafExp & \#DIV/0! & \#DIV/0! & \#DIV/0! & 1 \\
\hline
\end{tabular}

\begin{tabular}{cl|}
\hline Grau de & $\mathrm{Se}>0.1$ \\
Consistência & $\mathrm{Se}=0.1$
\end{tabular}$\quad \begin{gathered}\text { Revise seus julgamentos! } \\
\text { Julgamentos consistentes! }\end{gathered}$

Matriz 5 - Comparação dos indicadores relacionados ao Tema DespInvestEstratEco

\begin{tabular}{|c|c|c|c|c|c|c|}
\hline & CapInvestMod & DespPublicTranspPriv & DespPublicTranspPublic & InvestInfraTransp & SubsidTransp & TaxVeicUtili \\
\hline CapInvestMod & 1 & & & & & \\
\hline DespPublicTranspPriv & \#DIV/0! & 1 & & & \\
\hline DespPublicTranspPublic & \#DIV/0! & \#DIV/0! & 1 & & \\
\hline InvestInfraTransp & \#DIV/0! & \#DIV/0! & \#DIV/0! & 1 & \\
\hline SubsidTransp & \#DIV/0! & \#DIV/0! & \#DIV/0! & \#DIV/0! & 1 & \\
\hline TaxVeicUtili & \#DIV/0! & \#DIV/0! & \#DIV/0! & \#DIV/0! & \#DIV/0! & 1 \\
\hline
\end{tabular}

\begin{tabular}{cl|}
\hline Grau de & $\mathrm{Se}>0.1$ \\
Consistência & $\mathrm{Se}=0.1$
\end{tabular}$\quad \begin{gathered}\text { Revise seus julgamentos! } \\
\text { Julgamentos consistentes! }\end{gathered}$


Matriz 6 - Comparação dos indicadores relacionados ao Tema GerencMonitor

\begin{tabular}{|c|c|c|c|}
\hline & AvalImpactAmb & GerencTrafFiscal & SistMonitorTranspAmb \\
\hline AvalImpact Amb & 1 & & \\
\hline GerencTrafFiscal & \#DIV/0! & 1 & \\
\hline SistMonitorTranspAmb & $\# \mathrm{DIV} / 0 !$ & $\# \mathrm{DIV} / 0 !$ & 1 \\
\hline
\end{tabular}

\begin{tabular}{cc|}
\hline Grau de & $\mathrm{Se}>0.1$ \\
Consistência & $\mathrm{Se}=0.1$
\end{tabular}$\quad \begin{gathered}\text { Revise seus julgamentos! } \\
\text { Julgamentos consistentes! }\end{gathered}$

Matriz 7 - Comparação dos indicadores relacionados ao Tema MedIncrementMob

\begin{tabular}{|c|c|c|c|c|c|c|}
\hline & PlanRedViag & RegulaDensidMin & EstratAmbTransp & OperaEficVeic & MelhoraTransp & PriorViagPedCiclist \\
\hline PlanRedViag & 1 & & & & & \\
\hline RegulaDensidMin & \#DIV/0! & 1 & & & & \\
\hline EstratAmbTransp & \#DIV/0! & \#DIV/0! & 1 & & & \\
\hline OperaEficVeic & \#DIV/0! & \#DIV/0! & \#DIV/0! & 1 & & \\
\hline MelhoraTransp & \#DIV/0! & \#DIV/0! & \#DIV/0! & \#DIV/0! & 1 & \\
\hline PriorViagPedCiclist & \#DIV/0! & \#DIV/0! & \#DIV/0! & \#DIV/0! & \#DIV/0! & \\
\hline
\end{tabular}

Grau de

Consistência

$\mathrm{Se}>0.1$
$\mathrm{Se}=0.1$

Revise seus julgamentos!

Julgamentos consistentes!

Matriz 8 -Comparação dos indicadores relacionados ao Tema NovaTecno

\begin{tabular}{|c|c|c|c|c|c|c|c|}
\hline & CombustLimpAlter & GastCombustLimp & GastVeicEco & NovaFormaTransp & CustIniciaVeicEco & TecnoCartIntelig & VidaUtilVeicEco \\
\hline CombustLimpAlter & 1 & & & & & & \\
\hline GastCombust Limp & \#DIV/0! & 1 & & & & & \\
\hline GastVeicEco & \#DIV/0! & \#DIV/0! & 1 & & & & \\
\hline NovaFormaTransp & \#DIV/0! & \#DIV/0! & \#DIV/0! & 1 & & & \\
\hline CustIniciaVeicEco & \#DIV/0! & \#DIV/0! & \#DIV/0! & \#DIV/0! & 1 & & \\
\hline TecnoCartIntelig & \#DIV/0! & \#DIV/0! & \#DIV/0! & \#DIV/0! & \#DIV/0! & 1 & \\
\hline VidaUtilVeicEco & \#DIV/0! & \#DIV/0! & \#DIV/0! & \#DIV/0! & \#DIV/0! & \#DIV/0! & 1 \\
\hline
\end{tabular}

$\begin{array}{cc}\text { Grau de } & \mathrm{Se}>0.1 \\ \text { Consistência } & \mathrm{Se}=0.1\end{array}$

Grau de

$\mathrm{Se}=0.1$
Revise seus julgamentos!

Julgamentos consistentes! 
Matriz 9 - Comparação dos indicadores relacionados ao Tema Frota

\begin{tabular}{|c|c|c|c|c|c|c|}
\hline & FrotVeicRodo & IdadMedVeic & FrotConvertRedPolu & PropAutoPriv & VeicEficVeicNaoefic & VeicCircula \\
\hline FrotVeicRodo & 1 & & & & & \\
\hline IdadMedVeic & \#DIV/0! & 1 & & & & \\
\hline FrotConvertRedPolu & \#DIV/0! & \#DIV/0! & 1 & & & \\
\hline PropAutoPriv & \#DIV/0! & \#DIV/0! & \#DIV/0! & 1 & & \\
\hline VeicEficVeicNaoefic & \#DIV/0! & \#DIV/0! & \#DIV/0! & \#DIV/0! & 1 & \\
\hline VeicCircula & \#DIV/0! & \#DIV/0! & \#DIV/0! & \#DIV/0! & \#DIV/0! & 1 \\
\hline
\end{tabular}

Grau de

Consistência

\section{$\mathrm{Se}>0.1$} $\mathrm{Se}=0.1$
Revise seus julgamentos!

Julgamentos consistentes!

\begin{tabular}{|c|c|c|c|c|c|c|c|c|}
\hline & & & & & & & & \\
\hline & CapacidadInfra & CompViaCicilst & ViaOtimTraf & RedVia & ExtViaPedest & EstacionaCar & AcessTranspPavi & TrafficCalming \\
\hline CapacidadInfra & 1 & & & & & & & \\
\hline CompViaCicilst & \#DIV/0! & 1 & & & & & & \\
\hline ViaOtimTraf & \#DIV/0! & \#DIV/0! & 1 & & & & & \\
\hline RedVia & \#DIV/0! & \#DIV/0! & \#DIV/0! & 1 & & & & \\
\hline ExtViaPedest & \#DIV/0! & \#DIV/0! & \#DIV/0! & \#DIV/0! & 1 & & & \\
\hline EstacionaCar & \#DIV/0! & \#DIV/0! & \#DIV/0! & \#DIV/0! & \#DIV/0! & 1 & & \\
\hline AcessTranspPavi & \#DIV/0! & \#DIV/0! & \#DIV/0! & \#DIV/0! & \#DIV/0! & \#DIV/0! & 1 & \\
\hline TrafficCalming & \#DIV/0! & \#DIV/0! & \#DIV/0! & \#DIV/0! & \#DIV/0! & \#DIV/0! & \#DIV/0! & 1 \\
\hline
\end{tabular}

Grau de

Se $>0.1$

Revise seus julgamentos!

Consistência

$\mathrm{Se}=0.1$

Julgamentos consistentes!

Matriz 11 - Comparação dos indicadores relacionados ao Tema TecnoServTrans

\begin{tabular}{|c|c|c|c|c|c|}
\multicolumn{7}{c}{ Matriz 11 - Comparação dos indicadores relacionados ao Tema TecnoServTransp } \\
\hline & AquisBic & MudaModTransp & TrafRodo & TranspCarg & TranspPassag \\
\hline AquisBic & 1 & & & & \\
\hline MudaModTransp & \#DIV/0! & 1 & & & \\
\hline TrafRodo & \#DIV/0! & \#DIV/0! & 1 & & \\
\hline TranspCarg & \#IV/0! & \#DIV/0! & \#DIV/0! & 1 & \\
\hline TranspPassag & \#DIV/0! & \#DIV/0! & \#DIV/0! & \#DIV/0! & 1 \\
\hline
\end{tabular}

TranspPassag

Revise seus julgamentos!

Grau de

$\mathrm{Se}>0.1$

Julgamentos consistentes! 
Matriz 12 - Comparação dos indicadores relacionados ao Tema Trafego

\begin{tabular}{|c|c|c|c|c|c|c|}
\hline & CongestionaTraf & DensidTraf & VolTraf & OcupaVeicPassag & TempTraf & VelocTraf \\
\hline CongestionaTraf & 1 & & & & & \\
\hline DensidTraf & $\# \mathrm{DIV} / 0 !$ & 1 & & & & \\
\hline VolTraf & $\# \mathrm{DIV} / 0 !$ & $\# \mathrm{DIV} / 0 !$ & 1 & & & \\
\hline OcupaVeicPassag & \#DIV/0! & \#DIV/0! & \#DIV/0! & 1 & & \\
\hline TempTraf & \#DIV/0! & \#DIV/0! & \#DIV/0! & $\#$ DIV/0! & 1 & \\
\hline VelocTraf & $\# \mathrm{DIV} / 0 !$ & \#DIV/0! & \#DIV/0! & $\# \mathrm{DIV} / 0 !$ & $\#$ DIV/0! & 1 \\
\hline
\end{tabular}

\begin{tabular}{|cc|}
\hline Grau de & $\mathrm{Se}>0.1$ \\
Consistência & $\mathrm{Se} \leq 0.1$
\end{tabular}$\quad \begin{gathered}\text { Revise seus julgamentos! } \\
\text { Julgamentos consistentes! }\end{gathered}$

\begin{tabular}{|c|c|c|c|c|c|c|}
\hline \multicolumn{7}{|c|}{ Matriz 13 - Comparação dos indicadores relacionados ao Tema AcessServAtivUrb } \\
\hline & AcessBairro & AcessCentro & AcessServBasic & AcessServTransp & EmpregDistResid & PessoaDistLazer \\
\hline AcessBairro & 1 & & & & & \\
\hline AcessCentro & \#DIV/0! & 1 & & & & \\
\hline AcesSServBasic & \#DIV/0! & \#DIV/0! & 1 & & & \\
\hline AcessServTransp & \#DIV/0! & \#DIV/0! & \#DIV/0! & 1 & & \\
\hline EmpregDistResid & \#DIV/0! & \#DIV/0! & \#DIV/0! & \#DIV/0! & 1 & \\
\hline PessoaDistLazer & \#DIV/0! & \#DIV/0! & \#DIV/0! & \#DIV/0! & \#DIV/0! & \\
\hline
\end{tabular}

\begin{tabular}{|cc|}
\hline Grau de & $\mathrm{Se}>0.1$ \\
Consistência & $\mathrm{Se} \leq 0.1$
\end{tabular}$\quad \begin{aligned} & \text { Revise seus julgamentos! } \\
& \text { Julgamentos consistentes! }\end{aligned}$

\begin{tabular}{|c|c|c|}
\hline & CategorUsoSolo & VerdVersusAutoPirv \\
\hline CategorUsoSolo & 1 & \\
\hline VerdVersusAutoPirv & $\#$ DIV/0! & 1 \\
\hline DeconcAtiv & $\#$ DIV/0! & \#DIV/0! \\
\hline FormUrb & \#DIV/0! & \#DIV/0! \\
\hline IncentUsoMistAltaDensid & \#DIV/0! & \#DIV/0! \\
\hline MudaSoloInfraTransp & $\# \mathrm{DIV} / 0 !$ & $\#$ DIV/0! \\
\hline PlanejaSoloUrb & $\# \mathrm{DIV} / 0 !$ & \#DIV/0! \\
\hline PoliticPedestCiclistPublic & \#DIV/0! & \#DIV/0! \\
\hline
\end{tabular}

Matriz 14 - Comparação dos indicadores relacionados ao Tema DesenvolvUrbUsoSolo

\begin{tabular}{|c|c|c|c|c|c|}
\hline DeconcAtiv & FormUrb & IncentUsoMistAltaDensid & MudaSoloInfraTransp & PlanejaSoloUrb & PoliticPedestCiclistPublic \\
\hline & & & & & \\
\hline 1 & & & & & \\
\hline$\#$ \#IV/0! & 1 & & & & \\
\hline$\#$ \#IV/0! & $\#$ \#IV/0! & 1 & & & \\
\hline$\# \mathrm{DIV} / 0 !$ & \#DIV/0! & $\#$ DIV/0! & 1 & & \\
\hline$\# \mathrm{DIV} / 0 !$ & $\#$ DIV/0! & $\# \mathrm{DIV} / 0 !$ & $\# \mathrm{DIV} / 0 !$ & 1 & \\
\hline \#DIV/0! & \#DIV/0! & \#DIV/0! & \#DIV/0! & \#DIV/0! & 1 \\
\hline
\end{tabular}

\begin{tabular}{|cc|}
\hline Grau de & $\mathrm{Se}>0.1$ \\
Consistência & $\mathrm{Se} \leq 0.1$ \\
\hline
\end{tabular}

Revise seus julgamentos.

Julgamentos consistentes! 
Matriz 15 - Comparação dos indicadores relacionados ao Tema PopUrb

\begin{tabular}{|c|c|c|c|c|c|}
\hline & UnidFamCrescPop & DensidPop & EstrutEtarPop & RendFamPercapita & TaxCrescPop \\
\hline UnidFamCrescPop & 1 & & & & \\
\hline DensidPop & \#DIV/0! & 1 & & & \\
\hline EstrutEtarPop & \#DIV/0! & \#DIV/0! & 1 & & \\
\hline RendFamPercapita & \#DIV/0! & \#DIV/0! & \#DIV/0! & 1 & \\
\hline TaxCrescPop & \#DIV/0! & \#DIV/0! & \#DIV/0! & \#DIV/0! & 1 \\
\hline
\end{tabular}

\begin{tabular}{cl|}
$\begin{array}{c}\text { Grau de } \\
\text { Consistência }\end{array}$ & $\mathrm{Se}>0.1$ \\
$\mathrm{Se}=0.1$ & Revise seus julgamentos! \\
Julgamentos consistentes!
\end{tabular}

\begin{tabular}{|c|c|c|c|c|c|c|c|c|}
\hline & & & & & & & & \\
\hline Deslocacriançaksc & 1 & & & & & & & \\
\hline DistServBasic & \#DIV/0! & 1 & & & & & & \\
\hline DistFam & \#DIV/0! & \#DIV/0! & 1 & & & & & \\
\hline DistPedBiciDia & \#DIV/0! & \#DIV/0! & \#DIV/0! & 1 & & & & \\
\hline MobLocal & \#DIV/0! & \#DIV/0! & \#DIV/0! & \#DIV/0! & 1 & & & \\
\hline PopVivTrabLocal & \#DIV/0! & \#DIV/0! & \#DIV/0! & \#DIV/0! & \#DIV/0! & 1 & & \\
\hline UtliAutoDistInferior & \#DIV/0! & \#DIV/0! & \#DIV/0! & \#DIV/0! & \#DIV/0! & \#DIV/0! & 1 & \\
\hline TempViag & \#DIV/0! & \#DIV/0! & \#DIV/0! & \#DIV/0! & \#DIV/0! & \#DIV/0! & \#DIV/0! & 1 \\
\hline
\end{tabular}

$\begin{array}{ll}\text { Grau de } & \mathrm{Se}>0.1 \\ \text { Covise seus julgamentos! }\end{array}$

Consistência $\quad \mathrm{Se}=0.1 \quad$ Julgamentos consistentes!

Matriz 17 - Comparação dos indicadores relacionados ao Tema CustPreçoTar

\begin{tabular}{|c|c|c|c|c|c|}
\hline & CustPassagTransp & EvoluPreçoCombust & MudaPreçoTranspModo & PreçoCombustTax & PreçoTranspPublic \\
\hline CustPassagTransp & 1 & & & & \\
\hline EvoluPreçoCombust & \#DIV/0! & 1 & & & \\
\hline MudaPreçoTranspModo & \#DIV/0! & \#DIV/0! & 1 & & \\
\hline PreçoCombustTax & \#DIV/0! & \#DIV/0! & \#DIV/0! & 1 & \\
\hline PreẹoTranspPublic & \#DIV/0! & \#DIV/0! & \#DIV/0! & \#DIV/0! & 1 \\
\hline
\end{tabular}

Grau de

Consistência
$\mathrm{Se}>0.1$

$\mathrm{Se}=0.1$
Revise seus julgamentos!

Julgamentos consistentes! 
Matriz 18 - Comparação dos indicadores relacionados ao Tema ImpactSocioEcoTransp

\begin{tabular}{|c|c|c|c|c|}
\hline & BeneficUsaTransp & CustCongestiona & CustSocial & RendOperaTransp \\
\hline BeneficUsaTransp & 1 & & & \\
\hline CustCongestiona & \#DIV/0! & 1 & & \\
\hline CustSocial & \#DIV/0! & \#DIV/0! & 1 & \\
\hline RendOperaTransp & \#DIV/0! & \#DIV/0! & \#DIV/0! & 1 \\
\hline
\end{tabular}

\begin{tabular}{|c|c|}
\hline Grau de & $\mathrm{Se}>0.1$ \\
Consistência & $\mathrm{Se}=0.1$ \\
\hline
\end{tabular}

\begin{tabular}{|c|c|c|c|c|c|}
\hline & AcidentTranspFatal & FeridoAcidentTraf & CrimeTransit & AcidentPedestCiclist & SegurViaResidencia \\
\hline AcidentTranspFatal & 1 & & & & \\
\hline FeridoAcidentTraf & \#DIV/0! & 1 & & & \\
\hline CrimeTransit & \#DIV/0! & \#DIV/0! & 1 & & \\
\hline AcidentPedestCiclist & \#DIV/0! & \#DIV/0! & \#DIV/0! & 1 & \\
\hline SegurViaResidencia & \#DIV/0! & \#DIV/0! & \#DIV/0! & \#DIV/0! & 1 \\
\hline
\end{tabular}

\begin{tabular}{cc|} 
Grau de & $\mathrm{Se}>0.1$ \\
Consistência & $\mathrm{Se}=0.1$
\end{tabular}$\quad \begin{gathered}\text { Revise seus julgamentos! } \\
\text { Julgamentos consistentes! }\end{gathered}$

\begin{tabular}{|c|c|c|c|}
\multicolumn{5}{|c}{ Matriz 20 - Comparação dos indicador } \\
\hline & DemandTranspPassag & DispTranspPublic & DiversidadTransp \\
\hline DemandTranspPassag & 1 & & \\
\hline DispTranspPublic & \#DIV/0! & 1 & 1 \\
\hline DiversidadTransp & \#DIV/0! & \#DIV/0! & \#DIV/0! \\
\hline NecessTransp & \#DIV/0! & \#DIV/0! & \#DIV/0! \\
\hline NivServTranspPublic & \#DIV/0! 0 & \#DIV/0! & \#DIV/0! \\
\hline TranspPublicInsegur & \#DIV/0! & \#DIV/0! & \#DIV/0! \\
\hline TranspPublicVersusCar & \#DIV/0! & \#DIV/0! & \\
\hline
\end{tabular}

\begin{tabular}{l} 
cadores relacionados ao Tema TranspPublic \\
\hline
\end{tabular}

\begin{tabular}{|cc|}
\hline Grau de & $\mathrm{Se}>0.1$ \\
Consistência & $\mathrm{Se}=0.1$ \\
\hline
\end{tabular}

Revise seus julgamentos!

Julgamentos consistentes! 
ANEXO E - Pesos para os critérios avaliados nas Fases 1, 2 e 3 através do método $A H P$ 
Tabela E-1: Pesos obtidos para as Fases 1 e 2 do processo de avaliação $A H P$ para o Brasil

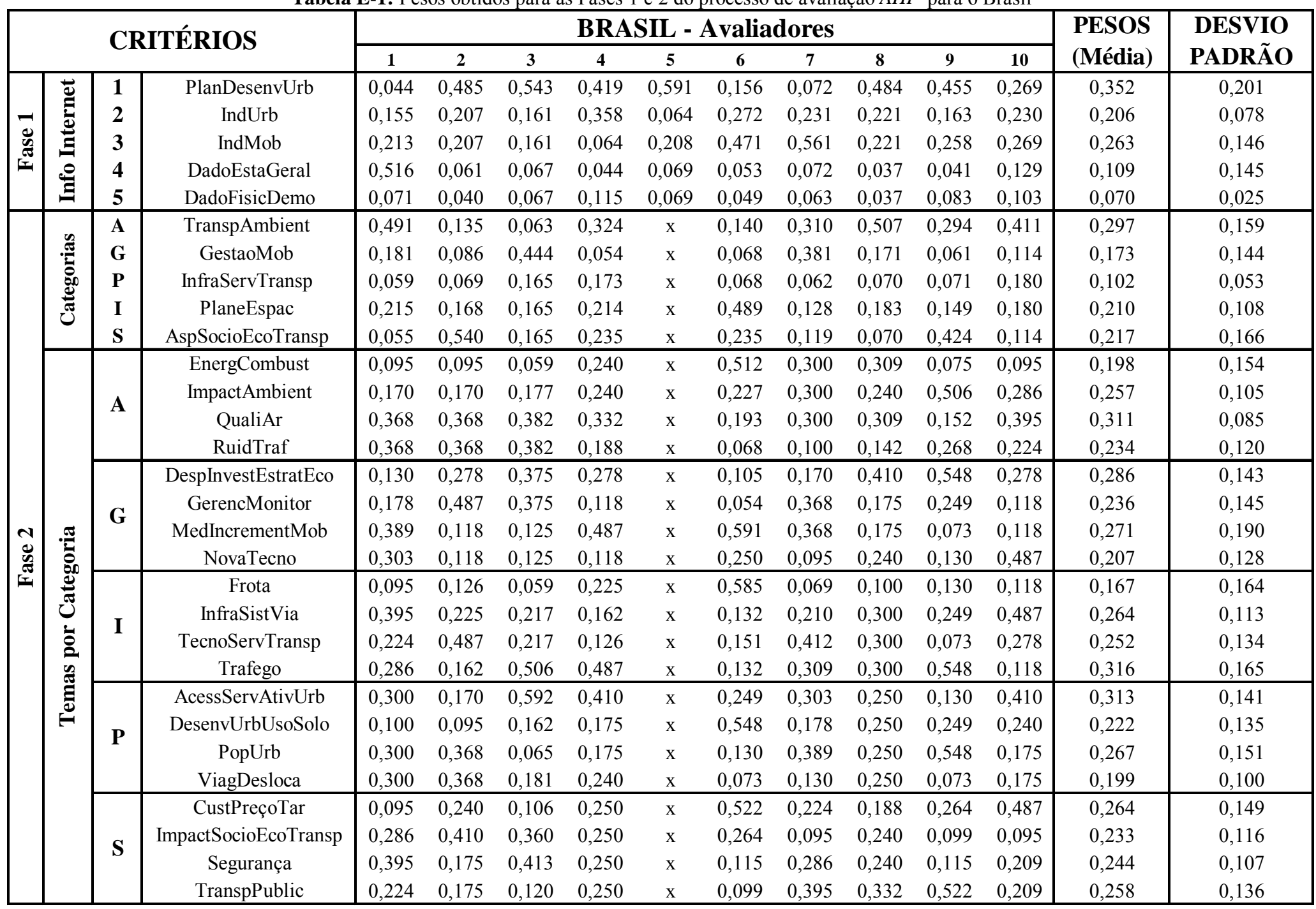


Tabela E-2: Pesos obtidos para as Fase 3 processo de avaliação AHP para o Brasil

\begin{tabular}{|c|c|c|c|c|c|c|c|c|c|c|c|c|c|c|c|}
\hline & & CR & ITÉRIOS & & & & & $\mathbf{L}$ & Avalia & lores & & & & PESOS & DESVIO \\
\hline & & & & 1 & 2 & 3 & 4 & 5 & 6 & 7 & 8 & 9 & 10 & (Média) & PADRÃO \\
\hline & & & ConCombustFos & $\mathrm{x}$ & $\mathrm{x}$ & $\bar{x}$ & $\bar{x}$ & $\mathrm{x}$ & 0,124 & 0,075 & 0,290 & $\mathrm{x}$ & $\mathrm{x}$ & 0,163 & 0,113 \\
\hline & & & EficTranspCarg & $\mathrm{x}$ & $\mathrm{x}$ & $\mathrm{x}$ & $\mathrm{x}$ & $\mathrm{x}$ & 0,040 & 0,255 & 0,152 & $\mathrm{x}$ & $\mathrm{x}$ & 0,149 & 0,108 \\
\hline & & A1 & EnergFinalTransp & $\mathrm{x}$ & $\mathrm{x}$ & $\mathrm{x}$ & $\mathrm{x}$ & $\mathrm{x}$ & 0,320 & 0,434 & 0,116 & $\mathrm{x}$ & $\mathrm{x}$ & 0,290 & 0,161 \\
\hline & & & IntensEnergTransp & $\mathrm{x}$ & $\mathrm{x}$ & $\mathrm{x}$ & $\mathrm{x}$ & $\mathrm{x}$ & 0,383 & 0,103 & 0,152 & $\mathrm{x}$ & $\mathrm{x}$ & 0,213 & 0,150 \\
\hline & & & EnergFosNaofos & $\mathrm{x}$ & $\mathrm{x}$ & $\mathrm{x}$ & $\mathrm{x}$ & $\mathrm{x}$ & 0,133 & 0,132 & 0,290 & $\mathrm{x}$ & $\mathrm{x}$ & 0,185 & 0,091 \\
\hline & & & DescargOleo & $\mathrm{x}$ & $\mathrm{x}$ & $\bar{x}$ & $\bar{x}$ & $\mathrm{x}$ & 0,055 & 0,044 & 0,350 & $\mathrm{x}$ & $\mathrm{x}$ & 0,150 & 0,174 \\
\hline & & & Fragmentacao & $\mathrm{x}$ & $\mathrm{x}$ & $\mathrm{x}$ & $\mathrm{x}$ & $\mathrm{x}$ & 0,131 & 0,128 & 0,221 & $\mathrm{x}$ & $\mathrm{x}$ & 0,160 & 0,053 \\
\hline & & A2 & ImpactUsoAuto & $\mathrm{x}$ & $\mathrm{x}$ & $\mathrm{x}$ & $\mathrm{x}$ & $\mathrm{x}$ & 0,360 & 0,398 & 0,117 & $\mathrm{x}$ & $\mathrm{x}$ & 0,292 & 0,153 \\
\hline & & & ProxInfraProteg & $\mathrm{x}$ & $\mathrm{x}$ & $\mathrm{x}$ & $\mathrm{x}$ & $\mathrm{x}$ & 0,087 & 0,051 & 0,224 & $\mathrm{x}$ & $\mathrm{x}$ & 0,121 & 0,091 \\
\hline & & & ResidVeicRodo & $\mathrm{x}$ & $\mathrm{x}$ & $\mathrm{x}$ & $\mathrm{x}$ & $\mathrm{x}$ & 0,366 & 0,378 & 0,089 & $\mathrm{x}$ & $\mathrm{x}$ & 0,278 & 0,164 \\
\hline & & & DiasQualiAr & $\mathrm{x}$ & $\mathrm{x}$ & $\bar{x}$ & $\mathrm{x}$ & $\mathrm{x}$ & 0,169 & 0,096 & 0,063 & $\mathrm{x}$ & $\mathrm{x}$ & 0,109 & 0,054 \\
\hline & $\ddot{\Xi}$ & & EmissAcidTransp & $\mathrm{x}$ & $\mathrm{x}$ & $\mathrm{x}$ & $\mathrm{x}$ & $\mathrm{x}$ & 0,061 & 0,081 & 0,188 & $\mathrm{x}$ & $\mathrm{x}$ & 0,110 & 0,068 \\
\hline & E & 13 & EmissEstufTransp & $\mathrm{x}$ & $\mathrm{x}$ & $\mathrm{x}$ & $\mathrm{x}$ & $\mathrm{x}$ & 0,057 & 0,034 & 0,188 & $\mathrm{x}$ & $\mathrm{x}$ & 0,093 & 0,083 \\
\hline$m$ & 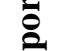 & A3 & EmissIntensTransp & $\mathrm{x}$ & $\mathrm{x}$ & $\mathrm{x}$ & $\mathrm{x}$ & $\mathrm{x}$ & 0,091 & 0,285 & 0,188 & $\mathrm{x}$ & $\mathrm{x}$ & 0,188 & 0,097 \\
\hline 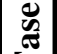 & $\ddot{z}$ & & PopExpoPolu & $\mathrm{x}$ & $\mathrm{x}$ & $\mathrm{x}$ & $\mathrm{x}$ & $\mathrm{x}$ & 0,364 & 0,326 & 0,188 & $\mathrm{x}$ & $\mathrm{x}$ & 0,292 & 0,093 \\
\hline & $\ddot{0}$ & & QualiAr & $\mathrm{x}$ & $\mathrm{x}$ & $\mathrm{x}$ & $\mathrm{x}$ & $\mathrm{x}$ & 0,259 & 0,178 & 0,188 & $\mathrm{x}$ & $\mathrm{x}$ & 0,208 & 0,044 \\
\hline & .ֶ. & & MedMiniRuid & $\mathrm{x}$ & $\mathrm{x}$ & $\mathrm{x}$ & $\mathrm{x}$ & $\mathrm{x}$ & 0,303 & 0,065 & 0,250 & $\mathrm{x}$ & $\mathrm{x}$ & 0,206 & 0,125 \\
\hline & 五 & $M$ & PoluSon & $\mathrm{x}$ & $\mathrm{x}$ & $\mathrm{x}$ & $\mathrm{x}$ & $x$ & 0,178 & 0,592 & 0,250 & $\mathrm{x}$ & $\mathrm{x}$ & 0,340 & 0,221 \\
\hline & & A4 & PopExpoRuid & $\mathrm{x}$ & $\mathrm{x}$ & $\mathrm{x}$ & $\mathrm{x}$ & $\mathrm{x}$ & 0,389 & 0,162 & 0,250 & $\mathrm{x}$ & $\mathrm{x}$ & 0,267 & 0,114 \\
\hline & & & RuiTrafExp & $\mathrm{x}$ & $\mathrm{x}$ & $\mathrm{x}$ & $\mathrm{x}$ & $\underline{x}$ & 0,130 & 0,181 & 0,250 & $\mathrm{x}$ & $\mathrm{x}$ & 0,187 & 0,060 \\
\hline & & & CapInvestMod & $\mathrm{x}$ & $\mathrm{x}$ & $\mathrm{x}$ & $\mathrm{x}$ & $\mathrm{x}$ & 0,082 & 0,305 & 0,198 & $\mathrm{x}$ & $\mathrm{x}$ & 0,195 & 0,112 \\
\hline & & & DespPublicTranspPriv & $\mathrm{x}$ & $\mathrm{x}$ & $\mathrm{x}$ & $\mathrm{x}$ & $\mathrm{x}$ & 0,039 & 0,047 & 0,078 & $\mathrm{x}$ & $\mathrm{x}$ & 0,055 & 0,021 \\
\hline & & $C_{5}$ & DespPublicTranspPublic & $\mathrm{x}$ & $\mathrm{x}$ & $\mathrm{x}$ & $\mathrm{x}$ & $\mathrm{x}$ & 0,149 & 0,055 & 0,358 & $\mathrm{x}$ & $\mathrm{x}$ & 0,187 & 0,155 \\
\hline & & Wo & InvestInfraTransp & $\mathrm{x}$ & $\mathrm{x}$ & $\mathrm{x}$ & $\mathrm{x}$ & $\mathrm{x}$ & 0,423 & 0,302 & 0,198 & $\mathrm{x}$ & $\mathrm{x}$ & 0,308 & 0,112 \\
\hline & & & SubsidTransp & $\mathrm{x}$ & $\mathrm{x}$ & $\mathrm{x}$ & $\mathrm{x}$ & $\mathrm{x}$ & 0,195 & 0,190 & 0,100 & $\mathrm{x}$ & $\mathrm{x}$ & 0,162 & 0,053 \\
\hline & & & TaxVeicUtili & $\mathrm{x}$ & $\mathrm{x}$ & $\mathrm{x}$ & $\mathrm{x}$ & $\mathrm{x}$ & 0,113 & 0,102 & 0,067 & $\mathrm{x}$ & $\mathrm{x}$ & 0,094 & 0,024 \\
\hline & & & AvalImpactAmb & $\mathrm{x}$ & $\mathrm{x}$ & $\mathrm{x}$ & $\mathrm{x}$ & $\mathrm{x}$ & 0,481 & 0,077 & 0,333 & $\mathrm{x}$ & $\mathrm{x}$ & 0,297 & 0,204 \\
\hline & & G6 & GerencTrafFiscal & $\mathrm{x}$ & $\mathrm{x}$ & $\mathrm{x}$ & $\mathrm{x}$ & $\mathrm{x}$ & 0,114 & 0,231 & 0,333 & $\mathrm{x}$ & $\mathrm{x}$ & 0,226 & 0,110 \\
\hline & & & SistMonitorTranspAmb & $\mathrm{x}$ & $\mathrm{x}$ & $\mathrm{x}$ & $\mathrm{x}$ & $\mathrm{x}$ & 0,405 & 0,692 & 0,333 & $\mathrm{x}$ & $\mathrm{x}$ & 0,477 & 0,190 \\
\hline
\end{tabular}




\begin{tabular}{|c|c|c|c|c|c|c|c|c|c|c|c|c|c|c|c|}
\hline & & CE & TÉRIOS & & & & & & Ivalia & lores & & & & PESOS & DESVIO \\
\hline & & & & 1 & 2 & 3 & 4 & 5 & 6 & 7 & 8 & 9 & 10 & (Média) & PADRÃO \\
\hline & & & PlanRedViag & $\bar{x}$ & $\mathrm{x}$ & $\bar{x}$ & $\mathrm{x}$ & $x$ & 0,174 & 0,271 & 0,129 & $\bar{x}$ & $\mathrm{x}$ & 0,191 & 0,072 \\
\hline & & & RegulaDensidMin & $\mathrm{x}$ & $\mathrm{x}$ & $\mathrm{x}$ & $\mathrm{x}$ & $x$ & 0,228 & 0,051 & 0,270 & $\mathrm{x}$ & $\mathrm{x}$ & 0,183 & 0,116 \\
\hline & & & EstratAmbTransp & $\mathrm{x}$ & $\mathrm{x}$ & $\mathrm{x}$ & $\mathrm{x}$ & $x$ & 0,103 & 0,154 & 0,244 & $\mathrm{x}$ & $\mathrm{x}$ & 0,167 & 0,072 \\
\hline & & G7 & OperaEficVeic & $\mathrm{x}$ & $\mathrm{x}$ & $\mathrm{x}$ & $\mathrm{x}$ & $x$ & 0,069 & 0,316 & 0,081 & $\mathrm{x}$ & $\mathrm{x}$ & 0,155 & 0,139 \\
\hline & & & MelhoraTransp & $\mathrm{x}$ & $\mathrm{x}$ & $\mathrm{x}$ & $\mathrm{x}$ & $x$ & 0,276 & 0,142 & 0,096 & $\mathrm{x}$ & $\mathrm{x}$ & 0,171 & 0,093 \\
\hline & & & PriorViagPedCiclist & $\mathrm{x}$ & $\mathrm{x}$ & $\mathrm{x}$ & $\underline{x}$ & $x$ & 0,151 & 0,066 & 0,179 & $\mathrm{x}$ & $\mathrm{x}$ & 0,132 & 0,059 \\
\hline & & & CombustLimpAlter & $\mathrm{x}$ & $\mathrm{x}$ & $\mathrm{x}$ & $\bar{x}$ & $x$ & 0,086 & 0,217 & 0,172 & $\mathrm{x}$ & $\mathrm{x}$ & 0,159 & 0,066 \\
\hline & & & GastCombustLimp & $\mathrm{x}$ & $\mathrm{x}$ & $\mathrm{x}$ & $\mathrm{x}$ & $x$ & 0,098 & 0,086 & 0,239 & $\mathrm{x}$ & $\mathrm{x}$ & 0,141 & 0,085 \\
\hline & & & GastVeicEco & $\mathrm{x}$ & $\mathrm{x}$ & $\mathrm{x}$ & $\mathrm{x}$ & $x$ & 0,068 & 0,103 & 0,198 & $\mathrm{x}$ & $\mathrm{x}$ & 0,123 & 0,068 \\
\hline & & G8 & NovaFormaTransp & $\mathrm{x}$ & $\mathrm{x}$ & $\mathrm{x}$ & $\mathrm{x}$ & $x$ & 0,285 & 0,373 & 0,153 & $\mathrm{x}$ & $\mathrm{x}$ & 0,270 & 0,111 \\
\hline & & & CustIniciaVeicEco & $\mathrm{x}$ & $\mathrm{x}$ & $\mathrm{x}$ & $\mathrm{x}$ & $x$ & 0,045 & 0,106 & 0,093 & $\mathrm{x}$ & $\mathrm{x}$ & 0,081 & 0,032 \\
\hline & & & TecnoCartIntelig & $\mathrm{x}$ & $\mathrm{x}$ & $\mathrm{x}$ & $\mathrm{x}$ & $x$ & 0,349 & 0,081 & 0,049 & $\mathrm{x}$ & $\mathrm{x}$ & 0,160 & 0,165 \\
\hline & & & VidaUtilVeicEco & $\mathrm{x}$ & $\mathrm{x}$ & $\mathrm{x}$ & $\mathrm{x}$ & $x$ & 0,068 & 0,034 & 0,095 & $\mathrm{x}$ & $\mathrm{x}$ & 0,066 & 0,031 \\
\hline & Е & & FrotVeicRodo & $\mathrm{x}$ & $\mathrm{x}$ & $\mathrm{x}$ & $\mathrm{x}$ & $x$ & 0,103 & 0,292 & 0,076 & $\mathrm{x}$ & $\mathrm{x}$ & 0,157 & 0,118 \\
\hline & 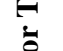 & & IdadMedVeic & $\mathrm{x}$ & $\mathrm{x}$ & $\mathrm{x}$ & $\mathrm{x}$ & $x$ & 0,091 & 0,191 & 0,208 & $\mathrm{x}$ & $\mathrm{x}$ & 0,163 & 0,063 \\
\hline 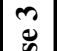 & $\sum_{0}^{2}$ & & FrotConvertRedPolu & $\mathrm{x}$ & $\mathrm{x}$ & $\mathrm{x}$ & $\mathrm{x}$ & $x$ & 0,271 & 0,054 & 0,093 & $\mathrm{x}$ & $\mathrm{x}$ & 0,139 & 0,116 \\
\hline 幽 & 党 & 19 & PropAutoPriv & $\mathrm{x}$ & $\mathrm{x}$ & $\mathrm{x}$ & $\mathrm{x}$ & $x$ & 0,063 & 0,185 & 0,158 & $\mathrm{x}$ & $\mathrm{x}$ & 0,135 & 0,064 \\
\hline & تृ & & VeicEficVeicNaoefic & $\mathrm{x}$ & $\mathrm{x}$ & $\mathrm{x}$ & $\mathrm{x}$ & $x$ & 0,352 & 0,058 & 0,257 & $\mathrm{x}$ & $\mathrm{x}$ & 0,222 & 0,150 \\
\hline & $\stackrel{0}{3}$ & & VeicCircula & $\mathrm{x}$ & $\mathrm{x}$ & $\mathrm{x}$ & $\mathrm{x}$ & $\underline{x}$ & 0,119 & 0,221 & 0,208 & $\mathrm{x}$ & $\mathrm{x}$ & 0,183 & 0,055 \\
\hline & & & CapacidadInfra & $\mathrm{x}$ & $\mathrm{x}$ & $\mathrm{x}$ & $\mathrm{x}$ & $x$ & 0,138 & 0,254 & 0,222 & $\mathrm{x}$ & $\mathrm{x}$ & 0,205 & 0,060 \\
\hline & & & CompViaCicilst & $\mathrm{x}$ & $\mathrm{x}$ & $\mathrm{x}$ & $\mathrm{x}$ & $x$ & 0,145 & 0,049 & 0,141 & $\mathrm{x}$ & $\mathrm{x}$ & 0,112 & 0,054 \\
\hline & & & ViaOtimTraf & $\mathrm{x}$ & $\mathrm{x}$ & $\mathrm{x}$ & $\mathrm{x}$ & $x$ & 0,086 & 0,069 & 0,084 & $\mathrm{x}$ & $\mathrm{x}$ & 0,079 & 0,009 \\
\hline & & & RedVia & $\mathrm{x}$ & $\mathrm{x}$ & $\mathrm{x}$ & $\mathrm{x}$ & $x$ & 0,064 & 0,225 & 0,063 & $\mathrm{x}$ & $\mathrm{x}$ & 0,117 & 0,093 \\
\hline & & 110 & ExtViaPedest & $\mathrm{x}$ & $\mathrm{x}$ & $\mathrm{x}$ & $\mathrm{x}$ & $x$ & 0,214 & 0,069 & 0,155 & $\mathrm{x}$ & $\mathrm{x}$ & 0,146 & 0,073 \\
\hline & & & EstacionaCar & $\mathrm{x}$ & $\mathrm{x}$ & $\mathrm{x}$ & $\mathrm{x}$ & $x$ & 0,037 & 0,022 & 0,065 & $\mathrm{x}$ & $\mathrm{x}$ & 0,042 & 0,021 \\
\hline & & & AcessTranspPavi & $\mathrm{x}$ & $\mathrm{x}$ & $\mathrm{x}$ & $\mathrm{x}$ & $x$ & 0,191 & 0,115 & 0,051 & $\mathrm{x}$ & $\mathrm{x}$ & 0,119 & 0,070 \\
\hline & & & TrafficCalming & $\mathrm{x}$ & $\mathrm{x}$ & $\mathrm{x}$ & $\mathrm{x}$ & $\underline{x}$ & 0,125 & 0,196 & 0,220 & $\mathrm{x}$ & $\mathrm{x}$ & 0,180 & 0,049 \\
\hline & & & AquisBic & $\mathrm{x}$ & $\mathrm{x}$ & $\mathrm{x}$ & $\mathrm{x}$ & $x$ & 0,196 & 0,070 & 0,059 & $\mathrm{x}$ & $\mathrm{x}$ & 0,108 & 0,076 \\
\hline & & & MudaModTransp & $\mathrm{x}$ & $\mathrm{x}$ & $\mathrm{x}$ & $\mathrm{x}$ & $x$ & 0,149 & 0,070 & 0,460 & $\mathrm{x}$ & $\mathrm{x}$ & 0,226 & 0,206 \\
\hline & & I11 & TrafRodo & $\mathrm{x}$ & $\mathrm{x}$ & $\mathrm{x}$ & $\mathrm{x}$ & $x$ & 0,087 & 0,507 & 0,246 & $\mathrm{x}$ & $\mathrm{x}$ & 0,280 & 0,212 \\
\hline & & & TranspCarg & $\mathrm{x}$ & $\mathrm{x}$ & $\mathrm{x}$ & $\mathrm{x}$ & $x$ & 0,064 & 0,183 & 0,124 & $\mathrm{x}$ & $\mathrm{x}$ & 0,124 & 0,060 \\
\hline & & & TranspPassag & $\mathrm{x}$ & $\mathrm{x}$ & $\mathrm{x}$ & $\mathrm{x}$ & $x$ & 0,504 & 0,171 & 0,112 & $\mathrm{x}$ & $\mathrm{x}$ & 0,262 & 0,211 \\
\hline
\end{tabular}




\begin{tabular}{|c|c|c|c|c|c|c|c|c|c|c|c|c|c|c|c|}
\hline \multirow{2}{*}{\multicolumn{4}{|c|}{ CRITÉRIOS }} & \multicolumn{10}{|c|}{ BRASIL - Avaliadores } & \multirow{2}{*}{$\begin{array}{l}\text { PESOS } \\
\text { (Média) }\end{array}$} & \multirow{2}{*}{$\begin{array}{l}\text { DESVIO } \\
\text { PADRÃO }\end{array}$} \\
\hline & & & & 1 & 2 & 3 & 4 & 5 & 6 & 7 & 8 & 9 & 10 & & \\
\hline \multirow{33}{*}{ 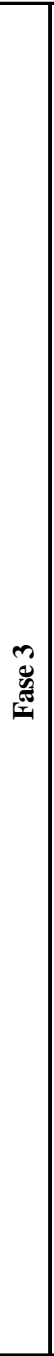 } & \multirow{33}{*}{ 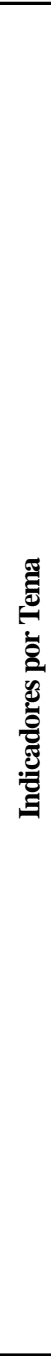 } & \multirow{6}{*}{ I12 } & CongestionaTraf & $\mathrm{x}$ & $\mathrm{x}$ & $\mathrm{x}$ & $\mathrm{x}$ & $\mathrm{x}$ & 0,149 & 0,249 & 0,390 & $\mathrm{x}$ & $\mathrm{x}$ & 0,262 & 0,121 \\
\hline & & & DensidTraf & $\mathrm{x}$ & $\mathrm{x}$ & $\mathrm{x}$ & $\mathrm{x}$ & $\mathrm{x}$ & 0,069 & 0,052 & 0,157 & $\mathrm{x}$ & $\mathrm{x}$ & 0,093 & 0,056 \\
\hline & & & VolTraf & $\mathrm{x}$ & $\mathrm{x}$ & $\mathrm{x}$ & $\mathrm{x}$ & $\mathrm{x}$ & 0,085 & 0,165 & 0,107 & $\mathrm{x}$ & $\mathrm{x}$ & 0,119 & 0,041 \\
\hline & & & OcupaVeicPassag & $\mathrm{x}$ & $\mathrm{x}$ & $\mathrm{x}$ & $\mathrm{x}$ & $\mathrm{x}$ & 0,312 & 0,087 & 0,048 & $\mathrm{x}$ & $\mathrm{x}$ & 0,149 & 0,143 \\
\hline & & & TempTraf & $\mathrm{x}$ & $\mathrm{x}$ & $\mathrm{x}$ & $\mathrm{x}$ & $\mathrm{x}$ & 0,208 & 0,344 & 0,168 & $\mathrm{x}$ & $\mathrm{x}$ & 0,240 & 0,092 \\
\hline & & & VelocTraf & $\mathrm{x}$ & $\mathrm{x}$ & $\mathrm{x}$ & $\mathrm{x}$ & $\mathrm{x}$ & 0,176 & 0,104 & 0,130 & $\mathrm{x}$ & $\mathrm{x}$ & 0,137 & 0,036 \\
\hline & & \multirow{6}{*}{ P13 } & AcessBairro & $\mathrm{x}$ & $\mathrm{x}$ & $\mathrm{x}$ & $\mathrm{x}$ & $\mathrm{x}$ & 0,119 & 0,131 & 0,101 & $\mathrm{x}$ & $\mathrm{x}$ & 0,117 & 0,015 \\
\hline & & & AcessCentro & $\mathrm{x}$ & $\mathrm{x}$ & $\mathrm{x}$ & $\mathrm{x}$ & $\mathrm{x}$ & 0,177 & 0,071 & 0,169 & $\mathrm{x}$ & $\mathrm{x}$ & 0,139 & 0,059 \\
\hline & & & AcessServBasic & $\mathrm{x}$ & $\mathrm{x}$ & $\mathrm{x}$ & $\mathrm{x}$ & $\mathrm{x}$ & 0,245 & 0,414 & 0,315 & $\mathrm{x}$ & $\mathrm{x}$ & 0,325 & 0,085 \\
\hline & & & AcessServTransp & $\mathrm{x}$ & $\mathrm{x}$ & $\mathrm{x}$ & $\mathrm{x}$ & $\mathrm{x}$ & 0,300 & 0,186 & 0,263 & $\mathrm{x}$ & $\mathrm{x}$ & 0,249 & 0,059 \\
\hline & & & EmpregDistResid & $\mathrm{x}$ & $\mathrm{x}$ & $\mathrm{x}$ & $\mathrm{x}$ & $\mathrm{x}$ & 0,101 & 0,150 & 0,095 & $\mathrm{x}$ & $\mathrm{x}$ & 0,115 & 0,030 \\
\hline & & & PessoaDistLazer & $\mathrm{x}$ & $\mathrm{x}$ & $\mathrm{x}$ & $\mathrm{x}$ & $\mathrm{x}$ & 0,058 & 0,048 & 0,057 & $\mathrm{x}$ & $\mathrm{x}$ & 0,054 & 0,005 \\
\hline & & \multirow{8}{*}{ P14 } & CategorUsoSolo & $\mathrm{x}$ & $\mathrm{x}$ & $\mathrm{x}$ & $\mathrm{x}$ & $\mathrm{x}$ & 0,050 & 0,146 & 0,126 & $\mathrm{x}$ & $\mathrm{x}$ & 0,107 & 0,050 \\
\hline & & & VerdVersusAutoPirv & $\mathrm{x}$ & $\mathrm{x}$ & $\mathrm{x}$ & $\mathrm{x}$ & $\mathrm{x}$ & 0,028 & 0,031 & 0,055 & $\mathrm{x}$ & $\mathrm{x}$ & 0,038 & 0,015 \\
\hline & & & DeconcAtiv & $\mathrm{x}$ & $\mathrm{x}$ & $\mathrm{x}$ & $\mathrm{x}$ & $\mathrm{x}$ & 0,144 & 0,051 & 0,060 & $\mathrm{x}$ & $\mathrm{x}$ & 0,085 & 0,051 \\
\hline & & & FormUrb & $\mathrm{x}$ & $\mathrm{x}$ & $\mathrm{x}$ & $\mathrm{x}$ & $\mathrm{x}$ & 0,103 & 0,217 & 0,232 & $\mathrm{x}$ & $\mathrm{x}$ & 0,184 & 0,071 \\
\hline & & & IncentUsoMistAltaDensid & $\mathrm{x}$ & $\mathrm{x}$ & $\mathrm{x}$ & $\mathrm{x}$ & $\mathrm{x}$ & 0,128 & 0,204 & 0,033 & $\mathrm{x}$ & $\mathrm{x}$ & 0,122 & 0,086 \\
\hline & & & MudaSoloInfraTransp & $\mathrm{x}$ & $\mathrm{x}$ & $\mathrm{x}$ & $\mathrm{x}$ & $\mathrm{x}$ & 0,239 & 0,168 & 0,041 & $\mathrm{x}$ & $\mathrm{x}$ & 0,150 & 0,100 \\
\hline & & & PlanejaSoloUrb & $\mathrm{x}$ & $\mathrm{x}$ & $\mathrm{x}$ & $\mathrm{x}$ & $\mathrm{x}$ & 0,229 & 0,131 & 0,190 & $\mathrm{x}$ & $\mathrm{x}$ & 0,184 & 0,049 \\
\hline & & & PoliticPedestCiclistPublic & $\mathrm{x}$ & $\mathrm{x}$ & $\mathrm{x}$ & $\mathrm{x}$ & $\mathrm{x}$ & 0,079 & 0,051 & 0,261 & $\mathrm{x}$ & $\mathrm{x}$ & 0,131 & 0,114 \\
\hline & & \multirow{5}{*}{ P15 } & UnidFamCrescPop & $\mathrm{x}$ & $\bar{x}$ & $\mathrm{x}$ & $x$ & $\bar{x}$ & 0,048 & 0,051 & 0,054 & $\mathrm{x}$ & $\mathrm{x}$ & 0,051 & 0,003 \\
\hline & & & DensidPop & $\mathrm{x}$ & $\mathrm{x}$ & $\mathrm{x}$ & $\mathrm{x}$ & $\mathrm{x}$ & 0,475 & 0,303 & 0,278 & $\mathrm{x}$ & $\mathrm{x}$ & 0,352 & 0,107 \\
\hline & & & EstrutEtarPop & $\mathrm{x}$ & $\mathrm{x}$ & $\mathrm{x}$ & $\mathrm{x}$ & $\mathrm{x}$ & 0,114 & 0,129 & 0,304 & $\mathrm{x}$ & $\mathrm{x}$ & 0,182 & 0,106 \\
\hline & & & RendFamPercapita & $\mathrm{x}$ & $\mathrm{x}$ & $\mathrm{x}$ & $\mathrm{x}$ & $\mathrm{x}$ & 0,169 & 0,169 & 0,221 & $\mathrm{x}$ & $\mathrm{x}$ & 0,186 & 0,030 \\
\hline & & & TaxCrescPop & $\mathrm{x}$ & $\mathrm{x}$ & $\mathrm{x}$ & $\mathrm{x}$ & $\mathrm{x}$ & 0,194 & 0,348 & 0,143 & $\mathrm{x}$ & $\mathrm{x}$ & 0,228 & 0,107 \\
\hline & & \multirow{8}{*}{ P16 } & DeslocaCriançaEsc & $\mathrm{x}$ & $\mathrm{x}$ & $\mathrm{x}$ & $\mathrm{x}$ & $\mathrm{x}$ & 0,025 & 0,063 & 0,046 & $\mathrm{x}$ & $\mathrm{x}$ & 0,045 & 0,019 \\
\hline & & & DistServBasic & $\mathrm{x}$ & $\mathrm{x}$ & $\mathrm{x}$ & $\mathrm{x}$ & $\mathrm{x}$ & 0,227 & 0,215 & 0,130 & $\mathrm{x}$ & $\mathrm{x}$ & 0,191 & 0,053 \\
\hline & & & DistFam & $\mathrm{x}$ & $\mathrm{x}$ & $\mathrm{x}$ & $\mathrm{x}$ & $\mathrm{x}$ & 0,027 & 0,038 & 0,028 & $\mathrm{x}$ & $\mathrm{x}$ & 0,031 & 0,006 \\
\hline & & & DistPedBiciDia & $\mathrm{x}$ & $\mathrm{x}$ & $\mathrm{x}$ & $\mathrm{x}$ & $\mathrm{x}$ & 0,043 & 0,031 & 0,126 & $\mathrm{x}$ & $\mathrm{x}$ & 0,067 & 0,052 \\
\hline & & & MobLocal & $\mathrm{x}$ & $\mathrm{x}$ & $\mathrm{x}$ & $\mathrm{x}$ & $\mathrm{x}$ & 0,276 & 0,261 & 0,270 & $\mathrm{x}$ & $\mathrm{x}$ & 0,269 & 0,008 \\
\hline & & & PopVivTrabLocal & $\mathrm{x}$ & $\mathrm{x}$ & $\mathrm{x}$ & $\mathrm{x}$ & $\mathrm{x}$ & 0,060 & 0,194 & 0,083 & $\mathrm{x}$ & $\mathrm{x}$ & 0,113 & 0,072 \\
\hline & & & UtliAutoDistInferior & $\mathrm{x}$ & $\mathrm{x}$ & $\mathrm{x}$ & $\mathrm{x}$ & $\mathrm{x}$ & 0,079 & 0,090 & 0,083 & $\mathrm{x}$ & $\mathrm{x}$ & 0,084 & 0,006 \\
\hline & & & TempViag & $\mathrm{x}$ & $\mathrm{x}$ & $\mathrm{x}$ & $\mathrm{x}$ & $\mathrm{x}$ & 0,262 & 0,107 & 0,232 & $\mathrm{x}$ & $\mathrm{x}$ & 0,201 & 0,082 \\
\hline
\end{tabular}




\begin{tabular}{|c|c|c|c|c|c|c|c|c|c|c|c|c|c|c|c|}
\hline \multirow{2}{*}{\multicolumn{4}{|c|}{ CRITÉRIOS }} & \multicolumn{10}{|c|}{ BRASIL - Avaliadores } & \multirow{2}{*}{$\begin{array}{l}\text { PESOS } \\
\text { (Média) }\end{array}$} & \multirow{2}{*}{$\begin{array}{r}\text { DESVIO } \\
\text { PADRÃO } \\
\end{array}$} \\
\hline & & & & 1 & 2 & 3 & 4 & 5 & 6 & 7 & 8 & 9 & 10 & & \\
\hline \multirow{21}{*}{ 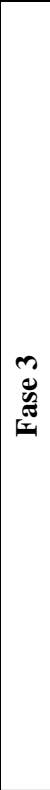 } & \multirow{21}{*}{ 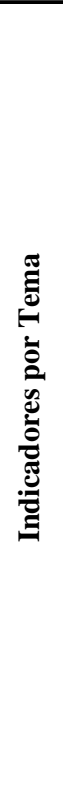 } & \multirow{5}{*}{ S17 } & CustPassagTransp & $\mathrm{x}$ & $\mathrm{x}$ & $\mathrm{x}$ & $\mathrm{x}$ & $\mathrm{x}$ & 0,417 & 0,213 & 0,141 & $\mathrm{x}$ & $\mathrm{x}$ & 0,257 & 0,143 \\
\hline & & & EvoluPreçoCombust & $\mathrm{x}$ & $\mathrm{x}$ & $\mathrm{x}$ & $\mathrm{x}$ & $\mathrm{x}$ & 0,072 & 0,056 & 0,044 & $\mathrm{x}$ & $\mathrm{x}$ & 0,057 & 0,014 \\
\hline & & & MudaPreçoTranspModo & $\mathrm{x}$ & $\mathrm{x}$ & $\mathrm{x}$ & $\mathrm{x}$ & $\mathrm{x}$ & 0,186 & 0,561 & 0,141 & $\mathrm{x}$ & $\mathrm{x}$ & 0,296 & 0,230 \\
\hline & & & PreçoCombustTax & $\mathrm{x}$ & $\mathrm{x}$ & $\mathrm{x}$ & $\mathrm{x}$ & $\mathrm{x}$ & 0,081 & 0,051 & 0,141 & $\mathrm{x}$ & $\mathrm{x}$ & 0,091 & 0,046 \\
\hline & & & PreçoTranspPublic & $\mathrm{x}$ & $\mathrm{x}$ & $\mathrm{x}$ & $\mathrm{x}$ & $\mathrm{x}$ & 0,244 & 0,119 & 0,534 & $\mathrm{x}$ & $\mathrm{x}$ & 0,299 & 0,213 \\
\hline & & \multirow{4}{*}{ S18 } & BeneficUsaTransp & $\mathrm{x}$ & $\mathrm{x}$ & $\mathrm{x}$ & $\mathrm{x}$ & $\mathrm{x}$ & 0,400 & 0,233 & 0,548 & $\mathrm{x}$ & $\mathrm{x}$ & 0,394 & 0,157 \\
\hline & & & CustCongestiona & $\mathrm{x}$ & $\mathrm{x}$ & $\mathrm{x}$ & $\mathrm{x}$ & $\mathrm{x}$ & 0,160 & 0,410 & 0,249 & $\mathrm{x}$ & $\mathrm{x}$ & 0,273 & 0,127 \\
\hline & & & CustSocial & $\mathrm{x}$ & $\mathrm{x}$ & $\mathrm{x}$ & $\mathrm{x}$ & $\mathrm{x}$ & 0,359 & 0,297 & 0,130 & $\mathrm{x}$ & $\mathrm{x}$ & 0,262 & 0,119 \\
\hline & & & RendOperaTransp & $\mathrm{x}$ & $\mathrm{x}$ & $\mathrm{x}$ & $\mathrm{x}$ & $\mathrm{x}$ & 0,081 & 0,059 & 0,073 & $\mathrm{x}$ & $\mathrm{x}$ & 0,071 & 0,011 \\
\hline & & \multirow{5}{*}{ S19 } & AcidentFatalTransp & $\mathrm{x}$ & $\mathrm{x}$ & $\mathrm{x}$ & $\mathrm{x}$ & $\mathrm{x}$ & 0,175 & 0,263 & 0,237 & $\mathrm{x}$ & $\mathrm{x}$ & 0,225 & 0,045 \\
\hline & & & FeridoAcidentTraf & $\mathrm{x}$ & $\mathrm{x}$ & $\mathrm{x}$ & $\mathrm{x}$ & $\mathrm{x}$ & 0,175 & 0,138 & 0,292 & $\mathrm{x}$ & $\mathrm{x}$ & 0,202 & 0,080 \\
\hline & & & CrimeTransit & $\mathrm{x}$ & $\mathrm{x}$ & $\mathrm{x}$ & $\mathrm{x}$ & $\mathrm{x}$ & 0,220 & 0,066 & 0,058 & $\mathrm{x}$ & $\mathrm{x}$ & 0,114 & 0,091 \\
\hline & & & AcidentPedestCiclist & $\mathrm{x}$ & $\mathrm{x}$ & $\mathrm{x}$ & $\mathrm{x}$ & $\mathrm{x}$ & 0,356 & 0,196 & 0,270 & $\mathrm{x}$ & $\mathrm{x}$ & 0,274 & 0,080 \\
\hline & & & SegurViaResidencia & $\mathrm{x}$ & $\mathrm{x}$ & $\mathrm{x}$ & $\mathrm{x}$ & $\mathrm{x}$ & 0,073 & 0,337 & 0,143 & $\mathrm{x}$ & $\mathrm{x}$ & 0,185 & 0,137 \\
\hline & & \multirow{7}{*}{ S20 } & DemandTranspPassag & $\mathrm{x}$ & $\mathrm{x}$ & $\mathrm{x}$ & $\mathrm{x}$ & $\mathrm{x}$ & 0,039 & 0,355 & 0,232 & $\mathrm{x}$ & $\mathrm{x}$ & 0,209 & 0,159 \\
\hline & & & DispTranspPublic & $\mathrm{x}$ & $\mathrm{x}$ & $\mathrm{x}$ & $\mathrm{x}$ & $\mathrm{x}$ & 0,219 & 0,147 & 0,144 & $\mathrm{x}$ & $\mathrm{x}$ & 0,170 & 0,043 \\
\hline & & & DiversidadTransp & $\mathrm{x}$ & $\mathrm{x}$ & $\mathrm{x}$ & $\mathrm{x}$ & $\mathrm{x}$ & 0,042 & 0,149 & 0,102 & $\mathrm{x}$ & $\mathrm{x}$ & 0,098 & 0,053 \\
\hline & & & NecessTransp & $\mathrm{x}$ & $\mathrm{x}$ & $\mathrm{x}$ & $\mathrm{x}$ & $\mathrm{x}$ & 0,272 & 0,104 & 0,270 & $\mathrm{x}$ & $\mathrm{x}$ & 0,216 & 0,097 \\
\hline & & & NivServTranspPublic & $\mathrm{x}$ & $\mathrm{x}$ & $\mathrm{x}$ & $\mathrm{x}$ & $\mathrm{x}$ & 0,208 & 0,090 & 0,150 & $\mathrm{x}$ & $\mathrm{x}$ & 0,150 & 0,059 \\
\hline & & & TranspPublicInsegur & $\mathrm{x}$ & $\mathrm{x}$ & $\mathrm{x}$ & $\mathrm{x}$ & $\mathrm{x}$ & 0,127 & 0,071 & 0,031 & $\mathrm{x}$ & $\mathrm{x}$ & 0,077 & 0,048 \\
\hline & & & TranspPublicVersusCar & $\mathrm{x}$ & $\mathrm{x}$ & $x$ & $\mathrm{x}$ & $\mathrm{x}$ & 0,092 & 0,084 & 0,070 & $\mathrm{x}$ & $\mathrm{x}$ & 0,082 & 0,011 \\
\hline
\end{tabular}


Tabela E-3: Pesos obtidos para as Fases 1 e 2 do processo de avaliação $A H P$ para Portugal

\begin{tabular}{|c|c|c|c|c|c|c|c|c|c|c|c|c|c|c|c|}
\hline \multirow{2}{*}{\multicolumn{4}{|c|}{ CRITÉRIOS }} & \multicolumn{10}{|c|}{ PORTUGAL - Avaliadores } & \multirow{2}{*}{$\begin{array}{l}\text { PESOS } \\
\text { (Média) }\end{array}$} & \multirow{2}{*}{$\begin{array}{l}\text { DESVIO } \\
\text { PADRÃO }\end{array}$} \\
\hline & & & & 11 & 12 & 13 & 14 & 15 & 16 & 17 & 18 & 19 & 20 & & \\
\hline \multirow{5}{*}{ 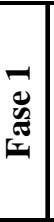 } & \multirow{5}{*}{ 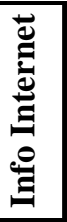 } & 1 & PlanDesenvUrb & 0,510 & $\mathrm{x}$ & 0,158 & 0,575 & 0,130 & 0,186 & 0,201 & 0,231 & 0,077 & 0,468 & 0,282 & 0,184 \\
\hline & & 2 & IndUrb & 0,130 & $\mathrm{x}$ & 0,246 & 0,148 & 0,263 & 0,357 & 0,086 & 0,144 & 0,261 & 0,201 & 0,204 & 0,085 \\
\hline & & 3 & IndMob & 0,263 & $\mathrm{x}$ & 0,446 & 0,180 & 0,510 & 0,098 & 0,468 & 0,536 & 0,478 & 0,201 & 0,353 & 0,167 \\
\hline & & 4 & DadoEstaGeral & 0,033 & $\mathrm{x}$ & 0,058 & 0,064 & 0,033 & 0,180 & 0,043 & 0,053 & 0,042 & 0,086 & 0,066 & 0,046 \\
\hline & & 5 & DadoFisicDemo & 0,063 & $\mathrm{x}$ & 0,092 & 0,033 & 0,063 & 0,180 & 0,201 & 0,035 & 0,142 & 0,043 & 0,095 & 0,064 \\
\hline \multirow{25}{*}{ 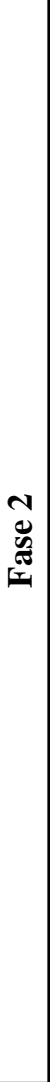 } & \multirow{5}{*}{ 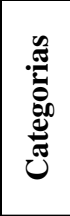 } & $\overline{\mathbf{A}}$ & TranspAmbient & $\mathrm{x}$ & $\bar{x}$ & 0,269 & 0,316 & $\mathrm{x}$ & $\mathrm{x}$ & 0,256 & $\mathrm{x}$ & $\mathrm{x}$ & 0,041 & 0,221 & 0,122 \\
\hline & & G & GestaoMob & $\mathrm{x}$ & $\mathrm{x}$ & 0,048 & 0,235 & $\mathrm{x}$ & $\mathrm{x}$ & 0,071 & $\mathrm{x}$ & $\mathrm{x}$ & 0,337 & 0,173 & 0,137 \\
\hline & & $\mathbf{P}$ & InfraServTransp & $\mathrm{x}$ & $\mathrm{x}$ & 0,102 & 0,145 & $\mathrm{x}$ & $\mathrm{x}$ & 0,162 & $\mathrm{x}$ & $\mathrm{x}$ & 0,107 & 0,129 & 0,029 \\
\hline & & $\mathbf{I}$ & PlaneEspac & $\mathrm{x}$ & $\mathrm{x}$ & 0,355 & 0,273 & $\mathrm{x}$ & $\mathrm{x}$ & 0,428 & $\mathrm{x}$ & $\mathrm{x}$ & 0,396 & 0,363 & 0,067 \\
\hline & & $\mathbf{S}$ & AspSocioEcoTransp & $\mathrm{x}$ & $\mathrm{x}$ & 0,225 & 0,031 & $\mathrm{x}$ & $\mathrm{x}$ & 0,082 & $\mathrm{x}$ & $\mathrm{x}$ & 0,118 & 0,114 & 0,082 \\
\hline & \multirow{20}{*}{ 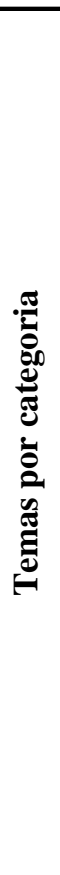 } & \multirow{4}{*}{$\mathbf{A}$} & EnergCombust & $\mathrm{x}$ & $\mathrm{x}$ & 0,086 & 0,034 & $\mathrm{x}$ & $\mathrm{x}$ & 0,240 & $\mathrm{x}$ & $\mathrm{x}$ & 0,054 & 0,104 & 0,093 \\
\hline & & & ImpactAmbient & $\mathrm{x}$ & $\mathrm{x}$ & 0,383 & 0,224 & $\mathrm{x}$ & $\mathrm{x}$ & 0,142 & $\mathrm{x}$ & $\mathrm{x}$ & 0,143 & 0,223 & 0,113 \\
\hline & & & QualiAr & $\mathrm{x}$ & $\mathrm{x}$ & 0,432 & 0,519 & $\mathrm{x}$ & $\mathrm{x}$ & 0,309 & $\mathrm{x}$ & $\mathrm{x}$ & 0,402 & 0,415 & 0,087 \\
\hline & & & RuidTraf & $\mathrm{x}$ & $\mathrm{x}$ & 0,099 & 0,224 & $\mathrm{x}$ & $\mathrm{x}$ & 0,309 & $\mathrm{x}$ & $\mathrm{x}$ & 0,402 & 0,258 & 0,129 \\
\hline & & \multirow{4}{*}{$\mathbf{G}$} & DespInvestEstratEco & $\mathrm{x}$ & $\mathrm{x}$ & 0,400 & 0,090 & $\mathrm{x}$ & $\mathrm{x}$ & 0,400 & $\mathrm{x}$ & $\mathrm{x}$ & 0,069 & 0,240 & 0,185 \\
\hline & & & GerencMonitor & $\mathrm{x}$ & $\mathrm{x}$ & 0,359 & 0,097 & $\mathrm{x}$ & $\mathrm{x}$ & 0,081 & $\mathrm{x}$ & $\mathrm{x}$ & 0,193 & 0,183 & 0,128 \\
\hline & & & MedIncrementMob & $\mathrm{x}$ & $\mathrm{x}$ & 0,160 & 0,475 & $\mathrm{x}$ & $\mathrm{x}$ & 0,160 & $\mathrm{x}$ & $\mathrm{x}$ & 0,545 & 0,335 & 0,204 \\
\hline & & & NovaTecno & $\mathrm{x}$ & $\mathrm{x}$ & 0,081 & 0,337 & $\mathrm{x}$ & $\mathrm{x}$ & 0,359 & $\mathrm{x}$ & $\mathrm{x}$ & 0,193 & 0,243 & 0,131 \\
\hline & & \multirow{4}{*}{$\mathbf{I}$} & Frota & $\mathrm{x}$ & $x$ & 0,309 & 0,052 & $\mathrm{x}$ & $\mathrm{x}$ & 0,095 & $x$ & $x$ & 0,047 & 0,126 & 0,124 \\
\hline & & & InfraSistVia & $\mathrm{x}$ & $\mathrm{x}$ & 0,309 & 0,528 & $\mathrm{x}$ & $\mathrm{x}$ & 0,487 & $\mathrm{x}$ & $\mathrm{x}$ & 0,395 & 0,430 & 0,098 \\
\hline & & & TecnoServTransp & $\mathrm{x}$ & $\mathrm{x}$ & 0,142 & 0,210 & $\mathrm{x}$ & $\mathrm{x}$ & 0,209 & $\mathrm{x}$ & $\mathrm{x}$ & 0,163 & 0,181 & 0,034 \\
\hline & & & Trafego & $\mathrm{x}$ & $\mathrm{x}$ & 0,240 & 0,210 & $\mathrm{x}$ & $\mathrm{x}$ & 0,209 & $\mathrm{x}$ & $\mathrm{x}$ & 0,395 & 0,264 & 0,089 \\
\hline & & \multirow{4}{*}{$\mathbf{P}$} & AcessServAtivUrb & $\mathrm{x}$ & $\mathrm{x}$ & 0,375 & 0,433 & $\mathrm{x}$ & $\mathrm{x}$ & 0,390 & $x$ & $\mathrm{x}$ & 0,390 & 0,397 & 0,025 \\
\hline & & & DesenvUrbUsoSolo & $\mathrm{x}$ & $\mathrm{x}$ & 0,125 & 0,413 & $\mathrm{x}$ & $\mathrm{x}$ & 0,153 & $\mathrm{x}$ & $\mathrm{x}$ & 0,153 & 0,211 & 0,135 \\
\hline & & & PopUrb & $\mathrm{x}$ & $\mathrm{x}$ & 0,125 & 0,055 & $\mathrm{x}$ & $\mathrm{x}$ & 0,068 & $\mathrm{x}$ & $\mathrm{x}$ & 0,068 & 0,079 & 0,031 \\
\hline & & & ViagDesloca & $\mathrm{x}$ & $\mathrm{x}$ & 0,375 & 0,099 & $\mathrm{x}$ & $\mathrm{x}$ & 0,390 & $\mathrm{x}$ & $\mathrm{x}$ & 0,390 & 0,313 & 0,143 \\
\hline & & \multirow{4}{*}{$\mathbf{S}$} & CustPreçoTar & $\mathrm{x}$ & $\mathrm{x}$ & 0,118 & 0,059 & $\mathrm{x}$ & $\mathrm{x}$ & 0,101 & $x$ & $x$ & 0,068 & 0,086 & 0,028 \\
\hline & & & ImpactSocioEcoTransp & $\mathrm{x}$ & $\mathrm{x}$ & 0,118 & 0,126 & $\mathrm{x}$ & $\mathrm{x}$ & 0,101 & $\mathrm{x}$ & $\mathrm{x}$ & 0,390 & 0,184 & 0,138 \\
\hline & & & Segurança & $\mathrm{x}$ & $\mathrm{x}$ & 0,278 & 0,391 & $\mathrm{x}$ & $\mathrm{x}$ & 0,449 & $\mathrm{x}$ & $\mathrm{x}$ & 0,390 & 0,377 & 0,072 \\
\hline & & & TranspPublic & $\mathrm{x}$ & $\mathrm{x}$ & 0,487 & 0,424 & $\mathrm{x}$ & $\mathrm{x}$ & 0,348 & $\mathrm{x}$ & $\mathrm{x}$ & 0,153 & 0,353 & 0,145 \\
\hline
\end{tabular}


Tabela E-4: Pesos obtidos para as Fase 3 do processo de avaliação $A H P$ para Portugal

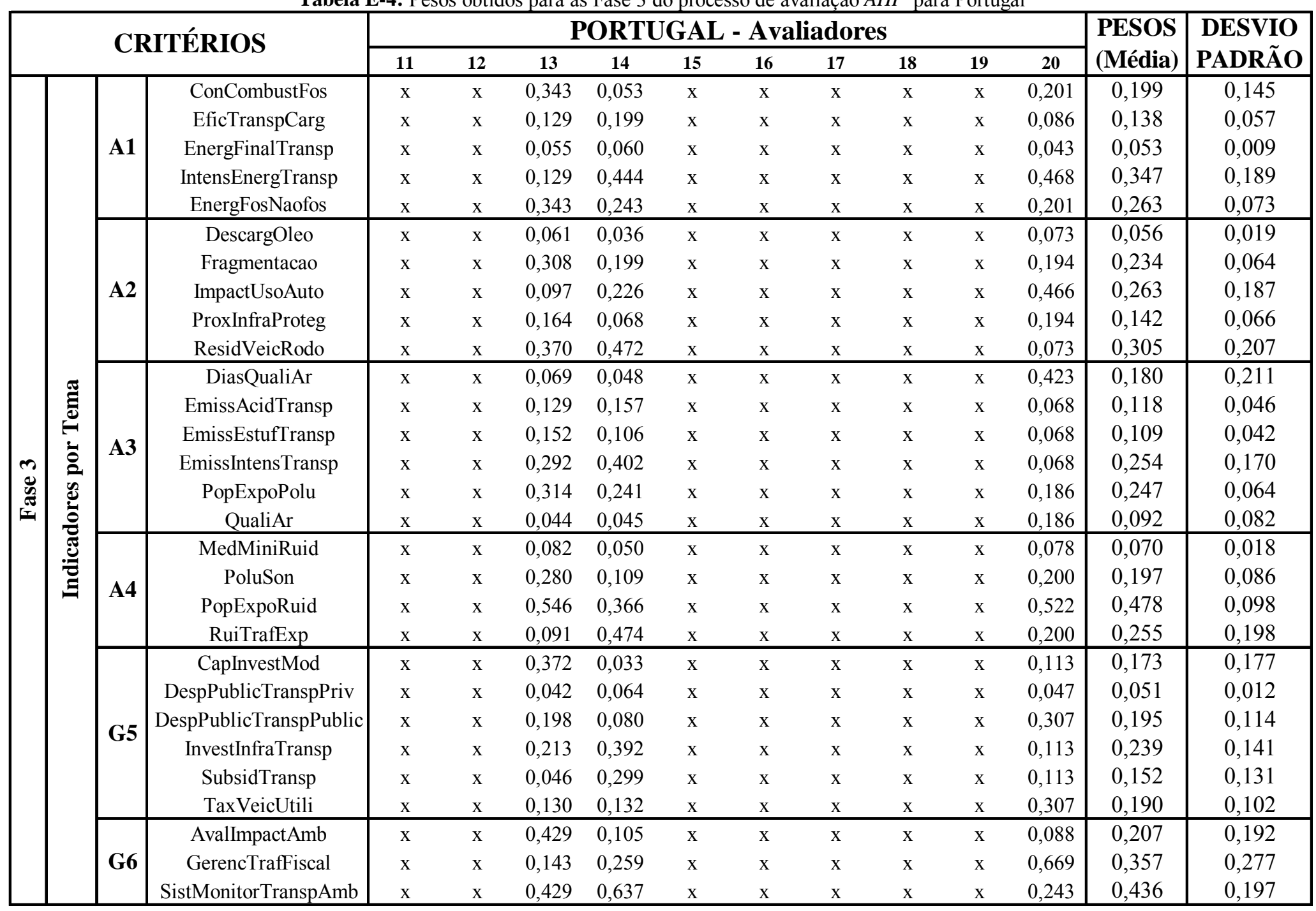




\begin{tabular}{|c|c|c|c|c|c|c|c|c|c|c|c|c|c|c|c|}
\hline & & CF & TÉRIOS & & & & ORT & $\mathbf{A}$ & Av & & & & & PESOS & DESVIO \\
\hline & & Cr & IENIUS & 11 & 12 & 13 & 14 & 15 & 16 & 17 & 18 & 19 & 20 & (Média) & PADRÃO \\
\hline & & & PlanRedViag & $\mathrm{x}$ & $\mathrm{x}$ & 0,245 & 0,161 & $\mathrm{x}$ & $\mathrm{x}$ & $\mathrm{x}$ & $\mathrm{x}$ & $\mathrm{x}$ & 0,336 & 0,247 & 0,087 \\
\hline & & & RegulaDensidMin & $\mathrm{x}$ & $\mathrm{x}$ & 0,036 & 0,102 & $\mathrm{x}$ & $\mathrm{x}$ & $\mathrm{x}$ & $\mathrm{x}$ & $\mathrm{x}$ & 0,069 & 0,069 & 0,033 \\
\hline & & & EstratAmbTransp & $\mathrm{x}$ & $\mathrm{x}$ & 0,268 & 0,041 & $\mathrm{x}$ & $\mathrm{x}$ & $\mathrm{x}$ & $\mathrm{x}$ & $\mathrm{x}$ & 0,157 & 0,155 & 0,114 \\
\hline & & G7 & OperaEficVeic & $\mathrm{x}$ & $\mathrm{x}$ & 0,071 & 0,247 & $\mathrm{x}$ & $\mathrm{x}$ & $\mathrm{x}$ & $\mathrm{x}$ & $\mathrm{x}$ & 0,033 & 0,117 & 0,114 \\
\hline & & & MelhoraTransp & $\mathrm{x}$ & $\mathrm{x}$ & 0,124 & 0,406 & $\mathrm{x}$ & $\mathrm{x}$ & $\mathrm{x}$ & $\mathrm{x}$ & $\mathrm{x}$ & 0,336 & 0,289 & 0,147 \\
\hline & & & PriorViagPedCiclist & $\mathrm{x}$ & $\mathrm{x}$ & 0,257 & 0,043 & $\mathrm{x}$ & $\mathrm{x}$ & $\mathrm{x}$ & $\mathrm{x}$ & $\mathrm{x}$ & 0,069 & 0,123 & 0,116 \\
\hline & & & CombustLimpAlter & $\mathrm{x}$ & $\mathrm{x}$ & 0,223 & 0,356 & $\mathrm{x}$ & $\mathrm{x}$ & $\mathrm{x}$ & $\mathrm{x}$ & $\mathrm{x}$ & 0,214 & 0,264 & 0,080 \\
\hline & & & GastCombustLimp & $\mathrm{x}$ & $\mathrm{x}$ & 0,223 & 0,034 & $\mathrm{x}$ & $\mathrm{x}$ & $\mathrm{x}$ & $\mathrm{x}$ & $\mathrm{x}$ & 0,214 & 0,157 & 0,107 \\
\hline & & & GastVeicEco & $\mathrm{x}$ & $\mathrm{x}$ & 0,223 & 0,030 & $\mathrm{x}$ & $\mathrm{x}$ & $\mathrm{x}$ & $\mathrm{x}$ & $\mathrm{x}$ & 0,214 & 0,156 & 0,109 \\
\hline & & G8 & NovaFormaTransp & $\mathrm{x}$ & $\mathrm{x}$ & 0,131 & 0,187 & $\mathrm{x}$ & $\mathrm{x}$ & $\mathrm{x}$ & $\mathrm{x}$ & $\mathrm{x}$ & 0,214 & 0,177 & 0,043 \\
\hline & & & CustIniciaVeicEco & $\mathrm{x}$ & $\mathrm{x}$ & 0,093 & 0,045 & $\mathrm{x}$ & $\mathrm{x}$ & $\mathrm{x}$ & $\mathrm{x}$ & $\mathrm{x}$ & 0,028 & 0,056 & 0,034 \\
\hline & & & TecnoCartIntelig & $\mathrm{x}$ & $\mathrm{x}$ & 0,054 & 0,238 & $\mathrm{x}$ & $\mathrm{x}$ & $\mathrm{x}$ & $\mathrm{x}$ & $\mathrm{x}$ & 0,085 & 0,126 & 0,098 \\
\hline & & & VidaUtilVeicEco & $\mathrm{x}$ & $\mathrm{x}$ & 0,054 & 0,110 & $\mathrm{x}$ & $\mathrm{x}$ & $\mathrm{x}$ & $\mathrm{x}$ & $\mathrm{x}$ & 0,029 & 0,065 & 0,041 \\
\hline & $\stackrel{\bar{\omega}}{\Leftrightarrow}$ & & FrotVeicRodo & $\mathrm{x}$ & $\mathrm{x}$ & 0,090 & 0,033 & $\mathrm{x}$ & $\mathrm{x}$ & $\mathrm{x}$ & $\mathrm{x}$ & $\mathrm{x}$ & 0,092 & 0,072 & 0,034 \\
\hline & $\ddot{0}$ & & IdadMedVeic & $\mathrm{x}$ & $\mathrm{x}$ & 0,083 & 0,127 & $\mathrm{x}$ & $\mathrm{x}$ & $\mathrm{x}$ & $\mathrm{x}$ & $\mathrm{x}$ & 0,329 & 0,180 & 0,131 \\
\hline m & $\frac{2}{2}$ & & FrotConvertRedPolu & $\mathrm{x}$ & $\mathrm{x}$ & 0,318 & 0,272 & $\mathrm{x}$ & $\mathrm{x}$ & $\mathrm{x}$ & $\mathrm{x}$ & $\mathrm{x}$ & 0,151 & 0,247 & 0,086 \\
\hline 胥 & 苞 & 19 & PropAutoPriv & $\mathrm{x}$ & $\mathrm{x}$ & 0,289 & 0,056 & $\mathrm{x}$ & $\mathrm{x}$ & $\mathrm{x}$ & $\mathrm{x}$ & $\mathrm{x}$ & 0,049 & 0,131 & 0,137 \\
\hline & 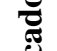 & & VeicEficVeicNaoefic & $\mathrm{x}$ & $\mathrm{x}$ & 0,124 & 0,127 & $\mathrm{x}$ & $\mathrm{x}$ & $\mathrm{x}$ & $\mathrm{x}$ & $\mathrm{x}$ & 0,329 & 0,193 & 0,117 \\
\hline & 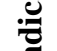 & & VeicCircula & $\mathrm{x}$ & $\mathrm{x}$ & 0,096 & 0,385 & $\mathrm{x}$ & $\mathrm{x}$ & $\mathrm{x}$ & $\mathrm{x}$ & $\mathrm{x}$ & 0,049 & 0,177 & 0,182 \\
\hline & & & CapacidadInfra & $\bar{x}$ & $\mathrm{x}$ & 0,048 & 0,042 & $\bar{x}$ & $\bar{x}$ & $\bar{x}$ & $\mathrm{x}$ & $\bar{x}$ & 0,112 & 0,067 & 0,039 \\
\hline & & & CompViaCicilst & $\mathrm{x}$ & $\mathrm{x}$ & 0,162 & 0,021 & $\mathrm{x}$ & $\mathrm{x}$ & $\mathrm{x}$ & $\mathrm{x}$ & $\mathrm{x}$ & 0,043 & 0,075 & 0,076 \\
\hline & & & ViaOtimTraf & $\mathrm{x}$ & $\mathrm{x}$ & 0,173 & 0,132 & $\mathrm{x}$ & $\mathrm{x}$ & $\mathrm{x}$ & $\mathrm{x}$ & $\mathrm{x}$ & 0,112 & 0,139 & 0,031 \\
\hline & & & RedVia & $\mathrm{x}$ & $\mathrm{x}$ & 0,048 & 0,054 & $\mathrm{x}$ & $\mathrm{x}$ & $\mathrm{x}$ & $\mathrm{x}$ & $\mathrm{x}$ & 0,132 & 0,078 & 0,047 \\
\hline & & 110 & ExtViaPedest & $\mathrm{x}$ & $\mathrm{x}$ & 0,162 & 0,087 & $\mathrm{x}$ & $\mathrm{x}$ & $\mathrm{x}$ & $\mathrm{x}$ & $\mathrm{x}$ & 0,043 & 0,097 & 0,060 \\
\hline & & & EstacionaCar & $\mathrm{x}$ & $\mathrm{x}$ & 0,076 & 0,092 & $\mathrm{x}$ & $\mathrm{x}$ & $\mathrm{x}$ & $\mathrm{x}$ & $\mathrm{x}$ & 0,043 & 0,070 & 0,025 \\
\hline & & & AcessTranspPavi & $\mathrm{x}$ & $\mathrm{x}$ & 0,204 & 0,191 & $\mathrm{x}$ & $\mathrm{x}$ & $\mathrm{x}$ & $\mathrm{x}$ & $\mathrm{x}$ & 0,241 & 0,212 & 0,026 \\
\hline & & & TrafficCalming & $\mathrm{x}$ & $\mathrm{x}$ & 0,127 & 0,381 & $\mathrm{x}$ & $\mathrm{x}$ & $\mathrm{x}$ & $\mathrm{x}$ & $\mathrm{x}$ & 0,273 & 0,261 & 0,127 \\
\hline & & & AquisBic & $\mathrm{x}$ & $\mathrm{x}$ & 0,217 & 0,031 & $\mathrm{x}$ & $\mathrm{x}$ & $\mathrm{x}$ & $\mathrm{x}$ & $\mathrm{x}$ & 0,063 & 0,104 & 0,100 \\
\hline & & & MudaModTransp & $\mathrm{x}$ & $\mathrm{x}$ & 0,164 & 0,513 & $\mathrm{x}$ & $\mathrm{x}$ & $\mathrm{x}$ & $\mathrm{x}$ & $\mathrm{x}$ & 0,165 & 0,281 & 0,201 \\
\hline & & I11 & TrafRodo & $\mathrm{x}$ & $\mathrm{x}$ & 0,138 & 0,242 & $\mathrm{x}$ & $\mathrm{x}$ & $\mathrm{x}$ & $\mathrm{x}$ & $\mathrm{x}$ & 0,444 & 0,274 & 0,156 \\
\hline & & & TranspCarg & $\mathrm{x}$ & $\mathrm{x}$ & 0,072 & 0,069 & $\mathrm{x}$ & $\mathrm{x}$ & $\mathrm{x}$ & $\mathrm{x}$ & $\mathrm{x}$ & 0,165 & 0,102 & 0,054 \\
\hline & & & TranspPassag & $\mathrm{x}$ & $\mathrm{x}$ & 0,409 & 0,145 & $\mathrm{x}$ & $\mathrm{x}$ & $\mathrm{x}$ & $\mathrm{x}$ & $\mathrm{x}$ & 0,165 & 0,240 & 0,147 \\
\hline
\end{tabular}




\begin{tabular}{|c|c|c|c|c|c|c|c|c|c|c|c|c|c|c|c|}
\hline \multirow{2}{*}{\multicolumn{4}{|c|}{ CRITÉRIOS }} & \multicolumn{10}{|c|}{ PORTUGAL - Avaliadores } & \multirow{2}{*}{$\begin{array}{l}\text { PESOS } \\
\text { (Média) }\end{array}$} & \multirow{2}{*}{$\begin{array}{c}\text { DESVIO } \\
\text { PADRÃO }\end{array}$} \\
\hline & & & & 11 & 12 & 13 & 14 & 15 & 16 & 17 & 18 & 19 & 20 & & \\
\hline \multirow{33}{*}{$\begin{array}{l}m \\
0 \\
0 \\
0 \\
0 \\
0 \\
\text { c1 }\end{array}$} & \multirow{33}{*}{ 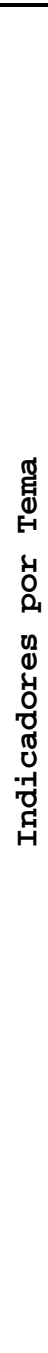 } & \multirow{6}{*}{ I12 } & 9 & $\mathrm{x}$ & $\mathrm{x}$ & 0,317 & 0,201 & $\mathrm{x}$ & $\mathrm{x}$ & $\mathrm{x}$ & $\mathrm{x}$ & $\mathrm{x}$ & 0,130 & 0,216 & 0,094 \\
\hline & & & DensidTraf & $\mathrm{x}$ & $\mathrm{x}$ & 0,088 & 0,083 & $\mathrm{x}$ & $\mathrm{x}$ & $\mathrm{x}$ & $\mathrm{x}$ & $\mathrm{x}$ & 0,130 & 0,100 & 0,026 \\
\hline & & & VolTraf & $\mathrm{x}$ & $\mathrm{x}$ & 0,268 & 0,035 & $\mathrm{x}$ & $\mathrm{x}$ & $\mathrm{x}$ & $\mathrm{x}$ & $\mathrm{x}$ & 0,130 & 0,144 & 0,117 \\
\hline & & & OcupaVeicPassag & $\mathrm{x}$ & $\mathrm{x}$ & 0,196 & 0,051 & $\mathrm{x}$ & $\mathrm{x}$ & $\mathrm{x}$ & $\mathrm{x}$ & $\mathrm{x}$ & 0,288 & 0,178 & 0,119 \\
\hline & & & TempTraf & $\mathrm{x}$ & $\mathrm{x}$ & 0,088 & 0,471 & $\mathrm{x}$ & $\mathrm{x}$ & $\mathrm{x}$ & $\mathrm{x}$ & $\mathrm{x}$ & 0,161 & 0,240 & 0,203 \\
\hline & & & VelocTraf & $\mathrm{x}$ & $\mathrm{x}$ & 0,044 & 0,160 & $\mathrm{x}$ & $\mathrm{x}$ & $\mathrm{x}$ & $\mathrm{x}$ & $\mathrm{x}$ & 0,161 & 0,121 & 0,067 \\
\hline & & \multirow{6}{*}{ P13 } & AcessBairro & $\mathrm{x}$ & $\mathrm{x}$ & 0,132 & 0,115 & $\mathrm{x}$ & $\mathrm{x}$ & $\mathrm{x}$ & $\mathrm{x}$ & $\mathrm{x}$ & 0,047 & 0,098 & 0,045 \\
\hline & & & AcessCentro & $\mathrm{x}$ & $\mathrm{x}$ & 0,233 & 0,039 & $\mathrm{x}$ & $\mathrm{x}$ & $\mathrm{x}$ & $\mathrm{x}$ & $\mathrm{x}$ & 0,113 & 0,128 & 0,098 \\
\hline & & & AcessServBasic & $\mathrm{x}$ & $\mathrm{x}$ & 0,336 & 0,373 & $\mathrm{x}$ & $\mathrm{x}$ & $\mathrm{x}$ & $\mathrm{x}$ & $\mathrm{x}$ & 0,307 & 0,339 & 0,033 \\
\hline & & & AcessServTransp & $\mathrm{x}$ & $\mathrm{x}$ & 0,189 & 0,073 & $\mathrm{x}$ & $\mathrm{x}$ & $\mathrm{x}$ & $\mathrm{x}$ & $\mathrm{x}$ & 0,307 & 0,190 & 0,117 \\
\hline & & & EmpregDistResid & $\mathrm{x}$ & $\mathrm{x}$ & 0,066 & 0,359 & $\mathrm{x}$ & $\mathrm{x}$ & $\mathrm{x}$ & $\mathrm{x}$ & $\mathrm{x}$ & 0,113 & 0,179 & 0,158 \\
\hline & & & PessoaDistLazer & $\mathrm{x}$ & $\mathrm{x}$ & 0,044 & 0,042 & $\mathrm{x}$ & $\mathrm{x}$ & $\mathrm{x}$ & $\mathrm{x}$ & $\mathrm{x}$ & 0,113 & 0,066 & 0,040 \\
\hline & & \multirow{8}{*}{ P14 } & CategorUsoSolo & $\mathrm{x}$ & $\mathrm{x}$ & 0,045 & 0,136 & $\mathrm{x}$ & $\mathrm{x}$ & $\mathrm{x}$ & $\mathrm{x}$ & $\mathrm{x}$ & 0,039 & 0,073 & 0,054 \\
\hline & & & VerdVersusAutoPirv & $\mathrm{x}$ & $\mathrm{x}$ & 0,189 & 0,101 & $\mathrm{x}$ & $\mathrm{x}$ & $\mathrm{x}$ & $\mathrm{x}$ & $\mathrm{x}$ & 0,101 & 0,130 & 0,051 \\
\hline & & & DeconcAtiv & $\mathrm{x}$ & $\mathrm{x}$ & 0,086 & 0,024 & $\mathrm{x}$ & $\mathrm{x}$ & $\mathrm{x}$ & $\mathrm{x}$ & $\mathrm{x}$ & 0,101 & 0,070 & 0,041 \\
\hline & & & FormUrb & $\mathrm{x}$ & $\mathrm{x}$ & 0,084 & 0,062 & $\mathrm{x}$ & $\mathrm{x}$ & $\mathrm{x}$ & $\mathrm{x}$ & $\mathrm{x}$ & 0,130 & 0,092 & 0,035 \\
\hline & & & IncentUsoMistAltaDensid & $\mathrm{x}$ & $\mathrm{x}$ & 0,038 & 0,022 & $\mathrm{x}$ & $\mathrm{x}$ & $\mathrm{x}$ & $\mathrm{x}$ & $\mathrm{x}$ & 0,044 & 0,035 & 0,011 \\
\hline & & & MudaSoloInfraTransp & $\mathrm{x}$ & $\mathrm{x}$ & 0,165 & 0,173 & $\mathrm{x}$ & $\mathrm{x}$ & $\mathrm{x}$ & $\mathrm{x}$ & $\mathrm{x}$ & 0,231 & 0,190 & 0,036 \\
\hline & & & PlanejaSoloUrb & $\mathrm{x}$ & $\mathrm{x}$ & 0,227 & 0,260 & $\mathrm{x}$ & $\mathrm{x}$ & $\mathrm{x}$ & $\mathrm{x}$ & $\mathrm{x}$ & 0,090 & 0,193 & 0,090 \\
\hline & & & PoliticPedestCiclistPublid & $\mathrm{x}$ & $\mathrm{x}$ & 0,166 & 0,221 & $\mathrm{x}$ & $\mathrm{x}$ & $\mathrm{x}$ & $\mathrm{x}$ & $\mathrm{x}$ & 0,263 & 0,217 & 0,048 \\
\hline & & \multirow{5}{*}{ P15 } & UnidFamCrescPop & $\mathrm{x}$ & $\mathrm{x}$ & 0,157 & 0,041 & $\mathrm{x}$ & $\mathrm{x}$ & $\mathrm{x}$ & $\mathrm{x}$ & $\mathrm{x}$ & 0,084 & 0,094 & 0,059 \\
\hline & & & DensidPop & $\mathrm{x}$ & $\mathrm{x}$ & 0,453 & 0,279 & $\mathrm{x}$ & $\mathrm{x}$ & $\mathrm{x}$ & $\mathrm{x}$ & $\mathrm{x}$ & 0,355 & 0,362 & 0,087 \\
\hline & & & EstrutEtarPop & $\mathrm{x}$ & $\mathrm{x}$ & 0,070 & 0,221 & $\mathrm{x}$ & $\mathrm{x}$ & $\mathrm{x}$ & $\mathrm{x}$ & $\mathrm{x}$ & 0,052 & 0,114 & 0,093 \\
\hline & & & RendFamPercapita & $\mathrm{x}$ & $\mathrm{x}$ & 0,070 & 0,114 & $\mathrm{x}$ & $\mathrm{x}$ & $\mathrm{x}$ & $\mathrm{x}$ & $\mathrm{x}$ & 0,154 & 0,113 & 0,042 \\
\hline & & & TaxCrescPop & $\mathrm{x}$ & $\mathrm{x}$ & 0,250 & 0,345 & $\mathrm{x}$ & $\mathrm{x}$ & $\mathrm{x}$ & $\mathrm{x}$ & $\mathrm{x}$ & 0,355 & 0,317 & 0,058 \\
\hline & & \multirow{8}{*}{ P16 } & DeslocaCriançaEsc & $\mathrm{x}$ & $\mathrm{x}$ & 0,174 & 0,023 & $\mathrm{x}$ & $\mathrm{x}$ & $\mathrm{x}$ & $\mathrm{x}$ & $\mathrm{x}$ & 0,097 & 0,098 & 0,075 \\
\hline & & & DistServBasic & $\mathrm{x}$ & $\mathrm{x}$ & 0,285 & 0,318 & $\mathrm{x}$ & $\mathrm{x}$ & $\mathrm{x}$ & $\mathrm{x}$ & $\mathrm{x}$ & 0,307 & 0,303 & 0,017 \\
\hline & & & DistFam & $\mathrm{x}$ & $\mathrm{x}$ & 0,032 & 0,034 & $\mathrm{x}$ & $\mathrm{x}$ & $\mathrm{x}$ & $\mathrm{x}$ & $\mathrm{x}$ & 0,033 & 0,033 & 0,001 \\
\hline & & & DistPedBiciDia & $\mathrm{x}$ & $\mathrm{x}$ & 0,113 & 0,034 & $\mathrm{x}$ & $\mathrm{x}$ & $\mathrm{x}$ & $\mathrm{x}$ & $\mathrm{x}$ & 0,050 & 0,066 & 0,042 \\
\hline & & & MobLocal & $\mathrm{x}$ & $\mathrm{x}$ & 0,217 & 0,116 & $\mathrm{x}$ & $\mathrm{x}$ & $\mathrm{x}$ & $\mathrm{x}$ & $\mathrm{x}$ & 0,177 & 0,170 & 0,051 \\
\hline & & & PopVivTrabLocal & $\mathrm{x}$ & $\mathrm{x}$ & 0,040 & 0,066 & $\mathrm{x}$ & $\mathrm{x}$ & $\mathrm{x}$ & $\mathrm{x}$ & $\mathrm{x}$ & 0,081 & 0,062 & 0,021 \\
\hline & & & UtliAutoDistInferior & $\mathrm{x}$ & $\mathrm{x}$ & 0,054 & 0,165 & $\mathrm{x}$ & $\mathrm{x}$ & $\mathrm{x}$ & $\mathrm{x}$ & $\mathrm{x}$ & 0,054 & 0,091 & 0,064 \\
\hline & & & TempViag & $\mathrm{x}$ & $\mathrm{x}$ & 0,085 & 0,244 & $\mathrm{x}$ & $\mathrm{x}$ & $\mathrm{x}$ & $\mathrm{x}$ & $\mathrm{x}$ & 0,201 & 0,177 & 0,082 \\
\hline
\end{tabular}




\begin{tabular}{|c|c|c|c|c|c|c|c|c|c|c|c|c|c|c|c|}
\hline \multirow{2}{*}{\multicolumn{4}{|c|}{ CRITÉRIOS }} & \multicolumn{10}{|c|}{ PORTUGAL - Avaliadores } & \multirow{2}{*}{$\begin{array}{l}\text { PESOS } \\
\text { (Média) }\end{array}$} & \multirow{2}{*}{$\begin{array}{c}\text { DESVIO } \\
\text { PADRÃO }\end{array}$} \\
\hline & & & & 11 & 12 & 13 & 14 & 15 & 16 & 17 & 18 & 19 & 20 & & \\
\hline \multirow{21}{*}{ 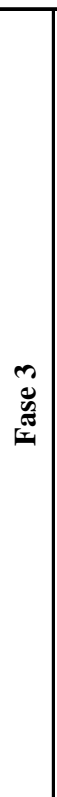 } & \multirow{21}{*}{ 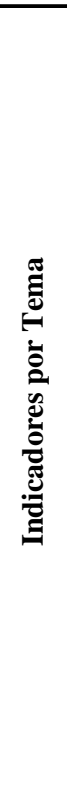 } & \multirow{5}{*}{ S17 } & CustPassagTransp & $\mathrm{x}$ & $\mathrm{x}$ & 0,326 & 0,141 & $\mathrm{x}$ & $\mathrm{x}$ & $\mathrm{x}$ & $\mathrm{x}$ & $\mathrm{x}$ & 0,111 & 0,193 & 0,116 \\
\hline & & & EvoluPreçoCombust & $\mathrm{x}$ & $\mathrm{x}$ & 0,326 & 0,148 & $\mathrm{x}$ & $\mathrm{x}$ & $\mathrm{x}$ & $\mathrm{x}$ & $\mathrm{x}$ & 0,111 & 0,195 & 0,115 \\
\hline & & & MudaPreçoTranspModo & $\mathrm{x}$ & $\mathrm{x}$ & 0,138 & 0,275 & $\mathrm{x}$ & $\mathrm{x}$ & $\mathrm{x}$ & $\mathrm{x}$ & $\mathrm{x}$ & 0,333 & 0,249 & 0,101 \\
\hline & & & PreçoCombustTax & $\mathrm{x}$ & $\mathrm{x}$ & 0,073 & 0,048 & $\mathrm{x}$ & $\mathrm{x}$ & $\mathrm{x}$ & $\mathrm{x}$ & $\mathrm{x}$ & 0,111 & 0,078 & 0,032 \\
\hline & & & PreçoTranspPublic & $\mathrm{x}$ & $\mathrm{x}$ & 0,138 & 0,388 & $\mathrm{x}$ & $\mathrm{x}$ & $\mathrm{x}$ & $\mathrm{x}$ & $\mathrm{x}$ & 0,333 & 0,286 & 0,131 \\
\hline & & \multirow{4}{*}{ S18 } & BeneficUsaTransp & $\mathrm{x}$ & $\bar{x}$ & 0,368 & 0,169 & $\mathrm{x}$ & $\mathrm{x}$ & $\mathrm{x}$ & $\mathrm{x}$ & $\bar{x}$ & 0,153 & 0,230 & 0,120 \\
\hline & & & CustCongestiona & $\mathrm{x}$ & $\mathrm{x}$ & 0,170 & 0,402 & $\mathrm{x}$ & $\mathrm{x}$ & $\mathrm{x}$ & $\mathrm{x}$ & $\mathrm{x}$ & 0,390 & 0,320 & 0,131 \\
\hline & & & CustSocial & $\mathrm{x}$ & $\mathrm{x}$ & 0,368 & 0,376 & $\mathrm{x}$ & $\mathrm{x}$ & $\mathrm{x}$ & $\mathrm{x}$ & $\mathrm{x}$ & 0,390 & 0,378 & 0,011 \\
\hline & & & RendOperaTransp & $\mathrm{x}$ & $\mathrm{x}$ & 0,095 & 0,053 & $\mathrm{x}$ & $\mathrm{x}$ & $\mathrm{x}$ & $\mathrm{x}$ & $\mathrm{x}$ & 0,068 & 0,072 & 0,021 \\
\hline & & \multirow{5}{*}{ S19 } & AcidentFatalTransp & $\mathrm{x}$ & $\mathrm{x}$ & 0,252 & 0,172 & $\bar{x}$ & $\mathrm{x}$ & $\mathrm{x}$ & $\mathrm{x}$ & $\mathrm{x}$ & 0,281 & 0,235 & 0,056 \\
\hline & & & FeridoAcidentTraf & $\mathrm{x}$ & $\mathrm{x}$ & 0,047 & 0,044 & $\mathrm{x}$ & $\mathrm{x}$ & $\mathrm{x}$ & $\mathrm{x}$ & $\mathrm{x}$ & 0,281 & 0,124 & 0,136 \\
\hline & & & CrimeTransit & $\mathrm{x}$ & $\mathrm{x}$ & 0,351 & 0,131 & $\mathrm{x}$ & $\mathrm{x}$ & $\mathrm{x}$ & $\mathrm{x}$ & $\mathrm{x}$ & 0,050 & 0,178 & 0,156 \\
\hline & & & AcidentPedestCiclist & $\mathrm{x}$ & $\mathrm{x}$ & 0,092 & 0,054 & $\mathrm{x}$ & $\mathrm{x}$ & $\mathrm{x}$ & $\mathrm{x}$ & $\mathrm{x}$ & 0,281 & 0,142 & 0,122 \\
\hline & & & SegurViaResidencia & $\mathrm{x}$ & $\mathrm{x}$ & 0,258 & 0,599 & $\mathrm{x}$ & $\mathrm{x}$ & $\mathrm{x}$ & $\mathrm{x}$ & $\mathrm{x}$ & 0,107 & 0,321 & 0,252 \\
\hline & & \multirow{7}{*}{ S20 } & DemandTranspPassag & $\mathrm{x}$ & $\mathrm{x}$ & 0,132 & 0,045 & $\mathrm{x}$ & $\mathrm{x}$ & $\mathrm{x}$ & $\mathrm{x}$ & $\mathrm{x}$ & 0,102 & 0,093 & 0,044 \\
\hline & & & DispTranspPublic & $\mathrm{x}$ & $\mathrm{x}$ & 0,116 & 0,179 & $\mathrm{x}$ & $\mathrm{x}$ & $\mathrm{x}$ & $\mathrm{x}$ & $\mathrm{x}$ & 0,285 & 0,193 & 0,085 \\
\hline & & & DiversidadTransp & $\mathrm{x}$ & $\mathrm{x}$ & 0,037 & 0,076 & $\mathrm{x}$ & $\mathrm{x}$ & $\mathrm{x}$ & $\mathrm{x}$ & $\mathrm{x}$ & 0,285 & 0,133 & 0,133 \\
\hline & & & NecessTransp & $\mathrm{x}$ & $\mathrm{x}$ & 0,090 & 0,408 & $\mathrm{x}$ & $\mathrm{x}$ & $\mathrm{x}$ & $\mathrm{x}$ & $\mathrm{x}$ & 0,102 & 0,200 & 0,180 \\
\hline & & & NivServTranspPublic & $\mathrm{x}$ & $\mathrm{x}$ & 0,063 & 0,145 & $\mathrm{x}$ & $\mathrm{x}$ & $\mathrm{x}$ & $\mathrm{x}$ & $\mathrm{x}$ & 0,102 & 0,103 & 0,041 \\
\hline & & & TranspPublicInsegur & $\mathrm{x}$ & $\mathrm{x}$ & 0,263 & 0,021 & $\mathrm{x}$ & $\mathrm{x}$ & $\mathrm{x}$ & $\mathrm{x}$ & $\mathrm{x}$ & 0,024 & 0,103 & 0,139 \\
\hline & & & TranspPublicVersusCar & $\mathrm{x}$ & $\mathrm{x}$ & 0,298 & 0,125 & $\mathrm{x}$ & $\mathrm{x}$ & $\mathrm{x}$ & $\mathrm{x}$ & $\mathrm{x}$ & 0,102 & 0,175 & 0,107 \\
\hline
\end{tabular}


ANEXO F - Estrutura de Temas, Categorias e Indicadores de mobilidade urbana 


\begin{tabular}{|c|c|c|}
\hline CATEGORIA & ID & TEMA \\
\hline \multirow{4}{*}{$\begin{array}{c}\text { TRANSPORTES E MEIO } \\
\text { AMBIENTE } \\
\text { (A) }\end{array}$} & A1 & Energia/Combustíveis \\
\hline & $\mathrm{A} 2$ & Impactos ambientais \\
\hline & A3 & Qualidade do ar \\
\hline & A4 & Ruído de tráfego \\
\hline \multirow{4}{*}{$\begin{array}{c}\text { GESTÃO DA } \\
\text { MOBILIDADE URBANA } \\
(\mathbf{G})\end{array}$} & G5 & Despesas/Investimentos/Estratégias econômicas \\
\hline & G6 & Gerenciamento/Monitoração \\
\hline & G7 & Medidas para o incremento da mobilidade urbana \\
\hline & G8 & Novas tecnologias \\
\hline \multirow{4}{*}{$\begin{array}{c}\text { INFRA-ESTRUTURA E } \\
\text { TECNOLOGIAS DE } \\
\text { TRANSPORTE } \\
\text { (I) }\end{array}$} & I9 & Frota \\
\hline & $\mathrm{I} 10$ & Infra-estrutura/Sistema viário \\
\hline & I11 & Tecnologias e serviços de transporte \\
\hline & $\mathrm{I} 12$ & Tráfego \\
\hline \multirow{4}{*}{$\begin{array}{c}\text { PLANEJAMENTO } \\
\text { ESPACIAL E DEMANDA } \\
\text { POR TRASPORTES } \\
(P)\end{array}$} & P13 & Acesso aos serviços e atividades urbanas \\
\hline & P14 & Desenvolvimento urbano/Uso do solo \\
\hline & P15 & População urbana \\
\hline & P16 & Viagens/Deslocamentos \\
\hline \multirow{4}{*}{$\begin{array}{c}\text { ASPECTOS } \\
\text { SOCIOECONÔMICOS } \\
\text { DOS TRANSPORTES (S) }\end{array}$} & S17 & Custos/Preços/Tarifas \\
\hline & S18 & Impactos socioeconômicos dos transportes \\
\hline & S19 & Segurança \\
\hline & S20 & Transporte público \\
\hline
\end{tabular}




\begin{tabular}{ccc}
\hline CATEGORIA & ID & TEMA \\
\hline TRANSPORTES E MEIO & A1 & Energia/Combustíveis \\
AMBIENTE & A2 & Impactos ambientais \\
(A) & A3 & Qualidade do ar \\
& A4 & Ruído de tráfego \\
\hline GESTÃO DA & G5 & Despesas/Investimentos/Estratégias econômicas \\
(G) & G6 & Gerenciamento/Monitoração \\
MOBILIDADE URBANA & G7 & Medidas para o incremento da mobilidade urbana \\
INFRA-ESTRUTURA E & G8 & Novas tecnologias \\
TECNOLOGIAS DE & I10 & Frota \\
TRANSPORTE & I11 & Tecnologias e serviços de transporte \\
(I) & I12 & Tráfego \\
\hline PLANEJAMENTO & P13 & Acesso aos serviços e atividades urbanas \\
ESPACIAL E DEMANDA & P14 & Desenvolvimento urbano/Uso do solo \\
POR TRASPORTES & P15 & População urbana \\
(P) & P16 & Viagens/Deslocamentos \\
\hline ASPECTOS & S17 & Custos/Preços/Tarifas \\
SOCIOECONÔMICOS & S18 & Impactos socioeconômicos dos transportes \\
DOS TRANSPORTES (S) & S20 & Segurança \\
& & Transporte público \\
\hline
\end{tabular}

\section{TEMA}

Energia/

Combustíveis

Impactos Ambientais

Qualidade do ar

Ruído de tráfego

\section{INDICADOR}

Consumo per capita de combustível fóssil por transporte em veículo motorizado Eficiência energética do transporte de passageiros e carga

Energia final consumida pelo setor de transportes Intensidade no uso de energia: transportes

Proporção de energia originada de fontes de combustível fósseis e não-fósseis

\section{Fragmentação de terras e florestas}

Impactos do uso de automóveis

Proximidade de infra-estrutura de transportes a áreas protegidas

Resíduos gerados por veículos rodoviários

Dias por ano em que os padrões de qualidade do ar não são atendidos

Emissão de gases acidificantes pelos transportes

Emissão de gases que geram o efeito estufa pelos transportes

Emissões causadas pelos transportes e intensidade das emissões

População exposta à poluição do ar causada pelos transportes Qualidade do ar

Medidas de minimização de ruído Poluição sonora

População exposta ao ruído acima de $65 \mathrm{~dB}$ (A) causado pelos transportes

Ruído de tráfego: exposição e incômodo 


\begin{tabular}{ccc}
\hline CATEGORIA & ID & TEMA \\
\hline TRANSPORTES E MEIO & A1 & Energia/Combustíveis \\
AMBIENTE & A3 & Impactos ambientais \\
(A) & A4 & Qualidade do ar \\
GESTÃO DA & G5 & Despesas/Investimentos dráfego \\
\hline (G) & G6 & Gerenciamentógias econômicas \\
MOBILIDADE URBANA & G7 & Medidas para o incremento da mobilidade urbana \\
INFRA-ESTRUTURA E & G8 & Novas tecnologias \\
TECNOLOGIAS DE & I10 & Frota \\
TRANSPORTE & I11 & Tecnologias e serviços de transporte \\
(I) & I12 & Tráfego \\
\hline PLANEJAMENTO & P13 & Acesso aos serviços e atividades urbanas \\
ESPACIAL E DEMANDA & P14 & Desenvolvimento urbano/Uso do solo \\
POR TRASPORTES & P15 & População urbana \\
(P) & P16 & Viagens/Deslocamentos \\
\hline ASPECTOS & S17 & Custos/Preços/Tarifas \\
SOCIOECONÔMICOS & S18 & Impactos socioeconômicos dos transportes \\
DOS TRANSPORTES (S) & S20 & Segurança \\
\hline
\end{tabular}

TEMA

Despesas/

Investimentos/

Estratégias

econômicas

\begin{tabular}{c}
\hline $\begin{array}{c}\text { Gerenciamento/ } \\
\text { Monitoração }\end{array}$ \\
\hline Medidas para o \\
incremento da \\
mobilidade urbana
\end{tabular}

\section{INDICADOR}

Capital investido por modo

Despesas públicas com transporte privado

Despesas públicas com transporte público

Investimentos em infra-estrutura de transportes

Subsídios diretos aos transportes

Taxação relativa de veículos e utilização de veículos

Avaliação de impacto ambiental

Gerenciamento efetivo do tráfego/fiscalização

Sistemas nacionais para a monitoração dos transportes e meio ambiente

Desenvolvimento de planos municipais para a redução das viagens

Estabelecimento de regulamentação para densidades mínimas na cidade

Implementação de estratégias ambientais para o setor de transportes

Medidas: operação eficiente da frota de veículos

Melhoria dos transportes

Priorizar viagens eficientes (a pé ou por bicicleta)

Desenvolvimento de combustíveis limpos e número de veículos que utilizam

combustíveis alternativos

Gastos com Pesquisa e Desenvolvimento de "combustíveis limpos"

Gastos com Pesquisa e Desenvolvimento de "veículos ecológicos

Novas formas de transporte

Possível custo inicial de veículos ecológicos

Uso de tecnologia de cartões inteligentes Vida útil dos veículos ecológicos 


\begin{tabular}{ccc}
\hline CATEGORIA & ID & TEMA \\
\hline TRANSPORTES E MEIO & A1 & Energia/Combustíveis \\
AMBIENTE & A3 & Impactos ambientais \\
(A) & A4 & Qualidade do ar \\
& Guído de tráfego \\
\hline GESTÃO DA & G6 & Despesas/Investimentos/Estratégias econômicas \\
(G) & Gerenciamento/Monitoração \\
MOBILIDADE URBANA & G8 & Medidas para o incremento da mobilidade urbana \\
INFRA-ESTRUTURA E & I9 & Novas tecnologias \\
TECNOLOGIAS DE & I10 & Infra-estrutura/Sistema viário \\
TRANSPORTE & I11 & Tecnologias e serviços de transporte \\
(I) & I12 & Tráfego \\
PLANEJAMENTO & P13 & Acesso aos serviços e atividades urbanas \\
ESPACIAL E DEMANDA & P14 & Desenvolvimento urbano/Uso do solo \\
POR TRASPORTES & P15 & População urbana \\
(P) & P16 & Viagens/Deslocamentos \\
\hline ASPECTOS & S17 & Custos/Preços/Tarifas \\
SOCIOECONOMICOS & S18 & Impactos socioeconômicos dos transportes \\
DOS TRANSPORTES (S) & S20 & Segurança \\
& & Transporte público \\
\hline
\end{tabular}

TEMA

Frota

\section{INDICADOR}

Estrutura da frota de veículos rodoviários Idade média dos veículos

Percentagem da frota municipal convertida para reduzir a emissão de poluentes Propriedade de automóveis privados

Relação entre veículos com consumo eficiente de combustível/veículos com consumo ineficiente de combustível Veículos em circulação

Capacidade das redes de infra-estrutura de transportes

Comprimento total das vias para ciclistas

Infra-estrutura/ Sistema Viário
Desenvolvimento de vias para otimizar o fluxo de tráfego

Estrutura da rede viária

Extensão total das vias designadas para pedestres

Número de estacionamentos para carros na cidade

Possibilidade de acesso de transporte coletivo (pavimentação)

Provisão de infra-estrutura para traffic calming e vias para bicicletas e pedestres
Aquisição de bicicletas em cidades menos desenvolvidas

Mudanças nos modos de transporte

Tendências do tráfego rodoviário e densidades

Transporte de carga por modo

Transporte de passageiros por modo de transporte

Congestionamento de tráfego

Densidade de tráfego

Tráfego
Geração de volume de tráfego e tipo

Taxa de ocupação dos veículos de passageiros

Tempo total gasto no tráfego

Velocidade de tráfego 


\begin{tabular}{ccc}
\hline CATEGORIA & ID & TEMA \\
\hline TRANSPORTES E MEIO & A1 & Energia/Combustíveis \\
AMBIENTE & A2 & Impactos ambientais \\
(A) & A3 & Qualidade do ar \\
Auído de tráfego \\
\hline GESTÃO DA & G5 & Despesas/Investimentos/Estratégias econômicas \\
(G) & G6 & Gerenciamento/Monitoração \\
MOBILIDADE URBANA & G7 & Medidas para o incremento da mobilidade urbana \\
\hline INFRA-ESTRUTURA E & G8 & Novas tecnologias \\
TECNOLOGIAS DE & I10 & Frota \\
TRANSPORTE & I11 & Tecnologias e serviços de transporte \\
(I) & I12 & Tráfego \\
\hline PLANEJAMENTO & P13 & Acesso aos serviços e atividades urbanas \\
ESPACIAL E DEMANDA & P14 & Desenvolvimento urbano/Uso do solo \\
POR TRASPORTES & P15 & População urbana \\
(P) & P16 & Viagens/Deslocamentos \\
ASPECTOS & S17 & Custos/Preços/Tarifas \\
SOCIOECONOMICOS & S18 & Impactos socioeconômicos dos transportes \\
DOS TRANSPORTES (S) & S19 & Segurança \\
& S20 & Transporte público \\
\hline
\end{tabular}

\section{TEMA}

Acesso aos serviços e atividades urbanas

\section{INDICADOR}

Acessibilidade ao bairro

Acessibilidade ao centro

Acesso aos serviços básicos

Acesso aos serviços de transportes

Percentagem de empregos situados a até $3 \mathrm{~km}$ de distância das residências Percentagem de pessoas que vivem a até $3 \mathrm{~km}$ de distância das facilidades de lazer Área total em categorias significativas de uso do solo

Áreas verdes versus áreas destinadas ao automóvel privado Desconcentração das atividades

Forma urbana

Desenvolvimento urbano/Uso do solo
Incentivo ao uso misto/alta densidade

Mudanças no uso do solo devido a infra-estrutura de transportes

Planejamento do uso do solo urbano

Políticas de uso do solo para pedestres, ciclistas e transporte público

Crescimento do número de unidades unifamiliares comparado ao crescimento da

\section{População urbana}

$$
\text { população }
$$

Densidade populacional

Estrutura etária da população

Rendimento familiar per capita

Taxa de crescimento da população

Deslocamento de crianças para a escola

Distância aos serviços básicos

Distância média entre os moradores e os demais membros de sua família

Distância percorrida a pé ou por bicicleta per capita por dia

Mobilidade local e passageiros transportados

Número de pessoas vivendo e trabalhando no local

Percentagem de pessoas que utilizam o automóvel para viagens com distância inferior a $3 \mathrm{~km}$ 


\begin{tabular}{ccc}
\hline CATEGORIA & ID & TEMA \\
\hline TRANSPORTES E MEIO & A1 & Energia/Combustíveis \\
AMBIENTE & A2 & Impactos ambientais \\
(A) & A3 & Qualidade do ar \\
A4 & G5 & Despesas/Investimente tráfego \\
\hline GESTÃO DA & G6 & Gerenciamento/Monitorasceconômicas \\
MOBILIDADE URBANA & G7 & Medidas para o incremento da mobilidade urbana \\
(G) & G8 & Novas tecnologias \\
\hline INFRA-ESTRUTURA E & I9 & Frota \\
TECNOLOGIAS DE & I10 & Infra-estrutura/Sistema viário \\
TRANSPORTE & I11 & Tecnologias e serviços de transporte \\
(I) & I12 & Tráfego \\
\hline PLANEJAMENTO & P13 & Acesso aos serviços e atividades urbanas \\
ESPACIAL E DEMANDA & P14 & Desenvolvimento urbano/Uso do solo \\
POR TRASPORTES & P15 & População urbana \\
(P) & P16 & Viagens/Deslocamentos \\
\hline ASPECTOS & S17 & Custos/Preços/Tarifas \\
\hline SOCIOECONOMICOS & S18 & Impactos socioeconômicos dos transportes \\
DOS TRANSPORTES (S) & S19 & Segurança \\
& S20 & Transporte público \\
\hline
\end{tabular}

\section{TEMA}

Custos/Preços/ Tarifas

\section{INDICADOR}

Custo por passageiro transportado, corrigido pela inflação Evolução dos preços dos diferentes tipos de combustíveis e eletricidade

Mudanças reais nos preços de transporte por modo Preço dos combustíveis e taxas

Tendências dos preços do transporte público

\section{Impactos sócio- econômicos dos transportes}

\section{Segurança} Benefícios dos usuários de transportes

Custos do congestionamento

Custos sociais dos transportes

Rendimento dos operadores de transportes Acidentes fatais de transportes Feridos por acidentes de tráfego Número de crimes violentos ocorridos no trânsito Pedestres e ciclistas feridos em acidentes de trânsito Segurança e proteção para as vias residenciais

Demanda por transporte de passageiros

Disponibilidade de transporte público

Fator de diversidade para serviços de transporte Necessidade de sistemas de transporte Nível de serviço do transporte público e modalidades lentas Percentagem de pessoas que consideram o transporte público inseguro Percentagem de pessoas que escolhem o transporte público em detrimento ao 
Tabela G-1: Indicadores de mobilidade sustentável

\begin{tabular}{|c|c|c|}
\hline \multicolumn{3}{|c|}{ CATEGORIA A - TRANSPORTES E MEIO AMBIENTE } \\
\hline \multicolumn{3}{|c|}{ A1 - Energia/Combustíveis } \\
\hline Indicador & Sistema & Definição \\
\hline $\begin{array}{c}\text { Consumo per capita de combustível fóssil por } \\
\text { transporte em veículo motorizado } \\
\text { (ConCombustFos) }\end{array}$ & Ag_21 & $\begin{array}{c}\text { Indicador do número anual de litros por pessoa } \\
\text { de combustível fóssil (gasolina, diesel e GLP) } \\
\text { consumido por transporte em veículo } \\
\text { motorizado na área urbana. }\end{array}$ \\
\hline $\begin{array}{c}\text { Eficiência energética do transporte de passageiros } \\
\text { e carga } \\
\text { (EficTranspCarg) }\end{array}$ & TERM & $\begin{array}{l}\text { Indicador relacionado à redução do consumo } \\
\text { de energia e emissão de poluentes pelos } \\
\text { veículos de transporte de carga e passageiros. }\end{array}$ \\
\hline $\begin{array}{l}\text { Energia final consumida pelo setor de transportes } \\
\text { (EnergFinalTransp) }\end{array}$ & OECD & $\begin{array}{l}\text { Indicador para medir a contribuição relativa } \\
\text { dos transportes para a energia final consumida } \\
\text { em um determinado nível. Pode ser obtido por } \\
\text { unidade de Produto Doméstico Bruto ou per } \\
\text { capita. }\end{array}$ \\
\hline $\begin{array}{l}\text { Intensidade no uso de energia: transportes } \\
\text { (IntensEnergTransp) }\end{array}$ & UNCDS & $\begin{array}{l}\text { Indicador da energia consumida pelos } \\
\text { transportes relativa à quantidade de carga ou } \\
\text { passageiros transportados e distância viajada. }\end{array}$ \\
\hline $\begin{array}{l}\text { Proporção de energia originada de fontes de } \\
\text { combustível fósseis e não-fósseis } \\
\text { (EnergFosNaoFos) }\end{array}$ & Sust_Meas & $\begin{array}{l}\text { Indicador que mede a participação e utilização } \\
\text { de combustíveis não-fósseis e formas de } \\
\text { energia alternativas no consumo de } \\
\text { combustíveis pelo setor de transportes. }\end{array}$ \\
\hline \multicolumn{3}{|c|}{ A2 - Impactos ambientais } \\
\hline $\begin{array}{l}\text { Descargas acidentais de óleo no mar por navios } \\
\text { (DescargOleo) }\end{array}$ & TERM & $\begin{array}{c}\text { Indicador que mede os eventos que } \\
\text { influenciam de maneira direta o ambiente e a } \\
\text { economia das cidades costeiras. }\end{array}$ \\
\hline $\begin{array}{l}\text { Fragmentação de terras e florestas } \\
\qquad \text { (Fragmentação) }\end{array}$ & TERM & $\begin{array}{l}\text { Indicador relacionado à preservação da } \\
\text { biodiversidade e à manutenção da } \\
\text { conectividade entre áreas naturais. A } \\
\text { fragmentação está diretamente associada ao } \\
\text { desenvolvimento de infra-estrutura de } \\
\text { transportes. }\end{array}$ \\
\hline $\begin{array}{l}\text { Impactos do uso de automóveis } \\
\text { (ImpactUsoAuto) }\end{array}$ & Dickey & $\begin{array}{l}\text { Indicador que relaciona de forma direta os } \\
\text { impactos decorrentes do uso de automóveis: } \\
\text { emissão de poluentes, ruído, dispersão das } \\
\text { cidades, entre outros. }\end{array}$ \\
\hline $\begin{array}{c}\text { Proximidade de infra-estrutura de transportes a } \\
\text { áreas protegidas } \\
\text { (ProxInfraProteg) }\end{array}$ & TERM & $\begin{array}{l}\text { Indicador que mede a percentagem de áreas de } \\
\text { interesse ambiental com infra-estrutura de } \\
\text { transportes localizadas a menos de } 5 \mathrm{~km} \text { de seu } \\
\text { centro. }\end{array}$ \\
\hline $\begin{array}{l}\text { Resíduos gerados por veículos rodoviários } \\
\text { (ResidVeicRodo) }\end{array}$ & TERM & $\begin{array}{c}\text { Este indicador refere-se não só a minimização } \\
\text { dos resíduos gerados pelo transporte rodoviário } \\
\text { como também à reciclagem e reutilização cada } \\
\text { vez maior destes resíduos. }\end{array}$ \\
\hline \multicolumn{3}{|c|}{ A3 - Qualidade do ar } \\
\hline $\begin{array}{c}\text { Dias por ano em que os padrões de qualidade do ar } \\
\text { não são atendidos } \\
\text { (DiasQualiAr) }\end{array}$ & Sust_Meas & $\begin{array}{c}\text { Indicador que mede o número de dias por ano } \\
\text { em que os padrões de poluição (concentração } \\
\text { média dos principais poluentes) excedem os } \\
\text { padrões estabelecidos pelos órgãos } \\
\text { competentes. }\end{array}$ \\
\hline $\begin{array}{l}\text { Emissão de gases acidificantes pelos transportes } \\
\text { (EmissAcidTransp) }\end{array}$ & SPARTACUS & $\begin{array}{l}\text { Indicador que proporciona o cálculo de } \\
\text { emissões baseado no número de veículos ou } \\
\text { passageiros-km, utilizando fórmulas e } \\
\text { coeficientes que relacionam os diferentes tipos } \\
\text { de veículos e emissões específicas. }\end{array}$ \\
\hline $\begin{array}{c}\text { Emissão de gases que geram o efeito estufa pelos } \\
\text { transportes } \\
\text { (EmissEstufTransp) }\end{array}$ & TERM & $\begin{array}{l}\text { Indicador para monitorar o cumprimento das } \\
\text { metas estabelecidas pelo Protocolo de Kyoto. }\end{array}$ \\
\hline $\begin{array}{c}\text { Emissões causadas pelos transportes e intensidade } \\
\text { das emissões } \\
\text { (EmissIntensTransp) }\end{array}$ & OECD & $\begin{array}{l}\text { Emissões de } \mathrm{CO}_{2}, \mathrm{CO}, \mathrm{NOx}, \mathrm{VOC} \text { e SOx, } \\
\text { contribuição relativa no total de emissões, } \\
\text { intensidade de emissões per capita e por } \\
\text { unidade de PDB. Emissões para o tráfego } \\
\text { rodoviário por unidade de volume de tráfego. }\end{array}$ \\
\hline
\end{tabular}




\begin{tabular}{|c|c|c|}
\hline $\begin{array}{l}\text { População exposta à poluição do ar causada pelos } \\
\text { transportes } \\
\text { (PopExpoPolu) }\end{array}$ & OECD & $\begin{array}{c}\text { Indicador que mede a percentagem da } \\
\text { população exposta a padrões inferiores de } \\
\text { qualidade do ar devido a emissões causadas } \\
\text { pelos transportes. } \\
\end{array}$ \\
\hline $\begin{array}{l}\text { Qualidade do ar } \\
\text { (QualiAr) }\end{array}$ & SIDS & $\begin{array}{c}\text { Índice que inclui diversos parâmetros } \\
\text { indicativos da qualidade do ar, medidos e } \\
\text { comparados com limites estabelecidos pela } \\
\text { legislação em vigor. }\end{array}$ \\
\hline \multicolumn{3}{|c|}{ A4 - Ruído de tráfego } \\
\hline $\begin{array}{l}\text { Medidas de minimização de ruído } \\
\text { (MedMiniRuid) }\end{array}$ & SIDS & $\begin{array}{l}\text { Indicador que proporciona um inventário das } \\
\text { medidas de isolamento e minimização de ruído } \\
\text { utilizadas para proteger a população afetada } \\
\text { por níveis de intensidade sonora superiores aos } \\
\text { limiares de comodidade. }\end{array}$ \\
\hline $\begin{array}{l}\text { Poluição sonora } \\
\quad \text { (PoluSon) }\end{array}$ & Ind_Euro & $\begin{array}{l}\text { Indicador que mede a distribuição da } \\
\text { população exposta a longo prazo a pesados } \\
\text { níveis de ruído ambiental. Níveis de ruído em } \\
\text { áreas selecionadas. Existência e nível de } \\
\text { implementação de planos de controle de ruído. }\end{array}$ \\
\hline $\begin{array}{c}\text { População exposta ao ruído acima de } 65 \mathrm{~dB}(\mathrm{~A}) \\
\text { causado pelos transportes } \\
\text { (PopExpoRuid) }\end{array}$ & OECD & $\begin{array}{l}\text { Indicador da população total ou } \\
\text { percentagem da população vivendo em áreas } \\
\text { cujo ruído produzido pelos transportes } \\
\text { ultrapassa } 65 \mathrm{~dB}(\mathrm{~A}) \text {. }\end{array}$ \\
\hline $\begin{array}{l}\text { Ruído de tráfego: exposição e incômodo } \\
\text { (RuiTrafExp) }\end{array}$ & TERM & $\begin{array}{l}\text { Indicador obtido a partir da percentagem da } \\
\text { população exposta a } 4 \text { diferentes níveis de } \\
\text { ruído }(\mathrm{dbA}): 45-55 \mathrm{~dB}, 55-65 \mathrm{~dB}, 65-75 \mathrm{~dB} \text { e } \\
>75 \mathrm{~dB} \text {. Percentagem da população exposta ao } \\
\text { ruído de tráfego por modo de transporte. }\end{array}$ \\
\hline \multicolumn{3}{|c|}{ CATEGORIA G - GESTÃO DA MOBILIDADE URBANA } \\
\hline \multicolumn{3}{|c|}{ G5 - Despesas/Investimentos/Estratégias econômicas } \\
\hline $\begin{array}{l}\text { Capital investido por modo } \\
\text { (CapInvestMod) }\end{array}$ & OECD & $\begin{array}{c}\text { Indicador sobre o capital total investido no } \\
\text { setor de transportes e parcela de capital } \\
\text { investido por modo. }\end{array}$ \\
\hline $\begin{array}{c}\text { Despesas públicas com transporte privado } \\
\text { (DespPublicTranspPriv) }\end{array}$ & Sust_Meas & $\begin{array}{l}\text { Indicador que mede a parcela do } \\
\text { dinheiro público gasto com o desenvolvimento } \\
\text { de infra-estrutura e tecnologia para o transporte } \\
\text { privado. }\end{array}$ \\
\hline $\begin{array}{l}\text { Despesas públicas com transporte público } \\
\text { (DespPublicTranspPublic) }\end{array}$ & Sust_Meas & $\begin{array}{l}\text { Indicador que mede a parcela do } \\
\text { dinheiro público gasto com o desenvolvimento } \\
\text { de infra-estrutura e tecnologia para o transporte } \\
\text { publico. }\end{array}$ \\
\hline $\begin{array}{l}\text { Investimentos em infra-estrutura de transportes } \\
\text { (InvestInfraTransp) }\end{array}$ & TERM & $\begin{array}{c}\text { Indicador que mede os investimentos } \\
\text { em manutenção e desenvolvimento de } \\
\text { infra-estrutura por modo e investimento em } \\
\text { infra-estrutura para modalidades } \\
\text { ambientalmente amigáveis. }\end{array}$ \\
\hline $\begin{array}{l}\text { Subsídios diretos aos transportes } \\
\text { (SubsidTransp) }\end{array}$ & OECD & $\begin{array}{l}\text { Indicador dos subsídios diretos aos transportes } \\
\text { (tarifas, combustíveis, entre outros) e } \\
\text { externalidades (custos ou benefícios que não } \\
\text { são refletidos em sua totalidade nos preços). }\end{array}$ \\
\hline $\begin{array}{c}\text { Taxação relativa de veículos e utilização de } \\
\text { veículos } \\
\text { (TaxVeicUtili) }\end{array}$ & OECD & $\begin{array}{l}\text { Indicador que mede as taxações sobre a } \\
\text { emissão de ruído, emissão de poluentes e } \\
\text { ocupação dos veículos. Taxações podem ser } \\
\text { aplicadas a fim de desestimular a circulação } \\
\text { em vias, áreas ou horários pré-estabelecidos e } \\
\text { ainda, diminuir a demanda por combustíveis. }\end{array}$ \\
\hline
\end{tabular}




\section{G6 - Gerenciamento/Monitoração}

Avaliação de impacto ambiental (AvalImpactAmb)

Gerenciamento efetivo do tráfego/fiscalização (GerencTrafFiscal)

Sistemas nacionais para a monitoração dos transportes e meios ambiente (SistMonitorTranspAmb)
Ag 21

Indicador para monitorar a existência de instrumentos legais para a elaboração de

Relatórios de Impacto Ambiental para projetos em nível urbano.

Monitora a existência de sistemas de gerenciamento de tráfego em larga escala e fiscalização efetiva do tráfego urbano. Indicador para monitorar a existência de instrumentos (indicadores ou sistemas de TERM indicadores) para a monitoração do progresso e eficiência das políticas para o setor de transportes.

\section{G7 - Medidas para o incremento da mobilidade urbana}

Desenvolvimento de planos municipais para a redução das viagens (PlanRedViag)

Estabelecimento de regulamentação para densidades mínimas na cidade (RegulaDensidMin)

mplementação de estratégias ambientais para o setor de transportes (EstratAmbTransp)

Medidas: operação eficiente da frota de veículos (OperaEficVeic)

Indicador para monitorar a existência de instrumentos ou políticas de planejamento urbano a fim de reduzir a necessidade por viagens.

Indicador para monitorar a existência de instrumentos legais para o estabelecimento de uma densidade mínima para cada zona da cidade. Relaciona-se ao controle da dispersão e espalhamento urbano.

Este indicador refere-se à aplicação de estratégias ambientais como suporte a políticas, planos e programas para o setor de transportes.

Indicador para monitorar a existência

de medidas ou políticas para o uso mais eficiente dos veículos: incentivo a maior ocupação dos veículos, financiamento de novas tecnologias, entre outras.

Indicador para monitorar a implementação de

planos e políticas para a melhoria dos

transportes, principalmente do transporte público urbano.

Melhoria dos transportes $\quad$ Dickey
(MelhoraTransp)

Indicador para monitorar medidas que

Priorizar viagens eficientes (a pé ou por bicicleta) (PriorViagPedCiclist)

Dickey priorizam o desenvolvimento de infra-estrutura para pedestres e ciclistas.

\section{G8 - Novas tecnologias}

Desenvolvimento de combustíveis limpos e número de veículos que utilizam combustíveis alternativos

(CombustLimpAlter)

Gastos com Pesquisa e Desenvolvimento de

"combustíveis limpos"

(GastCombustLimp)

Gastos com Pesquisa e Desenvolvimento de

"veículos ecológicos"

(GastVeicEco)

Novas formas de transporte

(NovaFormaTransp)

Possível custo inicial de veículos ecológicos

(CustIniciaVeicEco)

Uso de tecnologia de cartões inteligentes (TecnoCartIntelig)
TERM

Indicador para monitorar a utilização de combustíveis isentos de chumbo e a adoção de catalisadores e conversores para os automóveis.

Indicador para monitorar capital total ou parcela de capital investido no

desenvolvimento de combustíveis limpos (reduzem a emissão de poluentes ou atendem a especificações quanto ao teor de determinadas substâncias tóxicas).

Indicador para monitorar o capital ou parcela de capital investido no desenvolvimento de veículos ecológicos (veículos elétricos ou "híbridos" de elevada eficiência).

Indicador para acompanhar o desenvolvimento, introdução e incentivo ao desenvolvimento de novas formas de transporte em nível urbano. Indicador que permite avaliar a viabilidade da introdução de novas tecnologias, tais como os veículos ecológicos.

Indicador que permite monitorar a introdução, aceitação, bem como os impactos (custos e benefícios) do uso da tecnologia de cartões inteligentes no sistema de transporte público urbano. 


\begin{tabular}{|c|c|c|}
\hline $\begin{array}{l}\text { Vida útil dos veículos ecológicos } \\
\text { (VidaUtilVeicEco) }\end{array}$ & Dickey & $\begin{array}{l}\text { Indicador que fornece uma medida do } \\
\text { número médio de anos que um veículo } \\
\text { ecológico pode ser utilizado, considerando a } \\
\text { sua eficiência e segurança. }\end{array}$ \\
\hline \multicolumn{3}{|c|}{ CATEGORIA I - INFRA-ESTRUTURA E TECNOLOGIAS DE TRANSPORTE } \\
\hline \multicolumn{3}{|c|}{ I9- Frota } \\
\hline $\begin{array}{l}\text { Estrutura da frota de veículos rodoviários } \\
\text { (FrotVeicRodo) }\end{array}$ & OECD & $\begin{array}{l}\text { Indicador que revela a estrutura da frota de } \\
\text { veículos por tipo de veículo (cargas e } \\
\text { passageiros) e por tipo de combustível. }\end{array}$ \\
\hline $\begin{array}{l}\text { Idade média dos veículos } \\
\text { (IdadMedVeic)Sust_meas }\end{array}$ & SIDS & $\begin{array}{c}\text { Indicador do número médio de anos dos } \\
\text { veículos em circulação, uma vez que a idade } \\
\text { dos veículos pode ser indicativa da tecnologia } \\
\text { empregada em sua fabricação. }\end{array}$ \\
\hline $\begin{array}{l}\text { Percentagem da frota municipal convertida para } \\
\text { reduzir a emissão de poluentes } \\
\text { (FrotConvertRedPolu }\end{array}$ & Sust_Meas & $\begin{array}{l}\text { Indicador medido através da percentagem de } \\
\text { veículos convertidos para a utilização de gás } \\
\text { natural, eletricidade ou outra forma alternativa } \\
\text { de energia não-poluente. }\end{array}$ \\
\hline $\begin{array}{l}\text { Propriedade de automóveis privados } \\
\text { (PropAutoPriv) }\end{array}$ & OECD & $\begin{array}{c}\text { Índice de motorização da cidade } \\
\text { (frota de veículos do município dividida pela } \\
\text { população municipal, com resultado } \\
\text { multiplicado por 100). }\end{array}$ \\
\hline $\begin{array}{l}\text { Relação entre veículos com consumo eficiente de } \\
\text { combustível/veículos com consumo ineficiente de } \\
\text { combustível } \\
\text { (VeicEficVeicNaoefic) }\end{array}$ & Sust_Meas & $\begin{array}{c}\text { Para o desenvolvimento deste indicador } \\
\text { são necessárias informações sobre a economia } \\
\text { de combustíveis e emissões de CO2 por tipo de } \\
\text { veículo. }\end{array}$ \\
\hline $\begin{array}{c}\text { Veículos em circulação } \\
\text { (VeicCircula) }\end{array}$ & SIDS & $\begin{array}{l}\text { Indicador que fornece o número de veículos } \\
\text { em circulação na área urbana. }\end{array}$ \\
\hline \multicolumn{3}{|c|}{ I10 - Infra-estrutura/Sistema Viário } \\
\hline $\begin{array}{c}\text { Capacidade das redes de infra-estrutura de } \\
\text { transportes } \\
\text { (CapacidadInfra) }\end{array}$ & TERM & $\begin{array}{l}\text { Indicador que permite acompanhar a evolução } \\
\text { da infra-estrutura de transporte (para cada } \\
\text { modo) em um período determinado. }\end{array}$ \\
\hline $\begin{array}{l}\text { Comprimento total das vias para ciclistas } \\
\text { (CompViaCicilst) }\end{array}$ & Sust_Meas & $\begin{array}{c}\text { Este indicador pode ser expresso também } \\
\text { como proporção do total de vias urbanas } \\
\text { destinadas aos ciclistas. Constitui uma medida } \\
\text { do incentivo à adoção deste modo de } \\
\text { transporte. }\end{array}$ \\
\hline $\begin{array}{c}\text { Desenvolvimento de vias para otimizar } \\
\text { o fluxo de tráfego } \\
\text { (ViaOtimTraf) }\end{array}$ & Dickey & $\begin{array}{l}\text { Indicador para monitorar o desenvolvimento de } \\
\text { novas vias na área urbana (extensão, tipo, } \\
\text { capacidade, volume de tráfego, entre outros). }\end{array}$ \\
\hline $\begin{array}{l}\text { Estrutura da rede viária } \\
\text { (RedVia) }\end{array}$ & SIDS & $\begin{array}{c}\text { Indicador sobre a evolução da rede viária, } \\
\text { por tipo de via. }\end{array}$ \\
\hline $\begin{array}{l}\text { Extensão total das vias designadas para pedestres } \\
\text { (ExtViaPedest) }\end{array}$ & Sust_Meas & $\begin{array}{l}\text { Este indicador pode ser expresso também como } \\
\text { proporção do total de vias urbanas. Relaciona- } \\
\text { se à exclusão social, segurança e conforto dos } \\
\text { deslocamentos feitos a pé. }\end{array}$ \\
\hline $\begin{array}{l}\text { Número de estacionamentos para carros na cidade } \\
\text { (EstacionaCar) }\end{array}$ & Unit_King & $\begin{array}{l}\text { Este indicador pode ser expresso também como } \\
\text { área de estacionamento por habitante. }\end{array}$ \\
\hline $\begin{array}{c}\text { Possibilidade de acesso de transporte coletivo } \\
\text { (pavimentação) } \\
\text { (AcessTranspPavi) }\end{array}$ & IQVUBH & $\begin{array}{l}\text { Indicador que mede a percentagem ou extensão } \\
\text { de vias com pavimentação adequada para o } \\
\text { acesso de veículos de transporte coletivo. }\end{array}$ \\
\hline $\begin{array}{c}\text { Provisão de infra-estrutura para traffic calming e } \\
\text { vias para bicicletas e pedestres } \\
\text { (TrafficCalming) }\end{array}$ & Unit_King & $\begin{array}{c}\text { Indicador para acompanhar a implementação } \\
\text { de medidas de traffic calming. Estas } \\
\text { medidas visam, de um modo geral, a redução } \\
\text { da velocidade dos veículos em vias urbanas, } \\
\text { garantindo maior segurança para } \\
\text { pedestres e ciclistas. }\end{array}$ \\
\hline \multicolumn{3}{|c|}{ I11 - Tecnologias e serviços de transporte } \\
\hline $\begin{array}{c}\text { Aquisição de bicicletas em cidades menos } \\
\text { desenvolvidas } \\
\text { (AquisBic) }\end{array}$ & Dickey & $\begin{array}{c}\text { Este indicador visa monitorar a aceitação e o } \\
\text { uso da bicicleta em nível urbano. Pode estar } \\
\text { relacionado ao desenvolvimento de infra- } \\
\text { estrutura adequada para este modo de } \\
\text { transporte. }\end{array}$ \\
\hline
\end{tabular}




\begin{tabular}{|c|c|c|}
\hline $\begin{array}{l}\text { Mudanças nos modos de transporte } \\
\text { (MudaModTransp) }\end{array}$ & Dickey & $\begin{array}{l}\text { Indicador relacionado à introdução e utilização } \\
\text { de novas formas de transporte em nível urbano. }\end{array}$ \\
\hline $\begin{array}{l}\text { Tendências do tráfego rodoviário e densidades } \\
\text { (TrafRodo) }\end{array}$ & OECD & $\begin{array}{l}\text { Indicador que fornece medidas do volume de } \\
\text { passageiros e carga transportados pelo modo } \\
\text { rodoviário, densidades e impactos ambientais. }\end{array}$ \\
\hline $\begin{array}{l}\text { Transporte de carga por modo } \\
\text { (TranspCarg) }\end{array}$ & TERM & $\begin{array}{l}\text { Este indicador permite avaliar se há equilíbrio } \\
\text { na divisão modal do transporte de cargas. }\end{array}$ \\
\hline $\begin{array}{l}\text { Transporte de passageiros por modo de transporte } \\
\text { (TranspPassag) }\end{array}$ & SIDS & $\begin{array}{l}\text { Indicador que mede a intensidade de utilização } \\
\text { do transporte de passageiros por modo de } \\
\text { transporte. }\end{array}$ \\
\hline \multicolumn{3}{|c|}{ I12 - Tráfego } \\
\hline $\begin{array}{l}\text { Congestionamento de tráfego } \\
\text { (CongestionaTraf) }\end{array}$ & Dickey & $\begin{array}{c}\text { Indicador para avaliar a extensão e os prejuízos } \\
\text { causados pelos congestionamentos de tráfego } \\
\text { na área urbana. }\end{array}$ \\
\hline $\begin{array}{l}\text { Densidade de tráfego } \\
\text { (DensidTraf) }\end{array}$ & Dikey & $\begin{array}{l}\text { Indicador que fornece o número de veículos } \\
\text { que ocupam um trecho de via ou uma via em } \\
\text { um instante determinado. }\end{array}$ \\
\hline $\begin{array}{c}\text { Geração de volume de tráfego e tipo } \\
\text { (VolTraf) }\end{array}$ & Dickey & $\begin{array}{l}\text { Indicador para monitorar o volume de tráfego } \\
\text { por tipo de veículo na área urbana. Volume de } \\
\text { tráfego é definido como o número de veículos } \\
\text { passando por uma seção de controle durante } \\
\text { um intervalo de tempo. }\end{array}$ \\
\hline $\begin{array}{l}\text { Taxa de ocupação dos veículos de passageiros } \\
\text { (OcupaVeicPassag) }\end{array}$ & TERM & $\begin{array}{c}\text { Este indicador permite acompanhar a evolução } \\
\text { da taxa de ocupação dos veículos na área } \\
\text { urbana ao longo do tempo. }\end{array}$ \\
\hline $\begin{array}{l}\text { Tempo total gasto no tráfego } \\
\text { (TempTraf) }\end{array}$ & SPARTACUS & $\begin{array}{l}\text { Indicador obtido a partir da soma de todos os } \\
\text { tempos de viagem (anuais) dividido por mil } \\
\text { habitantes. }\end{array}$ \\
\hline $\begin{array}{l}\text { Velocidade de tráfego } \\
\text { (VelocTraf) }\end{array}$ & Dickey & $\begin{array}{l}\text { Este indicador pode ser definido pela média } \\
\text { aritmética das velocidades de veículos } \\
\text { individuais ou baseada no tempo necessário } \\
\text { para um veículo viajar determinada distância. }\end{array}$ \\
\hline \multicolumn{3}{|c|}{$\begin{array}{c}\text { CATEGORIA P - PLANEJAMENTO ESPACIAL E DEMANDA POR } \\
\text { TRASPORTES }\end{array}$} \\
\hline \multicolumn{3}{|c|}{ P13 - Acesso aos serviços e atividades urbanas } \\
\hline $\begin{array}{l}\text { Acessibilidade ao bairro } \\
\quad \text { (AcessBairro) }\end{array}$ & Dickey & $\begin{array}{l}\text { Indicador que oferece uma medida da } \\
\text { facilidade de contato ou acesso aos diferentes } \\
\text { bairros da cidade. Relaciona-se à localização e } \\
\text { à facilidade com que um indivíduo vence a } \\
\text { separação espacial a locais específicos. }\end{array}$ \\
\hline $\begin{array}{l}\text { Acessibilidade ao centro } \\
\text { (AcessCentro) }\end{array}$ & SPARTACUS & $\begin{array}{l}\text { Indicador obtido a partir do tempo médio de } \\
\text { todas as viagens feitas para o centro da cidade. }\end{array}$ \\
\hline $\begin{array}{l}\text { Acesso aos serviços básicos } \\
\text { (AcessServBasic) }\end{array}$ & TERM & $\begin{array}{l}\text { Indicador obtido a partir da distância } \\
\text { média percorrida para acessar os serviços } \\
\text { básicos (trabalho, estudo e comércio), } \\
\text { principalmente através de modos de transporte } \\
\text { ambientalmente amigáveis. }\end{array}$ \\
\hline $\begin{array}{l}\text { Acesso aos serviços de transportes } \\
\text { (AcessServTransp) }\end{array}$ & TERM & $\begin{array}{c}\text { Indicador utilizado para monitorar o } \\
\text { acesso a serviços de transporte de qualidade } \\
\text { por todos os cidadãos. De um modo geral, o } \\
\text { acesso aos transportes cresce com a provisão } \\
\text { de infra-estrutura. }\end{array}$ \\
\hline $\begin{array}{c}\text { Percentagem de empregos situados a até } 3 \\
\text { quilômetros de distância das residências } \\
\text { (EmpregDistResid) }\end{array}$ & Unit_King & $\begin{array}{l}\text { Indicador relacionado de forma direta ao tempo } \\
\text { médio de viagem gasto para viagens ao } \\
\text { trabalho e ao modo utilizado. }\end{array}$ \\
\hline $\begin{array}{c}\text { Percentagem de pessoas que vivem a até } 3 \\
\text { quilômetros de distância das facilidades de lazer } \\
\text { (PessoaDistLazer }\end{array}$ & Unit_King & $\begin{array}{l}\text { Indicador relacionado ao acesso às atividades } \\
\text { de lazer e recreação em nível urbano. }\end{array}$ \\
\hline \multicolumn{3}{|c|}{ P14 - Desenvolvimento urbano/Uso do solo } \\
\hline $\begin{array}{c}\text { Área total em categorias significativas de uso do } \\
\text { solo } \\
\text { (CategorUsoSolo })\end{array}$ & Sust_Meas & $\begin{array}{l}\text { Indicador que revela a área total designada a } \\
\text { cada uma das diferentes categorias de uso do } \\
\text { solo (espaços abertos, indústrias, moradias, } \\
\text { áreas de expansão, preservação, entre outras). }\end{array}$ \\
\hline
\end{tabular}




\begin{tabular}{|c|c|c|}
\hline $\begin{array}{c}\text { Áreas verdes versus áreas destinadas ao automóvel } \\
\text { privado } \\
\text { (VerdVersusAutoPirv) }\end{array}$ & Unit_King & $\begin{array}{c}\text { Indicador que revela a proporção da área } \\
\text { urbana destinada a parques e áreas verdes } \\
\text { comparada à proporção destinada a infra- } \\
\text { estrutura para o transporte privado. }\end{array}$ \\
\hline $\begin{array}{l}\text { Desconcentração das atividades } \\
\text { (DeconcAtiv) }\end{array}$ & Dickey & $\begin{array}{c}\text { Indicador relacionado de forma direta à } \\
\text { necessidade de viagens e ao tempo gasto para a } \\
\text { realização das mesmas. }\end{array}$ \\
\hline $\begin{array}{l}\text { Forma urbana } \\
\text { (FormUrb) }\end{array}$ & Dickey & $\begin{array}{l}\text { Indicador que relaciona a forma urbana aos } \\
\text { custos de transportes, distância e tempo de } \\
\text { viagem, acessibilidade, entre outros. }\end{array}$ \\
\hline $\begin{array}{l}\text { Incentivo ao uso misto/alta densidade } \\
\text { (IncentUsoMistAltaDensid) }\end{array}$ & Dickey & $\begin{array}{l}\text { Indicador relacionado à necessidade de } \\
\text { viagens, custos de transportes, acesso às } \\
\text { atividades urbanas, entre outros. }\end{array}$ \\
\hline $\begin{array}{c}\text { Mudanças no uso do solo devido à infra-estrutura } \\
\text { de transportes } \\
\text { (MudaSoloInfraTransp) }\end{array}$ & OECD & $\begin{array}{l}\text { Este indicador visa monitorar os } \\
\text { impactos da construção de novas infra- } \\
\text { estruturas de transportes sobre os } \\
\text { equipamentos e atividades urbanas. }\end{array}$ \\
\hline $\begin{array}{l}\text { Planejamento do uso do solo urbano } \\
\text { (PlanejaSoloUrb) }\end{array}$ & SNIU & $\begin{array}{c}\text { Indicador para monitorar a existência e } \\
\text { ano de criação de legislação específica sobre o } \\
\text { uso do solo urbano (perímetro urbano, } \\
\text { parcelamento do solo, zoneamento, áreas de } \\
\text { interesse especial, código de obras ou outros } \\
\text { instrumentos). }\end{array}$ \\
\hline $\begin{array}{c}\text { Políticas de uso do solo para pedestres, ciclistas e } \\
\text { transporte público } \\
\text { (PoliticPedestCiclistPublic) }\end{array}$ & Dickey & $\begin{array}{l}\text { Indicador para monitorar a implementação de } \\
\text { políticas de uso do solo que visam o } \\
\text { incremento dos deslocamento feitos a pé, por } \\
\text { bicicleta ou transporte público (incentivos, } \\
\text { infra-estrutura, etc). }\end{array}$ \\
\hline
\end{tabular}

\section{P15 - População urbana}

Crescimento do número de unidades unifamiliares comparado ao crescimento da população (UnidFamCrescPop)

Densidade populacional (DensidPop)

Estrutura etária da população (EstrutEtarPop)

Sust emas (RendFamPercapita

IBGE

Taxa de crescimento da população (TaxCrescPop)

UNCSD

\section{P16 - Viagens/Deslocamentos}

Deslocamento de crianças para a escola (DeslocaCriançaEsc)

Ind_Euro

Indicador para monitorar o modo de

$\mathrm{Na}$ área urbana, este indicador pode ser obtido para as diferentes regiões da cidade. Constitui ponto de interesse para o processo de planejamento urbano e de transportes.

Indicador que revela a proporção de homens e mulheres em cada faixa etária com relação à população total. Permite revelar, dentro outros aspectos, a proporção de crianças e idosos que possuem necessidades especiais de transporte, redirecionando ou adaptando projetos em nível urbano.

Indicador que revela a distribuição das famílias por classes de rendimento familiar per capita. Relacionado com o número de viagens diárias per capita e o modo de transporte escolhido. Indicador que revela a taxa média anual de mudança no tamanho da população durante um período determinado.

\begin{tabular}{ccc}
\multicolumn{2}{c}{ P16 - Viagens/Deslocamentos } & período determinado. \\
\hline $\begin{array}{c}\text { Deslocamento de crianças para a escola } \\
\text { (DeslocaCriançaEsc) }\end{array}$ & Ind_Euro & $\begin{array}{c}\text { Indicador para monitorar o modo de } \\
\text { transporte usado por crianças em viagens entre } \\
\text { a casa e a escola. }\end{array}$ \\
\hline $\begin{array}{c}\text { Distância aos serviços básicos } \\
\text { (DistServBasic) }\end{array}$ & Unit_King & $\begin{array}{c}\text { Indicador obtido a partir da distância média a } \\
\text { equipamentos de educação, saúde, comércio, } \\
\text { entre outros. }\end{array}$ \\
\hline $\begin{array}{c}\text { Distância média entre os moradores e os demais } \\
\text { membros de sua família } \\
\text { (DistFam) }\end{array}$ & Sust_Mes & $\begin{array}{c}\text { Indicador relacionado a questones de } \\
\text { conectividade social, deslocamentos e modos } \\
\text { de transporte. }\end{array}$ \\
\hline $\begin{array}{c}\text { Distância percorrida a pé ou por bicicleta per } \\
\text { capita por dia } \\
\text { (DistPedBiciDia) }\end{array}$ & Bossel & $\begin{array}{c}\text { Este indicador pode ser utilizado como base } \\
\text { para o desenvolvimento de infra-estrutura } \\
\text { adequada ou medidas de segurança que } \\
\text { incentivem a realização de deslocamentos a pé } \\
\text { ou por bicicleta. Relaciona-se também à saúde } \\
\text { e bem-estar da população. }\end{array}$ \\
\hline
\end{tabular}




\begin{tabular}{|c|c|c|}
\hline $\begin{array}{l}\text { Mobilidade local e passageiros transportados } \\
\text { (MobLocal) }\end{array}$ & UNCSD & $\begin{array}{c}\text { Indicador que revela o número de viagens } \\
\text { diárias e tempo gasto per capita por tipo de } \\
\text { viagem e modo de transporte. Distância média } \\
\text { per capita por tipo de viagem e modo de } \\
\text { transporte. }\end{array}$ \\
\hline $\begin{array}{l}\text { Número de pessoas vivendo e trabalhando no local } \\
\text { (PopVivTrabLocal) }\end{array}$ & Unit_King & $\begin{array}{c}\text { Indicador relacionado à realização de } \\
\text { deslocamentos diários extensos e ao número de } \\
\text { veículos que circulam diariamente na área } \\
\text { urbana. }\end{array}$ \\
\hline $\begin{array}{l}\text { Percentagem de pessoas que utilizam o automóvel } \\
\text { para viagens com distância inferior a } 3 \text { quilômetros } \\
\text { (UtliAutoDistInferior) }\end{array}$ & Unit_King & $\begin{array}{c}\text { Este indicador transmite uma noção do nível de } \\
\text { dependência do automóvel pela população } \\
\text { urbana. Alerta para a existência de possíveis } \\
\text { falhas no sistema de transporte público urbano } \\
\text { e infra-estrutura inadequada para pedestres e } \\
\text { ciclistas. }\end{array}$ \\
\hline $\begin{array}{l}\text { Tempo de viagem } \\
\text { (TempViag) }\end{array}$ & UNCHS & $\begin{array}{c}\text { Indicador obtido através do tempo médio gasto } \\
\text { para uma viagem de trabalho (em um único } \\
\text { sentido). Média para todas as modalidades de } \\
\text { transporte. }\end{array}$ \\
\hline
\end{tabular}

CATEGORIA S - ASPECTOS SOCIOECONÔMICOS DOS TRANSPORTES
S17 - Custos/Preços/Tarifas

Custo por passageiro transportado, corrigido pela inflação

Sust Meas

Indicador relacionado à viabilidade

(CustPassagTransp) econômica e à eficiência dos diferentes modos de transporte, à qualidade do serviço ofertado, além dos insumos que compõem os custos de transporte.

Evolução dos preços dos diferentes tipos de combustíveis e eletricidade

SIDS

Indicador para monitorar a evolução dos preços

(EvoluPreçoCombust)

dos principais combustíveis (gás natural, diesel, gasolina, óleo, GLP) e eletricidade, junto ao consumidor final.

Mudanças reais nos preços de transporte por modo (MudaPreçoTranspModo)

TERM Indicador para acompanhar as variações de preços das diferentes modalidades de transporte, buscando estabelecer um preço justo e eficiente.

Preço dos combustíveis e taxas (PreçoCombustTax)

TERM O preço dos combustíveis constitui um misto entre preços de mercado e taxas ditadas pelo governo. Este indicador permite visualizar a parcela do preço dos combustíveis determinada por cada um destes fatores.

Tendências dos preços do transporte público (PreçoTranspPublic)

OECD

Indicador para monitorar as variações nos custos do transporte público em um período determinado.

\section{S18 - Impactos socioeconômicos dos transportes}

Benefícios dos usuários de transportes (BeneficUsaTransp)

Custos do congestionamento (CustCongestiona)

Dickey

Custos sociais dos transportes (CustSocial)

OECD

SPARTACUS

Índice econômico que agrega fatores como custos dos recursos, externalidades (ruído, emissões, acidentes) além de benefícios generalizados aos usuários de transportes. Indicador que revela os prejuízos ambientais, econômicos e sociais causados pelos congestionamentos de tráfego.

Indicador dos custos sociais decorrentes dos investimentos no controle dos congestionamentos de tráfego, prevenção à poluição, desenvolvimento de infra-estrutura, segurança e transporte público.

\begin{tabular}{ccc}
\hline $\begin{array}{c}\text { Rendimentos dos operadores de transportes } \\
\text { (RendOperaTransp) }\end{array}$ & SPARTACUS & $\begin{array}{c}\text { Indicador dos benefícios econômicos dos } \\
\text { operadores de transporte urbano. }\end{array}$ \\
\hline $\begin{array}{c}\text { S19 - Segurança } \\
\text { (AcidentTranspFatal) }\end{array}$ & TERM & $\begin{array}{c}\text { Este indicador alerta para a implementação } \\
\text { de medidas para educação no trânsito, } \\
\text { mudanças na legislação, manutenção da rede } \\
\text { viária, entre outros. }\end{array}$ \\
\hline $\begin{array}{c}\text { Feridos por acidentes de tráfego } \\
\text { (FeridoAcidentTraf) }\end{array}$ & SPARTACUS & $\begin{array}{c}\text { Indicador que fornece o número de indivíduos } \\
\text { que tenham sofrido lesões corporais em } \\
\text { acidentes ocorridos na área urbana. }\end{array}$ \\
\hline
\end{tabular}




\begin{tabular}{|c|c|c|}
\hline $\begin{array}{l}\text { Número de crimes violentos ocorridos no trânsito } \\
\text { (CrimeTransit) }\end{array}$ & Sust_Meas & $\begin{array}{c}\text { Indicador que oferece uma medida da } \\
\text { segurança no trânsito relacionada ao } \\
\text { comportamento de motoristas e pedestres. }\end{array}$ \\
\hline $\begin{array}{c}\text { Pedestres e ciclistas feridos em acidentes de } \\
\text { trânsito } \\
\text { (AcidentPedestCiclist) }\end{array}$ & Sust_Meas & $\begin{array}{c}\text { Indicador relacionado à segurança e proteção } \\
\text { de pedestres e ciclistas e que pode revelar uma } \\
\text { carência de infra-estrutura para os } \\
\text { deslocamentos feitos a pé ou por bicicleta. }\end{array}$ \\
\hline $\begin{array}{c}\text { Segurança e proteção para as vias residenciais } \\
\text { (SegurViaResidencia) }\end{array}$ & Dickey & $\begin{array}{c}\text { Indicador relacionado às medidas } \\
\text { desenvolvidas para assegurar o conforto e } \\
\text { segurança em vias residenciais: } \\
\text { sinalização, fiscalização, cruzamentos para } \\
\text { pedestres, entre outros. }\end{array}$ \\
\hline \multicolumn{3}{|c|}{ S20 - Transporte público } \\
\hline $\begin{array}{l}\text { Demanda por transporte de passageiros } \\
\text { (DemandTranspPassag) }\end{array}$ & TERM & $\begin{array}{c}\text { Indicador relacionado ao número de } \\
\text { passageiros transportados por quilômetro pelos } \\
\text { diferentes modos de transporte (incluindo } \\
\text { automóvel privado) ao Produto Doméstico } \\
\text { Bruto. Pode revelar ligações entre o } \\
\text { crescimento econômico e o crescimento no } \\
\text { transporte de passageiros. }\end{array}$ \\
\hline $\begin{array}{l}\text { Disponibilidade de transporte público } \\
\text { (DispTranspPublic) }\end{array}$ & Dickey & $\begin{array}{l}\text { Indicador relacionado à cobertura do } \\
\text { transporte público urbano. Número ou } \\
\text { percentagem de vias atendidas por alguma } \\
\text { modalidade de transporte público. }\end{array}$ \\
\hline $\begin{array}{l}\text { Fator de diversidade para serviços de transporte } \\
\text { (DiversidadTransp) }\end{array}$ & Bossel & $\begin{array}{l}\text { Indicador do número médio de alternativas de } \\
\text { transporte público disponíveis na zona urbana. }\end{array}$ \\
\hline $\begin{array}{l}\text { Necessidade de sistemas de transporte } \\
\text { (NecessTransp) }\end{array}$ & Bossel & $\begin{array}{l}\text { Indicador que revela a percentagem de } \\
\text { domicílios que não possuem meios de } \\
\text { transporte próprios. }\end{array}$ \\
\hline $\begin{array}{c}\text { Nível de serviço do transporte público e } \\
\text { modalidades lentas } \\
\text { (NivServTranspPublic) } \\
\end{array}$ & SPARTACUS & $\begin{array}{l}\text { Indicador relacionado à freqüência de } \\
\text { atendimento do transporte público } \\
\text { e ao tempo de viagem. }\end{array}$ \\
\hline $\begin{array}{l}\text { Percentagem de pessoas que consideram o } \\
\text { transporte público inseguro } \\
\text { (TranspPublicInsegur) }\end{array}$ & Sust_Meas & $\begin{array}{c}\text { Indicador que fornece uma medida da } \\
\text { segurança e confiabilidade, que pode estar } \\
\text { intimamente ligada à demanda por transporte } \\
\text { público. }\end{array}$ \\
\hline $\begin{array}{l}\text { Percentagem de pessoas que escolhem o transporte } \\
\text { público em detrimento ao carro } \\
\text { (TranspPublicVersusCar) }\end{array}$ & Sust_Meas & $\begin{array}{c}\text { Indicador associado ao conforto, segurança e } \\
\text { disponibilidade de transporte público de } \\
\text { passageiros. }\end{array}$ \\
\hline
\end{tabular}

